\section{Pacific Northwest}

National Laboratory

Operated by Battelle for the

U.S. Department of Energy

\title{
Grays River Watershed Geomorphic Analysis
}

August 2005

Prepared by Herrera Environmental Consultants, Inc., for Pacific Northwest National Laboratory under Contract DE-AC05-76RL01830 with the U.S. Department of Energy 


\title{
GRAYS RIVER WATERSHED
}

\section{Geomorphic Analysis}

\author{
Prepared for
}

Pacific Northwest National Laboratory 
Note:

Some pages in this document have been purposefully skipped or blank pages inserted so that this document will copy correctly when duplexed. 


\title{
GRAYS RIVER WATERSHED
}

\section{Geomorphic Analysis}

\author{
Prepared for \\ Pacific Northwest National Laboratory \\ 902 Battelle Boulevard \\ Richland, Washington 99352
}

Prepared by

Herrera Environmental Consultants, Inc.

2200 Sixth Avenue, Suite 1100

Seattle, Washington 98121

Telephone: 206/441-9080

August 3, 2005 



\section{Contents}

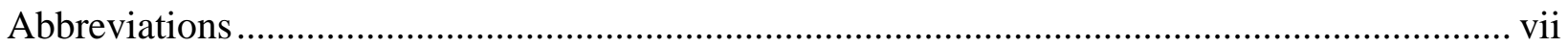

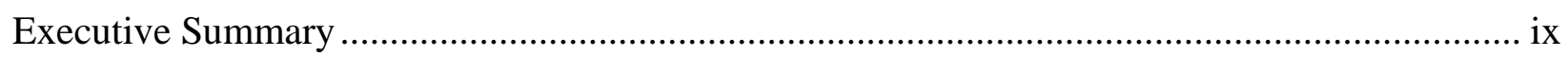

Introduction and Purpose .............................................................................................

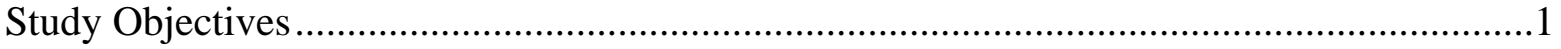

Background Information and Watershed Characterization.....................................................3

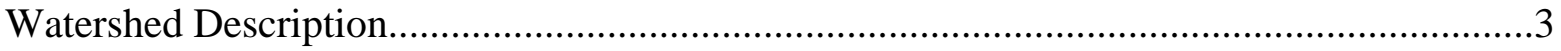

Geologic and Geomorphic Overview ...........................................................................4

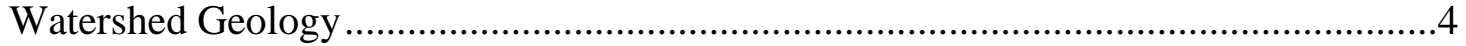

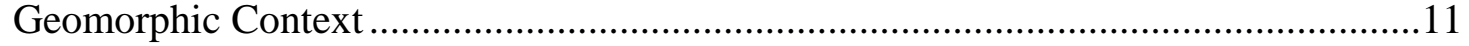

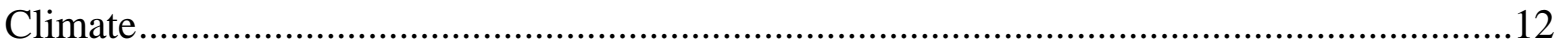

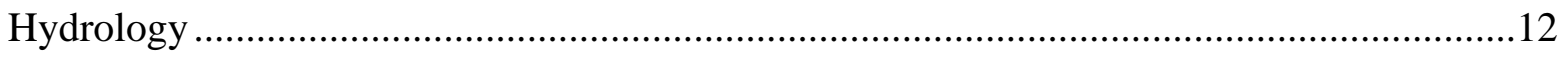

Land Ownership and Historical Forest Clearing ......................................................15

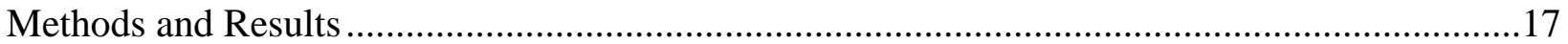

Assessment of Mass Wasting and Surface Erosion .........................................................17

Current Hillslope Conditions ..........................................................................17

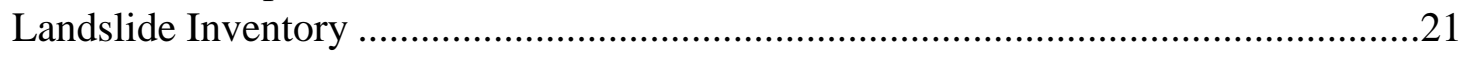

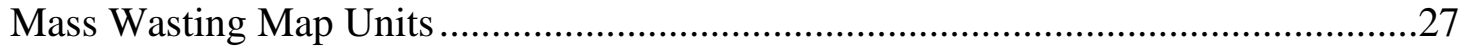

Assessment of Surface Erosion from Disturbed Hillslopes ......................................31

Assessment of Surface Erosion from Roads ..............................................................32

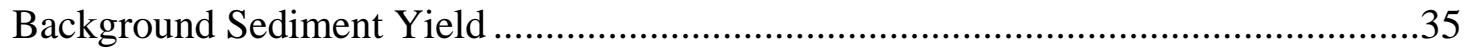

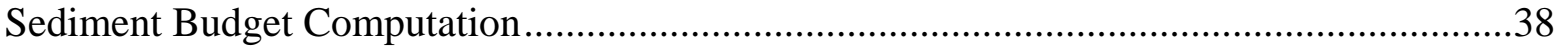

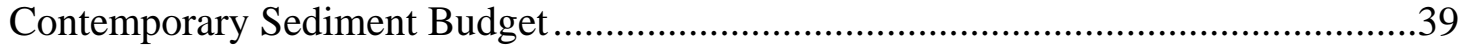

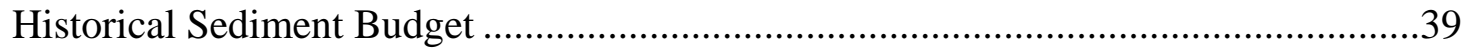

Geomorphic Characterization of the Channel Network ................................................43

Delineation of Channel Network and Partitioning of Geomorphic Channel

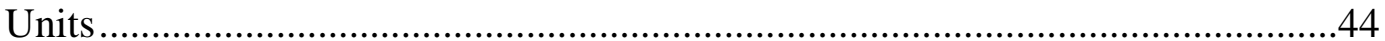

Current Channel Conditions......................................................................................55

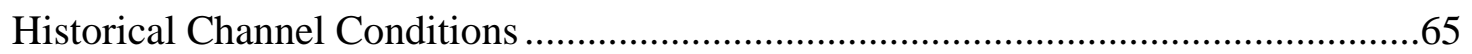

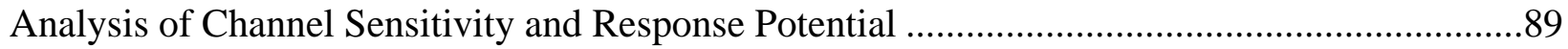

Main Stem Response to Historical Watershed Disturbance ...............................................89

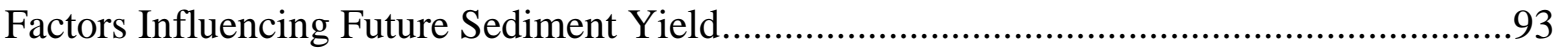

Projected Channel Response................................................................................93

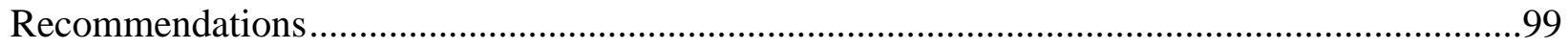

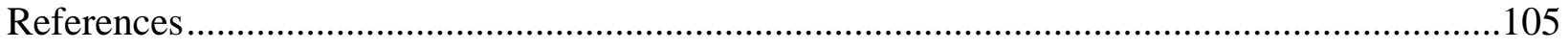


Appendix A Historical Forest Clearing

Appendix B Photographic Documentation of Field Reconnaissance

Appendix C Channel Survey Field Notes

Appendix D Laboratory Results

Appendix E Landslide Inventory

Appendix F Analysis of Surface Erosion from Roads

Appendix G Reconstruction of Historical Sediment Yield

Appendix H Channel Locations and Radii of Curvature for Each Photo Year

Appendix I Floodplain Cross-sections: Grays River Response Reach 


\section{Tables}

Table 1. Estimated flood frequency discharge (in cubic feet per second) for the main stem Grays River at State Highway 4, estimated using the data transfer procedure and Naselle River gauge (USGS gauge 12010000).

Table 2. Summary of forest clearing in the Grays River watershed.

Table 3. Summary of Grays River watershed sediment sample characteristics.

Table 4. Average depth and sediment delivery ratios for upper Grays River watershed landslide types.

Table 5. Historical sediment yield to the upper Grays River watershed from landslides..........24

Table 6. Landslide association with roads and channels in the upper Grays River watershed.

Table 7. Upper Grays river watershed sediment yield (tons $/ \mathrm{km}^{2} /$ year) by mass wasting map unit.

Table 8. Erodibility ratings based on $\mathrm{K}_{\mathrm{w}}$ factors and slope (WDNR 1997).

Table 9. Summary of surface erosion factors and rates for roads within the upper Grays River watershed.

Table 10. Soil creep rates and watershed characteristics from prior studies.

Table 11. Sediment yield from mass wasting in undisturbed watersheds from prior studies.

Table 12. Average sediment yield in the upper Grays River watershed under current conditions (2003) and long-term background conditions.

Table 13. Predicted channel response to a declining ratio of transport capacity to sediment supply.

Table 14. Summary of channel response to land use practices.

Table 15. Slope range and contributing drainage area used to predict Grays River channel network reach morphology.

Table 16. Length and percentage of each geomorphic channel unit in the upper Grays River watershed.

Table 17. Aerial photographs used in the analysis of historical channel migration patterns in the Grays River.

Table 18. Linear analysis of lateral channel migration rates for the main stem Grays River.

Table 19. Polygon analysis of erosion rates and lateral channel migration rates for the main stem, West Fork, and South Fork Grays River. 
Table 20. Radii of curvature for each Grays River meander bend measured for the period of record (1939-2003).

Table 21. Summary of historical observations for the main stem Grays River.

\section{Figures}

Figure 1. Vicinity map, upper Grays River watershed, Washington.

Figure 2. Grays River response reach from RK 20 to 22 in 1996, prior to the 1999 avulsions, and in 2003. .7

Figure 3. Geologic map of the upper Grays River watershed, Washington......

Figure 4. Mean monthly rainfall at the Grays River hatchery weather station on the West Fork Grays River from 1962 through 2004.

Figure 5. Annual rainfall totals at the Grays River hatchery weather station on the West Fork Grays River from 1962 through 2004.

Figure 6. Monthly rainfall totals at the Grays River hatchery weather station on the West Fork Grays River from 1962 through 2004.

Figure 7. Grain-size distributions for bulk sediment samples collected from Grays River watershed landslide deposits.

Figure 8. Variation in landslide frequency with maximum time since timber harvest in the upper Grays River watershed.

Figure 9. Root growth and decay contributions of lateral root cohesion after clear-cut logging for two sites in the Oregon Coast Range (Schmidt et al. 2001).

Figure 10. Landslide association with roads in the upper Grays River watershed.

Figure 11. Locations of historical and potential debris flow initiation based on GISderived intersections of roads and colluvial channels in the upper Grays River watershed, Washington.

Figure 12. Ground surface erosion potential based on whole soil erosion factors (NRCS 2004) and slope in the upper Grays River watershed, Washington.

Figure 13. Predicted temporal variation in total upper Grays River watershed sediment yield by (a) subbasin group and (b) source.

Figure 14. Log-bin-averaged local slope derived from 10-meter grid size digital elevation model (DEM) for the upper Grays River watershed.

Figure 15. Predicted spatial distribution of channel-reach morphology based on channel slope (Montgomery and Buffington 1997) in the upper Grays River watershed, Washington. 
Figure 16. Relative transport capacity in terms of unit stream power in the channel network of the upper Grays River watershed, Washington.

Figure 17. Geomorphic channel units and locations of survey reaches within the upper Grays River watershed, Washington.

Figure 18. Locations of radiocarbon dating samples and the extent of remaining and estimated historical terrace surfaces upstream of the observed debris dam evidence in the South Fork Grays River, Washington.

Figure 19. Splash-dam near the mouth of the South Fork Grays River, June 12, 1937. .66

Figure 20. Historical channel locations for 1939-2004, Grays River response reach (RK 18.5 to 22.5).

Figure 21. Avulsion paths and locations of longitudinal profile and cross-sections based on 2004 PNNL topographic survey of Grays River response reach (RK 18.5 to 22.5).

Figure 22. Schematic diagram of the measurement of radius of curvature of a meander bend (adapted from Nanson and Hickin 1983). .77

Figure 23. Bedrock and levee controls on channel migration in the Grays River response reach (RK 18.5 to 22.5 ).

Figure 24. Average radius of curvature for five meander bends on the Grays River, Washington, during the period of record (1939-2003).

Figure 25. Meander migration rate versus bend curvature $\left(r_{c} / w\right)$ for the Beatton River, British Columbia (Nanson and Hickin 1983), illustrating optimal range of channel avulsions for $1<\mathrm{r}_{\mathrm{C}} / \mathrm{w}<2$ (A) and maximum migration rate for 2.5 $<\mathrm{r}_{\mathrm{C}} / \mathrm{W}<4$ (B)

Figure 26. Temporal variation in meander bend curvature relative to the 1999 avulsions in the Grays River, Washington.

Figure 27. Temporal variation in sinuosity of the main stem Grays River.

Figure 28. Channel profile of the Grays River response reach from State Highway 4 to the bedrock canyon.

Figure 29. Composite plot illustrating relations between forcing functions and response variables.

Figure 30. Conceptual model of temporal trends in sediment yield to the upper Grays River channel network and channel response to an assumed historical timber harvest.

Figure 31. Conceptual restoration strategy for the Grays Rivr response reach (RK 18.5 to 22.5). 



\section{Abbreviations}

bp before the present time

cm centimeter

CMZ channel migration zone

DEM digital elevation model

DOQQ digital orthophoto quarter quadrangle

ELJ engineered logjam

GIS geographic information system

GPS global positioning system

km kilometer

$\mathrm{km}^{2} \quad$ square kilometer

LWD large woody debris

$\mathrm{m}^{2} \quad$ square meter

$\mathrm{m}^{3} \quad$ cubic meter

mm millimeter

NRCS Natural Resources Conservation Service

PNNL Pacific Northwest National Laboratory

RK river kilometer

$\mathrm{RMZ} \quad$ riparian management zone

USGS U.S. Geological Survey

USLE universal soil loss equation

WAGDA Washington Geospatial Data Archive

WDFW Washington Department of Fish and Wildlife

WDNR Washington Department of Natural Resources 



\section{Executive Summary}

This report presents the findings of a geomorphic investigation of sediment production and channel response in the Grays River watershed upstream of State Highway 4, 18.5 kilometers upstream of the river's confluence with the Columbia River in southwest Washington state. This investigation was completed for Pacific Northwest National Laboratory as part of the Grays River Watershed and Biological Assessment commissioned by Bonneville Power Administration (project number 2003-013-00) to assess impacts on salmon habitat in the upper Grays River watershed and present recommendations for habitat improvement.

The objective of this investigation is to assess general habitat degradation within the watershed, and in particular, the causal mechanisms underlying a 1999 channel avulsion at river kilometer 21.5 that destroyed a state chum spawning channel. Historical land use practices were found to be the principal agent of habitat loss within the river system.

The upper Grays River watershed has experienced major changes in land use and alterations to the channel network that have significantly affected geomorphic processes and resulted in chronic habitat degradation. Over 98 percent of the 230-square-kilometer upper watershed has been logged since the early 1900s. Results indicate that current sediment production in the watershed is 9 to 20 times greater than the background erosion rate. Sediment production (mass wasting) was found to lag approximately 10 to 30 years behind forest clearing. The maximum rate of forest harvest occurred between 1976 and 1983; hence a peak in sediment production may not have yet occurred. The large increase in sediment supply has had the most noticeable impact in the 4-kilometer reach of the Grays River upstream of State Highway 4 where much of the coarse sediment coming out of the upper watershed is deposited.

A survey of channels throughout the watershed indicates high sediment loads, limited channel complexity, and a loss of sediment storage potential in reaches that could act as capacitors to moderate downstream sediment flux. The watershed is dominated by relatively steep, confined channels that efficiently route sediment to the broad alluvial valley of the lower Grays River.

Channel response in the lower Grays River (river kilometer 18.5 to 22.5) is estimated to lag behind the forest harvest by approximately 25 to 45 years. Channel response has been moderated by diking and levee construction intended to control channel migration and flooding within this reach. The diking began by 1966 and has resulted in constriction of the channel migration zone. Artificial confinement and high sediment loads created unstable conditions that led to the catastrophic 1999 channel avulsion, which destroyed the state spawning channel and the historical Gorley residence.

Without significant efforts to restore riparian forests and instream wood debris, together with more sustainable land management practices to reduce sediment production, instability of the lower river channel is expected to continue causing adverse impacts on habitat and property for decades to come. If historical levels of timber harvest are not significantly reduced, soil loss will 
severely reduce the long-term productivity of the watershed, in addition to aggravating sedimentation, erosion, and flooding within the lower Grays River valley.

Three primary objectives are recommended to guide watershed restoration efforts toward the goal of improving salmonid habitat:

1. Improve capacity of the lower Grays River (RK 18.5 to 22.5) to accommodate sedimentation and channel migration by restoring riparian forests, introducing large woody debris to the channel, and retiring existing levees (either by proactive removal, setback, or allowing river processes to erode levees).

2. Restore riparian forests and promote wood loading to increase sediment storage within response channels and improve instream habitat.

3. Limit land use activities that trigger sediment production in the upper watershed.

These actions will allow the Grays River to naturally create and sustain habitat previously provided by the state spawning channel destroyed in 1999. 


\section{Introduction and Purpose}

This investigation, completed for the Pacific Northwest National Laboratory (PNNL), is part of the Grays River Watershed and Biological Assessment commissioned by Bonneville Power Administration under project number 2003-013-00 to assess impacts on salmon habitat in the upper Grays River watershed and present recommendations for habitat improvement.

Like many watersheds in western Washington, the Grays River watershed has been subjected to significant changes in land use, including timber harvest, road construction, floodplain clearing, agriculture, and diking. The overall objectives of the Grays River Watershed and Biological Assessment are to 1) perform a comprehensive watershed and biological analysis, including hydrologic, geomorphic, and ecological assessments; 2) develop a prioritized list of actions to protect and restore critical salmon spawning habitat in the Grays River based on comprehensive geomorphic, hydrologic, and stream channel assessments; 3) and gain a better understanding of salmon habitat requirements and survival within the lower Columbia River and the Grays River subbasin.

This report presents the findings of the geomorphic assessment and is intended to support the overall PNNL project by evaluating the following:

- The effects of historical and current land use practices on erosion and sedimentation within the channel network

- The ways in which these effects have influenced the sediment budget of the upper watershed

- $\quad$ The resulting responses in the main stem Grays River upstream of State Highway 4

- $\quad$ The past and future implications for salmon habitat.

\section{Study Objectives}

The objective of this investigation is to assess how sediment production in the upper Grays River watershed and alterations to floodplains have affected the morphology of the channel network. The elements of this geomorphic investigation include 1) analysis of mass wasting and surface erosion, 2) construction of a sediment budget, 3) geomorphic characterization of the channel network, and 4) analysis of channel sensitivity and response potential. This report also includes a discussion of potential restoration strategies to improve processes associated with sediment production and channel response that are responsible for the formation of quality habitat conditions for salmon. 
The report is divided into six sections:

- Introduction and Purpose

- Background Information and Watershed Characterization

- Methods and Results

- Analysis of Channel Sensitivity and Response Potential

- Recommendations for Improving Salmonid Habitat

- References. 


\section{Background Information and Watershed Characterization}

The upper Grays River watershed is located within Wahkiakum, Pacific, and Lewis counties in the southwest corner of Washington state (Figure 1). The Grays River watershed was once noted for its large runs of salmon. In 1936, 6,286 spawning or spawned-out chum salmon were counted below the falls within the confined bedrock canyon on the main stem of the Grays River, which extends from river kilometer (RK) 22.5 to RK 27, and an additional 1,388 chum were counted in the West Fork Grays River (Bryant 1949). Today the Grays River chum run is a fraction of its historical size. Peak fish counts for Grays River chum salmon for 1987 through 2000 ranged from 224 to 2,490 fish (adapted from Roler 2001). Various land use activities in the watershed (timber harvest, road construction, agriculture, and diking) have resulted in landslides, erosion and channel instability, and the loss of riparian function that have caused serious damage to salmon spawning habitat and have been largely responsible for the decline in chum stocks (Washington Conservation Commission 2001; WDFW 2001).

The few stable spawning areas in the Grays River that are still available are subject to extremely variable conditions that further threaten the chum stocks. This instability is illustrated by a channel avulsion that occurred in December 1999 (Figure 2). The avulsion occurred within a floodplain reach of the main stem Grays River at the lower extent of the upper watershed project area. This reach, which extends from the State Highway 4 bridge at RK 18.5 to the downstream end of the confined bedrock canyon at RK 22.5, is the farthest upstream part of the wide alluvial floodplain that characterizes the lower part of the Grays River. Because this reach is less confined and has a lower gradient than the upstream portions of the Grays River, it responds to changes in the hillslope condition and channel processes occurring upstream. Hence this reach is termed the Grays River response reach within this report (Figure 2).

The 1999 avulsion that occurred within the response reach breached a levee that was constructed in the 1960s and destroyed the Washington Department of Fish and Wildlife (WDFW) chum salmon spawning project on the main stem Grays River near the confluence of the main stem and West Fork Grays River. Deposition associated with the avulsion event inundated a part-time residence (the Gorley residence) on the floodplain with 1 meter of alluvial sediment, and the new channel alignment isolated this property from access roads.

\section{Watershed Description}

The entire Grays River watershed encompasses 322 square kilometers ( $\mathrm{km}^{2}$. The upper Grays River watershed (the study area for this investigation, shown in Figure 1) totals $230 \mathrm{~km}^{2}$. The downstream end of the study area is defined by the intersection of the main stem Grays River with State Highway 4, located approximately $18.5 \mathrm{~km}$ upstream of the Columbia River. The upper watershed ranges in elevation from 820 meters (2,691 feet) in the northwest portion of the watershed to 14 meters (45 feet) at State Highway 4. 
The northern portion of the watershed is steep and is dissected by a dense stream network. The southern portion of the watershed is characterized by moderately steep terrain and a stream network with relatively lower density. Unconfined floodplain rivers are located in the lower portion of the study area and locally within the watershed interior along the West, East, and South forks of the Grays River. The lower main stem of the Grays River is tidally influenced from approximately State Highway 4 to the point where it enters Grays Bay on the lower Columbia River.

\section{Geologic and Geomorphic Overview}

\section{Watershed Geology}

The geologic history of the Grays River watershed has been governed largely by regional tectonics associated with the Cascadia subduction zone. Compression resulting from the northeast subduction of the Juan de Fuca Plate beneath the North American Plate is responsible for uplift of both the Olympic Mountains to the north of the project site and the Oregon Coast Range located to the south. The rock units exposed in the upper Grays River watershed consist of oceanic crust accreted to the North American Plate during subduction. Some of these rock units include marine sediments that have been recycled by the erosion and subsequent accretion of previously uplifted oceanic rocks (Walsh et al. 1987).

The topography of the watershed is characterized by steep mountainous uplands, moderately sloping hills and ridges, and unconfined alluvial valleys. The main stem and tributary forks of the Grays River form a dendritic network fed by a trellis pattern of headwater channels, particularly in the northeast portion of the watershed. Tributary channels are typically steep and confined, whereas the unconfined valley segments occupy broad floodplains.

The oldest rock unit exposed in the watershed is a sequence of Lower Eocene submarine basalts and volcaniclastic rocks of the Crescent Formation (Figure 3). Rocks of the Crescent Formation locally contain interbedded basaltic tuff and siltstone and are deformed and highly fractured. The Crescent Formation occurs throughout the northern third of the upper Grays River watershed, which coincides with the headwaters of the main stem and West Fork (Walsh et al. 1987).

Eocene marine sedimentary rocks (primarily siltstones and sandstones) overlie the Crescent Formation and occur along an east-west-trending band in the central region of the watershed. Marine sediments are also found in the lower half of the West Fork Grays River watershed. The southern half of the watershed is underlain by younger Eocene basalt flows and flow breccias. These rocks occur in subbasins of the South Fork and middle reach of the main stem Grays River. The contact between the Eocene basalt and marine sediments is associated with an abrupt change in the valley morphology of the main stem Grays River. The Grays River is confined within a narrow valley where it cuts through relatively hard basalts, whereas the river occupies a wide alluvial floodplain downstream where it encounters softer marine sediments. 


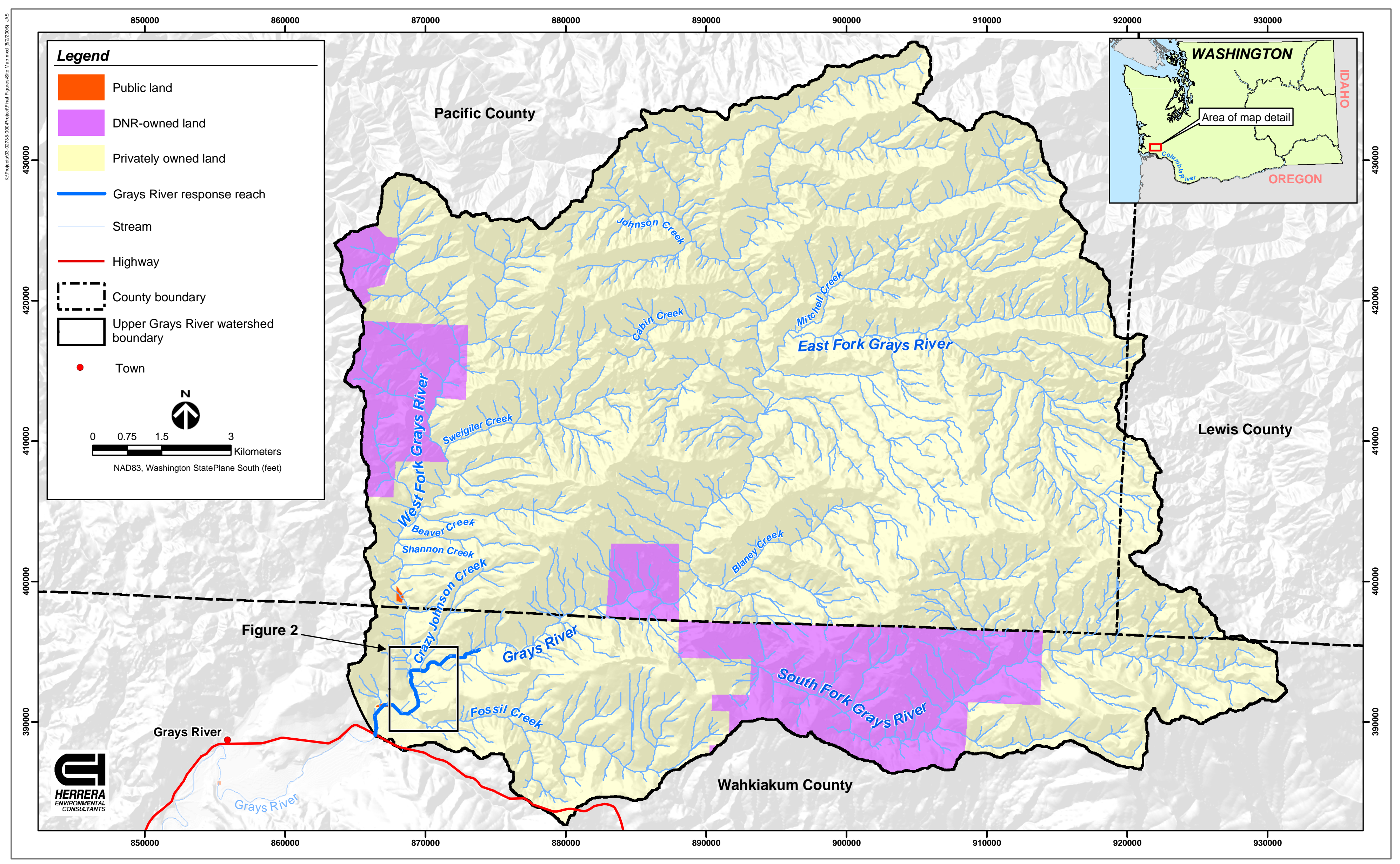

Figure 1. Vicinity map, upper Grays River watershed, Washington. 


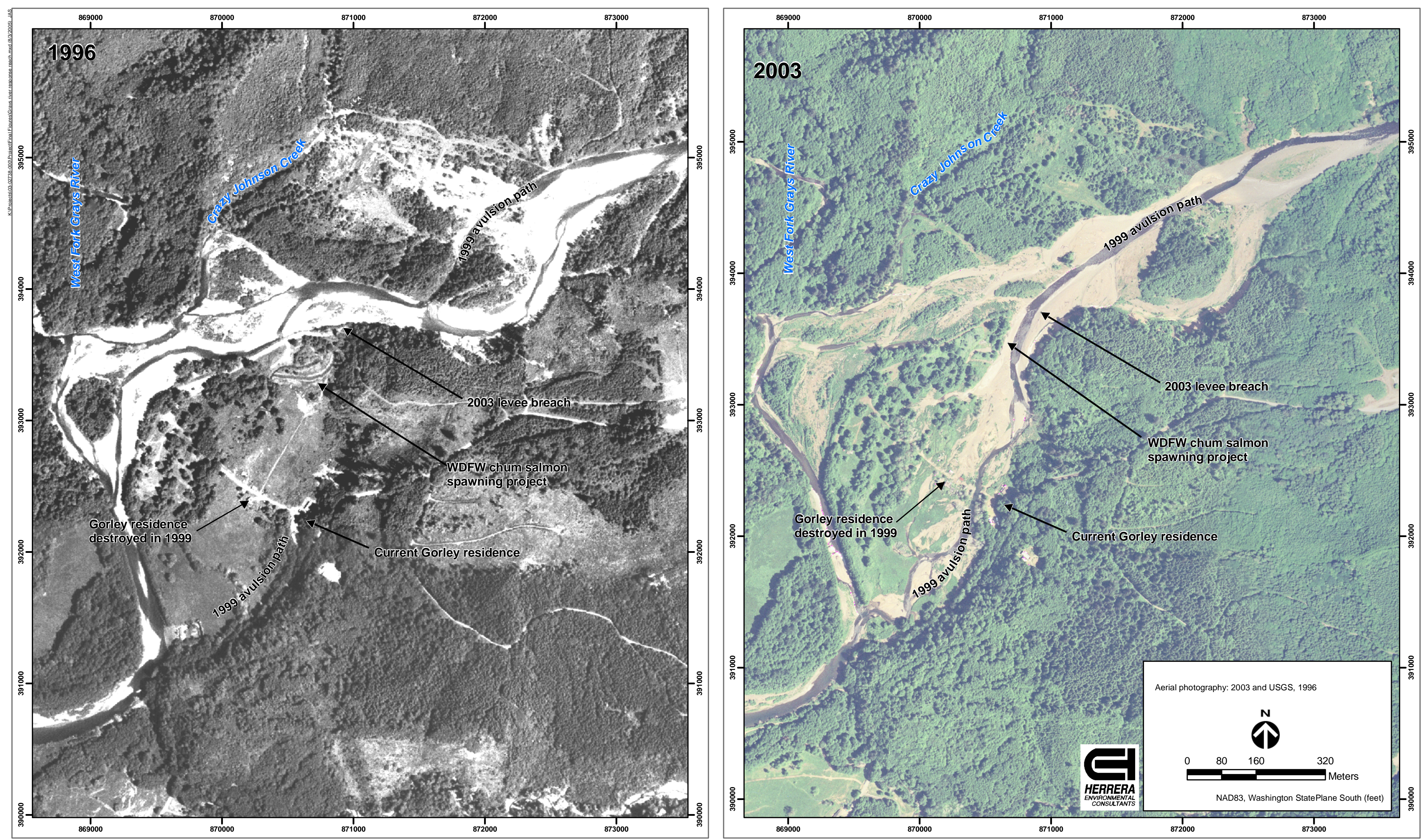

Figure 2. Grays River response reach from RK 20 to 22 in 1996, prior to the 1999 avulsions, and in 2003 



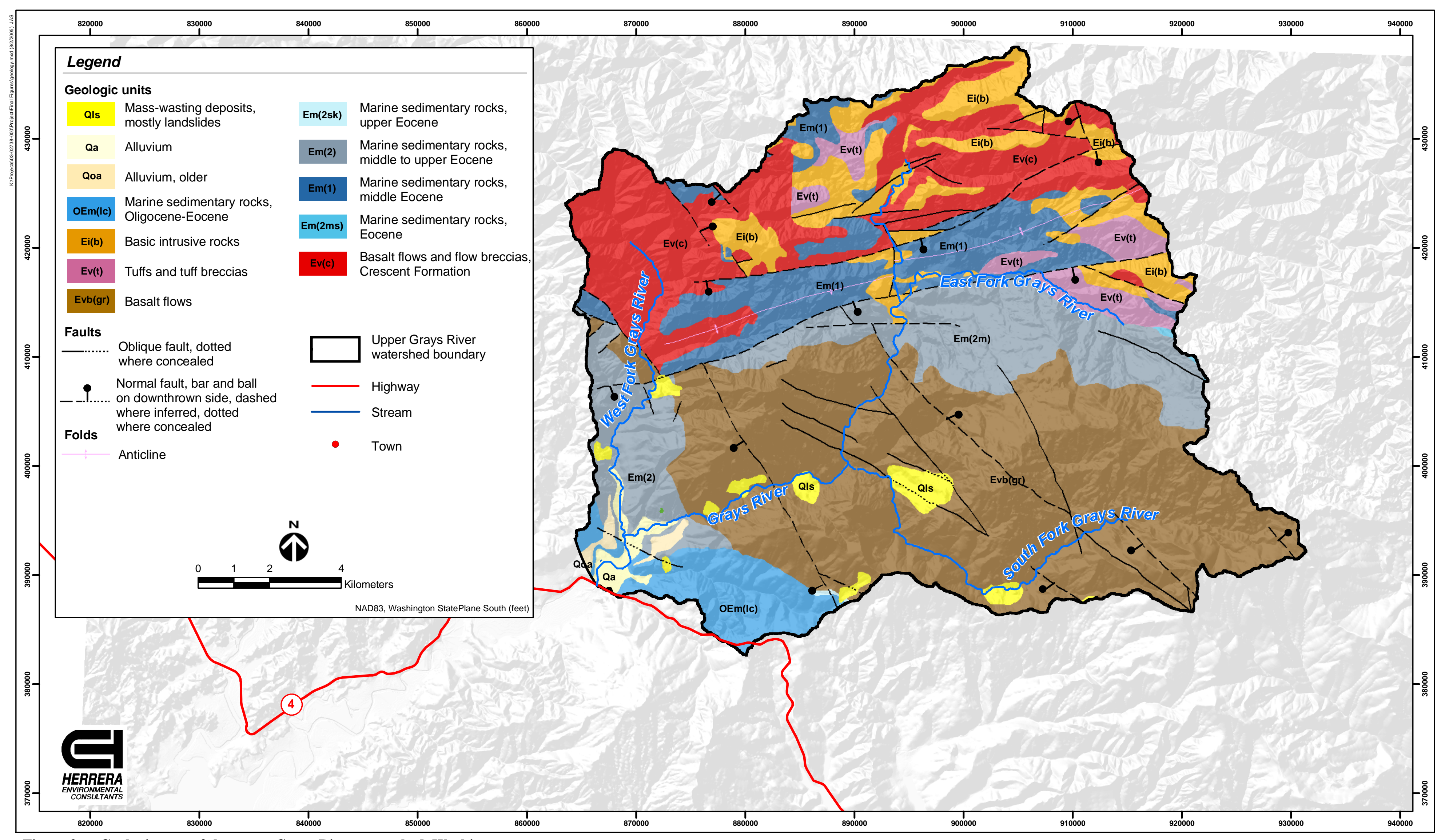

Figure 3. Geologic map of the upper Grays River watershed, Washington. 

Secondary rocks within the upper Grays River watershed include fault-bounded Eocene tuffs and tuffacious breccia. These rocks occur in the northern half of the watershed in contact with the Crescent Formation and marine sedimentary rocks. The tuff is poorly indurated and weathers rapidly to silty sand. Minor occurrences of basic igneous rocks intrude into the Crescent Formation in the northern portion of the study area. The gabbro and basalt sills of these basic intrusive rocks are interpreted as possible feeders of other Tertiary volcanic rocks in the region.

Oligocene marine sedimentary rocks are found in the extreme southwest corner of the study area, primarily within the Fossil Creek basin, and beneath the alluvial cover of the main stem Grays River valley near State Highway 4. Tuffaceous siltstone and basaltic sandstone of the Oligocene marine sediments form the valley walls of the lower Grays River floodplain.

Recent alluvium covers the basement rocks in all of the major river valleys. The most extensive deposits are mapped in the lower Grays River main stem below the contact with the marine sediments and basalt. Older alluvium forms terraces above the floodplain of the lower main stem. Mass-wasting deposits occur throughout the upper Grays River watershed. The largest mass-wasting deposits are mapped in the southern half of the watershed within the basalt and marine sedimentary units.

\section{Geomorphic Context}

Within the channel network of the upper watershed, the Grays River response reach is of particular interest because of its historical and potential future value as salmon habitat and because it is sensitive to disturbances resulting from upstream changes in land use. Recent instability exhibited within the Grays River response reach indicates that the hillslope condition and channel processes within the upper watershed have been significantly affected by widespread timber harvest activities. This investigation evaluates the magnitude of the disturbances that have resulted from these land use changes as well as the anticipated duration of the instability.

Timber harvest is the principal land use in the upper Grays River watershed. Approximately 95 percent of the watershed is privately owned industrial forest land, and the remainder is held by the Washington Department of Natural Resources (WDNR). The watershed was once forested by old-growth Sitka spruce, western hemlock, and Douglas-fir, but by 2003 only 2 percent of the original old growth remained and a dense network of forest roads covered the watershed.

Forest clearing and the associated construction of roads have been shown to significantly affect a variety of landscape processes including watershed hydrology, sediment production, and the morphologic characteristics of stream channels (Montgomery 1994; Jones and Grant 1996). Swanson and Dyrness (1975) found that timber harvest and road construction appear to have increased landslide activity on road and clear-cut sites five-fold relative to forested areas over a period of about 20 years. Furniss et al. (1991) reviewed nine studies providing estimates of landslides resulting from various sources and found that slides and sediment yield from logging 
roads were greater than all other forest activities combined, and that these activities resulted in sediment yields 26 to 346 times greater than undisturbed sites. Reid and Dunne (1984) reported a 40 percent increase in fine sediments from gravel-surfaced logging roads, which were heavily used by logging trucks.

The increased sediment production that results from timber harvest can significantly affect downstream channel processes. A variety of potential channel responses following changes in sediment supply are dependent on channel confinement, sediment transport capacity, slope, and roughness elements (Montgomery and Buffington 1997). Stover and Montgomery (2001) found that channel aggradation and flooding on the main stem Skokomish River followed timber harvesting, road construction, and in-channel debris removal. Additional channel instability results from the harvest of riparian forest vegetation. Micheli et al. (2003) found that unforested agricultural floodplains are likely to erode twice as fast as forested floodplains. Further, the harvest of riparian vegetation removes the most immediate source of large woody debris, which can act not only to provide channel stability and habitat complexity but also to effectively trap bed material and store large volumes of sediment (Abbe 2000; Massong and Montgomery 2000; Lancaster et al. 2001; Abbe and Montgomery 2003).

\section{Climate}

The Grays River watershed receives heavy rainfall from moist frontal systems originating in the Pacific Ocean. Precipitation records have been recorded at the WDFW Grays River fish hatchery since 1962. Approximately 77 percent of precipitation falls during the winter months from October through March (Figure 4). Annual precipitation measured at the hatchery for the period 1962 to 2004 ranged from 191 to 346 centimeters (cm), with a mean of 279 centimeters (Figure 5). Precipitation increases with elevation in the watershed, from approximately 200 centimeters near the mouth of the Grays River to 300 centimeters in the upper watershed. The annual precipitation measured at the Grays River hatchery during the period 1962 to 2004 ranged from 191 to 346 centimeters (Figure 5).

The variability in monthly precipitation for the period of record presented in Figure 6 illustrates how similar annual rainfall totals for 2 years can result from distinct patterns of rainfall over a given year. Annual rainfall totals for 1998 and 1999 are comparable (Figure 5). The rainfall total in 1998 resulted from a number of moderately high monthly totals, whereas rainfall in 1999 began and ended with consecutive months of very high rainfall, thereby displaying a similar monthly average but one that results from greater variability (Figure 6).

\section{Hydrology}

Limited discharge data are available for the Grays River watershed. Prior to the onset of this investigation there had been no active gauges in the Grays River watershed since the 1970s; however, four U.S. Geological Survey (USGS) gauges were active between the 1950s and 1970s. The historical gauges were located on the South Fork Grays River, the main stem Grays River 


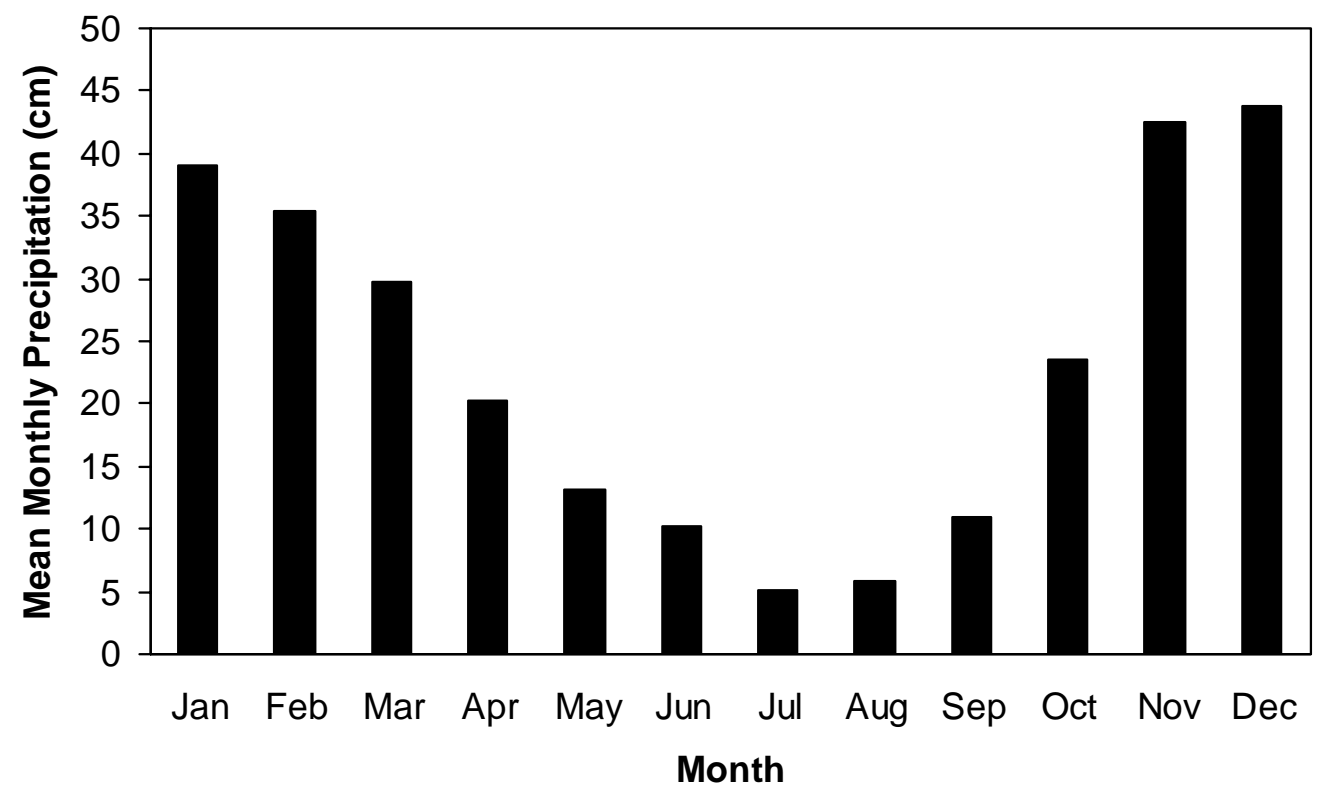

Figure 4. Mean monthly rainfall at the Grays River hatchery weather station on the West Fork Grays River from 1962 through 2004.

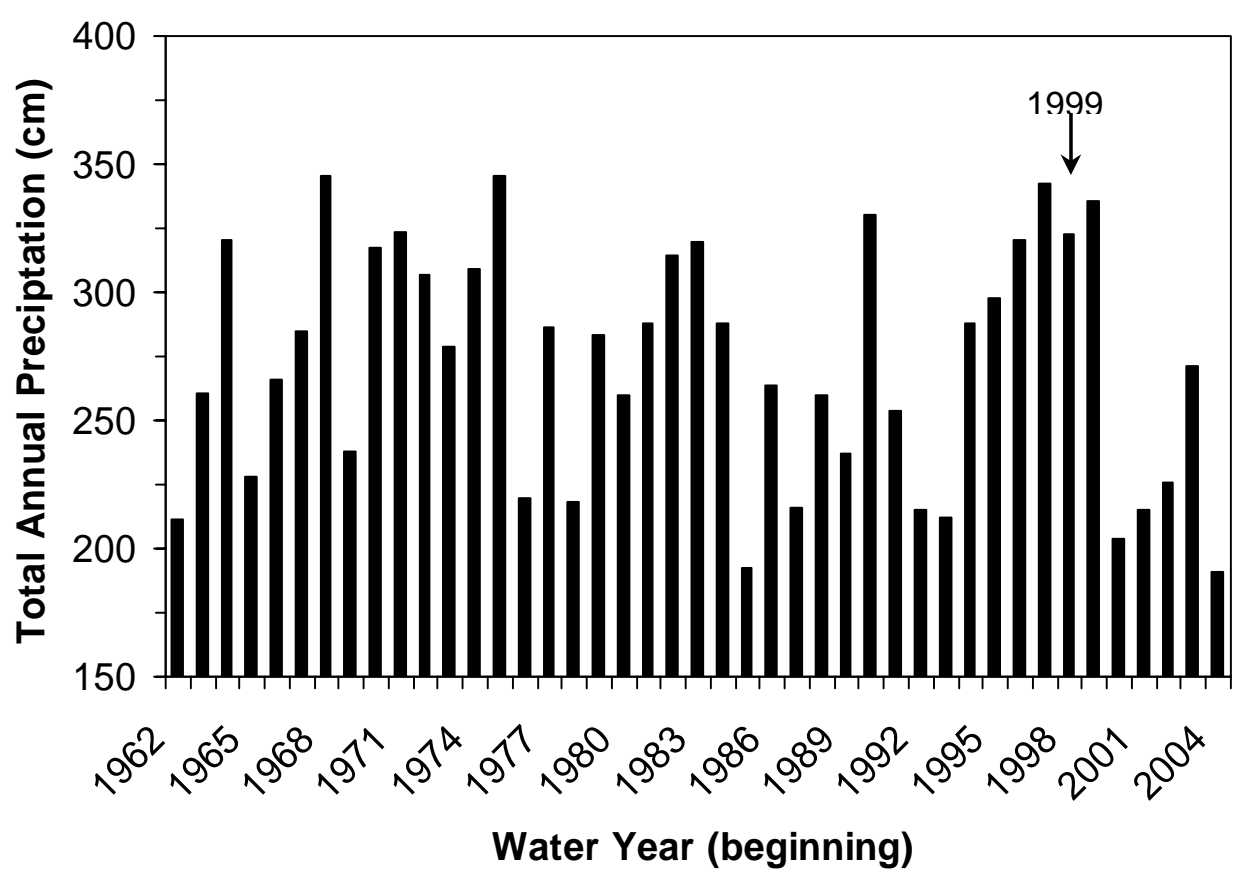

Figure 5. Annual rainfall totals at the Grays River hatchery weather station on the West Fork Grays River from 1962 through 2004. 
just downstream of its confluence with the South Fork, the West Fork Grays River, and the main stem Grays River near the town of Grays River, Washington. A recent analysis of these data and correlation with long-term gauge records from nearby drainage basins provide the best available estimate of flood frequency values (West Consultants, Inc. 2004).

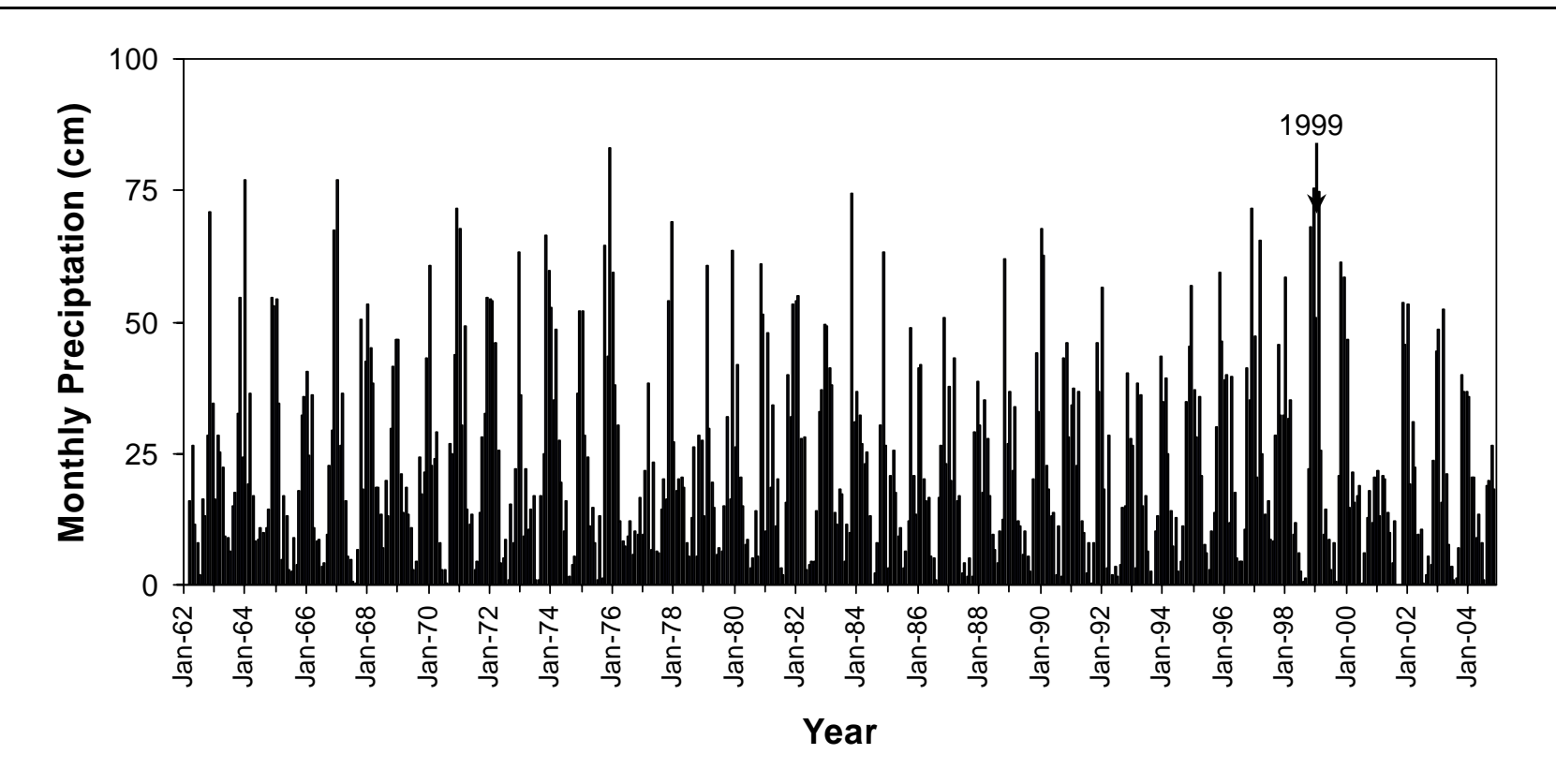

Figure 6. Monthly rainfall totals at the Grays River hatchery weather station on the West Fork Grays River from 1962 through 2004.

The results from three analytical methods were compared to determine the most appropriate method of estimating flood frequency values for the main stem of the Grays River at State Highway 4 (West Consultants, Inc. 2004). Flood frequency values were calculated using the data area transfer procedure, the USGS regional regression equation, and a localized regression analysis. Evaluating the produced results and assumptions inherent in using these methods indicated that the data transfer procedure supplies the most reliable flood frequency values when applied to the Naselle River gauge (USGS gauge 12010000) near Naselle, Washington (Table 1).

Table 1. Estimated flood frequency discharge (in cubic feet per second) for the main stem Grays River at State Highway 4, estimated using the data transfer procedure and Naselle River gauge (USGS gauge 12010000).

\begin{tabular}{cc}
\hline \hline Recurrence Interval & Discharge (cfs) \\
\hline 2-year & 8,590 \\
10-year & 14,300 \\
50-year & 18,500 \\
100-year & 20,200 \\
500-year & 24,300 \\
\hline \hline
\end{tabular}

Source: West Consultants, Inc. (2004). 


\section{Land Ownership and Historical Forest Clearing}

Approximately 95 percent of the upper Grays River watershed is owned by private timber companies. The remainder is held by the Washington Department of Natural Resources. The history of early timber harvest activities within the Grays River watershed is described in detail by Scott (2004 personal communication) and references cited therein. Geographic information system (GIS) mapping coverages illustrating the temporal patterns of forest clearing for the period of record (1942-2003) are presented graphically in Appendix A. Harvest rates and rotation are summarized in Table 2.

Table 2. Summary of forest clearing in the Grays River watershed.

\begin{tabular}{cccccc}
\hline \hline \multirow{2}{*}{ Period } & \multirow{2}{*}{$\begin{array}{c}\text { Average } \\
\text { Harvest Rate } \\
\left(\mathrm{km}^{2} / \text { year }\right)\end{array}$} & $\begin{array}{c}\text { Total Percentage of } \\
\text { Upper Watershed } \\
\text { Harvested }^{\mathrm{a}}\end{array}$ & \multicolumn{3}{c}{ Percentage of Harvest Area by Stand-Age Category } \\
\cline { 6 - 6 } & 3.0 & 8.2 & Old Growth & Second Growth & Third Growth \\
\hline $1905-1942$ & 3.3 & 19.1 & 100.0 & 0.0 & 0.0 \\
$1942-1953$ & 5.0 & 40.7 & 94.4 & 5.6 & 0.0 \\
$1953-1964$ & 5.3 & 73.6 & 93.2 & 3.0 & 0.0 \\
$1964-1976$ & 9.1 & 88.9 & 83.3 & 15.7 & 0.0 \\
$1976-1983$ & 5.5 & 94.4 & 40.0 & 58.0 & 0.5 \\
$1983-1990$ & 4.1 & 97.6 & 20.1 & 77.4 & 2.0 \\
$1990-1996$ & 3.1 & - & - & - & 1.5 \\
$1996-2003$ & & &
\end{tabular}

Note: Data before 1996 from Scott (2004 personal communication).

${ }^{a}$ Represents the proportion of the watershed that has been harvested at least once.

Timber harvest began in the Grays River watershed in 1905 within a land lease located in the central portion of the watershed (Figure A-1, Appendix A). Prior to 1942, the average harvest rate was $3.0 \mathrm{~km}^{2} /$ year, or approximately 1.3 percent of the watershed per year (Table 2 ). By 1942, approximately 8 percent of the upper watershed had been harvested. Timber harvesting continued at a rate of $3.3 \mathrm{~km}^{2} /$ year between 1942 and 1953 during expansion of activities into the eastern and northern portions of the study area. Widespread use of roads in harvesting operations began in the 1950s.

The harvesting of second-growth forest had begun by 1953. Harvest operations expanded throughout the study area and increased to $5.0 \mathrm{~km}^{2} /$ year between 1953 and 1964 . During this period (1953 to 1964), the fraction of remaining old growth declined from 59 percent to 39 percent. The period between 1964 and 1976 marked expansion of harvest practices to the northeast portion of the Gray River watershed. During this period, the average harvest rate was $5.3 \mathrm{~km}^{2} /$ year. By 1976, only 18 percent of the original old-growth forest in the watershed remained.

Between 1976 and 1983, timber harvest rates peaked at $9.1 \mathrm{~km}^{2} /$ year, or 4 percent of the watershed per year, and included the logging of some third-growth forest. Ninety-five percent of the old-growth forest within the Grays River watershed had been harvested by 1983. Annual 
harvest rates declined thereafter to $5.5 \mathrm{~km}^{2} /$ year between 1983 and 1990, $4.1 \mathrm{~km}^{2} /$ year between 1990 and 1996, and $3.1 \mathrm{~km}^{2} /$ year between 1996 and 2003. Approximately 2 percent, or $4.6 \mathrm{~km}^{2}$ (1,137 acres), of the original old-growth forest remained as of 2003. 


\section{Methods and Results}

The assessment of current and historical geomorphic conditions within the upper Grays River watershed was conducted at both the watershed scale and reach scale. Historical trends in sediment production from hillslopes were reconstructed at the watershed scale from timber harvest records and historical aerial photographs, as well as from prior studies of natural background erosion rates for undisturbed forested basins. The aerial photographic record was also used to evaluate the reach-scale response of alluvial valley segments to historical increases in sediment loading related to land use practices. Historical records were augmented with field investigations of the study area.

The methods and results of the geomorphic assessment begin with a discussion of sediment generation from mass wasting, road-surface erosion, and soil creep. Records of historical land use are then used to reconstruct a historical sediment budget for the watershed, which is followed by a description of current channel conditions and channel response to increased sediment inputs.

\section{Assessment of Mass Wasting and Surface Erosion}

Sediment production from hillslopes begins with the chemical and mechanical weathering of bedrock to create colluvium and soil. The rate at which colluvium is produced is dependent on the regional tectonics, bedrock lithology, precipitation, ambient temperature, and vegetation. Much of the bedrock exposed at the surface within the Grays River watershed is highly weathered and prone to erosion where vegetation has been removed. Hence, the watershed has the potential to yield large quantities of sediment. In the past, dense forests that once mantled the watershed moderated both the production of sediment from hillslopes and the routing of sediment through the channel network. Colluvium produced from the weathering of bedrock is transported downslope by soil creep, surface runoff, and mass wasting. Mobilized sediment either is deposited at the base of slopes or enters the channel network where it is routed downstream by fluvial processes.

Sediment generation within the Grays River watershed was evaluated in terms of the dominant geomorphic processes observed during the field reconnaissance of the watershed and from aerial photographic analysis of principal sediment source terrains. Geomorphic processes responsible for sediment delivery to the channel network and included within this analysis are classified as mass wasting, surface erosion from disturbed hillslopes, road-surface erosion, and soil creep.

\section{Current Hillslope Conditions}

Current mass-wasting and surface-erosion conditions were documented during a field investigation of the upper Grays River watershed on October 26-28, 2004. Field conditions are documented in the photographic log (Appendix B). The field investigation focused on landslides 
identified in the 2003 aerial photographs to quantify failure mechanisms, in-place and run-out volumes, landslide depth, and fraction of sediment delivered to the channel network.

Ten bulk sediment samples were collected from landslide deposits located throughout the upper Grays River watershed to characterize grain-size distributions of colluvial sediment supplied to the channel system. The sediment samples are representative of the various types of masswasting features (described later in this report) and parent rock type from which the deposits originated (Table 3). Sediment samples were submitted to a geotechnical laboratory for sieve analysis of sediment greater than 0.067 millimeters $(\mathrm{mm})$. The laboratory data sheets are compiled in Appendix D.

Table 3. Summary of Grays River watershed sediment sample characteristics.

\begin{tabular}{llccc}
\hline \hline $\begin{array}{c}\text { Sample } \\
\text { Identification }\end{array}$ & \multicolumn{1}{c}{ Lithology } & $\begin{array}{c}\mathrm{D}_{10} \\
(\mathrm{~mm})\end{array}$ & $\begin{array}{c}\mathrm{D}_{50} \\
(\mathrm{~mm})\end{array}$ & $\begin{array}{c}\mathrm{D}_{90} \\
(\mathrm{~mm})\end{array}$ \\
\hline Grays-1 & Evb(gr) basalt & 0.03 & 0.55 & 35.70 \\
Grays-2 & Evb(gr) basalt & 0.06 & 25.44 & 106.49 \\
Grays-3 & Evb(gr) basalt & 1.76 & 35.65 & 117.41 \\
Grays-4 & Evb(gr) basalt & 0.45 & 29.81 & 104.65 \\
Grays-5 & Eib intrusive & 0.03 & 1.09 & 109.02 \\
Grays-8 & Eib intrusive & 0.01 & 2.22 & 27.35 \\
Grays-7 & Evt tuff & 0.02 & 0.11 & 0.69 \\
Grays-9 & Evt tuff & 0.02 & 1.37 & 50.20 \\
Grays-6 & Em(1) marine sed & 0.02 & 0.77 & 20.31 \\
Grays-10 & Em(1) marine sed & 0.04 & 3.46 & 19.77 \\
\hline \hline
\end{tabular}

Results of the sieve analyses are presented as cumulative grain-size distribution curves (Figure 7). Sediment dominated by fines tends to reach a cumulative fraction of 50 percent or greater within the sand domain (0.067 to 2.0 millimeters). Coarser sediment has a small cumulative fraction in the sand domain and an increasing fraction in the gravel domain.

A comparison of the cumulative particle-size distribution curves and lithology indicates that sediment samples can be aggregated into two groups based on lithology (Figure 7). With the exception of sample Grays-1, all of the Crescent basalt samples have weathered to a relatively coarse-grained distribution. Landslide deposits derived from the remaining geologic units (intrusive rocks, volcanic tuff, and marine sediments) include a greater proportion of fine-grained particles in their distribution (Figure 7).

The field reconnaissance also included the detailed investigation of three large-scale rotational failures identified in aerial photographs and on geologic maps of the upper Grays River watershed (Photo MW-2-1 in Appendix B). Most of these large failures terminate on the valley floor, yet only a small fraction of the total volume of this sediment has been delivered to the channel network. These large landslides can form valley-spanning dams that cause significant realignment of the channel and local convexities in the channel longitudinal profile, which can 


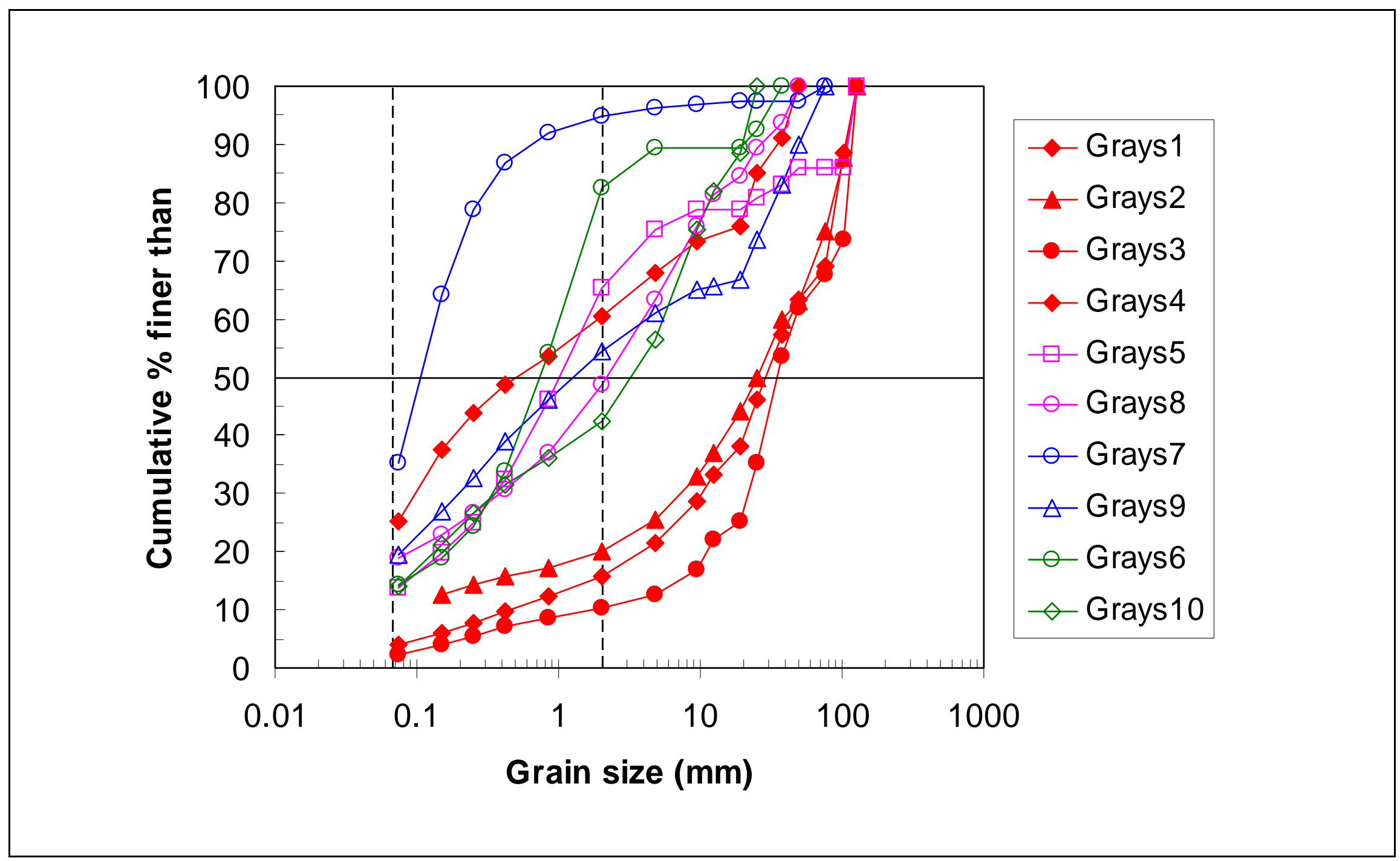

Figure 7. Grain-size distributions for bulk sediment samples collected from Grays River watershed landslide deposits. Note: Colors denote similar lithology (red = basalt, magenta = intrusive rocks, blue $=$ volcanic tuff, and green $=$ marine sediments) Open symbols indicate lithologic group 1 (fine-grained), and solid symbols indicate lithologic group 2 (predominantly coarsegrained). 

interrupt sediment transport through the affected reach. Large boulders armoring the channel bed and a convex channel profile observed in the field at the terminus of one of these large landslides suggest that these landslides can deliver sediment volumes and particle sizes exceeding the transport capacity of some channels. Lag boulders exhumed from the landslide deposit by the winnowing of finer sediment during incision formed a step-pool morphology. Large woody debris at the front of the landslide also appeared to play a significant role in creating and sustaining a step-pool morphology.

Armoring of the bed by lag boulders and large woody debris inhibits incision of these large landslide deposits by dissipating flow energy. Consequently, valley-spanning landslides can act as large sediment capacitors by both shielding landslide deposits from erosion and trapping sediment upstream of the deposit in backwater ponds. The discontinuity in sediment transport through reaches affected by these large landslides should be considered in future analyses of sediment routing.

Surface erosion was evaluated qualitatively based on hillslope gradient, geology, and forest harvest. Relatively minor surface erosion was observed in recently clear-cut areas during the field reconnaissance. However, significant surface erosion from gullies was observed on road embankments and on the surfaces of landslide deposits (Photos MW-2-2 and MW-2-3 in Appendix B). In all cases, gullies are located below culverts that apparently discharge concentrated flow to bare hillslope surfaces.

Prior studies in old-growth forests of the Olympic Peninsula found that timber provided an effective means of limiting gully development on large landslide deposits (Abbe 2000). Hence, gully development observed in the upper Grays River watershed is interpreted to be at least partially the result of timber removal. Gully incision of large rotational landslides accelerates the delivery of stored sediment to the channel network. The gullies formed on the surface of a large rotational landslide suggest that the numerous historical landslides throughout the watershed may be a chronic source of sediment, particularly where runoff from roads is concentrated over landslide surfaces.

Physical parameters of the road network were collected in the field to evaluate surface erosion from roads. Current conditions of roads were characterized by measuring road width, centerline slope, cross-slope condition (i.e., crowned, in, or away from bank), and road-base condition. Measurements also included the height, slope, and fraction of vegetative cover on cut slopes and the dominant grain size of sediment stored in roadside ditches.

\section{Landslide Inventory}

An inventory of historical landslides in the upper Grays River watershed was compiled from 1970, 1996, and 2003 aerial photographs. A total of 216 landslides were identified in the historical photographs (Appendix E). The 1996 and 2003 photo series cover the entire study area, whereas the 1970 set covers approximately 76 percent of the watershed. The 1970 landslide inventory was adjusted in proportion to watershed coverage in order to account for the missing areas and allow comparison with the 1996 and 2003 data sets. 
Landslides were classified according to the three principal types of mass-wasting features identified in the aerial photographs and during the field reconnaissance: channelized debris flows, shallow translational slides, and deep-seated rotational slides. Debris flows and translational slides were observed to be the most common landsliding forms. Narrow masswasting features confined within low-order channels were classified as debris flows (Photos MW-2-4, MW-2-5, and MW-3-3 in Appendix B). Debris flows commonly scour steep channels to bedrock and may increase in bulk by entraining stored sediment as they travel downstream through the channel network. Translational landslides observed during the field reconnaissance were typically wider than debris flows; these often begin on hillslopes (within bedrock) in the absence of convergent topography (Photos MW-4-1 and MW-4-2 in Appendix B). Upon reaching stream channels, however, shallow translational slides can transform into debris flows. These dual failures were observed during the landslide inventory and were classified as debris flows. Rotational landslides were observed less frequently than either debris flows or translational slides and tended to exhibit visible headscarps and spoon-shaped failure masses (Photos MW-2-4 and MW-2-5 in Appendix B).

Annual rates of sediment yield from mass wasting were calculated from new landslides that occurred between the dates of the historical aerial photographs studied. Relative errors in the calculated sediment yield are reduced when the time elapsed between aerial photographs is significantly less than the time for revegetation of hillslopes disturbed by landsliding. The 7year span between the 1996 and 2003 photographs meets this criterion; however, some landslides that occurred early during the 26 years elapsed between the 1970 and 1996 photographs may not have been identified.

The general form of the equation for sediment yield to the channel network from landsliding is given by:

$$
S_{L S}=\frac{A_{L S} D \Phi \rho}{\Delta t A_{S}}
$$

where: $S_{L S}=$ sediment yield from landslides (tons $/ \mathrm{km}^{2} /$ year)

$A_{L S}=$ area of delineated landslide features in each map unit $\left(\mathrm{m}^{2}\right)$

$A_{S}=$ sample area for each year of aerial photographic coverage $\left(\mathrm{km}^{2}\right)$

$D=$ average landslide depth (meters)

$\Phi=$ delivery ratio

$\rho=$ sediment density (tons $/ \mathrm{m}^{3}$ )

$\Delta t=$ duration over which sediment yield to the channel network occurs (years).

The average landslide depth used in the analysis was based on field measurements of landslide features made during the field reconnaissance (Table 4). Rotational landslides were found to have the greatest depth. The depth of translational landslides ranged from 1.5 to 12 meters, with an average depth of 6 meters. Debris flows were the shallowest of all the landslide types and had an average depth of 3 meters. 
Grays River Watershed-Geomorphic Analysis

Table 4. Average depth and sediment delivery ratios for upper Grays River watershed landslide types.

\begin{tabular}{lccc}
\hline \hline Landslide Type & $\begin{array}{c}\text { Number } \\
\text { Measured }\end{array}$ & $\begin{array}{c}\text { Average Depth } \\
\text { (meters) }\end{array}$ & $\begin{array}{c}\text { Average Delivery } \\
\text { Ratio }\end{array}$ \\
\hline Rotational & 3 & 20 & 0.25 \\
Translational & 5 & 6 & 0.43 \\
Debris flow & 9 & 3 & 0.87 \\
\hline \hline
\end{tabular}

A significant fraction of the sediment mobilized by landslides may be redeposited on slopes, so short-term sediment production rates may not be equivalent to rates of sediment delivery to the channel network. The delivery ratio $(\Phi)$ is the ratio between the amount of sediment contributed to channels and that mobilized by landslides on the hillslope. Average delivery ratios for each landslide type were determined from field measurements of landslide scar volumes and the sediment volume remaining on slopes. Delivery ratios were highest for debris flows and lowest for large, deep-seated landslides (Table 4).

The delivery ratios computed from our field investigation are consistent with results from prior studies within the region. Nelson and Booth (2002) found that delivery ratios decreased with landslide volume, ranging from 65 percent for landslides between 256 cubic meters and about 1,000 cubic meters to 100 percent for small failures along the stream bank. Large, deep-seated landslides typically experience relatively small displacements and persist for thousands of years as a source of chronic sediment generation (Dietrich et al. 1982; Reid and Dunne 1996). Alternatively, debris flows may convey the majority of their sediment loads to the channel network because of greater water content and confinement within low-order hollows (Dietrich et al. 1982). Sediment volume delivered to the channel network was converted to metric tons using a density $(\rho)$ of 1.7 tons $/ \mathrm{m}^{3}$ (Madej 1982).

The time parameter $(\Delta t)$ in Equation 1 was evaluated from the rate of regrowth and stabilization of disturbed areas, as shown on the time series of aerial photographs and inferred from the age of vegetation observed growing on recent landslides during the field reconnaissance. The tracking of landslide features through the aerial survey record suggests 20 years as an appropriate recovery time for the revegetation and stabilization of landslide scars and associated deposits. Smith et al. (1983) also found that surface erosion processes are active for 20 years on landslide scars in coastal British Columbia. Based on these findings, 20 years was used for $\Delta t$ in Equation 1 to calculate the annual sediment yield from recent landslides.

The annual sediment yield calculated from the historical landslide inventory ranged from 209,000 to 238,000 tons/year for the entire upper Grays River watershed (Table 5). The calculated sediment yield (tons/year) represents the total mass of landslide-derived sediment delivered to the channel network during a one-year period. Sediment yield calculated from the landslide inventory was greatest in 2003. However, the relatively small scale and poor quality of the 1970 photos allow delineation of only the most recent and largest of the landslide features that existed at that time. Hence, the sediment yield calculated for 1970 should be considered a minimum rate. 
Table 5. Historical sediment yield to the upper Grays River watershed from landslides.

\begin{tabular}{cc}
\hline \hline Aerial Photograph Year & $\begin{array}{c}\text { Sediment Yield } \\
\text { (tons/year) }\end{array}$ \\
\hline 1970 & 209,000 \\
1996 & 221,000 \\
2003 & 238,000 \\
\hline \hline
\end{tabular}

Sediment yield for 1970 was extrapolated for the entire watershed area due to limited aerial coverage (76\% of watershed).

The lag time between timber harvest and the peak in mass wasting was estimated from the variation in landslide frequency with time since harvest. The frequency distribution of the historical landslide inventory indicates that 72 percent of the landslides occurred between 10 and 20 years after timber harvest (Figure 8 ). Because the landslides could have occurred anytime between the photograph date and previous harvest, these estimates represent maximum lag times between harvest and sediment production from landsliding. The lag time between harvest and peak in mass wasting may also be influenced by the timing of intense winter storms.

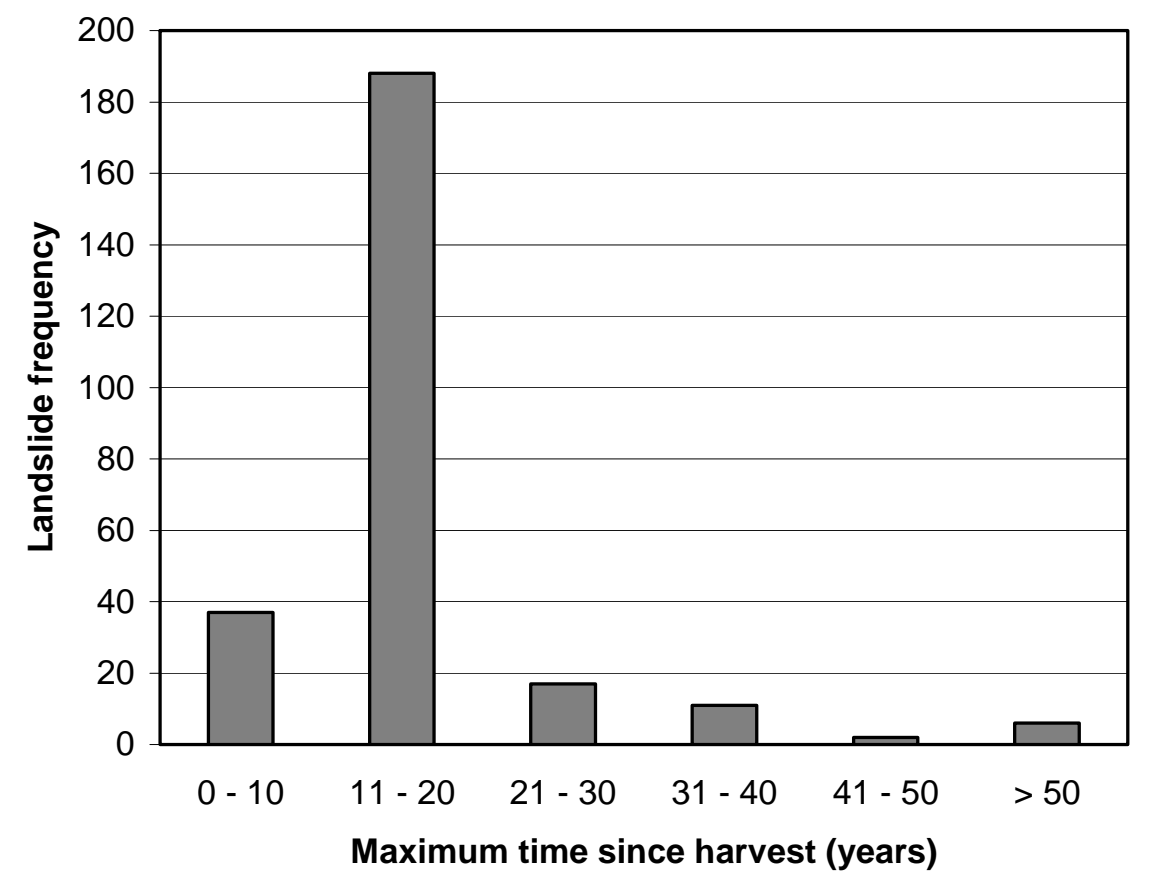

Figure 8. Variation in landslide frequency with maximum time since timber harvest in the upper Grays River watershed.

The lag time measured between timber harvest and landsliding in the upper Grays River watershed is comparable to the time after harvest for root decay to reach a maximum (Schmidt 
et al. 2001). Schmidt et al. (2001) found that the minimum root strength occurred between 6 and 10 years after harvest in the Oregon Coast Range (Figure 9). Root strength can decline to 10 percent of the original strength within 5 years and weaken further to 5 percent of the original strength 10 years after harvest (Schmidt et al. 2001). Regrowth provided only 10 percent of the original root strength 10 to 12 years after harvest.
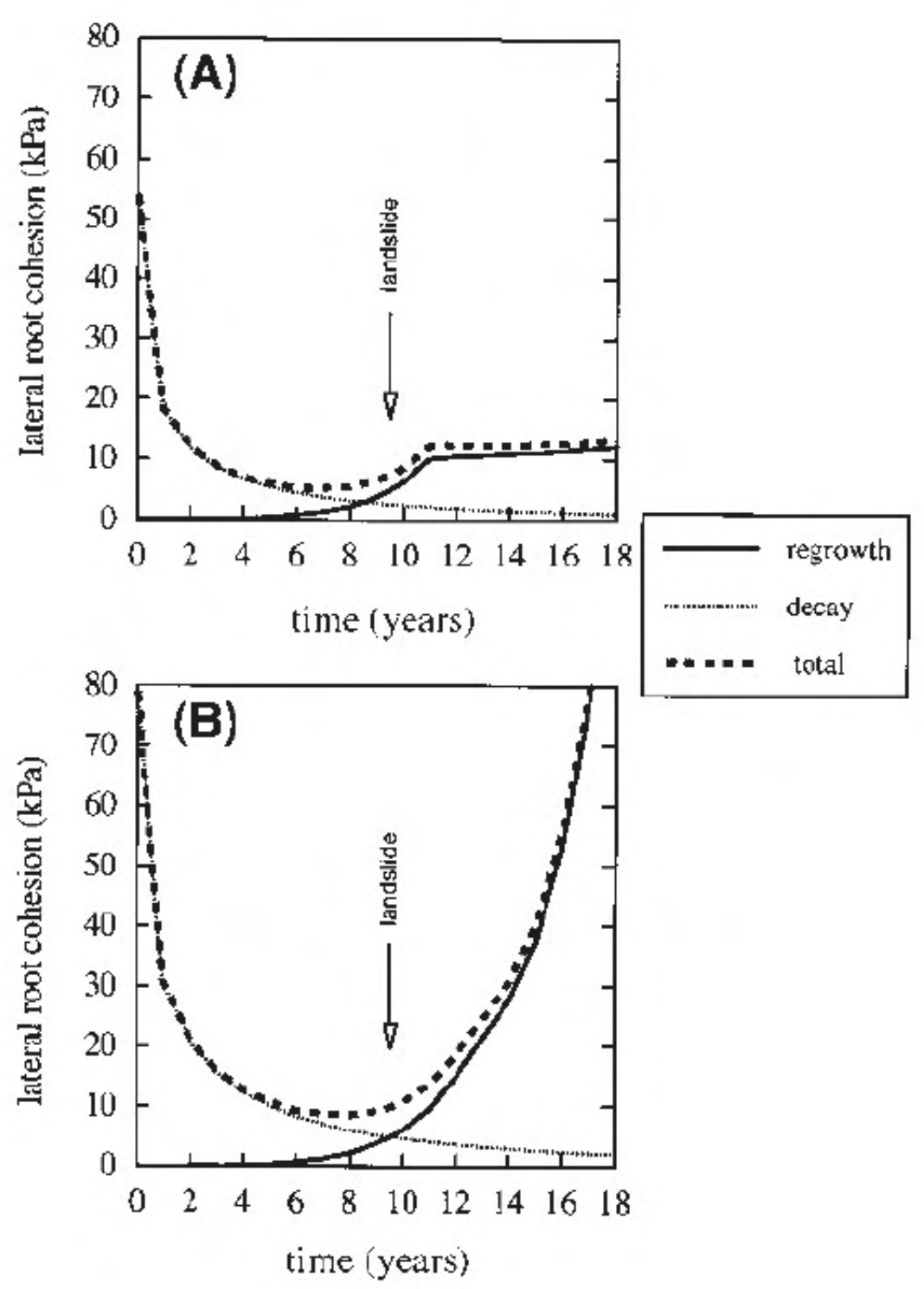

Figure 9. Root growth and decay contributions of lateral root cohesion after clear-cut logging for two sites in the Oregon Coast Range (Schmidt et al. 2001).

The combination of root strength decline from decay and increase from new regrowth provides an estimate of when the minimum root strength is likely to occur following harvest. The results 
of Schmidt et al. (2001) suggest that the greatest potential for storm-driven landsliding occurs within the decade following harvest. The root decay and regrowth curves of Schmidt et al. (2001) also suggest that the frequency-based lag time inferred from the aerial photographs may overestimate the actual lag time.

Based on the landslide inventory data and results from prior studies, it is anticipated that mass wasting should peak approximately 10 years after timber harvest and deliver the majority of landslide-derived sediment to the channel network over the following 20 years (i.e., the period between 10 and 30 years after timber harvest).

Results of the upper Grays River watershed landslide inventory indicate that roads contributed significantly to historical mass wasting, either directly through slope modifications or indirectly by concentrating storm runoff on unstable slopes. Roughly half of all landslide polygons delineated from the three aerial photographs studied were found by ArcGIS to intersect roads (Figure 10), whereas visual inspection of the aerial photographs during delineation found that approximately three-fourths of all landslides were associated with roads (Table 6). Based on the average length of landslides and the slope distance between roads, this proportion is greater than that expected from a random distribution. Results suggest that road construction and runoff may reactivate old landslides in addition to initiating new landslides, particularly in areas previously harvested. When grouped according to proximity to roads, landslides associated with roads showed approximately the same frequency distribution as landslides unrelated to roads, with a peak in landsliding between 10 and 20 years for both sample populations (Figure 10). However, landslides unrelated to roads appear to occur over a broader time period, between 10 and 30 years after timber harvest.

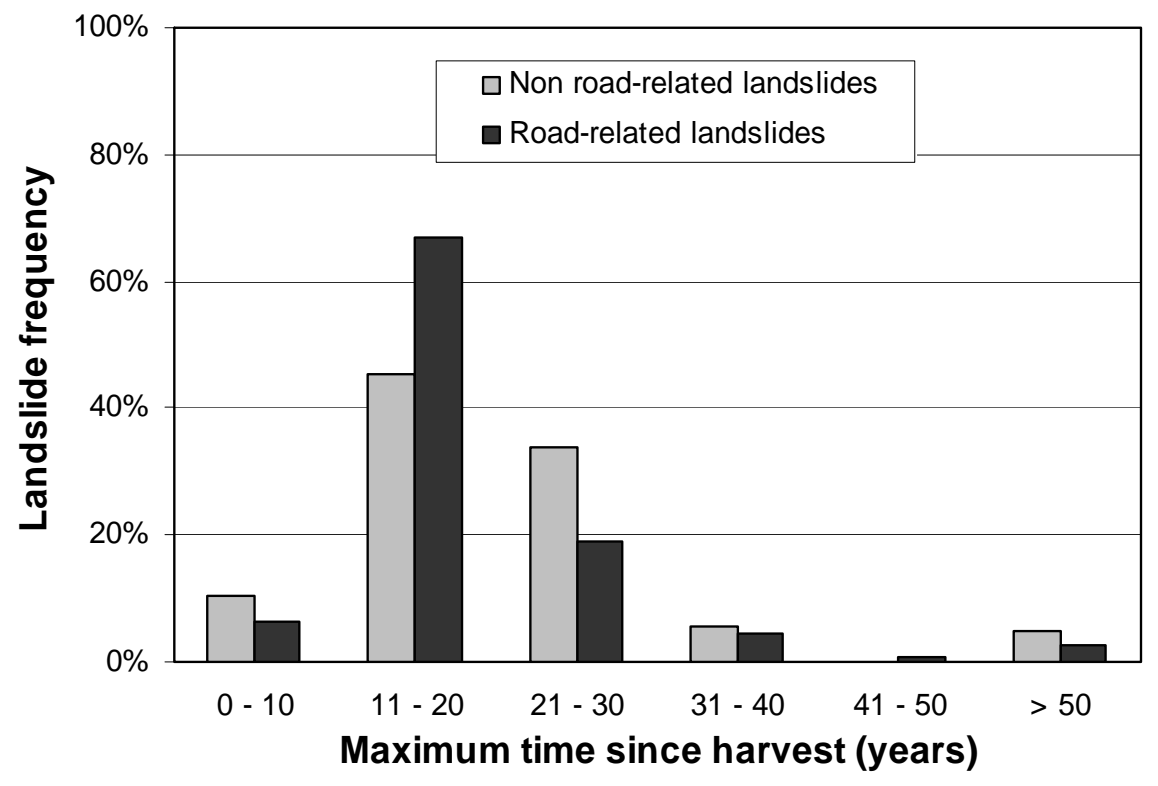

Figure 10. Landslide association with roads in the upper Grays River watershed. 
Grays River Watershed-Geomorphic Analysis

\section{Table 6. Landslide association with roads and channels in the upper Grays River watershed.}

\begin{tabular}{|c|c|c|c|}
\hline Photo Year & $\begin{array}{l}\text { Slides Intersecting } \\
\text { Roads (GIS) }\end{array}$ & $\begin{array}{l}\text { Slides Associated } \\
\text { with Roads (visual) }\end{array}$ & $\begin{array}{l}\text { Slides within } 60 \\
\text { Meters of Channel } \\
\text { Network (GIS) }\end{array}$ \\
\hline 1970 & $41 \%$ & - & $69 \%$ \\
\hline 1996 & $52 \%$ & - & $93 \%$ \\
\hline 2003 & $56 \%$ & $76 \%$ & $97 \%$ \\
\hline
\end{tabular}

A GIS analysis of potential debris-flow initiation at road crossings was performed by comparing the road network with the headwater channel network in the upper Grays River watershed. Headwater channels dominated by debris flow processes were delineated in GIS from grid cells in the 10-meter digital elevation model (DEM) with a drainage area between 0.05 and $0.2 \mathrm{~km}^{2}$ (Montgomery and Foufoula-Georgiou 1993; Stock and Dietrich 2003). Roads constructed over hollows and the concentration of runoff over colluvial deposits have the potential to initiate debris flows from low-order hollows. Many of these hollows have already failed as debris flows at road crossings. Results of the GIS analysis indicate the presence of an estimated 1,797 road crossings within the study area capable of generating debris flows. Of these intersections, 98 are associated with historical landslides delineated from aerial photographs (Figure 11). The remaining road crossings represent potential mass-wasting sites.

Results of the landslide inventory also indicate a high degree of geomorphic coupling between hillslopes and the channel network. The majority of landslides (69 to 97 percent) terminated within 60 meters (200 feet) of an active stream channel (see Table 6 and Appendix E). Hillslope-channel coupling is common in mountain channel networks such as the upper Grays River watershed, which are confined by adjacent hillslopes. Confined reaches lacking the buffering effects of a floodplain are more effective at routing the sediment generated by landslides. The strong hillslope-channel coupling in the upper Grays River watershed indicates a high response potential of the channel network to hillslope disturbance and sediment generation within the watershed.

\section{Mass Wasting Map Units}

Mass wasting map units were developed by correlating sediment yield from landslides with landscape characteristics (i.e., hillslope gradient and geology) and land use practices that prior studies have linked to an increase in landslide frequency (i.e., Madej 1982; Grant and Wolff 1991; Jakob 2000). Although hillslope gradient and geology are assumed constant through time, there have been temporal and spatial variations in timber harvest patterns throughout the upper Grays River watershed. The mass wasting map units provide a means of modeling the effects of both landscape characteristics and timber harvest rotation on patterns of historical sediment yield from mass wasting. 
Sediment yield from mass wasting was tabulated according to geology, forest age, and hillslope gradient into 24 mass wasting map units using the Spatial Analyst program in ArcMap 9.0. Map units were defined from geomorphic criteria developed for the analysis:

- Two geologic classes (Crescent basalt and marine sediments/intrusive rocks)

- $\quad$ Four forest-age classes (0-10 years, 10-30 years, 30-60 years, and >60 years)

- $\quad$ Three hillslope-gradient classes (0-30 percent, 30-65 percent, and >65 percent).

Geologic classes were defined according to the grain-size distribution of local colluvium and landslide deposits derived from weathered bedrock. Forest-age categories were defined based on 1) the anticipated time lag between timber harvest and peak in landslide frequency, when root strength is at a minimum (approximately 10 years), and 2) the duration of sediment delivery from landslides (20 years). The hillslope gradient coverage was derived from the 10-meter digital elevation model of the watershed. Map units were created in Spatial Analyst by combining the slope, geology, and forest-age coverages. A shorthand notation for the map units was developed based on geology, forest age, and slope. For instance, map unit 123 signifies geology class 1 (Crescent basalt), harvest-age class 2 (10-30 years), and hillslope-gradient class 3 (slope >65 percent).

Sediment yield from mass wasting (tons $/ \mathrm{km}^{2} /$ year) was calculated for map units in ArcGIS using the intersection of the 2003 landslide polygons with geology, forest age, and slope coverages. Sediment yield computed for each mass wasting map unit is tabulated in Table 7.

\section{Table 7. Upper Grays river watershed sediment yield (tons $/ \mathrm{km}^{2} /$ year) by mass wasting} map unit.

\begin{tabular}{lccccccc}
\hline \hline Slope and & \multicolumn{3}{c}{ Geology 1} & & \multicolumn{3}{c}{ Geology 2} \\
\cline { 2 - 4 } $\begin{array}{c}\text { Forest-Age } \\
\text { Class }\end{array}$ & $0 \%<\mathrm{S}<30 \%$ & $30 \%<\mathrm{S}<65 \%$ & $\mathrm{~S}>65 \%$ & & $0 \%<\mathrm{S}<30 \%$ & $30 \%<\mathrm{S}<65 \%$ & $\mathrm{~S}>65 \%$ \\
\hline $\mathrm{H}<10$ yrs & 30 & 30 & 30 & 30 & 30 & 30 \\
& $(111)$ & $(112)$ & $(113)$ & & $(211)$ & $(212)$ & $(213)$ \\
$10<\mathrm{H}<30$ yrs & 145 & 737 & 22,391 & & 137 & 2,041 & 33,659 \\
& $(121)$ & $(122)$ & $(123)$ & & $(221)$ & $(222)$ & $(223)$ \\
$30<\mathrm{H}<60$ yrs & 1,822 & 5,998 & 17,456 & & 1,822 & 6,792 & 17,456 \\
& $(131)$ & $(132)$ & $(133)$ & & $(231)$ & $(232)$ & $(233)$ \\
$\mathrm{H}>60$ yrs & 30 & 30 & 30 & & 30 & 30 & 30 \\
& $(141)$ & $(142)$ & $(143)$ & & $(241)$ & $(242)$ & $(243)$ \\
\hline \hline
\end{tabular}

Note: Map-unit shorthand shown in parentheses (see text for explanation).

Recent landslide features were not identified in either the youngest or the oldest forest-age classes except for map unit 143, in which two landslide polygons were found. Therefore, a 


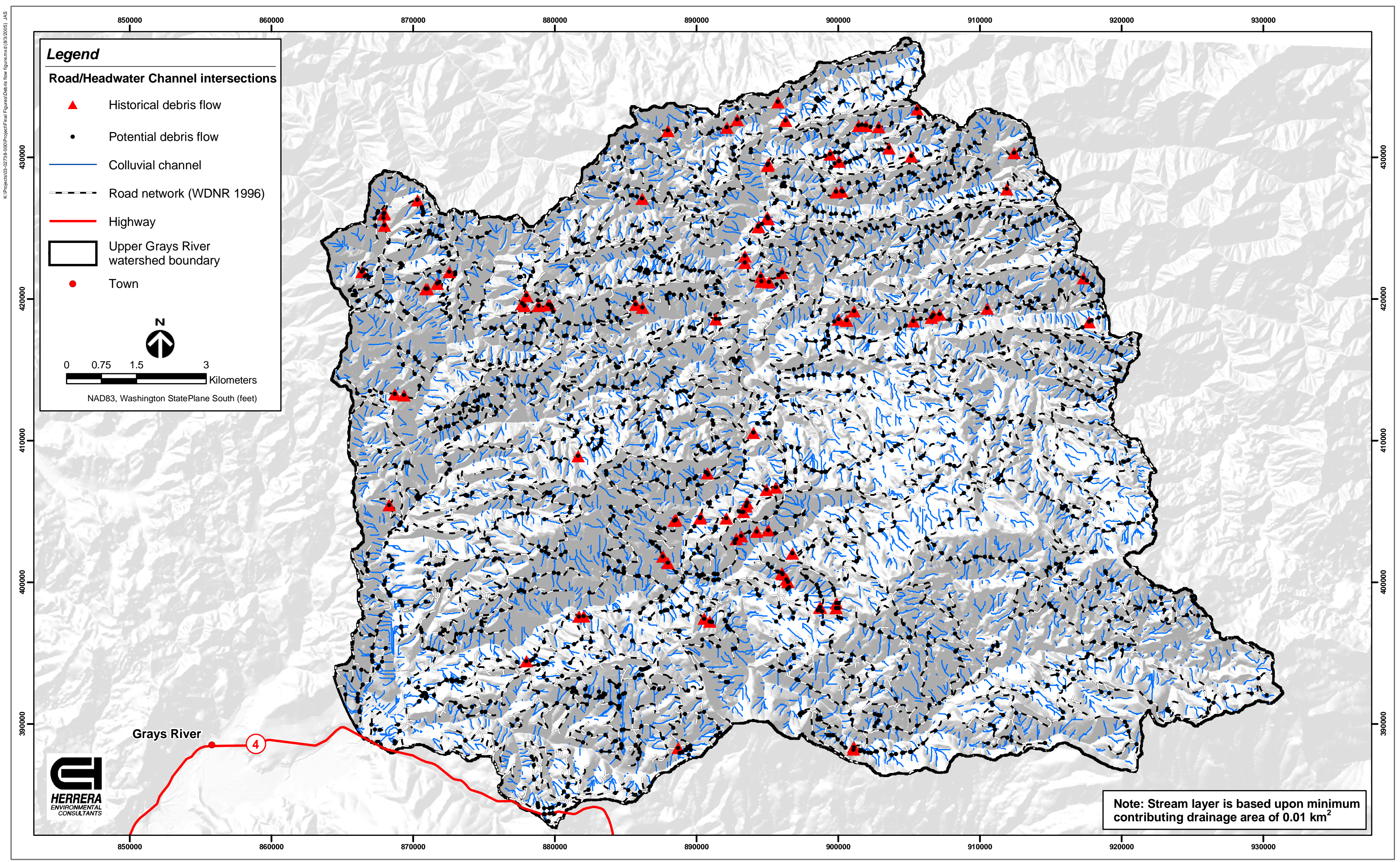

Figure 11. Locations of historical and potential debris flow initiation based on GIS-derived intersections of roads and colluvial channels in the upper Grays River watershed, Washington. 

background sediment yield of 30 tons $/ \mathrm{km}^{2} /$ year was assigned to these 12 map units. An anomalously low sediment yield from map unit 133 (the map unit with the smallest drainage area) was replaced with the sediment yield from a comparable map unit (233) in geology class 2.

Three large landslides (two in map unit 331 and one in map unit 231) occurred between 1996 and 2003 and were an order of magnitude larger than any other landslide feature. These three landslides are deep-seated bedrock failures unrelated to the road network and occurred several decades after local harvest activities. Deep-seated landslides such as these occur naturally in the region and may comprise a major component of the background sediment yield. Topographic features suggesting ancient landslides of a similar scale were also observed during field surveys. Inclusion of these landslides in sediment budget calculations, however, significantly skews the sediment yield for map units representing older forest-age classes, and causes annual sediment yield rates to fluctuate by about 50,000 tons $/ \mathrm{km}^{2} /$ year. Based on the results of several methods used to estimate background sediment yield (presented later in this report), the recurrence interval of such features is believed to far exceed the time period analyzed in this study, and these landslides were therefore removed from the sample population.

Results for map units indicate that the potential for sediment yield from mass wasting is greatest on steep slopes harvested between 10 and 30 years ago. Steep slopes harvested between 30 and 60 years ago have the second highest sediment yield. Overall, sediment yield appears to be independent of the underlying geology.

Sediment yield results by mass wasting map units were used for further analyses to reconstruct historical trends in sediment yield from the upper Grays River watershed.

\section{Assessment of Surface Erosion from Disturbed Hillslopes}

Surface erosion occurs where bare soil is exposed to rain and wind, particularly after the loss of vegetative cover. Surface erosion may also be triggered by the concentration of surface runoff from road drainage or logging activities. The factors that influence surface erosion include soil type, hillslope gradient, rainfall intensity and duration, vegetative cover, and soil compaction (WDNR 1997). The potential for surface erosion from disturbed hillslopes in the upper Grays River watershed was evaluated from GIS coverages of soil erodibility and hillslope gradient.

The erodibility of soil is expressed in terms of an empirical $\mathrm{K}$ factor developed from the universal soil loss equation (USLE). The K factor is based on the clay, silt, sand, and organic content of soil. Soils high in silt and fine sand content typically have a higher $\mathrm{K}$ value and are more erosive.

A GIS coverage of soil type in the upper Grays River watershed prepared by the Natural Resources Conservation Service (NRCS 2004) includes two types of K factors. The erodibility of fine soils less than 2 millimeters in particle diameter is characterized by the fine-earth factor, $\mathrm{K}_{\mathrm{f}}$. The reduction in erosion from the effects of shielding by rock fragments is accounted for in the whole-soil factor, $\mathrm{K}_{\mathrm{w}}$. Due to the presence of rock fragments in the upper Grays River watershed soils, surface erosion potential was evaluated using $\mathrm{K}_{\mathrm{w}}$ values. 
The use of hillslope gradient in the analysis of surface erosion accounts for the effects of gravity, which causes particles detached by rain-splash or sheet-wash to move downslope. Sheet-wash and rilling also become more effective erosional agents with increasing gradient. The combination of $K_{w}$ factors and slope categories was used by WDNR (1997) to define low, moderate, and high erodibility ratings (Table 8).

Table 8. Erodibility ratings based on $K_{w}$ factors and slope (WDNR 1997).

\begin{tabular}{cccc}
\hline \hline Slope Class & $\begin{array}{c}\mathrm{K}_{\mathrm{w}}<0.25 \\
\text { Not Easily Detached }\end{array}$ & $\begin{array}{c}0.25<\mathrm{K}_{\mathrm{w}}<0.40 \\
\text { Moderately Detached }\end{array}$ & $\begin{array}{c}\mathrm{K}_{\mathrm{w}}>0.40 \\
\text { Easily Detached }\end{array}$ \\
\hline$<30 \%$ & Low & Low & Moderate \\
$30-65 \%$ & Low & High & High \\
$>65 \%$ & Moderate & High & High \\
\hline \hline
\end{tabular}

Erodibility ratings were generated for the upper Grays River watershed by combining the GIS coverages for both $\mathrm{K}_{\mathrm{w}}$ factors and slope (Figure 12). The erodibility ratings shown on the erosion potential map reflect the maximum surface erosion from a bare hillslope as a function of soil type and slope and do not account for variations in vegetative cover, land use, or precipitation.

Approximately 37 percent of the Grays River watershed is rated with high soil erosion potential, 54 percent of the watershed is rated with a moderate soil erosion potential, and the remaining 9 percent of the watershed is rated as low for soil erosion potential. The majority of current timber harvest activities (between 1996 and 2003) are located in areas with relatively high erosion potential.

Field observations of surface erosion in areas of recent timber harvest indicate that sediment eroded by rain-splash and sheet-wash is displaced a relatively short distance downslope and deposited in transient storage sites provided in hummocky terrain and organic material remaining on disturbed hillslopes. The majority of surface erosion from gullies was observed on road embankments and on the surface of recent landslides. Hence, sediment yield from disturbed surfaces is not accounted for in the assessment of mass wasting and roads; it is expected to be an insignificant component of the total sediment yield for the watershed and therefore is not included in the sediment budget. However, the erodibility ratings and surface erosion potential map (Figure 12) provides valuable information on the potential for chronic erosion from landslide and road surfaces.

\section{Assessment of Surface Erosion from Roads}

The construction and operation of logging roads can comprise a significant fraction of the total sediment yield from harvested basins (Reid and Dunne 1984; Madej 1982). Based on a review of prior studies, WDNR (1997) compiled a list of factors that influence sediment production from road surfaces and delivery to the channel network: 


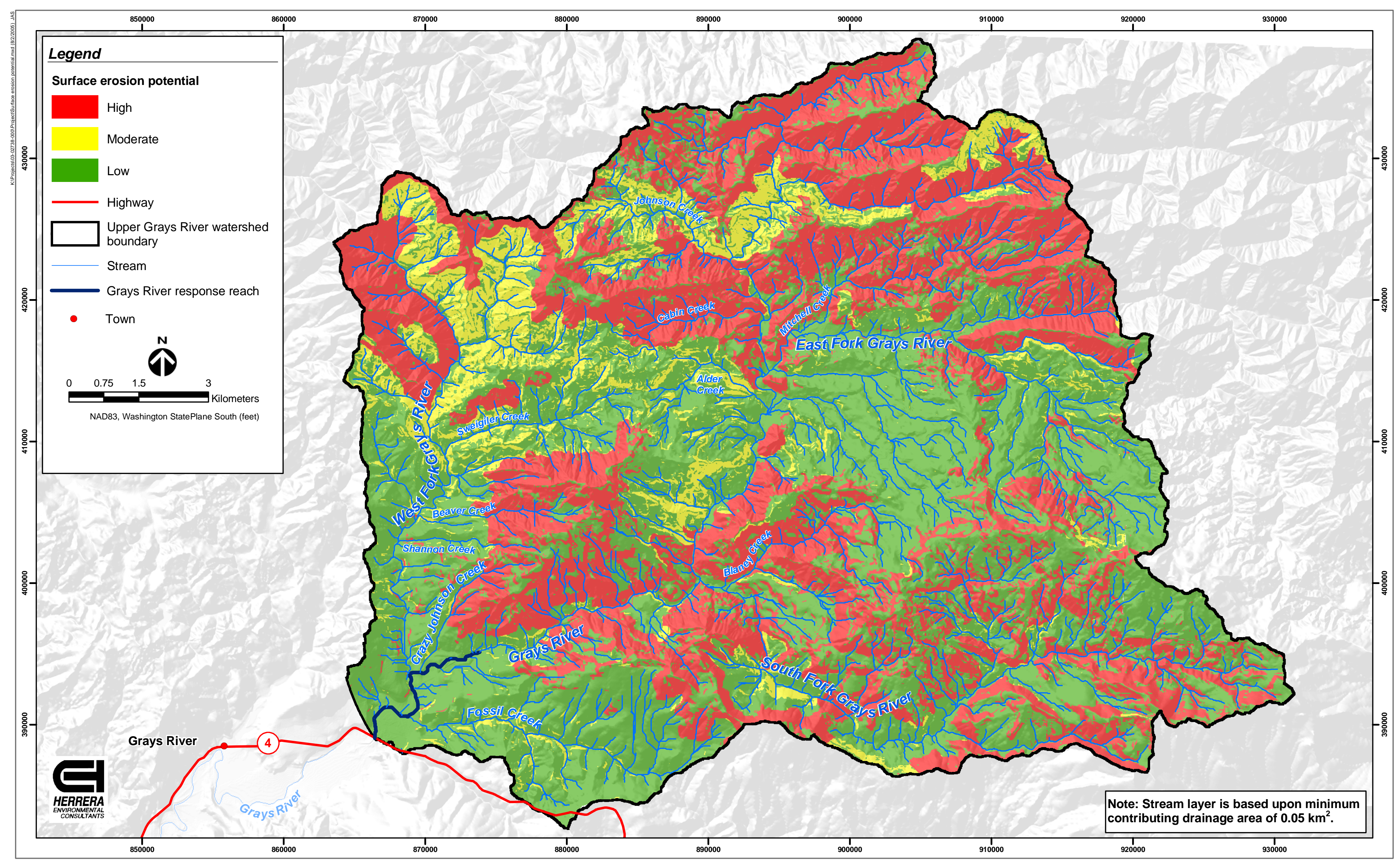

Figure 12. Ground surface erosion potential based on whole soil erosion factors (NRCS 2004) and slope in the upper Grays River watershed, Washington. 



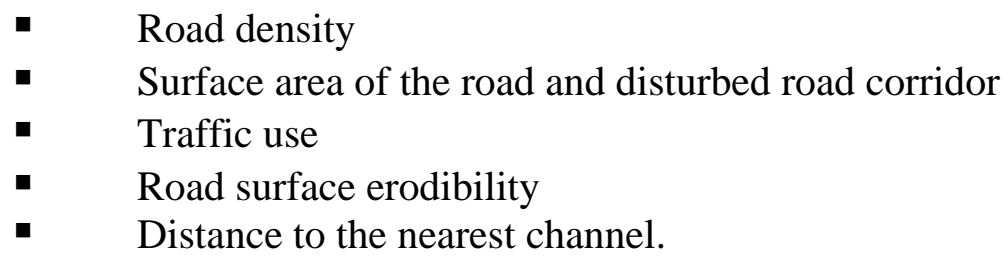

\section{Road Density Analysis}

The most current map of the road network to date has been prepared by The Campbell Group (TCG 2004). However, the most recent GIS coverage of roads was constructed by WDNR (1996) (see Figure 11). A road density analysis was performed to account for additional road construction in the harvested areas shown on 2003 photos to update the 1996 GIS coverage. The road density analysis is included in Appendix F.

\section{Road Surface Erosion}

The erosion of road surfaces and adjacent slopes and ditches within the road corridor (i.e., the road prism) was evaluated from a baseline erosion rate and several adjustment factors that correlate erosion rates with road characteristics (WDNR 1997). Roads were also classified according to use as mainline, secondary, non-active (inactive), and decommissioned. The full description of road types and the analysis of surface erosion from roads are included in Appendix F, and photographs of road types observed within the watershed are included in Appendix B.

Results of the analysis, presented in Table 9, indicate that an average of 27.0 tons/year is generated from each kilometer of the road network within the upper Grays River watershed. Mainline and active secondary roads together generate 86 percent of the total sediment from road surfaces but comprise only 0.5 percent and 80 percent of the road network length, respectively.

\section{Table 9. Summary of surface erosion factors and rates for roads within the upper Grays} River watershed.

\begin{tabular}{lccc}
\hline \hline Road Type & $\begin{array}{c}\text { 2003 Road Length } \\
\text { (meters) }\end{array}$ & $\begin{array}{c}\text { Adjusted Erosion Rate } \\
\text { (tons/year) }\end{array}$ & $\begin{array}{c}\text { Normalized Sediment Production Rate } \\
\text { (tons/km/year) }\end{array}$ \\
\hline Mainline & 42,011 & 10,334 & 246 \\
Active secondary & 717,073 & 12,495 & 17.4 \\
Inactive & 126,542 & 1,413 & 11.2 \\
Decommissioned & 15,737 & 69 & 0.4 \\
Watershed totals & 901,364 & 24,311 & 27.0 \\
\hline \hline
\end{tabular}

\section{Background Sediment Yield}

Background sediment yield is the long-term average sediment yield from a basin under natural geomorphic conditions prior to anthropogenic disturbance. Knowledge of the background 
sediment yield is important for understanding the increase in sediment yield caused by anthropogenic disturbance. The primary geomorphic processes that generate sediment in mountain watersheds are soil creep and mass wasting (Dietrich and Dunne 1978). The background sediment yield for the upper Grays River watershed was evaluated using two approaches:

1. Contemporary field studies and sediment budgets computed for undisturbed basins

2. Long-term tectonic uplift rates under steady-state conditions.

\section{Sediment Budget Approach}

Soil creep is the slow downslope movement of the soil mantle under the influence of gravity. Sediment production by tree wind-throw and animal burrowing are also included in soil creep (WDNR 1997). Soil creep introduces sediment along the entire length of a channel at an average rate of approximately $1.5 \mathrm{~mm}$ /year in undisturbed watersheds in western Washington (WDNR 1997). A summary of prior studies of soil creep in undisturbed watersheds is compiled in Table 10.

Table 10. Soil creep rates and watershed characteristics from prior studies.

\begin{tabular}{lccc}
\hline \hline \multicolumn{1}{c}{ Reference } & $\begin{array}{c}\text { Precipitation } \\
\text { (mm/year) }\end{array}$ & $\begin{array}{c}\text { Gradient } \\
(\%)\end{array}$ & $\begin{array}{c}\text { Creep Rate } \\
\text { (mm/year) }\end{array}$ \\
\hline Madej (1982) & $1,300-1,700$ & $0.2-5$ & 1.5 \\
Everett (1963) & 990 & $25-65$ & $0.0-2.2$ \\
Young (1960) & 1,400 & $35-55$ & $1.0-2.0$ \\
Kirkby (1967) & 1,710 & $15-35$ & $1.0-3.0$ \\
Lewis (1976) & $3,050-4,500$ & $35-32$ & $1.8-2.3$ \\
Eyles and Ho (1970) & 2,540 & 18 & 3.2 \\
\hline \hline
\end{tabular}

The factors required to calculate sediment yield from soil creep are length of the stream channel, average soil depth, and creep rate. Stream length $(L)$ can be estimated from GIS applications and is doubled to account for creep along both stream banks. Soil depth $(D)$ can be generalized over the subbasin using soil maps and field reconnaissance.

An average soil depth of 1.3 meters was computed from eight field measurements of the soil profile at road cuts that were not located near colluvial hollows in the study area. The average annual sediment yield from soil creep for the upper Grays River watershed is given by:

$$
S_{c}=\frac{2 \rho L D C}{A_{d}}
$$

where: $S_{c}=$ average annual sediment yield from soil creep (tons $/ \mathrm{km}^{2} /$ year) 


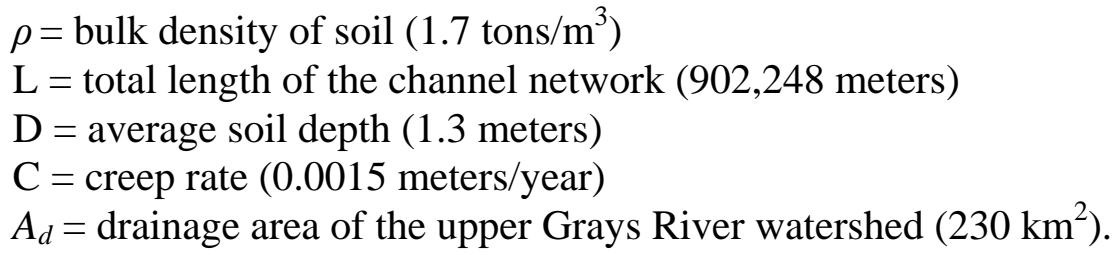

Based on field measurements of soil depth, length of the channel network, and the assumed creep rate, sediment yield from soil creep in the upper Grays River watershed calculated from Equation 2 is 26 tons $/ \mathrm{km}^{2} /$ year. Sediment yield from soil creep was also calculated for each subbasin within the watershed using the length of stream channels in each subbasin. Mass wasting processes such as landslides, debris flows, and channel bank erosion are the second major source of sediment quantified for the assessment of background sediment yield. Sediment yield calculated from previous studies of mass wasting in undisturbed watersheds is compiled in Table 11.

Table 11. Sediment yield from mass wasting in undisturbed watersheds from prior studies.

\begin{tabular}{|c|c|c|c|}
\hline Reference & $\begin{array}{l}\text { Precipitation } \\
\text { (mm/year) }\end{array}$ & Location & $\begin{array}{l}\text { Sediment Yield } \\
\text { from Mass Wasting } \\
\text { (tons } / \mathrm{km}^{2} / \text { year) }\end{array}$ \\
\hline Dietrich and Dunne (1978) & 3,400 & Oregon Coast Range & 17.2 \\
\hline Madej (1982) & $1,300-1,700$ & Kitsap Peninsula, WA & 15 \\
\hline Roberts and Church (1986) ${ }^{a}$ & $1,500-4,220$ & Queen Charlotte Islands, BC & $15.3-122$ \\
\hline Grant and Wolff (1991), total sediment yield & 2,300 & Western Cascade Range, OR & $18-170^{b}$ \\
\hline
\end{tabular}

a Various sources cited in Roberts and Church (1986). Cubic meters converted to tons using a density of 1.7 tons $/ \mathrm{m}^{3}$.

b Includes total sediment yield from the watershed measured as suspended load and bedload in two watersheds with 9 and 30 years of sediment yield data, respectively.

The average background sediment yield from mass wasting in undisturbed watersheds, as reported from these previous studies, is approximately 30 tons $/ \mathrm{km}^{2} /$ year. The combination of sediment yield from soil creep and mass wasting results in a total background sediment yield of 56 tons $/ \mathrm{km}^{2} /$ year. This rate is comparable to the total sediment yield measured by Grant and Wolff (1991) for undisturbed watersheds in the western Cascade Range of Oregon.

\section{Tectonic Uplift Approach}

The average background sediment yield can also be estimated from long-term tectonic uplift rates for the region. Tectonic uplift of the Olympic Mountains and the Coast Range has occurred over the past 15 million years (Brandon et al. 1998; Kelsey et al. 1996). These mountain ranges are considered to be in a condition of topographic steady state (Willett and Brandon 2002), whereby uplift equals erosion, and feedbacks between these processes moderate a steady topographic form at the regional scale. Although uplift rates for southern Washington within the region of the Grays River study area have not been measured, geochemical data indicate a longterm uplift rate in the southern Olympic Mountains of 0.0001 meters/year (Brandon et al. 1998). 
The minimum uplift rate for the northern Oregon Coast Range is also 0.0001 meters/year (Kelsey et al. 1996). Based on these studies, a long-term rock uplift rate of $0.0001 \mathrm{~mm} / \mathrm{year}$ was used for the analysis.

The long-term background erosion rate was calculated from the uplift rate by:

$$
S_{U}=U * \rho *\left(10^{6} \mathrm{~m}^{2} / \mathrm{km}^{2}\right)
$$

where: $S_{U}=$ average, long-term sediment yield (tons $/ \mathrm{km}^{2} /$ year)

$U=$ long-term rock uplift rate (0.0001 meters/year)

$\rho=$ bedrock density $\left(2.5\right.$ tons $\left./ \mathrm{m}^{3}\right)$

$10^{6}=$ the conversion from $\mathrm{m}^{2}$ to $\mathrm{km}^{2}$.

The steady-state assumption of Equation 3 requires that all of the sediment eroded from hillslopes is delivered to the channel network and is transported out of the watershed. Therefore the background sediment yield is equivalent to the long-term erosion rate. The long-term sediment yield calculated from Equation 3 must be modified to account for the fraction of sediment that leaves the watershed through solution weathering. Based on the assumption that approximately half of the sediment mass leaves the watershed in solution as dissolved load (Selby 1993), the average background sediment yield calculated from long-term uplift rates $\left(S_{U}\right)$ is 125 tons $/ \mathrm{km}^{2} /$ year.

The background sediment yield calculated from tectonic uplift is comparable with results from the contemporary measurements of sediment yield from undisturbed watersheds described above in the sediment budget approach. The difference in computed sediment yield is within the relative errors for the two approaches, which arise from the variability in the assumed creep rate used in the sediment budget approach and the assumed uplift rate used in the tectonic approach.

\section{Sediment Budget Computation}

Contemporary and historical sediment budgets were constructed for the Grays River watershed to compute both temporal and spatial trends in sediment yield within the watershed. Sediment yield was calculated for each of 60 subbasins delineated within the watershed. In order to quantify sediment yield to specific alluvial segments of the channel network, the 60 subbasins were aggregated into seven subbasin groups:

- Upper main stem Grays River

- $\quad$ Middle main stem Grays River

- Lower main stem Grays River

- $\quad$ East Fork

- $\quad$ South Fork

- West Fork

- Fossil Creek. 


\section{Contemporary Sediment Budget}

A contemporary sediment budget was constructed for the upper Grays River watershed using results from the detailed assessment of sediment yield for 2003. Sediment yield from mass wasting, roads, and soil creep were combined to compute the annual sediment yield for each aggraded subbasin group in the watershed (Appendix G).

Results of the sediment budget indicate that the contemporary sediment yield in the upper Grays River watershed in 2003 was 9 to 20 times greater than the long-term background sediment yield (Table 12). Local short-term sediment yield calculated solely from mass wasting, as indicated for some map units (see Table 7), were more than 1,000 times greater than estimated background rates.

\section{Table 12. Average sediment yield in the upper Grays River watershed under current conditions (2003) and long-term background conditions.}

\begin{tabular}{lc}
\hline \hline \multicolumn{1}{c}{ Sediment Source } & $\begin{array}{c}\text { Sediment Yield } \\
\text { (tons/ } \mathrm{km}^{2} / \text { year) }\end{array}$ \\
\hline 2003 Mass wasting & 1,032 \\
2003 Roads & 41 \\
2003 Soil creep & 26 \\
2003 Total & $\mathbf{1 , 0 9 9}$ \\
Long-term background (range) & $56-125$ \\
\hline \hline
\end{tabular}

The results of the detailed 2003 analysis of sediment yield provided the basis for reconstruction of the historical sediment budget.

\section{Historical Sediment Budget}

Historical sediment budgets were constructed for each subbasin group by synthesizing historical timber harvest records for the upper Grays River watershed with earlier correlations established between the time since harvest and sediment yield from mass wasting and roads. Sediment yield from soil creep, which is assumed to be independent of timber harvest practices, was also included in the historical sediment budget.

Historical sediment budgets were constructed for each of the eight reference years in which timber harvest data are available (Scott 2004 personal communication; The Campbell Group 2004). Sediment yield from mass wasting was calculated for each subbasin in ArcGIS using an overlay of historical harvest data and the mass wasting map units. Sediment yield from roads was calculated using the 2003 sediment yield normalized by the fraction of the subbasin previously harvested, by each reference year. Estimates of sediment yield from roads are conservative because this method assumes that roads generate sediment at a constant rate from the time of road construction. Sediment yield from mass wasting, roads, and soil creep were then combined to compute the annual sediment yield for each subbasin group. 
The reconstruction of the historical sediment yield for each subbasin group is presented graphically in Figure 13a. Total watershed sediment yield by source is shown in Figure 13b. Detailed results of the historical sediment budget are included in Appendix G.

Reconstruction of the sediment budget indicates that the total sediment yield for the upper Grays River watershed was nearly constant from 1942 through 1964 and ranged from approximately 13,000 to 18,000 tons/year. The estimated sediment yield increased sharply to 87,000 tons/year by 1976 and continued to climb at an unprecedented rate to more than 250,000 tons/year by 2003 (Figure 13a). Although the total sediment yield for the watershed has increased every year, local sediment yield from the Fossil Creek, middle main stem, and upper main stem subbasins declined between 1996 and 2003 (Figure 13a).

Results indicate that most of the sediment delivered to the channel network is derived from mass-wasting processes (Figure 13b). Roads and soil creep contribute a relatively minor proportion of the total sediment yield; however, earlier analyses identified roads as a likely contributor to landsliding for several decades following initial timber harvest activities. Hence, the jump in sediment yield between 1964 and 1976 may be linked to increased road construction.

The grain-size distribution of sediment delivered to the channel network varies among the different sediment sources. The analysis of sediment samples collected from landslide deposits and observations during the field reconnaissance indicate that landslides are characterized by a poorly sorted grain-size distribution that includes both fines and coarse gravel. Deep-seated landslides, which incorporate bedrock, produce coarser grain-size distributions. Sediment delivered to the channel network by soil creep is expected to have the same grain-size distribution as shallow landslides, which consist of colluvium. In contrast, the grain-size distribution of sediment originating from road surfaces should be dominated by fines. However, surface runoff and bank erosion associated with the road prism can also deliver some coarse sediment to the channel network.

Although landslide-derived sediment is coarser than sediment derived from road surfaces, landslides delivered 20 to 200 times more sediment than roads during the 20 to 30 years following timber harvest (see Figure F-1). Hence, the volume of fine sediment delivered by mass-wasting processes may exceed by many times the quantity of fine sediment generated from road surfaces during this same time period.

Most of the poorly sorted sediment supplied by mass wasting is broken down to suspended load by particle attrition during fluvial transport. Based on a sediment budget constructed for a small basin underlain by basalt in the Oregon Coast Range, Dietrich and Dunne (1978) determined that about half of the sediment delivered to the channel network by creep and mass wasting was coarser than 2 millimeters. Of this fraction, about 80 percent broke down to suspended load (less than 2 millimeters) during transport to the mouth of the basin. Tumbling mill experiments conducted by Collins and Dunne (1989) with basalt gravel obtained from rivers draining the Crescent formation yielded a mass reduction of about 2 percent per kilometer of transport for clasts greater than 0.5 millimeters. In a tumbling mill experiment performed by Perkins (1989) on unsorted sediment derived from landslide deposits, particle attrition accounted for a 58 percent reduction in the mass of bedload-size particles (greater than 0.5 millimeters) and a 


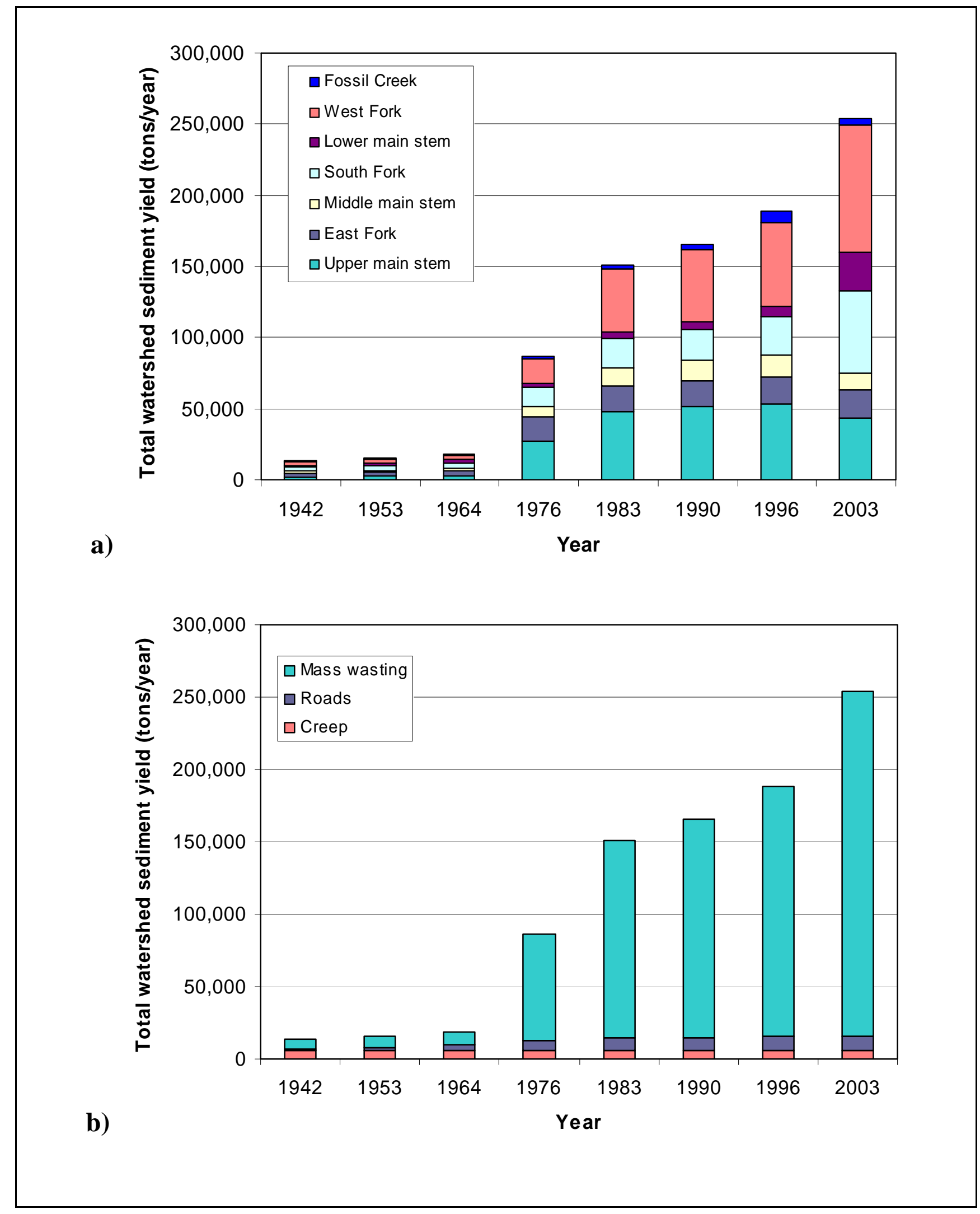

Figure 13. Predicted temporal variation in total upper Grays River watershed sediment yield by (a) subbasin group and (b) source. 

50 percent increase in the fraction of suspended-load particles finer than 0.5 millimeters after only 1.6 kilometers of simulated transport. In a similar experiment, Sutherland et al. (2002) reported a reduction in the mass of bedload particles that was 2 to 10 times greater for fresh landslide material than for ambient river gravel.

Based on these prior studies of bedload attrition, most of the coarse sediment delivered to the upper Grays River channel network by mass-wasting processes is likely converted to suspended load after moving relatively short distances (1 to $2 \mathrm{~km}$ ) through the channel network, and certainly by the time sediment reaches the main stem response reach (RK 22.5).

The contemporary sediment yield calculated for 2003 in the upper Grays River watershed is consistent with the findings of Grant and Wolff (1991), which indicate that the average annual production of sediment after clear-cutting was about 4 to 12 times greater than the undisturbed rate and remained higher than preharvest rates more than 20 years later. Based on their computed trends, Grant and Wolff (1991) forecast sediment production to remain elevated above background rates for 30 years after harvest. Montgomery et al. (2000) found sediment yield from landsliding in the Oregon Coast Range at 3 to 9 times the natural background rate for the region.

Given the current timber harvest rotation in the upper Grays River watershed of about 40 years, sediment production will remain relatively high and ultimately will result in significant soil loss and reduced timber productivity.

\section{Geomorphic Characterization of the Channel Network}

Predictions of alluvial channel response to disturbance can be made by considering general relationships between discharge $(Q)$, transport capacity $\left(Q_{c}\right)$, sediment supply rate $\left(Q_{s}\right)$, and various channel metrics. Building on the work of early fluvial geomorphologists (i.e., Gilbert 1917; Mackin 1948; Lane 1955; and Shumm 1971), Montgomery and Buffington (1998) developed a comprehensive conceptual relationship that expresses the ratio of transport capacity to sediment supply $\left(Q_{d} / Q_{s}\right)$ in terms of nine response variables:

$$
\frac{Q_{c}}{Q_{s}} \propto \frac{D n D_{50} p}{W D_{s} S_{s} S \lambda}
$$

where: $D=$ channel depth

$n=$ Manning's roughness coefficient

$D_{50}=$ the median bed-surface grain size

$p=$ sinuosity (the ratio of channel to valley length)

$W=$ channel width

$D_{s}=$ scour depth

$S_{S}=$ sediment storage

$S=$ channel slope

$\lambda=$ meander wavelength. 
Equation 4 implies that the changes in the ratio of transport capacity to sediment supply will evoke changes in response variables. For example, an increase in sediment supply relative to transport capacity would result in a net reduction in the numerator product or a net increase in the denominator product. With a net increase in sediment supply, numerator variables (depth, grain size, roughness, and sinuosity) would diminish, while denominator variables (width, scour depth, slope, and sediment storage) would tend to rise. Table 13 illustrates the application of Equation 4 to qualitatively predict trends in channel changes caused by a declining ratio of transport capacity to sediment supply $\left[\left(\Delta\left(Q_{d} / Q_{s}\right)<0\right]\right.$.

\section{Table 13. Predicted channel response to a declining ratio of transport capacity to sediment supply.}

\begin{tabular}{|c|c|c|c|c|c|c|c|c|c|}
\hline \multirow[b]{2}{*}{$\begin{array}{l}\text { Forcing } \\
\text { Function }\end{array}$} & \multicolumn{9}{|c|}{ Response Variable } \\
\hline & $\begin{array}{l}\text { Width } \\
\text { W }\end{array}$ & $\begin{array}{l}\text { Depth } \\
\text { D }\end{array}$ & $\begin{array}{c}\text { Scour Depth } \\
D_{s}\end{array}$ & $\begin{array}{c}\text { Grain Size } \\
D_{50}\end{array}$ & $\begin{array}{c}\text { Roughness } \\
n\end{array}$ & $\begin{array}{c}\text { Slope } \\
S\end{array}$ & $\begin{array}{c}\text { Sediment } \\
\text { Storage } \\
S_{S}\end{array}$ & $\begin{array}{c}\text { Meander } \\
\text { Wavelength } \\
\lambda\end{array}$ & $\begin{array}{c}\text { Sinuosity } \\
p\end{array}$ \\
\hline$\Delta\left(Q_{d} / Q_{s}\right)<0$ & + & - & + & - & - & + & + & + & - \\
\hline
\end{tabular}

Signs indicate relative change in response variables (plus sign = increase, minus sign = decrease).

Source: Adapted from Montgomery and Buffington (1997).

Land use practices that alter transport capacity and sediment supply can initiate channel responses through changes in the response variables. Response segments generally have alluvial channels and floodplains but can include bedrock channel segments that periodically store alluvium (in which case there is typically some evidence of periodic sediment storage such as alluvial floodplains or terraces). The larger the size and number of channel response segments, the greater the moderating effect on sediment flux downstream through a basin. Wood debris not only can act as a significant grade control element limiting incision but also can be very effective at trapping bed material and storing large volumes of sediment (e.g., Abbe 2000; Abbe and Montgomery 2003). Response reaches, however, can also be converted to transport reaches when wood debris and riparian vegetation are removed or discharge increases.

A reduction in the number and effectiveness of response reaches would result in greater sediment discharge to the lower main stem of the Grays River. Potential responses to land use practices are summarized in Table 14.

\section{Delineation of Channel Network and Partitioning of Geomorphic Channel Units}

The process-based classification of Montgomery and Buffington (1997) was applied to the upper Grays River watershed in order to predict the distribution of geomorphic channel types and divide the channel network into geomorphic channel units that would be useful for evaluating the impacts from changes in land use. The Montgomery and Buffington (1997) classification of channel-reach morphology was developed for mountain channels. The classification synthesizes stream morphologies into five fluvial channel types along opposing continua of increasing sediment supply and decreasing sediment transport capacity. The classification ranges from cascade and step-pool channels, which are supply limited (the stream's energy to move sediment 
exceeds the delivery of sediment to the channel), to plane-bed, pool-riffle, and dune-ripple (sandbedded) channels, which are transport limited (sediment supply exceeds the river's capacity for transport). The classification also recognizes colluvial channels, which are transport-limited reaches (also termed "supply reaches”) located high in the channel network above cascade channels. Hence, there is a peak in transport capacity between the tips of the channel network and the low-gradient, response reaches (Brummer and Montgomery 2003).

Table 14. Summary of channel response to land use practices.

\begin{tabular}{|c|c|c|}
\hline Disturbance & Change & Potential Channel Response \\
\hline \multirow[t]{3}{*}{ Upland forest clearing } & Increase in sediment supply to stream & Aggradation/sedimentation \\
\hline & & Channel widening \\
\hline & Increase in discharge to stream & Channel incision and widening \\
\hline \multirow{5}{*}{$\begin{array}{l}\text { Riparian forest clearing } \\
\text { and agricultural } \\
\text { conversion }\end{array}$} & Destabilization of banks & Channel widening \\
\hline & Increase of local sediment supply & Accelerated channel migration \\
\hline & $\begin{array}{l}\text { Reduction in functional wood debris } \\
\text { recruitment }\end{array}$ & $\begin{array}{l}\text { Channel sedimentation, increased sediment } \\
\text { storage }\end{array}$ \\
\hline & & $\begin{array}{l}\text { Decrease in channel complexity, reduction in } \\
\text { roughness }\end{array}$ \\
\hline & & Increase in turbidity \\
\hline \multirow[t]{3}{*}{ Roads } & Increase in fine sediment production & $\begin{array}{l}\text { Infilling of coarse bed sediment with fines, } \\
\text { reduction in bed-surface grain size, and } \\
\text { roughness }\end{array}$ \\
\hline & & Increase in turbidity \\
\hline & Increase in drainage density & Channel incision and widening \\
\hline \multirow[t]{4}{*}{ Channel clearing } & Increase in stream gradient & Downcutting, incision, and head-cuts \\
\hline & & Channel simplification, reduction in roughness \\
\hline & & $\begin{array}{l}\text { Bank destabilization, increase in sediment } \\
\text { supply }\end{array}$ \\
\hline & & $\begin{array}{l}\text { Initial channel narrowing followed by channel } \\
\text { widening }\end{array}$ \\
\hline
\end{tabular}

A number of researchers have identified the topographic signature of the transition from channels dominated by debris flow to fluvially dominated channels as an inflection in the relationship between contributing drainage area and channel slope (Montgomery and FoufoulaGeorgiou 1993; Stock and Dietrich 2003). An analysis of the relationship between these channel parameters was used to define the threshold between colluvial and fluvial channels in the upper Grays River channel network. The channel network of the upper Grays River watershed was defined with a minimum drainage area of $0.01 \mathrm{~km}^{2}$ using a 10 -meter digital elevation model derived from U.S. Geological Survey 1:24,000-scale topographic maps. Log-bin-averaged drainage area-to-slope relationships based on the channel network define transitional domains between debris flow and fluvial channels (Figure 14).

Debris flows are clearly dominant in channels with contributing drainage areas less than $0.05 \mathrm{~km}^{2}$, and a clear fluvial domain exists where drainage areas exceed approximately $0.2 \mathrm{~km}^{2}$. 
The transitional domain between colluvial and fluvial channels indicates where channels dominated by debris flow transition toward cascade and supply-limited fluvial channels. Additionally, a fluvial response domain is apparent as concavity increases where drainage area exceeds approximately $20 \mathrm{~km}^{2}$, which corresponds to slopes less than 0.02 . The Grays River response reach falls within this domain. Within the fluvial response domain, confined reaches of the main stem Grays River follow a slope consistent with the fluvial transport domain, representative of their high transport capacity relative to sediment supply.

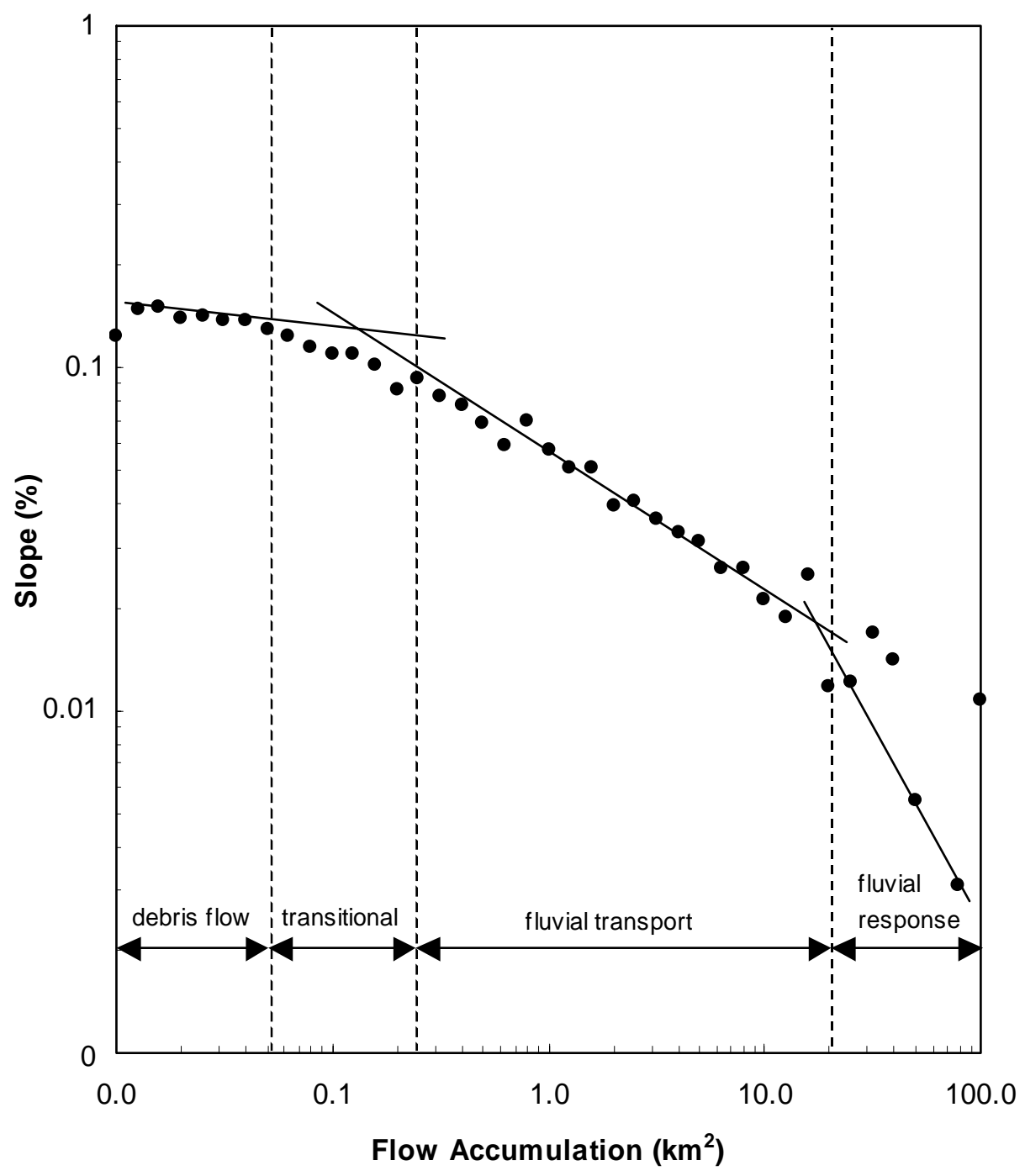

Figure 14. Log-bin-averaged local slope derived from 10-meter grid size digital elevation model (DEM) for the upper Grays River watershed.

Note: Channel divisions are based on Stock and Dietrich (2003). 
Based on the inflection in the relationship between contributing drainage area and channel slope, the threshold between colluvial and fluvial channels in the upper Grays River channel network was assumed to occur at $0.1 \mathrm{~km}^{2}$. Where drainage areas contributing to the channel network exceed $0.1 \mathrm{~km}^{2}$, the range in channel slope reported by Montgomery and Buffington (1997) was used to predict the reach morphology throughout the Grays River channel network (Table 15). The spatial distribution of channel types predicted by slope is illustrated in Figure 15.

\section{Table 15. Slope range and contributing drainage area used to predict Grays River} channel network reach morphology.

\begin{tabular}{lcc}
\hline \hline Reach Type & Slope & $\begin{array}{c}\text { Contributing Drainage Area } \\
\left(\mathrm{km}^{2}\right)\end{array}$ \\
\hline Pool-riffle & $<0.02$ & $>0.1$ \\
Plane bed & $0.02-0.04$ & $>0.1$ \\
Step pool & $0.04-0.08$ & $>0.1$ \\
Cascade & $>0.8$ & $>0.1$ \\
Colluvial & - & $>0.01$ and $<0.1$ \\
\hline \hline
\end{tabular}

Source: Adapted from Montgomery and Buffington (1997).

Although sediment supply throughout mountain channel networks may be difficult to quantify, transport capacity can be estimated from empirical relations and digital elevation models. Spatial variations in the relative magnitude of sediment transport capacity were evaluated throughout the upper Grays River channel network to distinguish transport and response reaches. Transport capacity varies with the rate of energy expenditure per unit area of the channel bed, which is defined in terms of unit stream power:

$$
\omega=\frac{\gamma Q S}{W}
$$

where: $\gamma=$ the unit weight of water

$Q=$ discharge

$S=$ slope

$W=$ channel width.

Bankfull discharge may be assumed to vary with drainage area A:

$$
Q \propto A^{d}
$$

where the exponent $d$ has been determined empirically to range from 0.7 for semi-arid regions to 1.0 for humid landscapes such as the Grays River watershed (Dunne and Leopold 1978; Leopold 1994; Rice 1998; Whiting et al. 1999). Regime theory and empirical data (e.g., Leopold and Maddock 1953; Ibbitt 1997; Knighton 1998) indicate that channel width varies as the square root of discharge (and thus can be expressed as a function of drainage area):

$$
W \propto \sqrt{A}
$$


Combining Equations 5 through 7 allows unit stream power to be recast in terms of parameters that are readily measured from digital elevation models:

$$
\omega \propto S \sqrt{A}
$$

Equation 8 was used to define the magnitude of transport capacity throughout the entire Grays River channel network in terms of an index of unit stream power. Results indicate that unit stream power (i.e., transport capacity) decreases downstream through the channel network, with the lowest values found in the low-gradient alluvial reaches of the main stem Grays River and major tributaries (Figure 16). The pattern of unit stream power in the Grays River channel network watershed is consistent with other field studies, which have found unit stream power decreases from headwater channels to lower-gradient alluvial reaches (e.g., Magilligan 1992; Lecce 1997; Knighton 1999; Brummer and Montgomery 2003).

Montgomery and Buffington (1997) demonstrated that the downstream sequence in which channel types are arranged affects the potential for a disturbance to affect a particular reach. Transport reaches are defined as morphologically resilient channels with high transport capacities relative to sediment supply (i.e., bedrock, cascade, and step-pool channels) that readily convey increases in sediment supply. In contrast, response segments are channels with a low ratio of transport capacity to sediment supply (i.e., plane-bed and pool-riffle channels) in which significant morphologic adjustment results when sediment supply is increased.

The spatial distribution of channel types predicted from slope and drainage area, along with patterns of unit stream power, were used to identify transport and response reaches in the upper Grays River watershed. In general, transport reaches are located high within the channel network, whereas response reaches are located in the larger alluvial valley segments.

In order to characterize the geomorphic conditions that have resulted from basinwide changes in land use, the channel network in the upper Grays River watershed was divided into the following nine distinct geomorphic channel units based on the predicted distribution of channel types and the observed channel conditions:
- Colluvial channels
- Headwater transport channels
- Tributary response channels
- $\quad$ East Fork Grays River
- $\quad$ South Fork Grays River
- West Fork Grays River
- $\quad$ Lower Crazy Johnson Creek
- Main stem Grays River
- Grays River response reach.

Figure 17 presents the locations of these geomorphic channel units within the upper Grays River watershed. 


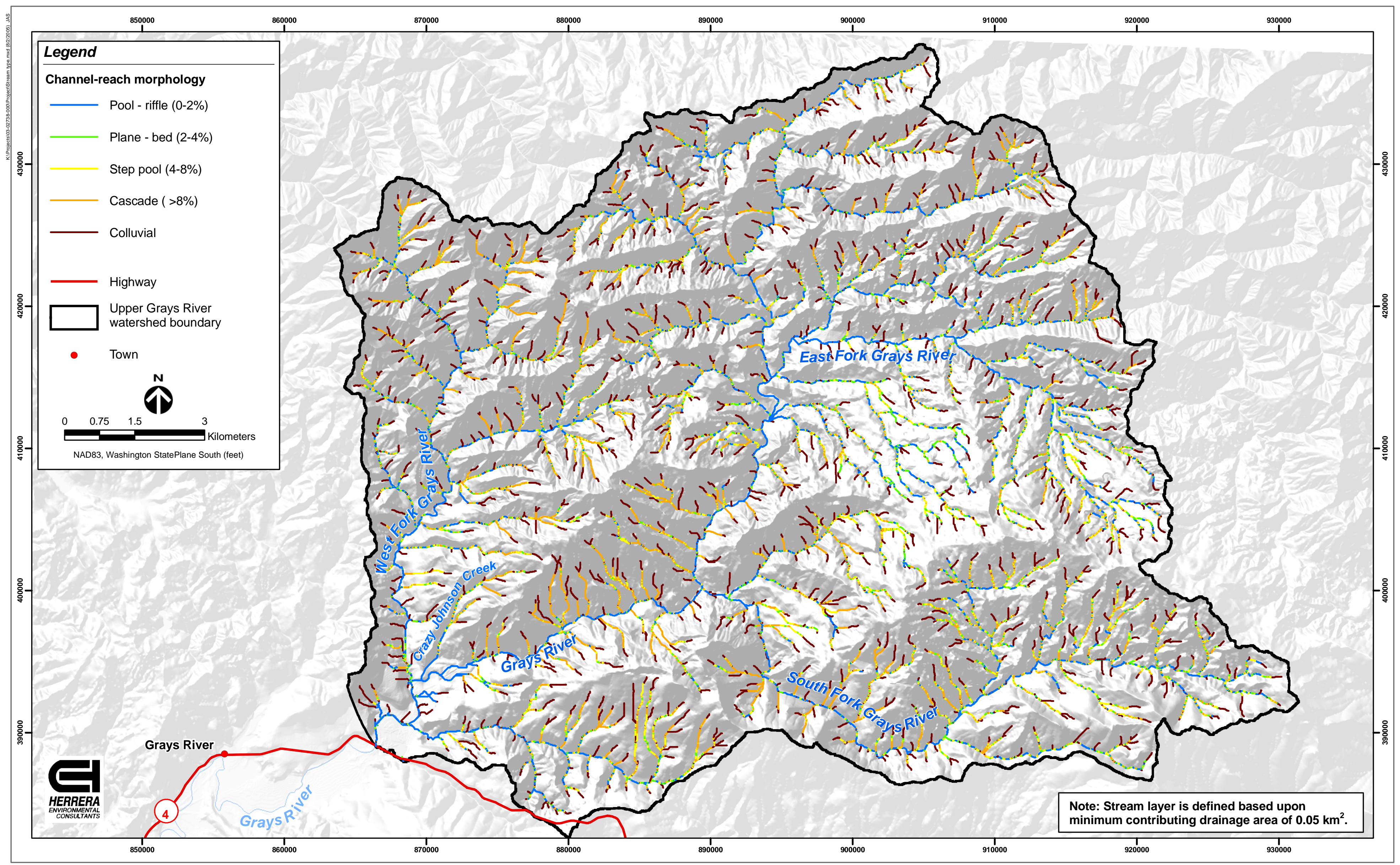

Figure 15. Predicted spatial distribution of channel-reach morphology based on channel slope (Montgomery and Buffington 1997) in the upper Grays River watershed, Washington. 



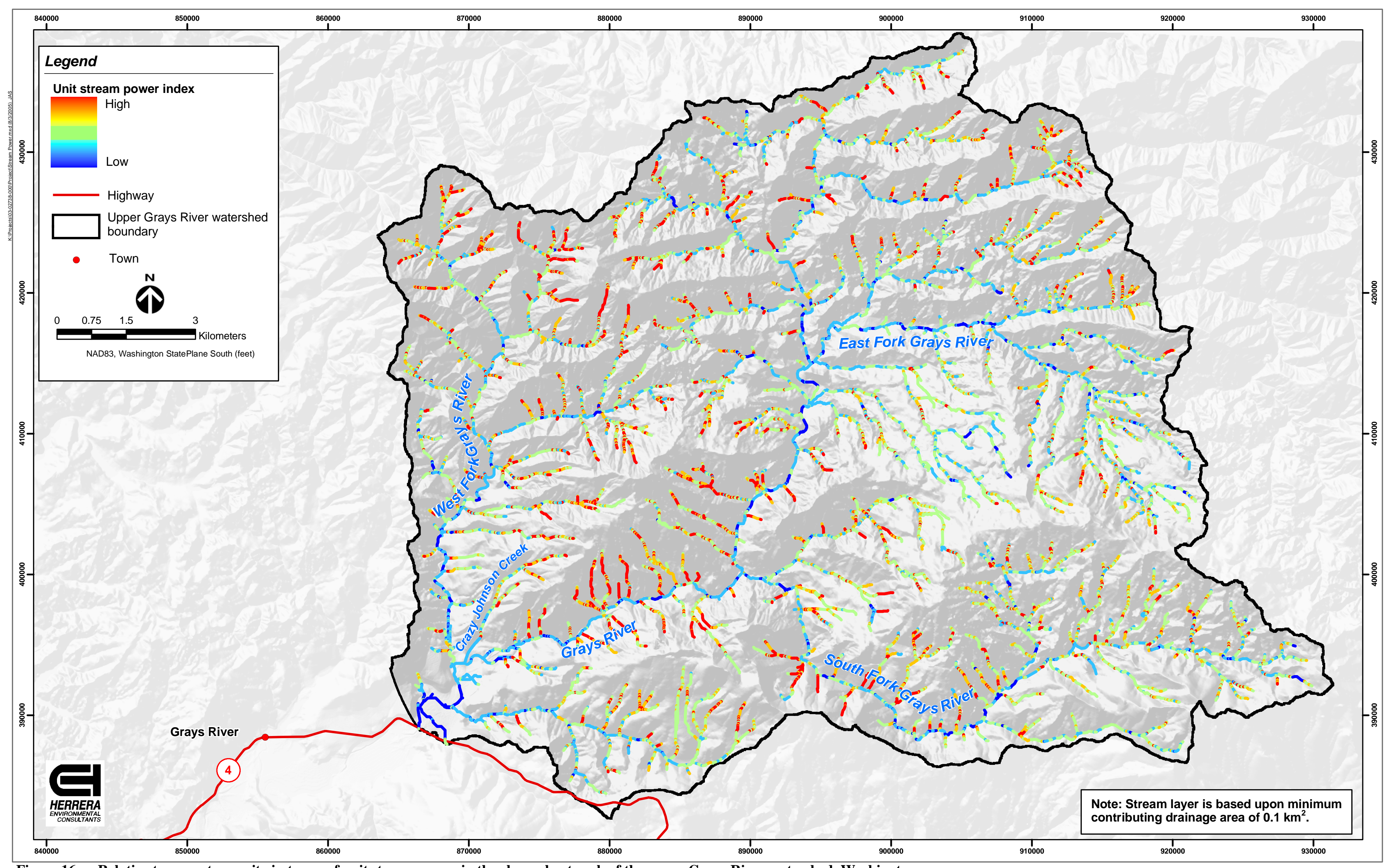

Figure 16. Relative transport capacity in terms of unit stream power in the channel network of the upper Grays River watershed, Washington. 



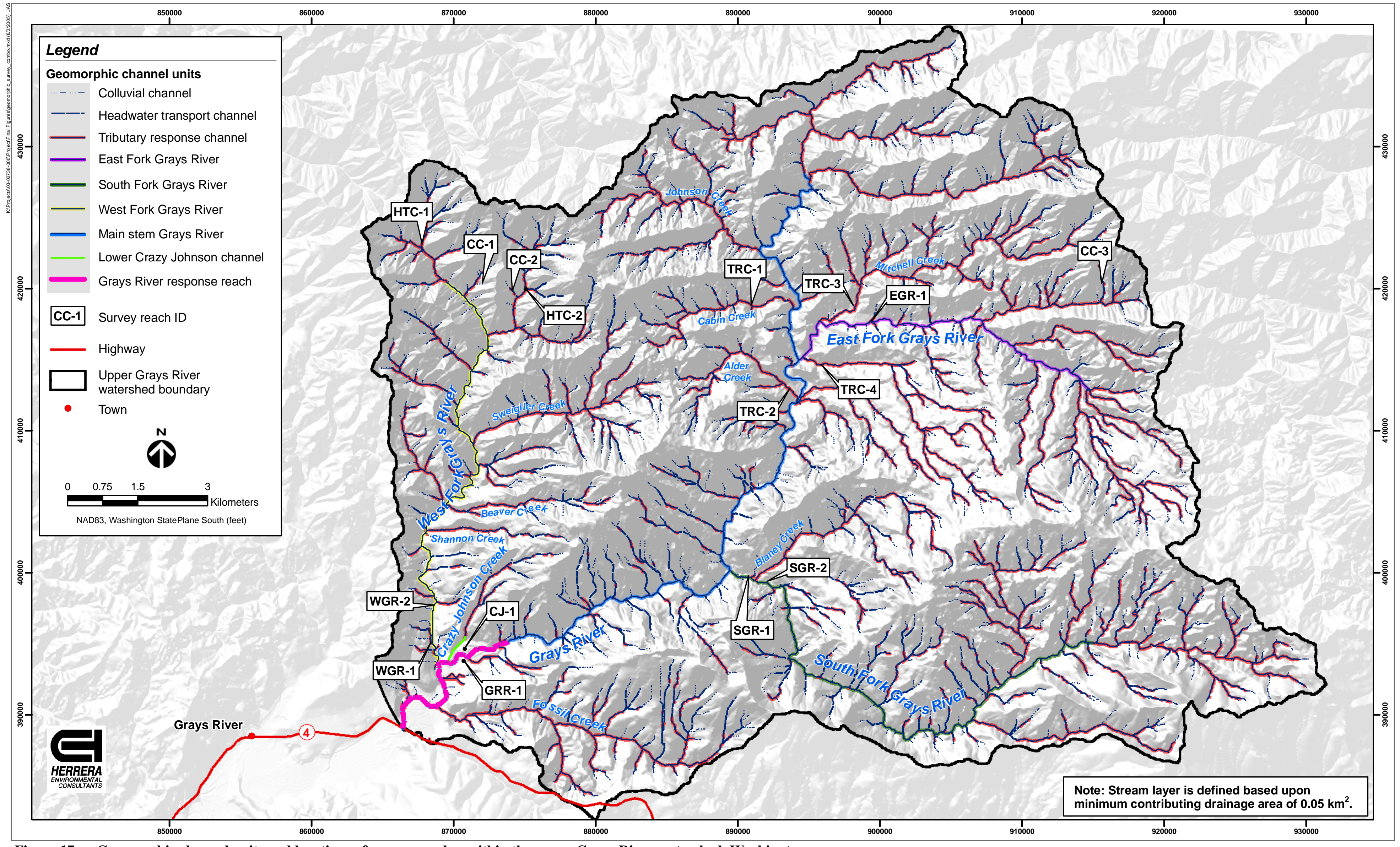

Figure 17. Geomorphic channel units and locations of survey reaches within the upper Grays River watershed, Washington. 



\section{Current Channel Conditions}

A field reconnaissance of the upper Grays River channel network was completed to assess how increases in sediment production have affected channel morphology and the extent to which channel segments may have changed. Because the entire channel network could not be observed, a survey was completed of selected reaches of each geomorphic channel unit. Field reconnaissance of selected survey reaches was conducted in March, September, and October 2004. Channel surveys extending a minimum of 20 bankfull widths in length were completed for each of the geomorphic channel units except the main stem Grays River (see Figure 17). Surveys of the Grays River were focused on the Grays River response reach, and observations of the main stem Grays River channel unit were limited to locations where the main stem was easily observable from forest roads and bridges.

To determine the extent of disturbance or degradation that has resulted from timber harvest within the channel network, the channel surveys documented evidence of sediment storage, routing, and channel response. Surveys included descriptions of the channel morphology, the conditions of instream sediment, the character and extent of large woody debris (LWD) loading, and the recruitment potential of adjacent riparian vegetation. Additionally, the channel surveys included measurements of local channel slope, bankfull width and depth, and valley confinement. The location of each survey reach was georeferenced using a hand-held global positioning system (GPS) instrument. Photographs of survey reach conditions are included in Appendix B. Summaries of each geomorphic channel unit survey reach are presented in Appendix C.

Wolman pebble counts of both the bed surface and subsurface were also conducted at select reconnaissance sites in order to characterize the grain-size distribution of streambed sediment (Wolman 1954). Reach average values of bed surface sediment were obtained by randomly selecting at least 100 surface grains (from both exposed bars and submerged locations) with the tip of an index finger. The medial axis of each grain was measured and recorded, and the grain was then discarded to avoid resampling. If feasible, bed surface sampling occurred across the entire width of the channel. Surface pebble counts were located at the top of riffle channel features or at the upstream end of exposed gravel bars when subsurface counts were also made. Subsurface pebble counts were conducted at the upstream end of exposed gravel bars by first removing surface sediment to a depth of the largest grain size over a 1-square-meter area. The subsurface sediment grain size was measured using the same method employed for surface sampling. Pebble count results are included in Appendix C.

\section{Colluvial Channels}

Colluvial channels are steep, headwater portions of the channel network that are largely dominated by hillslope processes such as soil creep and small-scale slope instability. Sediment transport in colluvial channels is limited by intermittent flow, large sediment grain sizes, woody debris and bedrock steps, and riparian vegetation. Sediment delivery to the alluvial channel 
network occurs primarily through episodic debris flows (Swanson et al. 1982, cited by Montgomery and Buffington 1998).

Colluvial channels were delineated as headwater channels with a contributing drainage area less than $0.1 \mathrm{~km}^{2}$. Colluvial channels in the upper Grays River watershed total approximately 623 kilometers and make up 67 percent of the channel network (Table 16).

Table 16. Length and percentage of each geomorphic channel unit in the upper Grays River watershed.

\begin{tabular}{|c|c|c|c|}
\hline Geomorphic Channel Unit & $\begin{array}{c}\text { Length } \\
\left(\mathrm{km}^{2}\right)\end{array}$ & $\begin{array}{l}\text { Percentage of Total } \\
\text { Channel Network }\end{array}$ & $\begin{array}{l}\text { Percentage of Response } \\
\text { Channel Network }\end{array}$ \\
\hline Colluvial channels & 623.2 & 67.4 & - \\
\hline Headwater transport channels & 157.0 & 17.0 & - \\
\hline Tributary response channels & 109.4 & 11.8 & 77.9 \\
\hline East Fork Grays River & 5.2 & 0.6 & 3.7 \\
\hline South Fork Grays River & 7.8 & 0.8 & 5.6 \\
\hline West Fork Grays River & 7.0 & 0.8 & 5.0 \\
\hline Lower Crazy Johnson Creek & 0.3 & 0.0 & 0.2 \\
\hline Main stem Grays River & 11.2 & 1.2 & 4.8 \\
\hline Grays River response reach & 4.0 & 0.3 & 2.8 \\
\hline Total channel network $^{\mathrm{a}}$ & 925.1 & - & - \\
\hline Response channel network ${ }^{\mathrm{b}}$ & 140.4 & 15.7 & - \\
\hline
\end{tabular}

Evidence of mass wasting and debris flows were common in colluvial channels observed in the upper Grays River watershed during field reconnaissance (also refer to the assessment of mass wasting and surface erosion). Many colluvial channels, such as survey reach CC-1, exhibited evidence of debris flows such as channels scoured to bedrock (Photo CC-1-1 in Appendix B). In other colluvial channels (e.g., survey reach CC-2), upstream mass wasting has deposited significant sediment that is slowly being transported farther downstream (Photo CC-2-1 in Appendix B). Where evidence of debris flows was not observed (e.g., survey reach CC-3), large woody debris (LWD) created steps in the channel profile and provided significant sediment storage. However, the recruitment potential of riparian forests adjacent to colluvial channels was typically poor. Because LWD increases channel roughness, the absence of future sources of LWD may increase the run-out distance of debris flows and sediment delivery to the channel network.

\section{Headwater Transport Channels}

Headwater transport channels include cascade and step-pool channels where transport capacity typically exceeds sediment supply. Headwater transport channels are frequently located between 
colluvial channels and response channels lower in the channel network and serve as a conduit to transport sediment derived through upland mass wasting processes (see Figure 17). These are high-gradient channels that in this analysis were delineated where channel gradient exceeds 4 percent and contributing drainage area exceeds $0.1 \mathrm{~km}^{2}$. Headwater transport channels in the upper Grays River watershed total approximately 157 kilometers and make up 17 percent of the channel network (Table 16).

Headwater transport channels observed during the channel survey were generally confined steppool channels. Channel steps were typically formed from boulders and occasionally from LWD (Photos HTC-1-1 and HTC-1-2 in Appendix B). The LWD recruitment potential from adjacent riparian forests was fair to poor, as the majority of riparian forests were observed to be dominated by alder (Photo HTC-2-1 in Appendix B). Although headwater transport channels are theoretically supply-limited, the widespread extent of bar deposition observed in survey reach HTC-1 indicates high rates of sediment loading that locally overwhelm transport capacity.

\section{Tributary Response Channels}

Tributary response channels include plane-bed and pool-riffle channels flowing to the main stem or a fork of the Grays River with channel gradients less than 4 percent (Figure 17). These alluvial response channels are sensitive to changes in influences on channel morphology such as sediment load, discharge, and the character of riparian vegetation. Tributary response channels in the upper Grays River watershed total approximately 109 kilometers and make up approximately 12 percent of the channel network and 78 percent of the alluvial response reaches (Table 16).

Tributary response channels are dominated by confined to moderately confined plane-bed channels (Photo TRC-1-1 in Appendix B). Where the channel was moderately confined, lateral instability and channel widening was commonly observed (Photo TRC-2-1 in Appendix B). Loose deposits of fine-grained sediment (silt to fine-grained gravel) composed of marine siltstone were observed in a number of the survey reaches and covered up to 40 percent of the streambed surfaces in depths up to 0.5 meters locally (Photo TRC-1-1 and TRC 1-2 in Appendix B). Clasts composed of the marine siltstone are weak and easily broken down.

Large woody debris loading was typically moderate to poor, and little functional wood was observed within the active channel of observed tributary response channels (Photo TRC-3-1 in Appendix B). Where functional LWD was observed, it was composed of relict old-growth LWD that entered the channel network prior to the harvest of the adjacent riparian forest. The general lack of functional LWD is significant because LWD plays a large role in determining the channel response to changes in sediment supply or transport capacity (Montgomery et al. 1996; Abbe and Montgomery 2003).

In all tributary response channels observed, the adjacent riparian community was dominated by immature red alder with little or no recruitment potential for functional LWD. The poor recruitment potential typical of the adjacent riparian community indicates that the potential for these response channels to function as capacitors that regulate the flux of sediment through the 
channel network will continue to diminish as relict LWD breaks down, further increasing sediment delivery to downstream reaches (Photo TRC-4-1 in Appendix B).

\section{East Fork Grays River}

The East Fork Grays River geomorphic channel unit includes the alluvial response portion of the river that extends 4.0 kilometers east from the confluence of the East Fork and main stem Grays River (Figure 17). The East Fork Grays River geomorphic channel unit is defined as the portion of the East Fork with a channel gradient less than 4 percent and includes plane-bed and poolriffle reaches. The East Fork Grays River geomorphic channel unit makes up 0.6 percent of the total channel network in the upper Grays River watershed and 3.7 percent of the alluvial response reaches (Table 16).

The surveyed reach of the East Fork Grays River is a moderately confined plane-bed channel exhibiting little complexity (Photos EGR-1-1 and EGR-1-2 in Appendix B). The channel substrate is predominantly gravel- and cobble-bedded with occasional boulders and lateral bars consisting of sand and fine gravel. Sand deposits were found on the active floodplain surface, indicating floodplain connectivity at high-flow stages and fine sediment storage within the active floodplain. A side channel observed at the left edge of the floodplain is not directly connected by surface flows to the main channel but contained flowing water, indicating hyporheic (subsurface) flow through floodplain sediments.

The role of LWD is limited in the survey reach. No functional LWD was observed in the 500-meter survey reach, and the riparian forest consists primarily of red alder with little future recruitment potential. An increase in wood loading would increase both floodplain connectivity and sediment storage potential within the channel, but this could be accomplished only by importing large functional LWD. Otherwise, up to several centuries of successional forest development is needed to reintroduce functional LWD to these reaches.

\section{South Fork Grays River}

The South Fork Grays River geomorphic channel unit includes 7.5 kilometers of the South Fork extending east from its confluence with the main stem Grays River (Figure 17). The South Fork Grays River geomorphic channel unit is defined as the portion of the South Fork with a channel gradient less than 4 percent and includes plane-bed and pool-riffle reaches. The South Fork Grays River geomorphic channel unit makes up 0.8 percent of the total channel network in the upper Grays River watershed and 5.6 percent of the alluvial response reaches (Table 16).

Field reconnaissance of the South Fork Grays River identified two distinct channel conditions. Survey reach SGR-2 was observed to be a complex, multiple-threaded pool-riffle channel network (Photo SGR-2-2 in Appendix B). The surveyed reach is moderately confined and dominated by forested islands, midchannel bars, buried jams, and high levels of LWD loading. Complex valley jams create steps in the channel profile, producing steep transverse hydraulic gradients between channels across the floodplain (Abbe and Montgomery 2003). Jam steps are up to 1.5 meters in height and extend almost the full valley width in some locations, up to 50 
meters (Photo SGR-2-1 in Appendix B). Much of the wood within these jams, however, is relict and is in a partial or significant state of decay. Recruitment potential in this reach is relatively limited due to immature riparian forests within the valley bottom and along the margins of the channel migration zone. As the relict LWD providing complexity and structure to the channel continues to break down and is not replaced when lost from the system, sediment currently stored by this LWD will be conveyed downstream and transport capacity within the reach will increase.

In contrast to the complexity observed in survey reach SGR-2, the lower of the two surveyed reaches (SGR-1) is a moderately confined predominantly cobble bedded plane-bed channel (Photo SGR-1-1 in Appendix B). Large bar deposits within the reach consist of coarse-grained gravel and cobble. LWD loading is low within the survey reach and provides little hydraulic complexity or opportunity for sediment storage. The forested floodplain surfaces adjacent to the channel are primarily alder-dominated and offer poor recruitment potential. The elevation of these floodplain surfaces is variable, however, and terraces ranging up to 3 meters above the current bankfull stage indicate a wide range of historical channel elevations.

At the downstream end of survey reach SGR-1, portions of a 4-meter-high terrace (3 meters above bankfull stage), which formed behind a debris dam resulting from a landslide, remain at the left margin and within the central part of the floodplain valley. The extent of this terrace provides an indication of historical sediment loads through this reach (Photo SGR-1-2 in Appendix B). The stratigraphy of the terrace includes clayey silt layers and foreset beds of sand with coarser alluvial deposits, representing a higher-energy depositional environment at the upstream end of the terrace (Photos SGR-1-3 and SGR-1-4 in Appendix B). Samples of wood collected from the debris dam and the terrace deposit were sent to an analytical laboratory for radiocarbon dating (Figure 18). Results from these samples, along with the observed extent of the remaining portions of the terrace surface, the terrace height, and the dimensions of the floodplain valley, were used to calculate historical deposition rates behind the debris dam.

Radiocarbon dating of LWD from the debris dam deposit at the downstream end of the terrace formation (Sample Grays RC 1) and from wood exhumed from within the terrace deposit (Sample Grays RC 2) at 2 meters above current bankfull stage (1 meter below the top of the terrace surface) indicate that the terrace began forming between 210 and 330 years ago (275 years before present \pm 60 years), and deposition continued through at least 130 and 250 years ago (205 years before present \pm 60 years). (See Appendix D for radiocarbon dating analysis results.) The reported radiocarbon dates of the debris dam and terrace sample (275 years and 205 years before present, respectively) provide a reasonable estimate of the duration of deposition to the terrace sample elevation. Based on this duration and the relative position of the terrace sample within the deposit, a period of 100 years was estimated for historical deposition rate calculations.

Based on the distribution of remaining terrace surfaces, the width of the floodplain, and the observed terrace height, terrace dimensions were estimated to be 300 meters in length, 120 meters in width, and 4 meters in depth, with a total sediment volume of approximately 144,000 cubic meters. Assuming a depositional period of 100 years, the depositional rate behind the debris jam was estimated at approximately 1,440 $\mathrm{m}^{3} /$ year, or 2,450 tons/year. With a subbasin 
area of $52 \mathrm{~km}^{2}$ for the South Fork Grays River, the depositional rate responsible for formation of the terrace behind the debris dam was 47 tons $/ \mathrm{km}^{2} /$ year. This rate is close to estimates of historical sediment production rates determined in the assessment of mass wasting and surface erosion, which range from 56 to 125 tons $/ \mathrm{km}^{2} /$ year, and supports the interpretation that sediment production has increased by many orders of magnitude since the onset of timber harvest.

\section{West Fork Grays River}

The West Fork Grays River geomorphic channel unit includes 7.0 kilometers of the West Fork extending north from the pre-avulsion confluence with the main stem Grays River (Figure 17). The West Fork Grays River geomorphic channel unit is defined as the portion of the West Fork with a channel gradient less than 4 percent and includes plane-bed and pool-riffle reaches. The West Fork geomorphic channel unit makes up 0.8 percent of the total channel network in the upper Grays River watershed and 5 percent of the alluvial response reaches (Table 16).

A reconnaissance stream survey of the West Fork Grays River was completed between the West Fork and main stem Grays River confluence and the Grays River state fish hatchery at West Fork (RK 2.0; see Figure 17). The West Fork exhibits two distinct characters over this distance. Between the confluence with the main stem Grays River and RK 1.25 (survey reach WFG-1), the West Fork is a moderately confined, predominantly straight, plane-bed channel with little channel complexity. The channel is aligned against bedrock outcrops at the floodplain valley margin along much of this reach (Photo WGR-1-1 in Appendix B). The gravel and cobble substrate material is loose, and lateral bar deposits are not armored and consist of finer-grained sediments. Although these conditions indicate moderate to high sediment loading, there is limited sediment storage in the simple channel configuration, which lacks functional LWD and recruitment potential from the adjacent alder-dominated riparian forest.

In contrast, survey reach WFG-2 contains moderate to high levels of LWD loading, and LWD jams in the reach frequently impart significant hydraulic complexity and provide considerable sediment storage in the active channel (see Figure 17 and Appendices B and C). The channel in this reach is predominantly a moderately confined, gravel-bedded, pool-riffle reach (Photo WGR-2-1 in Appendix B). Lateral channel instability is evidenced by undercut riparian vegetation and bank erosion into floodplain valley margins (Photo WGR-2-3 in Appendix B). Within the current alignment, the channel position appears to be unstable as a result of the combination of locally recruited LWD and high sediment loads. There is evidence of recent avulsion where the old channel alignment has been abandoned at the left valley margin and the current channel alignment has become established through an area of moderate to low LWD recruitment potential (Photo WGR-2-2 in Appendix B). Significant deposits of very loose marine siltstone sand and gravel were observed to fill pools and cover more consolidated substrate material in many locations. These conditions are indicative of high sediment delivery to this reach. A record of regular dredging at the bridge to the Grays River fish hatchery also indicates high sediment delivery to the reach.

According to discussions with Grays River state fish hatchery personnel, dredging of 50 meters of the West Fork Grays River upstream of the fish hatchery bridge has removed at least 2,500 


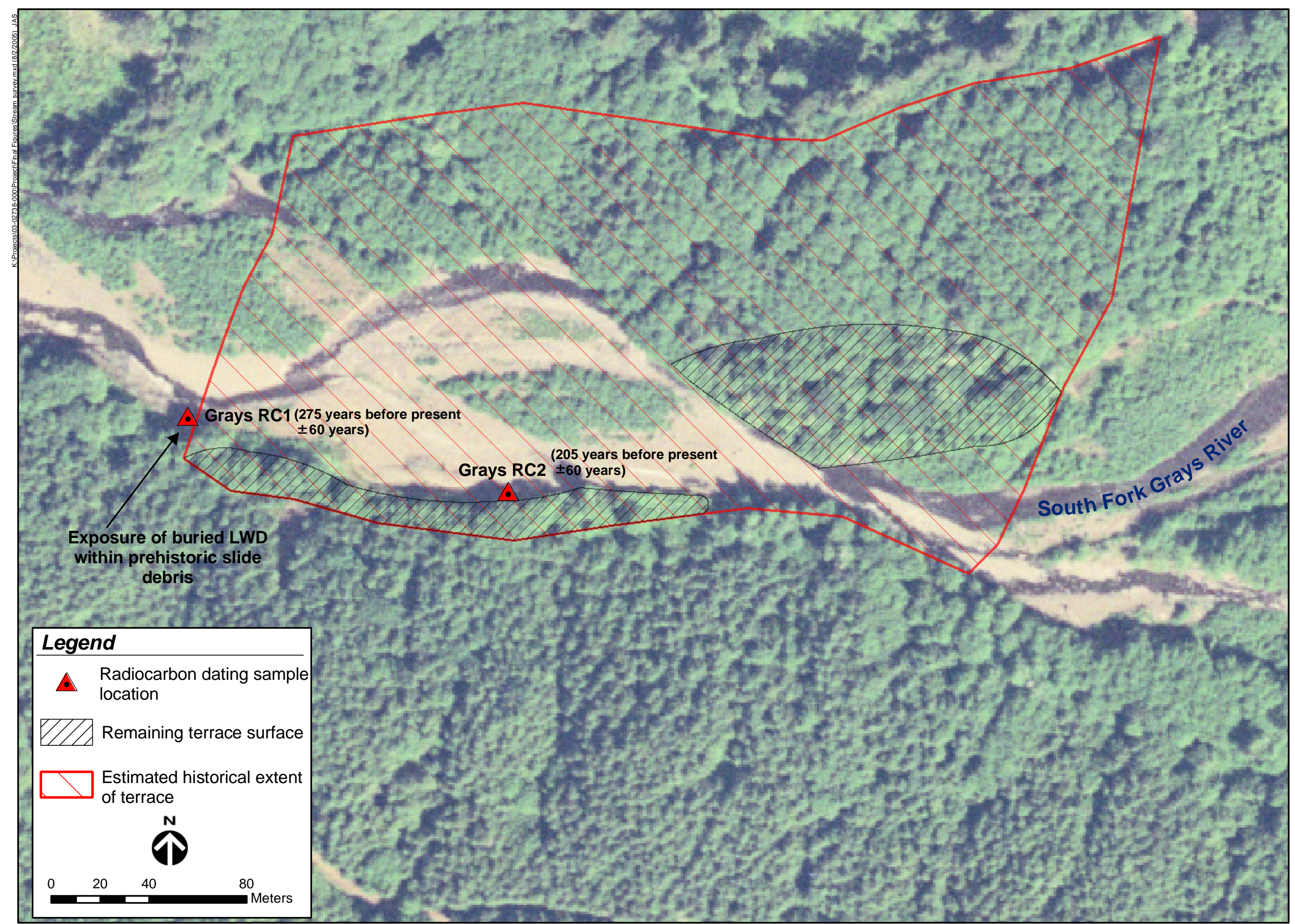

Figure 18. Locations of radiocarbon dating samples and the extent of remaining and estimated historical terrace surfaces upstream of the observed debris dam evidence in the South Fork Grays River, Washington. 

Grays River Watershed-Geomorphic Analysis

$\mathrm{m}^{3}$ /year (4,300 tons/year) of bedload sediment annually from 1999 to 2003 (Parker 2004 personal communication). The 4,300 tons/year dredged annually from the West Fork amounts to 5 percent of the estimated sediment production of approximately 89,000 tons/year in the West Fork Grays River subbasin. Because bedload sediment is thought to generally constitute approximately 5 to 20 percent of the total sediment transported through the channel network, the quantity of the dredged material suggests that sediment yield estimates are reasonably accurate (Dietrich and Dunne 1978; Hicks and Gomez 2003).

\section{Lower Crazy Johnson Creek}

Lower Crazy Johnson Creek is a gravel- and sand-bedded channel fed by a $1.8-\mathrm{km}^{2}$ drainage area (Figure 17). The lower reach of the Crazy Johnson Creek is located on the main stem Grays River floodplain. Stream banks are typically composed of alluvial sand, gravel, and cobble sediment, indicating historical deposition in this area from the main stem Grays River (Appendices B and C). Frequent beaver ponds along Crazy Johnson Creek create backwater environments and are often correlated with occurrences of LWD (Photo CJ-1-1 in Appendix B). The ponds create hydraulic gradients across the floodplain, and upwelling in Crazy Johnson Creek was clearly visible downstream of a pond. Portions of the length of Crazy Johnson Creek are likely inundated by floodwaters during high flows on the main stem Grays River. Such high flow events would increase the ground water table in floodplain deposits and increase the hyporheic recharge, or subsurface flow, to Crazy Johnson Creek.

\section{Main Stem Grays River}

The main stem Grays River geomorphic channel unit includes approximately 12 kilometers of the Grays River upstream of RK 22.5 (Figure 17). The main stem geomorphic channel unit is defined as the portion of the Grays River with a channel gradient less than 4 percent, although the unit also includes the confined bedrock reach from RK 22.5 to RK 27.0 where local gradients exceed 4 percent.

The main stem Grays River geomorphic channel unit makes up 1.3 percent of the total channel network length in the upper Grays River watershed and 4.8 percent of the total length of the alluvial response reaches (Table 16). The main stem Grays River is a moderately confined to confined, predominantly cobble-bedded, plane-bed channel that lacks significant hydraulic complexity. Large lateral bar deposits are visible within the channel, even where it is confined, indicating high levels of sediment loading. Observations of LWD were limited, as is the recruitment potential from adjacent riparian forests.

\section{Grays River Response Reach}

The Grays River response reach includes approximately 4 kilometers of the Grays River from the State Highway 4 bridge at RK 18.5 to the downstream end of the bedrock canyon at RK 22.5 (Figure 17). The present confluence of the main stem and West Fork Grays River is used to divide the Grays River response reach into two subreaches: the Highway 4 subreach and the Gorley subreach. The Highway 4 subreach (RK 18.5 to 20.3) extends from the State Highway 4 
bridge to the present confluence of the West Fork and main stem Grays River at the downstream end of the 1999 avulsion path. This subreach includes the two downstream meanders of the Grays River response reach. The Gorley subreach (RK 20.3 to 22.5) extends upstream from the present confluence of the West Fork and main stem Grays River (at the downstream end of the 1999 avulsion path) to the downstream end of the bedrock canyon, and includes both the preand post-avulsion main stem channel alignments and the three upstream meanders in the response reach.

Channel gradients throughout the response reach are generally less than 2 percent. The response reach makes up 0.3 percent of the total channel network length in the upper Grays River watershed and 2.8 percent of the total length of the alluvial response reaches (Table 16). The field survey of the response reach focused primarily on the Gorley subreach and extended from the present confluence of the West Fork and main stem Grays River (the downstream end of the 1999 avulsion path) to the downstream end of the bedrock canyon, including both the pre- and post-avulsion main stem channel alignments.

Before levee construction in the 1960s, the lateral channel migration zone along the Grays River response reach included the entire floodplain and was limited only by the bedrock walls of the valley margin. Levees constructed in the area of the West Fork confluence in the 1960s reduced the width of the historical channel migration zone from approximately 750 meters to 200 meters. The downstream segment of the pre-avulsion main stem alignment is confined to a narrow, 50-meter-wide corridor by levees constructed on both sides of the channel. A series of channel avulsions in 1999 (discussed in greater detail in the next section) breached the levees where they connected with bedrock at the left floodplain margin. The avulsions reconnected the channel with the former floodplain.

Valley width continues to increase downstream through the Highway 4 subreach to over 900 meters at the highway bridge. A stream bank revetment was constructed between 1982 and 1996 (date based on aerial photographs) along the outside meander of the Highway 4 subreach at the confluence with Fossil Creek. Construction of this revetment reduced the channel migration zone from approximately 600 meters to 350 meters. Levees were also constructed along the downstream segment of the Highway 4 subreach, where the channel alignment has remained stable since at least 1939. Lineaments apparent along the left bank in historical aerial photographs suggest that these levees were constructed before 1939.

Widespread bank erosion and channel adjustment are evident throughout the channel alignment created by the 1999 avulsion. Trees buried in growth position and floodplain surfaces at a wide range of elevations throughout the survey reach indicate significant changes in vertical channel elevation (Photo GRR-1-2 in Appendix B). When the levee was breached during the December 1999 avulsion event, approximately 1 meter of aggradation occurred over much of the floodplain surface that previously had been isolated from the active channel since at least 1966 (Photo GRR-1-4 in Appendix B). Significant deposition is also evident in pre-avulsion channel alignments upstream of the avulsion. Channel aggradation within this segment during the 1999 storms likely contributed to flows overtopping and breaching the levee. 
The main stem response reach is a pool-riffle channel lacking significant complexity (Photo GRR-1-1 in Appendix B). Large lateral and midchannel bars of fine and coarse sediments indicate high sediment loading and suggest a high response potential to increased wood loading. Grade control or hydraulic complexity evoked by channel obstructions would provide storage and sorting of alluvial sediment, yet few roughness elements such as functional LWD were observed within the study reach. Individual pieces of large wood resting on bar tops appear readily mobile at high-flow stages. In contrast, ancient logjams exhumed from the floodplain by bank erosion in a number of locations throughout the response reach suggest that historical wood loading was greater than at present (Photo GRR-1-3 in Appendix B). These ancient logjams are consistent with conditions that prevailed in the old-growth floodplain forest once found along the river.

\section{Historical Channel Conditions}

The analysis of historical channel conditions focuses primarily on the Highway 4 subreach and the Gorley subreach within the 4-kilometer response reach of the main stem Grays River (i.e., RK 18.5 to 22.5) (Figure 17). Historical channel patterns have been influenced by timber harvest, levee construction, bank protection structures, and the operation of splash-dams. Levees and bank revetments constructed along the main stem Grays River have affected channel patterns since at least the 1960s (Figure 17). Splash-dams functioned to store water that was then released during large storm events to enable log drives. This process had catastrophic impacts on channel conditions. Splash-dams are known to have been operated for at least several seasons on the South Fork, West Fork, and main stem Grays River during the period from 1880 to 1910 (Sedell and Luchessa 1982). Splash-dams were used within the upper Grays River watershed as late as 1937 (Figure 19).

Splash-damming causes significant bed scour that removes spawning gravel and LWD, widens the channel, and reduces channel complexity. Channel clearing prior to log drives removed obstructions such as woody debris, boulders, and riparian vegetation and compounded the habitat degradation associated with splash-damming. Because these practices were followed before detailed descriptions of the river morphology and aerial photographs were made, major portions of the Grays River had been severely altered by the time they were described.

Historical channel alignments of the Grays River were reconstructed from aerial photographs and information collected during the field reconnaissance. The geomorphic response of the main stem Grays River was evaluated quantitatively in terms of temporal changes in reach-scale meander geometry (i.e., sinuosity, meander wavelength, radius of curvature, and migration rates), as well as qualitatively through observations of changes in vegetation patterns and channel response (i.e., gravel bar deposition, channel aggradation, and avulsion). The following sections describe the methods and results of the historical channel analysis.

\section{Channel Alignments}

Historical analysis of channel position focused on the response reach segments of the main stem Grays River. The historical alignments of active channels were delineated from digital 
georeferenced aerial photographs. Orthorectified USGS digital orthophoto quarter quadrangles (DOQQs) from 1996 were obtained from the Washington Geospatial Data Archive (WAGDA). Channel migration patterns inferred from the sequence of aerial photographs were compared with the 2003 floodplain survey completed for the lower main stem by Pacific Northwest National Laboratory (PNNL). The aerial photographs used in the historical analysis of channel migration patterns are summarized in Table 17.

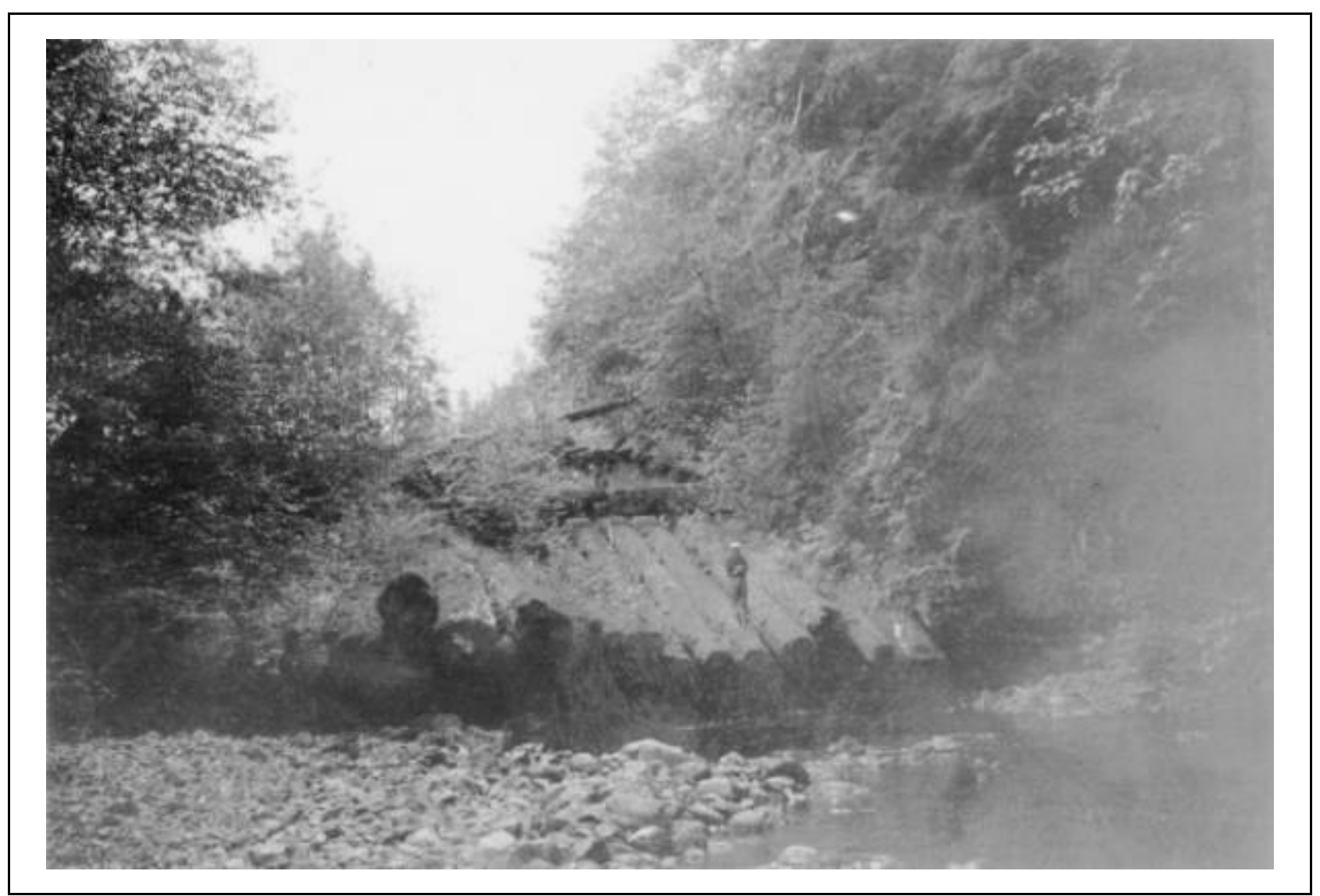

Figure 19. Splash-dam near the mouth of the South Fork Grays River, June 12, 1937. Source: Oregon State University Archives.

Table 17. Aerial photographs used in the analysis of historical channel migration patterns in the Grays River.

\begin{tabular}{clc}
\hline \hline Date of Aerial Photograph & \multicolumn{1}{c}{ Source } & Scale \\
\hline 1939 & U.S. Army Corps of Engineers & $1: 10,200$ \\
1966 & U.S. Army Corps of Engineers & unknown \\
1970 & Washington Department of Natural Resources & $1: 12,000$ \\
1982 & Washington Department of Natural Resources & $1: 12,000$ \\
1996 & U.S. Geological Survey (DOQQs) & $1: 12,000$ \\
2003 & Washington Department of Natural Resources & $1: 32,000$ \\
\hline \hline
\end{tabular}

DOQQs = Digital orthophoto quarter quadrangles. 
Aerial photographs were georeferenced to the 1996 USGS DOQQs using first-order polynomial (affine) transformation in ArcMap 9.0. Control points were placed evenly along the channel in each photograph to maximize georeferencing accuracy in this area. Road bends, road crossings, corners of buildings, bedrock outcrops, and large trees were used to guide control point placement for georeferencing. Six or more control points typically were used to georeference more recent photo sets. Five or more control points typically were used for older photo sets because older photo sets had fewer distinct features in common with the 1996 orthorectified photo set.

The boundaries of historical active channel alignments (channel polygons) were digitized from the georeferenced photographs at a scale of approximately 1:2,000, although the scale was adjusted between 1:750 and 1:10,000 to aid in interpretation. The extent of the unvegetated channel was used to define channel polygons to account for seasonal variability in river height and width. To minimize small differences in channel edge due to georeferencing error, one unvegetated channel polygon was created from the 1996 aerial photo set. This polygon was copied and modified to create the 1982 unvegetated channel. The process was repeated by modifying the unvegetated channel of one photo set to create the unvegetated channel of the previous photo set. Other photo sets were taken into account when unvegetated channels were digitized. For instance, the same channel edge was used when the previous and next aerial photographs indicated no change in the channel boundary. Side channels that were visibly carrying water or were unvegetated were included in the unvegetated channel layer if they were over 10 meters wide. Forested islands larger than approximately 1,000 square meters were not included as part of the unvegetated channel. The historical extent of the active channel is presented in Figure 20 (and for each photo year in Appendix H).

\section{Channel Migration}

Two principal forms of channel migration were identified on the Grays River: lateral migration and avulsion. Lateral migration involves persistent movement of the channel across the valley, particularly at the outer edge of the meanders. Lateral migration leaves a geomorphic legacy of scroll bars and arcuate erosion scars matching the channel curvature. Avulsion involves the rapid relocation of the channel to a new alignment across the floodplain. A shift in channel location between aerial photographs was classified as an avulsion if vegetation between the preand post-avulsion channel was not disturbed by channel movement (i.e., forest greater in age than the time span between the two photo sets).

\section{Lateral Migration}

Two methods were used to quantify lateral migration in the study reach through the period of aerial photographic record. The first method, based on a linear analysis, was used where lateral migration of recognizable channel features occurred between subsequent time periods. An alternative method, based on a polygon analysis, quantified erosion by subreach by determining the difference in spatial extent of the unvegetated channels between photographs.

Linear Analysis of Lateral Channel Migration Rates-Rates of historical lateral channel migration were calculated from the change in position of the outside edge of meander bends and 
the time elapsed between aerial photographs. The outside edge of the meander bend was defined using the extent of the unvegetated channel delineated from aerial photographs. Average annual rates of lateral bank erosion were calculated from the distance between the outward and downstream translation of a meander bend apex and the length of time between aerial photographs.

The five meander bends in the main stem response reach were classified as either translational, stable, or unstable, based on the historical pattern of lateral channel migration. A translational meander is defined as progressive meander growth and erosion of the outside bank identified in three or more consecutive aerial photographs. A stable meander is defined by lateral migration that varies by less than approximately one channel width between aerial photographs. An unstable meander is identified by erosion of the outside bank for less than three consecutive aerial photographs. For most of the unstable meanders, the direction of channel migration reversed between aerial photographs.

Historical channel migration patterns for each meander bend in the Grays River main stem response reach are summarized in Table 18. Both the rate and direction of lateral channel migration varied considerably during the period of historical record. Although the radius of curvature of Bend 1 increased through the historical period of record, the meander apex remained relatively fixed through the bedrock-confined segment. The meander in Bend 4 was also stable between 1996 and 2003, where aerial photographs indicate a levee and series of groin walls constructed along the outside (left) bank of this meander between 1982 and 1996 (Figure 20). Bend 4 is characterized by an unstable migration pattern prior to 1982. Unstable migration patterns were also identified in Bend 2 for the period of historical record, despite partial confinement by bedrock along the southern margin of the valley.

Translational migration patterns (i.e., progressive meander growth identified in three or more consecutive aerial photographs) were limited to Bends 3 and 5 for the period of historical record (Figure 20). Approximately 66 meters of bank erosion occurred in Bend 3 between 1970 and 1996. The average annual migration rate in Bend 3 for this period was 2.6 meters/year. The highest rate of average annual channel migration (3.8 meters/year) was measured in Bend 5 between 1970 and 2003, where 109 meters of bank erosion was measured during this 33-year period.

\section{Table 18. Linear analysis of lateral channel migration rates for the main stem Grays River.}

\begin{tabular}{clccc}
\hline \hline Meander Bend & Migration Pattern & Photographic Period & $\begin{array}{c}\text { Lateral Bank Erosion } \\
\text { (meters) }\end{array}$ & $\begin{array}{c}\text { Average Migration Rate } \\
\text { (meters/year) }\end{array}$ \\
\hline 1 & Stable & $1939-2003$ & - & - \\
2 & Unstable & $1939-2003$ & - & - \\
3 & Translational & $1970-1996$ & 66 & 2.6 \\
4 & Unstable & $1939-1982$ & - & - \\
& Stable & $1996-2003$ & - & - \\
5 & Translational & $1970-2003$ & 109 & 3.8 \\
\hline \hline
\end{tabular}




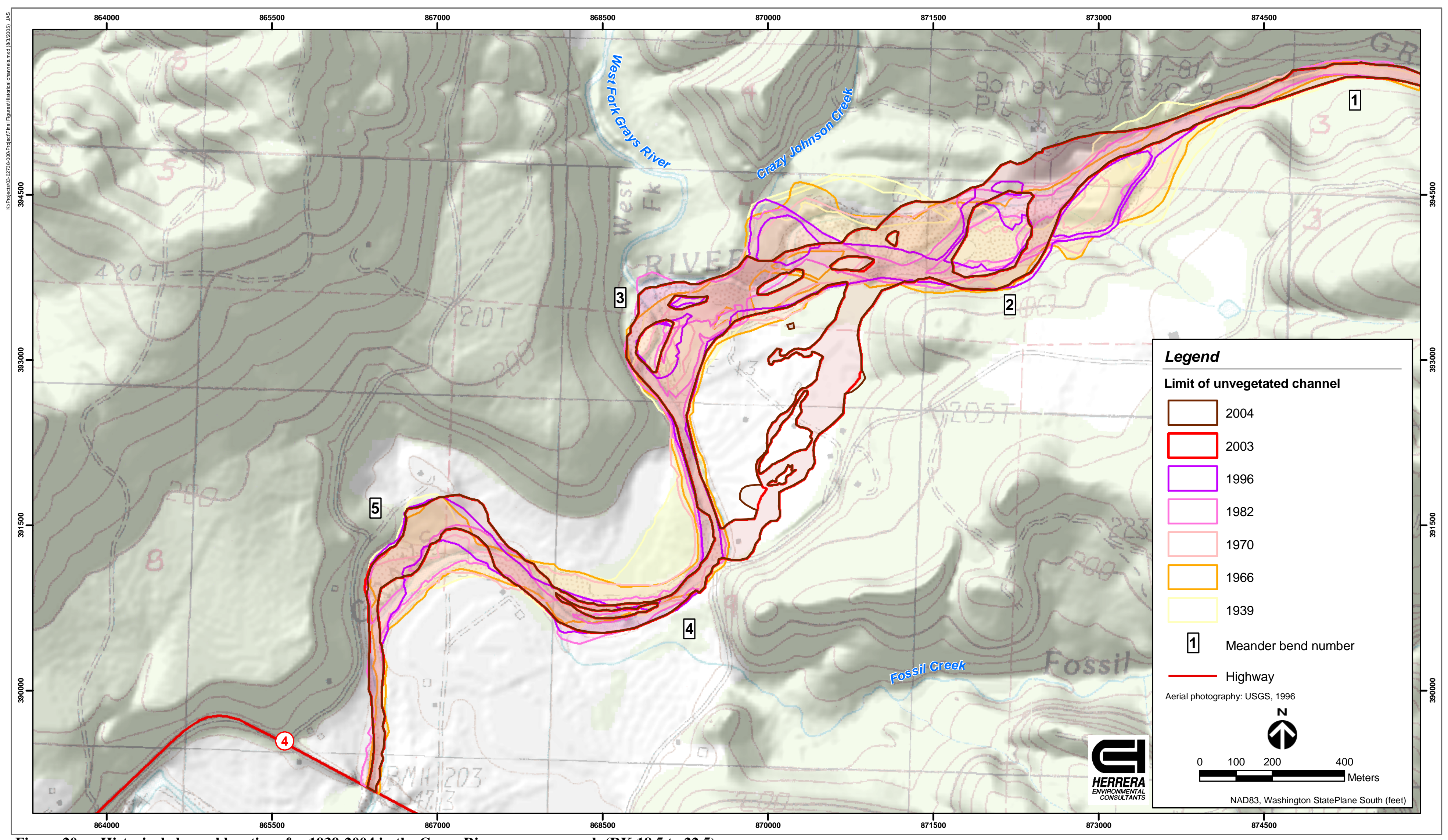

Figure 20. Historical channel locations for 1939-2004 in the Grays River response reach (RK 18.5 to 22.5). 

Polygon Analysis of Lateral Channel Migration Rates-A polygon analysis of lateral channel migration rates was performed for the Gorley and Highway 4 subreaches of the Grays River main stem response reach and the West Fork and South fork response reaches. Coverage by historical aerial photographs in the West and South forks was limited to 1970, 1996, and 2003. Reach-average lateral migration rates were calculated from the change in the area of unvegetated channel polygons between aerial photo sets. Spatial erosion rates ( $\mathrm{m}^{2} /$ year) were calculated for each channel reach by dividing the difference in polygon area by the time elapsed between aerial photographs. Reach-average lateral migration rates (meters/year) were calculated by dividing the spatial erosion rates by the average reach length between photographs.

Results of the polygon analysis of lateral channel migration are presented in Table 19. The polygon method differs from the linear method in that it first quantifies the reach-average area over which erosion of the floodplain surface has occurred. Reach-average erosion rates were greatest in the main stem Grays River (Highway 4 and Gorley subreaches), with the highest erosion rates measured between 1996 and 2003. Reach-average erosion rates were considerably lower in the West Fork and South Fork response reaches (Table 19).

\section{Table 19. Polygon analysis of erosion rates and lateral channel migration rates for the main stem, West Fork, and South Fork Grays River.}

\begin{tabular}{lcccc}
\hline \hline Reach/Subreach & $\begin{array}{c}\text { Photographic } \\
\text { Period }\end{array}$ & $\begin{array}{c}\text { Erosion Rate } \\
\text { (meters/year) }\end{array}$ & $\begin{array}{c}\text { Lateral Migration Rate } \\
\text { (meters/year) }\end{array}$ & $\begin{array}{c}\text { Average } \\
\text { Lateral Migration Rate } \\
\text { (meters/year) }\end{array}$ \\
\hline Highway 4 subreach & $1939-1966$ & 394 & 0.17 & - \\
& $1966-1960$ & 3,858 & 1.71 & - \\
& $1970-1982$ & 3,488 & 1.46 & - \\
& $1982-1996$ & 3,978 & 1.57 & 1.67 \\
\hline Gorley subreach & $1996-2003$ & 8,684 & 3.43 & - \\
& $1939-1966$ & 1,709 & 0.72 & - \\
& $1966-1960$ & 3,364 & 1.38 & - \\
& $1970-1982$ & 3,291 & 1.29 & - \\
& $1982-1996$ & 6,691 & 2.71 & - \\
\hline West Fork response reach & $1996-2003$ & 11,292 & 5.13 & - \\
& $1970-1996$ & 1,595 & 1.06 & 1.18 \\
\hline South Fork response reach & $1996-2003$ & 553 & 0.64 & 1.35 \\
& $1970-1996$ & 3,041 & 1.01 & \\
\hline \hline
\end{tabular}

Reach-average lateral migration rates were greatest in the Gorley subreach of the main stem, where lateral migration rates varied from 0.72 to 5.13 meters/year. The highest lateral migration rates in the main stem were measured between 1996 and 2003. Reach-average migration rates were relatively lower in the West Fork and South Fork response reaches, ranging from 0.64 meters/year in the West Fork to 1.35 meters/year in the South Fork (Table 19). 
Reach-average lateral migration rates calculated from the polygon method are lower than lateral migration rates measured using the linear method. The average lateral migration rates measured by the linear method (Bends 3 and 5) are 1.5 to 2 times greater than the reach-average rates measured in the main stem using the polygon method. The linear method best represents bank erosion rates, whereas the polygon method better represents the residence time of sediment stored in the floodplain between sediment-transporting events.

\section{Avulsion}

Channel avulsions typically occur in response to an increase in the local floodplain relief following channel aggradation. In rivers that regularly recruit large wood from their banks, the reduction in transport capacity caused by the flow resistance of large logjams can initiate channel aggradation and force periodic avulsions that maintain an anastomosing (multi-thread) channel network. The multiple channels that develop in forested floodplains increase the availability of aquatic habitat.

Channel aggradation and avulsion can also occur in response to an increase in sediment supply from logging operations (in the absence of an increase in transport capacity). The overtopping of channel banks following the loss of flood conveyance in aggrading channels can initiate an avulsion. However, the shallow braided channels and fine sediment that characterize most aggrading rivers may lack the habitat conditions selected by spawning salmonids.

Channel avulsions can also be triggered by feedback between flow dynamics and meander development. A gradual increase in meander amplitude reduces the channel gradient and corresponding transport capacity, thereby inhibiting further bank migration. Reduction below a threshold transport rate can cause a channel to rapidly aggrade and avulse (Knighton 1998). The increase in channel length during meander extension in the 1970s and 1980s may have reduced the local transport capacity in Bends 2 and 3 and promoted local aggradation prior to the 1999 avulsion.

Field observations by WDFW indicate that the two neck avulsions through Bends 2 and 3 occurred in December 1999. Both avulsions initiated at locations upstream of meander point bars and cut across the necks of the meanders (Figure 21). The avulsion in Bend 2 (point A in Figure 21) occurred sometime before December 3, 1999, and shifted the channel alignment to the north of the forested island. Field observations during high-flow conditions on December 3 document flow on both sides of the island through Bend 2; however, the majority of flow at this time was directed through the northern alignment and into the eastern end of the levee at a nearly perpendicular angle (point B in Figure 21). Lateral erosion of the levee and undermining of the levee toe, as observed on December 3, preceded the second and larger avulsion through Bend 3, which occurred on December 15, 1999 (Bicknell 2005 personal communication). The avulsion through Bend 3 reoccupied a former side channel along the eastern margin of the floodplain and rejoined the main stem by breaching the downstream end of the levee, where the levee formerly connected with bedrock of the valley margin (point C in Figure 21). 


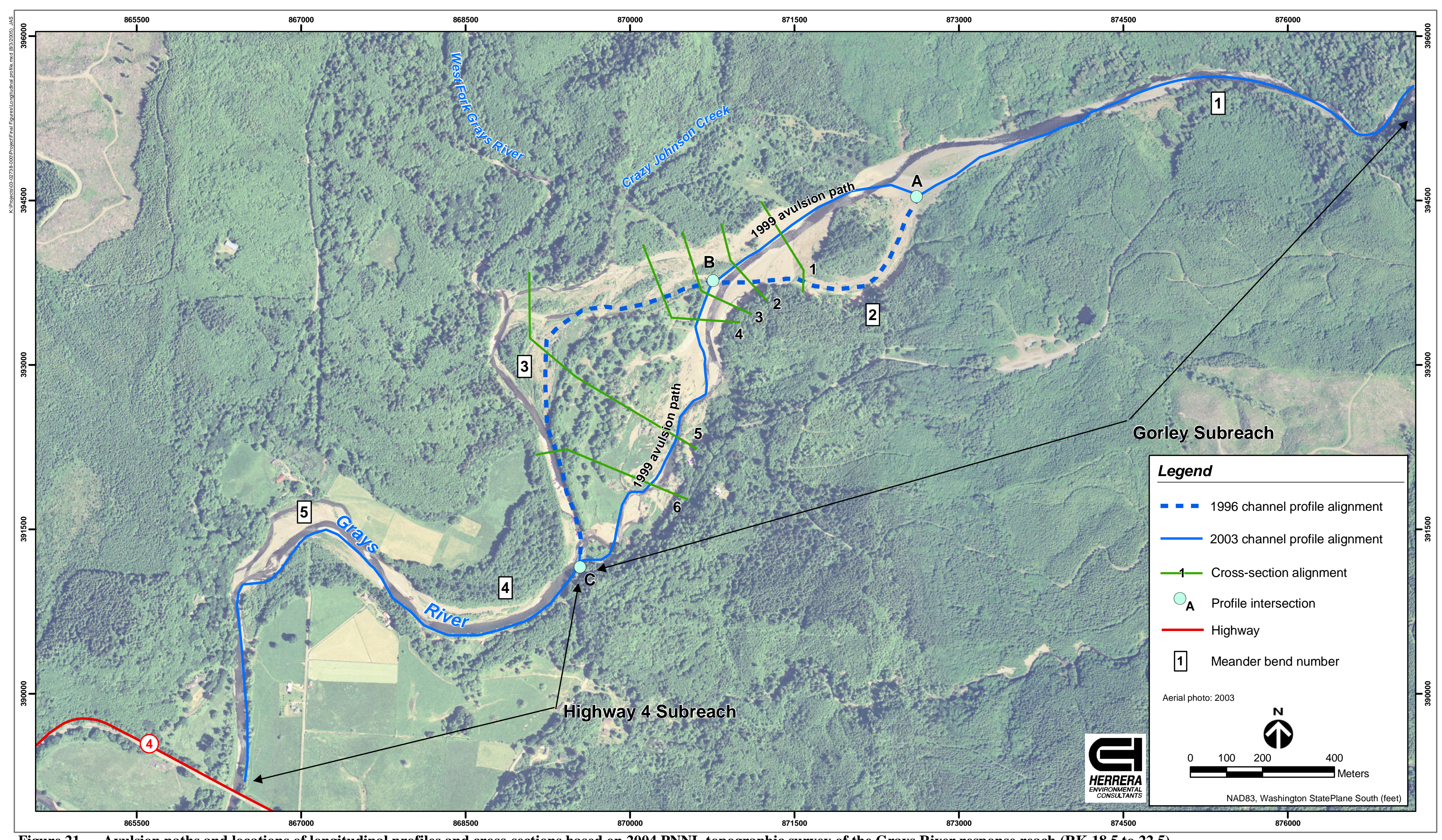

Figure 21. Avulsion paths and locations of longitudinal profiles and cross-sections based on 2004 PNNL topographic survey of the Grays River response reach (RK 18.5 to 22.5). 



\section{Meanders}

Historical trends in the radius of curvature $\left(\mathrm{r}_{\mathrm{c}}\right)$ of meanders can be used to evaluate channel stability. For instance, stable meanders are typically characterized by a large $r_{c}$ value, whereas channel instability in the form of bank erosion and avulsion can occur as a meander bend tightens and meander amplitude increases. Temporal changes in $r_{c}$ values can also be used to forecast trends in bank erosion and the potential for channel avulsion.

Temporal variations in meander geometry and channel stability of the Grays River response reach were evaluated in terms of the radius of curvature of channel meanders measured from historical aerial photographs, based on methods developed by Nanson and Hickin (1983). Channel width (w) was measured at several inflection points along the channel. The average channel width was then used as the length of an arc $(\Delta x)$ placed around the outside of the meander bend, starting from the point of maximum curvature $\left(\mathrm{c}_{\max }\right)$ (Figure 22). Two arcs with length $\Delta x$ were traced on the outside of the bend to create points $a_{1}, a_{2}, b_{1}$, and $b_{2}$. Two circles were fitted through $\mathrm{a}_{1}, \mathrm{c}_{\max }$, and $\mathrm{a}_{2}$; and $\mathrm{b}_{1}, \mathrm{c}_{\max }$, and $\mathrm{b}_{2}$. The average of the radii of these two circles $\left(r_{1}, r_{2}\right)$ is reported as $r_{c}$ of the meander bend.

The radius of curvature was measured for each of the five meander bends identified in the 19391996 aerial photographs and the three bends evident in the 2003 photographs. Bend 1 is located at the upstream extent of the Gorley subreach within the bedrock-confined segment. Bend 2 is located downstream of Bend 1 along the southern bedrock margin of the floodplain (Figure 23). Bend 3 is located north of the Gorley property and includes the Crazy Johnson Creek subreach along the upstream segment of Bend 3 and the confluence with the West Fork at the downstream segment of Bend 3. The left bank along the inside of Bend 3 is defined by a gravel levee and rock revetment constructed in the early 1960s. The northern and western extents of Bend 3 are defined by bedrock along the valley edge in the vicinity of the West Fork confluence. The meander neck between Bends 3 and 4 is confined by levees on both sides. The outside (left) bank of Bend 4 is also armored with a gravel/rock revetment and a series of groin walls constructed between the 1982 and 1996 aerial photographs (Figure 23). Bend 5 is located upstream of the State Highway 4 bridge and is unconfined by levees but is partially confined by bedrock along the right bank.

The radii of curvature of these five meander bends measured during the period of historical record are summarized in Table 20 and Figure 24. The radii of curvature measured for each year in the analysis are presented in Appendix H. The largest radius of curvature (prior to the 1999 avulsion) was measured in Bend 1. The radius of curvature in Bend 1 increased consistently during the period of historical record as the channel alignment progressively straightened downstream of the canyon opening. In contrast, the radii of curvature in Bends 2 and 3 declined steadily through the 1970s and 1980s, until the 1999 avulsions. The channel avulsions in 1999 forced the abandonment of Bends 2 and 3 and straightened the channel alignment. Consequently, the radii of curvature are not reported for Bends 2 and 3 in 2003 (Table 20). The radius of curvature of Bend 4 remained relatively stable during the period of record. Although there was significant movement of the channel alignment through Bend 5, the radius of curvature has remained relatively unchanged through the period of record. 
Table 20. Radii of curvature for each Grays River meander bend measured for the period of record (1939-2003).

\begin{tabular}{ccccccc}
\hline \hline Bend & \multicolumn{7}{c}{ Radius of Curvature (meters) } \\
\cline { 2 - 7 } Number & 1939 & 1966 & 1970 & 1982 & 1996 & 2003 \\
\hline 1 & 247 & 458 & 417 & 427 & 648 & 672 \\
2 & 202 & 314 & 195 & 194 & 168 & $-{ }^{\mathrm{a}}$ \\
3 & 120 & 132 & 272 & 142 & 91 & $-{ }^{\mathrm{a}}$ \\
4 & 112 & 124 & 132 & 119 & 131 & 216 \\
5 & 79 & 74 & 95 & 112 & 99 & 103 \\
\hline \hline
\end{tabular}

a Bends 3 and 4 were cut off by the 1999 avulsion events.

Meander geometry was also evaluated from trends in bend curvature by normalizing the radius of curvature by the channel width $\left(\mathrm{r}_{\mathrm{C}} / \mathrm{w}\right)$. Normalizing the radius of curvature by width allows for a scale-independent comparison of results with prior studies. In a study of the Beatton River in British Columbia, Nanson and Hickin (1983) showed that the meander migration rate (bank erosion) is greatest where $\mathrm{r}_{\mathrm{C}} / \mathrm{w}$ falls between 2.5 and 4 (Figure 25). Bank erosion is considerably less for $r_{c} / w$ outside this range. Bagnold (1960) found that when $r_{c} / w$ falls below a threshold of 2 , the formation of large eddies generates flow resistance that inhibits bank erosion and continued meander migration, thereby shifting channel adjustment from bank erosion to avulsion between meander bends. Results from similar studies indicate that the decline in bank erosion in tight meander bends, where $\mathrm{r}_{\mathrm{c}} / \mathrm{w}$ is less than 2, can lead to a channel avulsion through a chute or neck cutoff of the meander. In a study of Welsh rivers, Lewis and Lewin (1983) found that the maximum frequency of chute and neck avulsions coincided with $r_{c} / w$ between 1 and 2 .

Historical trends in bend curvature for Bends 2 and 3 leading up to the 1999 avulsions on the main stem Grays River are presented in Figure 26. Although $\mathrm{r}_{\mathrm{c}} / \mathrm{w}$ in Bend 2 fluctuated about the upper envelope of the critical range, $\mathrm{r}_{\mathrm{c}} / \mathrm{w}$ in Bend 3 (the site of the larger avulsion) declined to 2.0 (or possibly lower) prior to the 1999 avulsion. Based on a comparison with similar studies, the reduction in $\mathrm{r}_{\mathrm{c}} / \mathrm{w}$ through Bend 3 from 1970 to 1996 may have contributed to the 1999 avulsion.

\section{Sinuosity}

Sinuosity of the main stem Grays River was calculated from the ratio of channel length to straight-line valley length (a channel flowing along the centerline of a valley has a sinuosity of 1). Channel and valley lengths were measured in GIS from the digitized historical channels for the period of record (1939-2003). The historical trends in sinuosity are presented in Figure 27. Results indicate that sinuosity of the main stem declined steadily from 1.37 to 1.33 between 1939 and 1966. Meander growth after 1966 caused a rapid increase in sinuosity to 1.46 by 1982. Thereafter, sinuosity decreased rapidly to 1.42 by 1996 and declined further to 1.31 by 2003 following the channel avulsion event of 1999. 


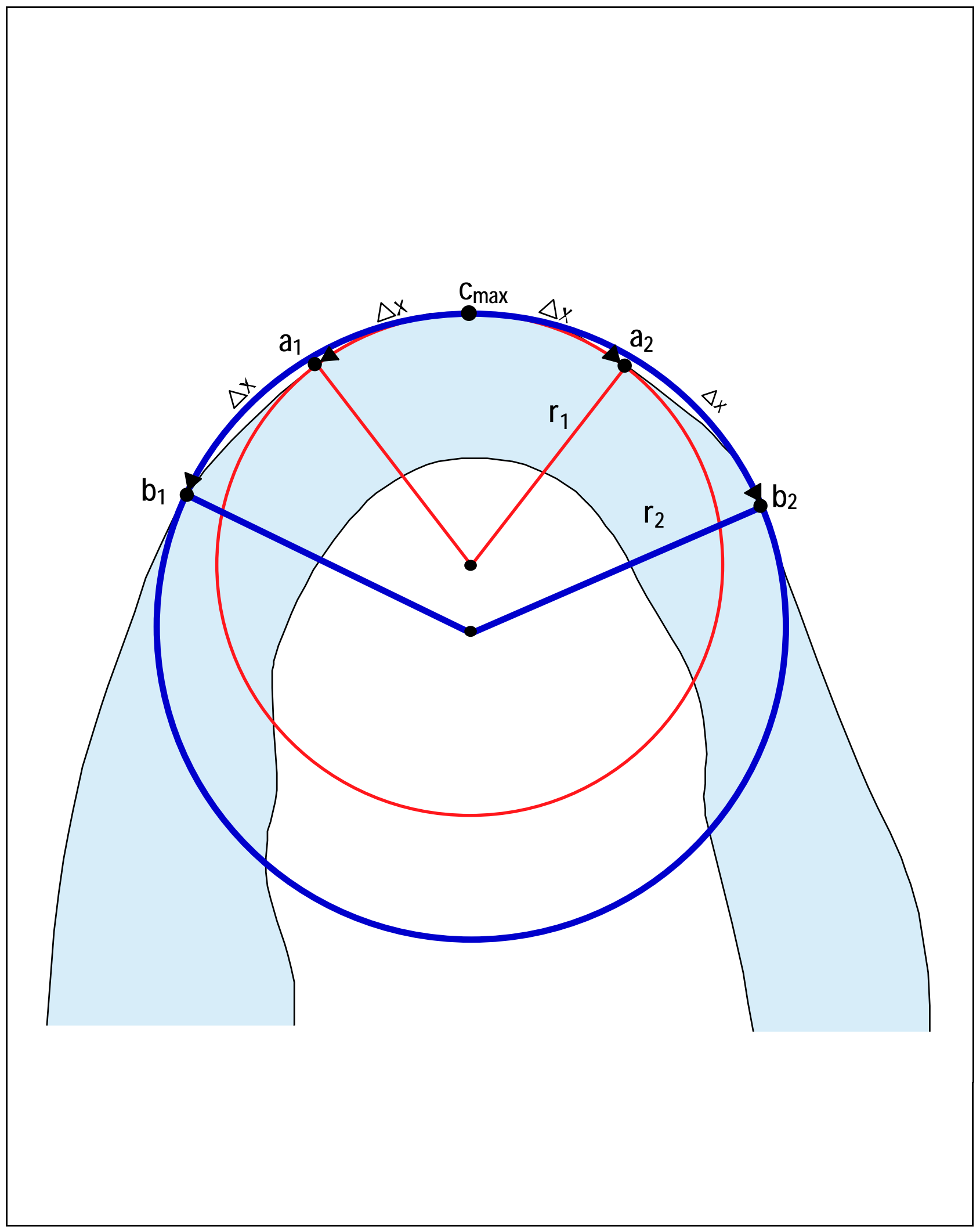

Figure 22. Schematic diagram of the measurement of radius of curvature of a meander bend (adapted from Nanson and Hickin 1983). 



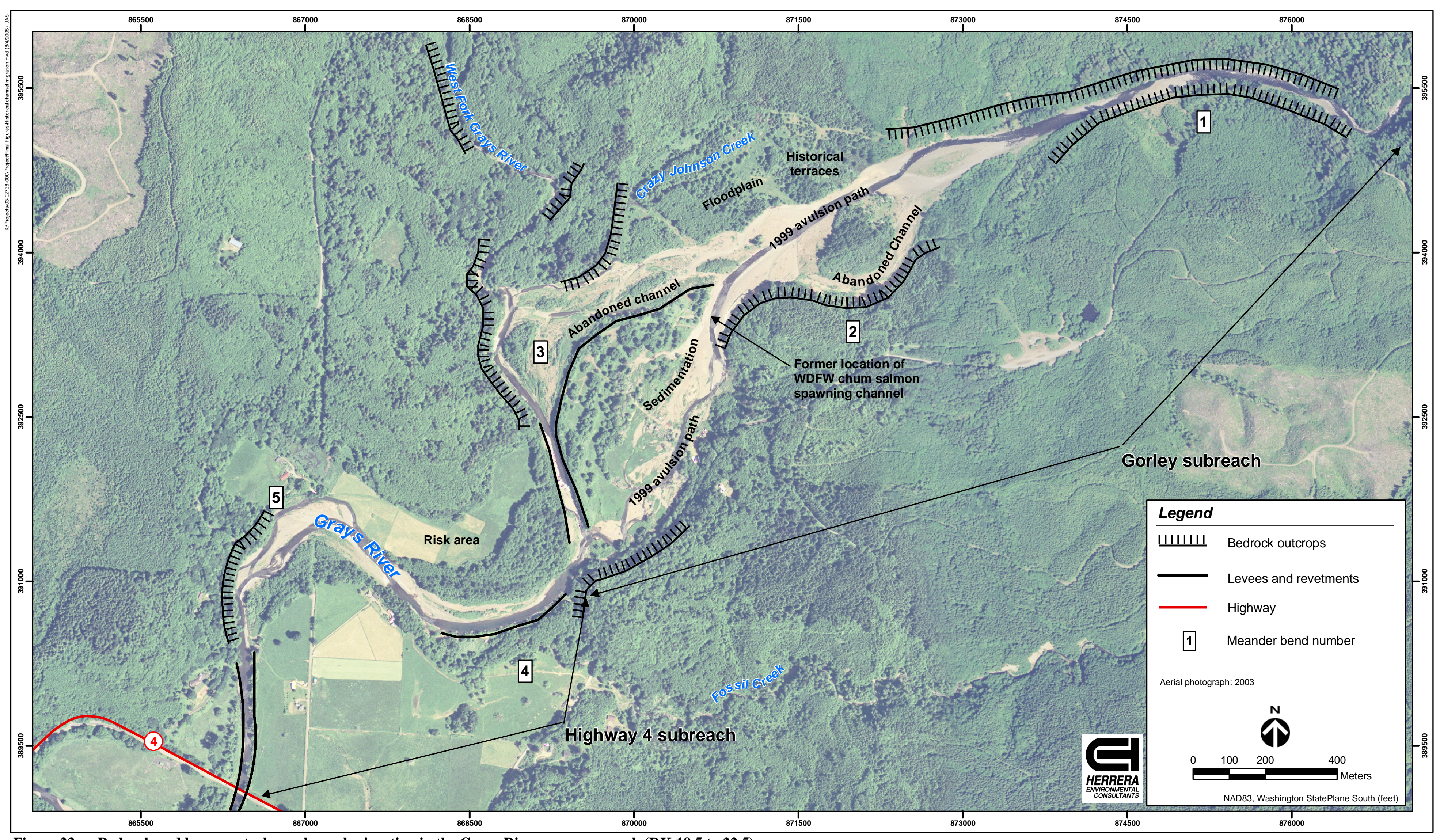

Figure 23. Bedrock and levee controls on channel migration in the Grays River response reach (RK 18.5 to 22.5). 



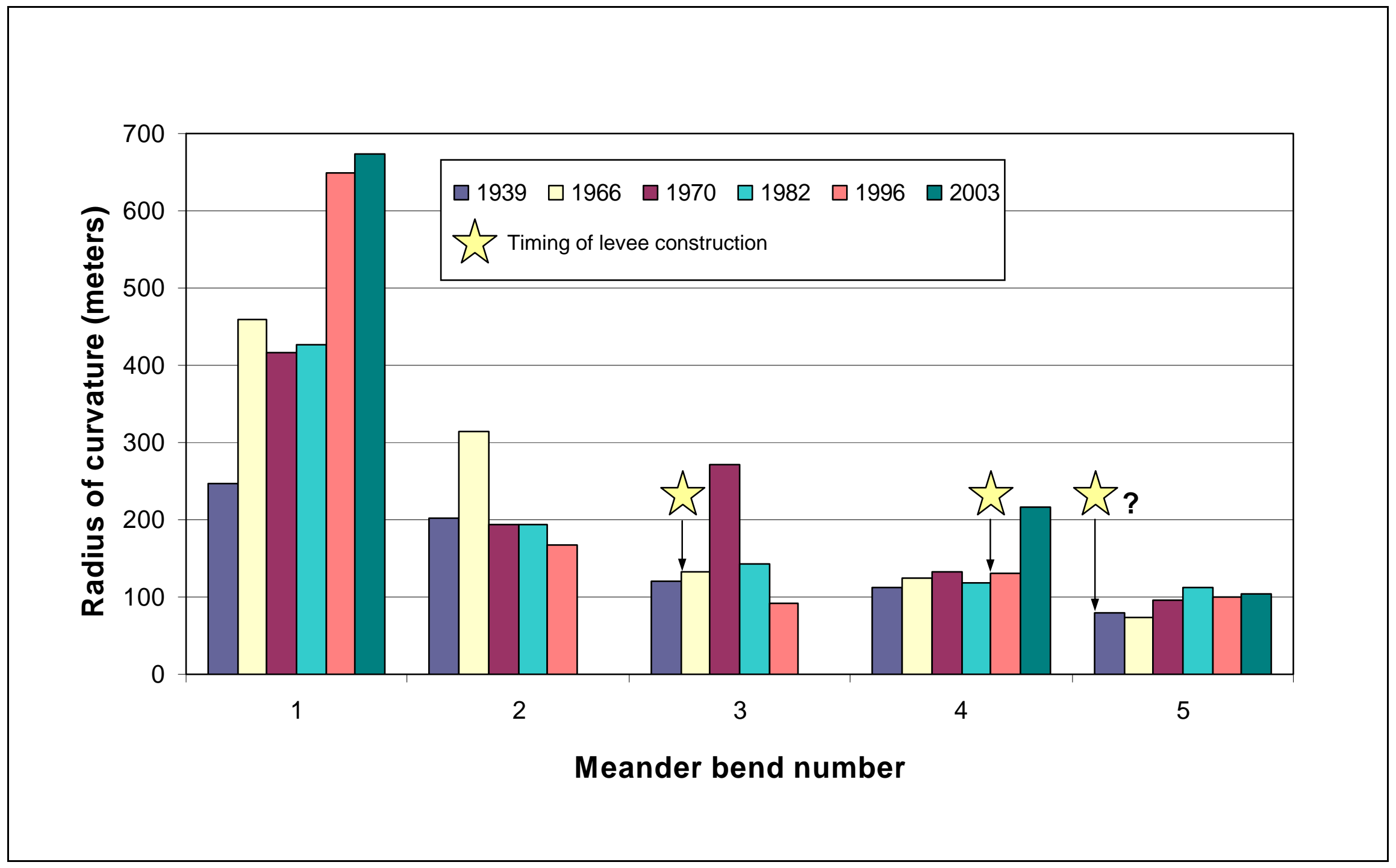

Figure 24. Average radius of curvature for five meander bends on the Grays River, Washington, during the period of record (1939-2003).

Note: Meander Bends 3 through 5 have been influenced by levee construction. The timing of levee construction is indicated by stars. 



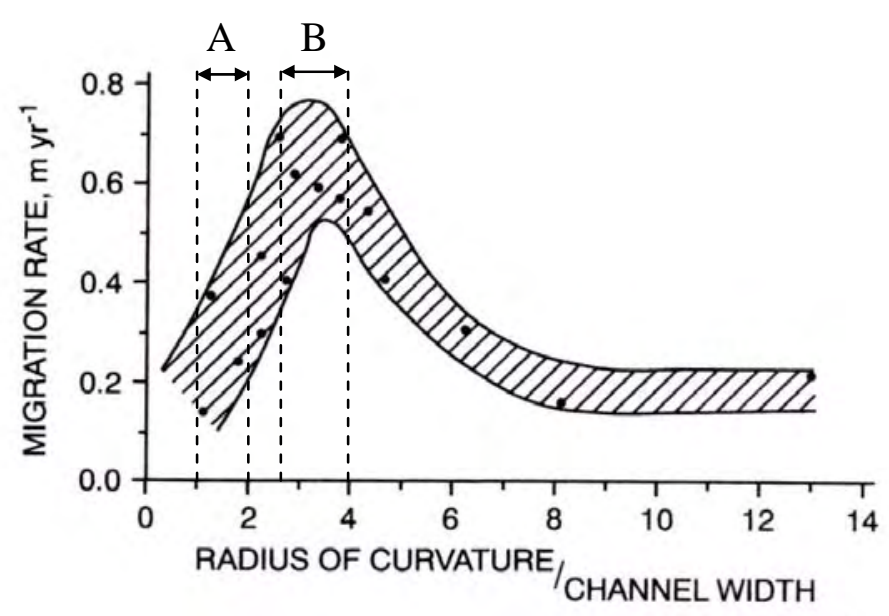

Figure 25. Meander migration rate versus bend curvature $\left(r_{c} / w\right)$ for the Beatton River, British Columbia (Nanson and Hickin 1983), illustrating optimal range of channel avulsions for $1<r_{c} / w<2$ (A) and maximum migration rate for $2.5<r_{c} / w$ $<4$ (B).

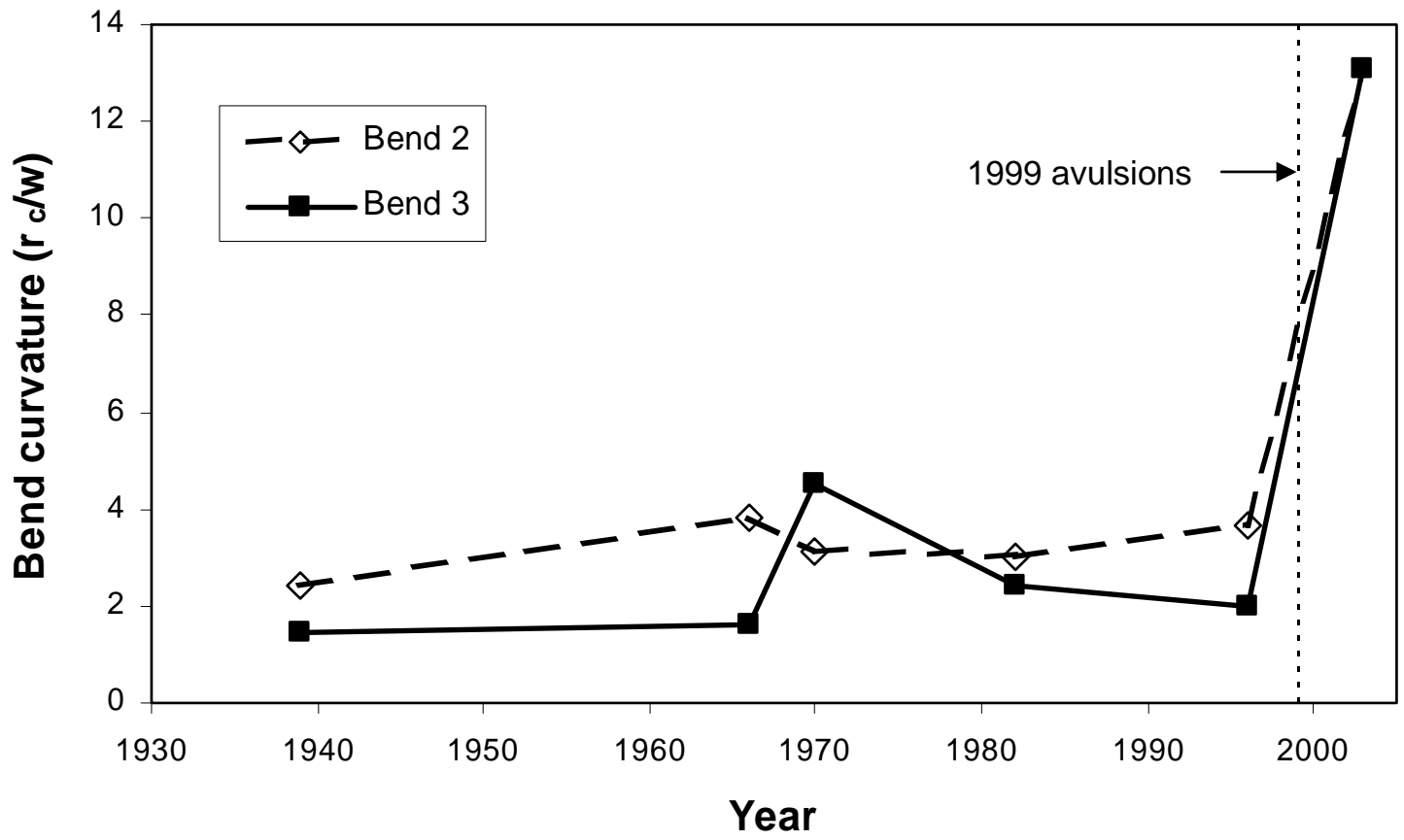

Figure 26. Temporal variation in meander bend curvature relative to the 1999 avulsions in the Grays River, Washington. 


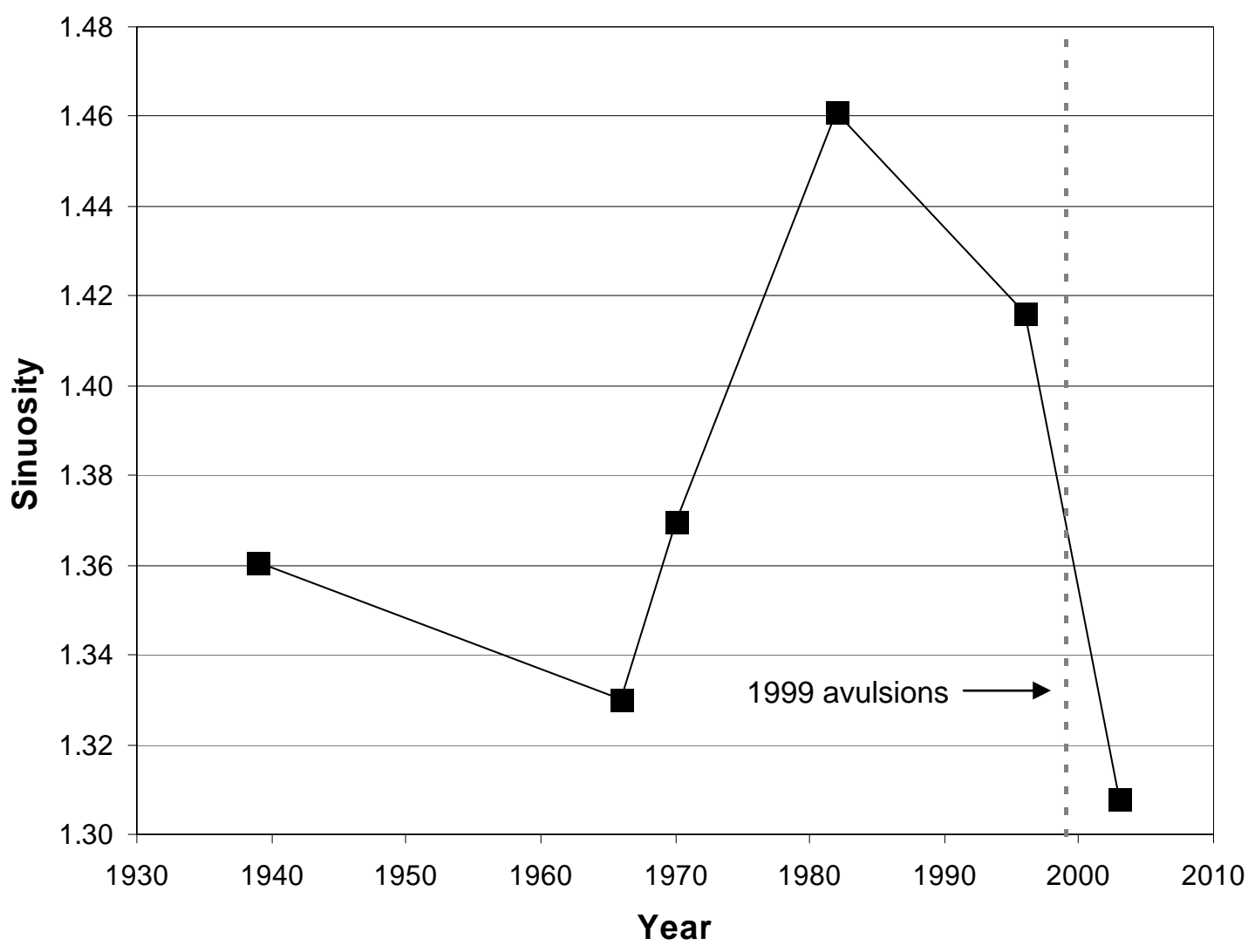

Figure 27. Temporal variation in sinuosity of the main stem Grays River.

The reduction in sinuosity through 1966 is consistent with the trends predicted by Equation 4 following an increase in sediment supply from timber harvest. The increase in sinuosity during the 1970s followed the construction of levees in the 1960s. The levees locked portions of the channel into their 1960s alignment and focused migration to shorter, unconstrained segments, where meander growth between 1966 and 1982 increased sinuosity. Sinuosity declined sharply after the 1999 avulsions as a result of channel shortening.

\section{Vertical Channel Adjustment}

Vertical changes in the elevation of alluvial surfaces caused by the 1999 avulsion were assessed by comparing profiles and cross-sections constructed along the channel alignments delineated from the 1996 and 2003 aerial photographs (see Figure 21). Longitudinal profiles were constructed using surface elevations at the edge of water in the 2004 PNNL survey of the response reach (Figure 28). Cross-sections were also constructed from topographic data derived from this survey (Appendix I). In Figure 21, the 2003 profile extends from Bend 1 at the upstream end of the Gorley subreach to the bridge at the downstream end of the Highway 4 subreach. The 1996 profile extends from point A, crosses the 2003 alignment at point B, and joins the 2003 profile at point C. 


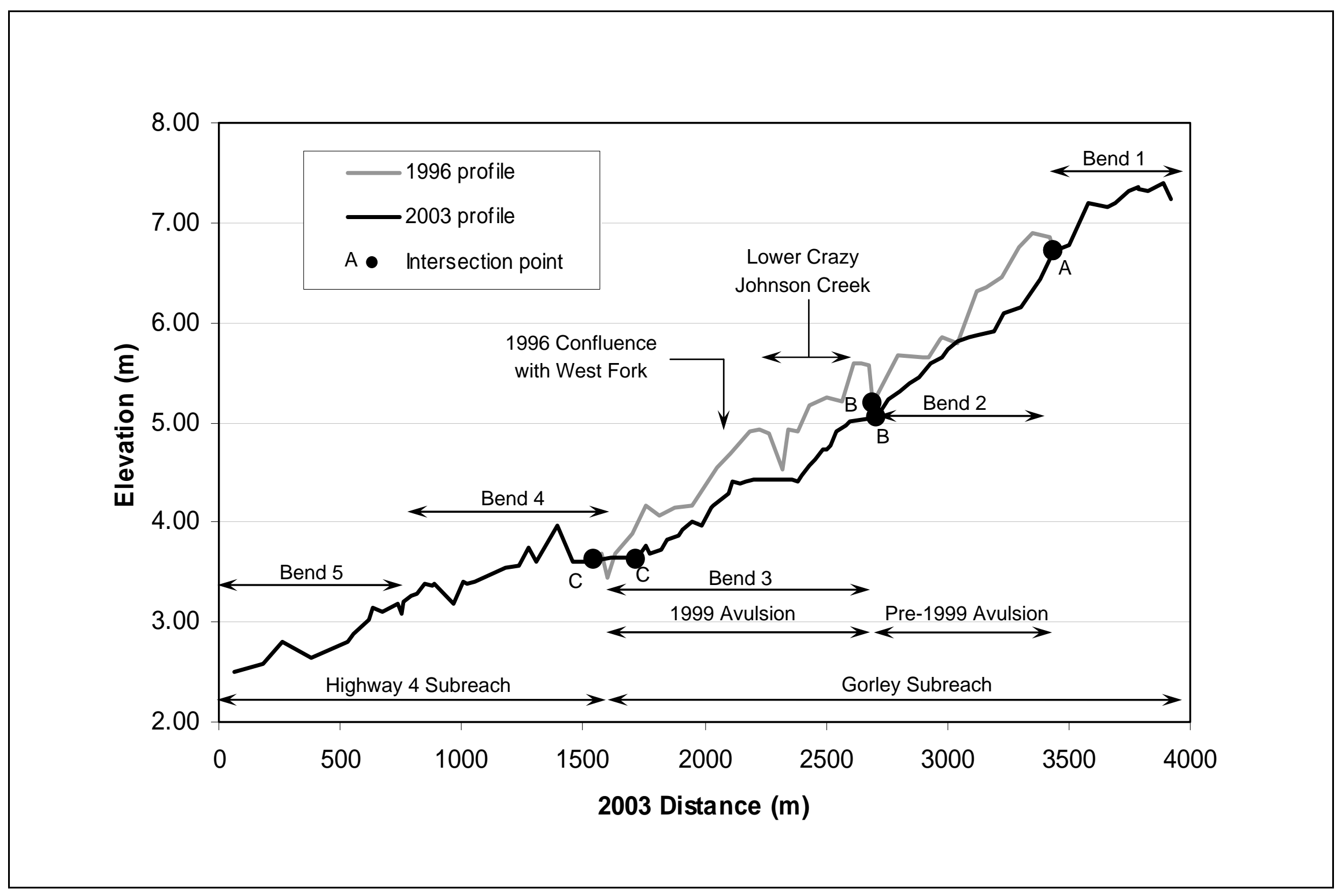

Figure 28. Channel profile of the Grays River response reach from State Highway 4 to the bedrock canyon. 
The 1999 avulsions decreased the length of the main stem by approximately 117 meters (the offset at point $\mathrm{C}$ in Figure 28) and increased the reach gradient from 0.16 percent to 0.18 percent. Most of the channel shortening and increase in gradient occurred through Bend 3. Subsequent meander development in the new channel above point $C$ since the 2003 aerial photograph has increased the channel length through Bend 3.

A comparison of the 1996 and 2003 profiles in Figure 28 suggests that the 1999 avulsions were triggered either by aggradation downstream of points A and B along the old (1996) channel alignment, or by levee failure and relocation through Bend 3 to an ancient channel alignment at a lower elevation, or by a combination of these two mechanisms. Field reconnaissance confirms the recent deposition of sediment along the 1996 alignment downstream of point B. A comparison of the profiles indicates up to 0.6 meters of aggradation along 1,900 meters of the river between 1996 and 2003. Based on the average width of the active channel in 1996 (100 meters), this change in bed elevation represents the deposition of approximately 114,000 cubic meters (194,000 tons) of sediment during this 7-year period, or approximately 10 percent of the estimated 1.5 million tons of sediment delivered to the entire channel network of the upper Grays River watershed (but not necessarily routed to the lower response reach) during this same period. Observations of historical channel conditions are summarized in Table 21. 
Table 21. Summary of historical observations for the main stem Grays River.

\begin{tabular}{|c|c|c|c|c|c|}
\hline Location & 1939-1966 & 1966-1970 & 1970-1982 & 1982-1996 & 1996-2003 \\
\hline $\begin{array}{l}\text { Between } \\
\text { Bend } 1 \text { and } \\
\text { Bend } 2\end{array}$ & $\begin{array}{l}\text { Wide active channel; north } \\
\text { bank migrates south. }\end{array}$ & $\begin{array}{l}\text { No significant } \\
\text { change in channel } \\
\text { position. }\end{array}$ & Active channel narrows. & $\begin{array}{l}\text { Active channel widens to } \\
\text { the north. }\end{array}$ & $\begin{array}{l}\text { Secondary channel to the } \\
\text { south is abandoned. }\end{array}$ \\
\hline Bend 2 & $\begin{array}{l}\text { Inside bank retreats south; } \\
\text { side channel to Crazy } \\
\text { Johnson Creek abandoned. }\end{array}$ & $\begin{array}{l}\text { Minor shift to north } \\
\text { of outside bend of } \\
\text { active channel. }\end{array}$ & $\begin{array}{l}\text { Active channel width } \\
\text { decreases; thalweg translates } \\
\text { to north of vegetated island; } \\
\text { secondary channel forms south } \\
\text { of island. }\end{array}$ & $\begin{array}{l}\text { Thalweg moves to the } \\
\text { south; north alignment } \\
\text { becomes secondary channel; } \\
\text { dense vegetation on } \\
\text { midchannel island. }\end{array}$ & $\begin{array}{l}\text { Thalweg abandons south } \\
\text { channel and avulses to } \\
\text { the north through } \\
\text { vegetated island. }\end{array}$ \\
\hline $\begin{array}{l}\text { Bend } 3 \\
\text { (upstream) }\end{array}$ & $\begin{array}{l}\text { Thalweg contacts bedrock } \\
\text { point and migrates south; } \\
\text { vegetated island forms } \\
\text { southeast of bedrock. }\end{array}$ & $\begin{array}{l}\text { No significant } \\
\text { change in channel } \\
\text { location. }\end{array}$ & $\begin{array}{l}\text { Meander translates } \\
\text { downstream and contacts } \\
\text { bedrock; radius of curvature } \\
\text { tightens and flows through } \\
\text { Crazy Johnson Creek. }\end{array}$ & $\begin{array}{l}\text { Thalweg abandons small } \\
\text { radius of curvature in north } \\
\text { bend and erodes through } \\
\text { vegetated island; flow splits } \\
\text { between Bends } 2 \text { and } 3 \text {. }\end{array}$ & $\begin{array}{l}\text { Bend abandoned during } \\
\text { large avulsion through } \\
\text { levee and Gorley } \\
\text { property. }\end{array}$ \\
\hline $\begin{array}{l}\text { Bend } 3 \\
\text { (downstream) }\end{array}$ & $\begin{array}{l}\text { Thalweg migrates northwest } \\
\text { against bedrock at West } \\
\text { Fork confluence; levees } \\
\text { constructed along inside } \\
\text { bend and between Bends } 3 \\
\text { and } 4 \text { in early 1960s. }\end{array}$ & $\begin{array}{l}\text { Migration rate to } \\
\text { northwest } \\
\text { decreases; } \\
\text { midchannel islands } \\
\text { densely vegetated. }\end{array}$ & $\begin{array}{l}\text { Channel continues to erode to } \\
\text { the west; radius of curvature } \\
\text { tightens; sinuosity increases. }\end{array}$ & $\begin{array}{l}\text { Split flow captures Crazy } \\
\text { Johnson Creek and West } \\
\text { Fork Grays River and joins } \\
\text { main stem between Bends } 3 \\
\text { and } 4 \text {. }\end{array}$ & $\begin{array}{l}\text { Bend abandoned by } \\
\text { large avulsion; West } \\
\text { Fork confluence with } \\
\text { main stem moves to } \\
\text { Bend 4; channel } \\
\text { shortened by } 177 \text { meters; } \\
\text { slope increases. }\end{array}$ \\
\hline Bend 4 & $\begin{array}{l}\text { Inside bend retreats south } \\
\text { across point bar. }\end{array}$ & $\begin{array}{l}\text { No significant } \\
\text { change. }\end{array}$ & $\begin{array}{l}\text { Channel erosion to the south } \\
\text { in the downstream portion of } \\
\text { Bend \#4. }\end{array}$ & $\begin{array}{l}\text { Levee and groin wall } \\
\text { constructed by } 1996 \text { along } \\
\text { outside (left) bank. }\end{array}$ & No significant change. \\
\hline Bend 5 & $\begin{array}{l}\text { Small high-flow channel at } \\
\text { tight bend in pasture; } \\
\text { erosion inside the } \\
\text { downstream bend; no } \\
\text { change in alignment at } \\
\text { bridge. }\end{array}$ & $\begin{array}{l}\text { Tight north bend } \\
\text { abandoned and } \\
\text { vegetated; no } \\
\text { significant change } \\
\text { in channel at } \\
\text { bridge. }\end{array}$ & $\begin{array}{l}\text { Bend migrates to the northeast } \\
\text { (slightly upstream); no } \\
\text { significant change in reach at } \\
\text { bridge. }\end{array}$ & $\begin{array}{l}\text { Channel erodes to the north } \\
\text { into } 1996 \text { alignment; no } \\
\text { significant change in reach } \\
\text { at bridge. }\end{array}$ & $\begin{array}{l}\text { Upstream reach of bend } \\
\text { migrates across point bar } \\
\text { to northeast; no } \\
\text { significant change in } \\
\text { reach at bridge. }\end{array}$ \\
\hline
\end{tabular}





\section{Analysis of Channel Sensitivity and Response Potential}

The main stem response reach of the Grays River (RK 18.5 to 22.5) has been significantly altered from its natural condition by accelerated sediment supply stemming from historical land use practices within the upper Grays River watershed and by the construction of floodplain levees.

Results of the geomorphic assessment indicate that the lower main stem is in a state of dynamic adjustment to the altered sediment regime and channel confinement by levees. The lower main stem is located at a point of reduction in channel gradient at the transition from the moderately confined bedrock canyon to the tidally influenced reach between the State Highway 4 bridge and the Columbia River. The reduction in transport capacity at this break in slope, combined with a reduction in channel confinement, has made the main stem reach particularly sensitive to minor increases in sediment supply.

Because fluvial systems are typically threshold-dominated, the response to cumulative effects can be abrupt when threshold conditions are exceeded. The 1999 avulsion represents the most significant historical response of the main stem channel to date, but events of similar magnitude are likely to continue and progress downstream as sediment stored in the Gorley subreach is transported to the Highway 4 subreach.

\section{Main Stem Response to Historical Watershed Disturbance}

Historical variations in harvest rate, estimated sediment yield, and channel response variables are illustrated in Figure 29. The assessment of mass wasting and surface erosion indicates that the majority of sediment supplied to the channel network is generated by mass-wasting processes brought about by road construction and road use associated with timber harvest operations.

Based mostly on the temporal relations among timber harvest and landslide frequency, and assumptions used in the model, historical sediment yield to the channel network appears to lag behind harvest operations by approximately 25 years. For example, the increase in the harvest rate in the 1950s corresponds to the predicted increase in sediment yield through the late 1970s and 1980s (Figure 29). Likewise, the relatively stable harvest rate through the 1960s corresponds with moderate increases in sediment yield in the late 1980s, and the sharp increase in harvest rate in the 1970s is followed by the increase in predicted sediment yield in the late 1990s.

The sediment budget does not route sediment through the channel network to response reaches, nor does the model account for sediment storage within the watershed. However, the historical response of the main stem Grays River was used as a basis to infer the lag time between sediment yield to the channel network and the supply of coarse sediment to the main stem 
response reach. The response time was then used to project future responses within the main stem to watershed disturbance.

Field observations indicate that large quantities of sediment are currently stored in headwater transport reaches and tributary floodplains. The additional lag time between sediment yield and delivery to response reaches will depend on the distance from the source, as well as transport rates and sediment capacitance (storage potential) within the intervening channel network.

The apparent lag time between timber harvest and sediment yield was used to forecast future trends in sediment yield to the channel network. Assuming that the 1999 harvest rate of 3.1 $\mathrm{km}^{2} /$ year remains constant, and using a lag time of 25 years, sediment yield $\left(S_{y}\right)$ expressed in kilotons/year is correlated to the harvest rate $(H)$ expressed in $\mathrm{km}^{2} / \mathrm{yr}$ according to the empirical relation.

$$
S_{y}=251 * \ln (H)-260 \quad\left(r^{2}=0.98, \mathrm{n}=7\right)
$$

Based on the assumed harvest rate and lag time, sediment yield to the channel network is projected to reach a maximum of approximately 290,000 tons/year in 2005 and decline to approximately 24,000 tons/year by 2025, but remain approximately 85 percent higher than the background erosion rate of 13,000 tons/year predicted by the analysis. The elevated erosion rate is attributed to sediment yield from mass wasting and surface erosion from the road network.

Temporal trends in channel form in the main stem Grays River provide information on the lag time between sediment yield and the supply of coarse sediment to the main stem. Changes in channel form have been significantly influenced by floodplain modifications and levee construction. Both sinuosity and bend curvature of the main stem increased shortly after levee construction in the 1960s and then declined by the early 1980s. The decline in sinuosity may be a response to the increase in sediment yield during the 1970s. If so, this response suggests a lag time of about 10 years between the basinwide increase in sediment yield and the onset of channel adjustment in the main stem channel.

When combined with the lag between harvest and sediment yield, results suggest 35 years as the characteristic response time for the cumulative effects of basinwide timber harvest to significantly affect the main stem response reach. Significant channel adjustment is expected to continue beyond this time period. A detailed sediment routing study is necessary to verify the response time between sediment yield and main stem response.

The model does not account for the effects of climate variability on landslide frequency. The natural variability in annual precipitation between wet and dry years is on the order of 2 to 5 years (Figure 29), which is significantly shorter than the predicted lag times between timber harvest, sediment yield, and channel response (i.e., 25 years). The 1999 avulsion followed 6 years of above-average precipitation but also occurred after 35 years of rising sediment yield within the watershed (Figure 29). Climate variability may provide a second-order control on channel response by mobilizing stored sediment and forcing channel change when conditions are near a threshold. The correspondence of the 1999 avulsion with the posited 35-year lag time 


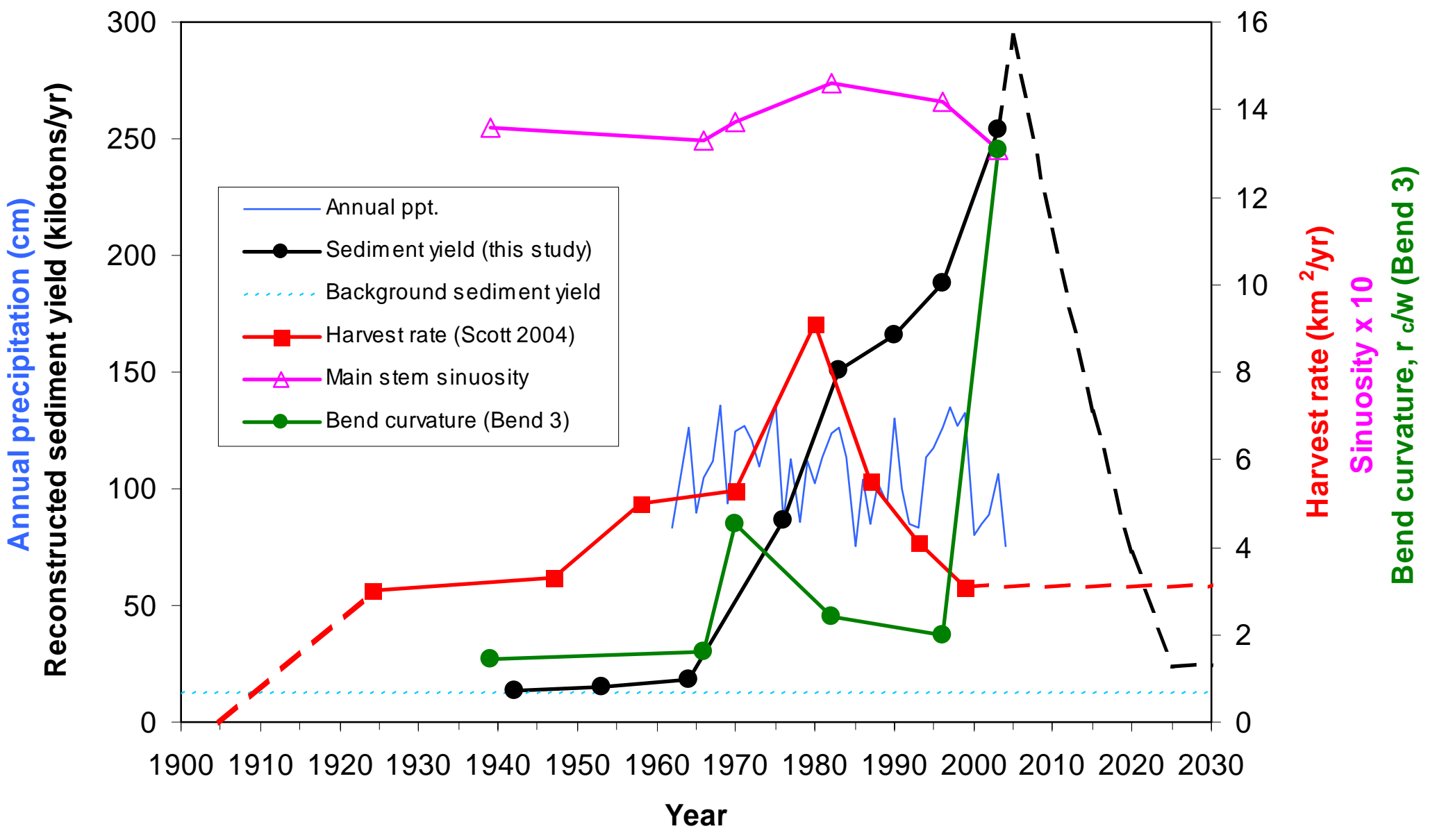

Figure 29. Composite plot illustrating relations between forcing functions and response variables.

Note: Harvest rate is derived from Scott (2004 personal communication), dashed where inferred. Sediment yield and background sediment yield are based on the model results (this study). Levee construction, avulsion, sinuosity, and bend curvature refer to response within the main stem. 

Grays River Watershed-Geomorphic Analysis

between harvest and the onset of main stem channel response suggests that the avulsion event was triggered by increased sediment influx combined with channel confinement by levees and the mobilization of stored sediment by above-average precipitation in the years preceding the avulsion.

\section{Factors Influencing Future Sediment Yield}

Past and future timber harvest practices will continue to influence the rate of sediment yield to the Grays River channel network. The current trend of second- and third-growth harvest rotation is expected to reduce the reported 10-year lag between the loss of root strength and the peak in landslide frequency, because smaller second- and third-growth roots are typically weaker than roots of old-growth trees. However, sediment yield might decline if the frequency of harvest rotation or the overall harvest rate is reduced. The harvest rate within the upper Grays River watershed has declined since 1980, and future sediment yield to the channel network is predicted to decline as well (Figure 29). Sediment yield could also be reduced by eliminating timber harvest from slopes steeper than about 65 percent, where sediment yield from mass wasting is estimated to be 1,000 times greater than the yield on slopes less than 65 percent.

Contemporary rates of sediment production by mass wasting are not sustainable with long-term soil production rates and could lead to the eventual depletion of soil on steep slopes, which in turn would severely impair timber production and other recreational and wildlife uses within the watershed. In a comparative study of debris-flow characteristics in old-growth and industrial forests, Bunn (2003) found that the sustained short-rotation harvest of headwater basins and removal of old-growth wood from headwater channels is diminishing soil depth on hillslopes and leaving headwater channels with an increased sediment flux and a consequent increase in sediment output to low-gradient response reaches.

Field observations in the upper Grays River watershed indicate that some hillslopes have already been stripped to bedrock by widespread mass wasting (Photo MW-4-1 in Appendix B). Past timber harvest practices that removed instream wood (either by snagging or splash-damming) and stripped floodplains of large trees severely reduced potential sediment storage sites within headwater channels of the upper Grays River watershed by disrupting the natural, self-sustaining processes that recruit wood to channels. Past timber harvest practices not only increased the rate of sediment yield to the channel network but also accelerated the delivery of this sediment to the main stem response reach by eliminating most of the natural sediment capacitance provided by instream wood. Under industrial forestry conditions, sediment storage locations within the watershed can be expected to shift from hillslopes to the response reaches of the channel network.

\section{Projected Channel Response}

If channel response in the Grays River main stem lags behind harvest by approximately 35 years, as predicted by this analysis, the current instability within the main stem (posited to be related to 
the 1980s spike in the timber harvest rate) can be expected to continue and possibly increase through 2030. Response reaches throughout the upper Grays River watershed may be prone to continued instability and more avulsions so long as sediment supply exceeds threshold transport rates. The remobilization and routing of sediment stored within the channel network may extend this response period through the latter half of the twenty-first century.

Confinement and straightening of the main stem response reach by levees increase the local transport capacity (through increases in both slope and flow depth, which in turn increase shear stress) and shift future sediment deposition and channel response downstream to the Highway 4 subreach (Figure 25). Additional channel avulsions are likely to occur if measures are not taken to maintain and raise existing levees and revetments concurrently with the anticipated sediment aggradation.

The current decreasing trend in channel sinuosity and increasing trend in meander bend curvature are expected to continue within the Grays River main stem. The reduction in sinuosity and development of a multi-threaded channel visible in the 1996 aerial photographs signal a shift toward a transport-limited regime. Aggradation and natural straightening of the channel are typical morphological responses to an increase in sediment loading. The local increase in slope caused by continued aggradation (as well as confinement by levees) will shift the depositional front of the main stem downstream. The downstream advance will eventually force Bends 4 and 5 to respond. Aggradation is likely to occur in the main stem at the confluence with the West Fork, where there is a local decrease in slope (point C, Figures 21 and 28). Backwater propagation up the West Fork would initiate aggradation in the diked reach between Bends 3 and 4. The reduction in channel depth that follows would increase the likelihood of an avulsion through Bend 4. Realignment of the channel through Bend 4 and continued downstream migration of the depositional front could trigger an avulsion through Bend 5 and threaten the State Highway 4 bridge crossing.

The response to increased sediment supply is compounded by levees within the main stem floodplain. In general, the levees restrict the natural tendency toward channel migration and floodplain sediment deposition. Isolation of the channel from the floodplain accelerates local aggradation and increases the potential for channel avulsion. Although levee construction may have initially provided short-term stability to portions of the channel and floodplain, channel confinement and floodplain isolation by the levees has forced channel adjustments to the shorter, unconfined segments of the river. Consequently, the floodplain may experience periods of channel stability punctuated by high-magnitude variability in channel configuration.

The 1999 avulsion to an ancient channel alignment of lower elevation (Figure 28 and Appendix I) suggests that the former channel alignment through Bend 3 has been aggrading. The sediment capacitance made available by the avulsion through the Gorley property may provide a temporary delay for future avulsions in Bend 3. Historically, the inflection point between Bends 3 and 4 has remained relatively stable due to levee construction and periodic dredging. However, the reduction in flows through this confined segment caused by the 1999 aggradation could accelerate aggradation and force an avulsion through Bend 4, where the levee contacts bedrock. 
The observed response of the main stem Grays River is analogous to historical channel changes in the lower Skokomish River of the southeastern Olympic Peninsula following extensive timber harvesting. Stover and Montgomery (2001) identified three phases of channel response to historical disturbance in the Skokomish River basin. The first phase involved rapid channel incision of nearly 0.5 meters following riparian timber harvesting and removal of instream wood. The second phase was characterized by fluctuations in bed-surface elevation of up to 1 meter that coincided with widespread timber harvest and road development in the basin during the 1940s and 1960s. Stover and Montgomery (2001) attributed the oscillations in bed elevation to sediment pulses moving through the channel network. The sediment pulses were linked to concurrent timber harvest activities in the upper basin and the release of sediment stored in the nearby south fork following the harvest of riparian forests and removal of instream wood. Channel filling, increased channel width, and fining of bed sediment characterized the third phase of channel response through at least the end of the study in the late 1990s.

In contrast with results of the analysis for the upper Grays River, the onset of channel aggradation on the Skokomish began rapidly, approximately 10 years after the commencement of intense upstream timber harvesting, and continued at a steady pace through 1997, at the end of the study period. Results of the Stover and Montgomery (2001) study suggest a minimum of 50 years for the lower response reach of the Skokomish River to adjust to the influx of sediment from timber harvesting. Timber harvesting and road construction in the headwaters continue to contribute to ongoing aggradation and recurrent flooding within the Skokomish River valley.

Observations from the field studies and modeling efforts can be generalized into temporal relations among watershed disturbance, sediment yield, and channel response within the upper Grays River (Figure 30). Sediment yield to the channel network increases sharply above natural background levels shortly after the onset of timber harvest activities and reaches a peak that lags behind the peak harvest rate by approximately 25 years. Included in this period is the 10 -year lag between harvest and peak in landslide frequency. Channel response to increased sediment yield may include aggradation, decreased sinuosity, increased bend curvature, and increased frequency of flooding and channel avulsions.

The onset of channel change may occur rapidly in alluvial reaches after timber harvest (10 years in the case of the Skokomish River), or several decades following harvest (35 years as indicated by the Grays River analysis). The magnitude of channel change continues to increase (despite the decline in sediment yield) due to the mobilization of sediment stored within the channel network during high-magnitude storm events. This reduction in sediment storage is magnified by the removal of instream wood and harvest of riparian forests that would otherwise supply large wood to channels. Under this conceptual model, channel adjustment continues for at least 50 years after widespread harvesting, based on data from the Skokomish study (Stover and Montgomery 2001). Channel response in the Grays River watershed is already 25 years out from the peak in harvest rate. Based on results of Stover and Montgomery (2001), channel adjustment in the lower Grays River will continue for at least another 25 years, and possibly into the second half of the century, under the current (2003) timber harvest rate. 
The magnitude of impacts on fish habitat caused by increased sediment yield and channel instability within the Grays River main stem response reach will be determined by the ability of restoration efforts to counteract the destructive effects of past and ongoing land use activities within the upper watershed. Rivers with high sediment loads can support productive fish populations if they contain abundant instream wood, which promotes pool formation, protective cover, substrate diversity, and channel migration into floodplain forests for self-sustaining wood recruitment. 


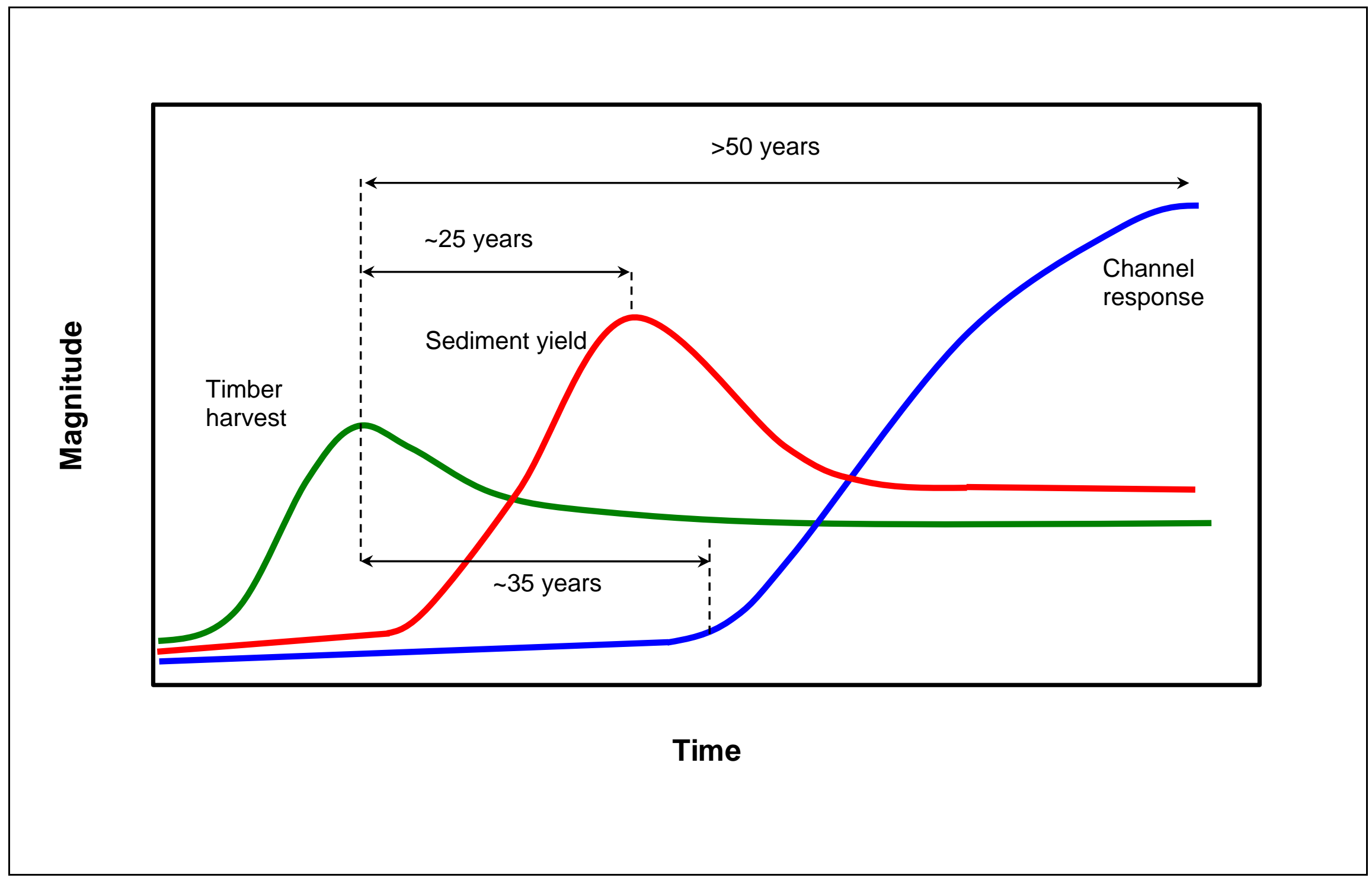

Figure 30. Conceptual model of temporal trends in sediment yield to the upper Grays River channel network and channel response to an assumed historical timber harvest. 



\section{Recommendations}

Deforestation and construction of floodplain levees and dikes within the Grays River watershed have impaired geomorphic processes and, in turn, salmonid habitat. Historical land use practices have resulted in increased sediment production, channel instability, and a decline in channel complexity, which have severely impaired salmonid habitat and increased flood and erosion risks to landowners in the lower Grays River valley.

The goal of improving salmonid habitat and reducing risks to property and infrastructure can be achieved by restoring riparian forests and instream roughness (i.e., wood debris) to appropriate channel reaches, and by focusing development, timber harvest, and agriculture toward portions of the watershed where they will not adversely affect geomorphic processes. Three primary objectives are recommended to guide watershed restoration efforts toward this goal:

1. Improve capacity of the lower Grays River (RK 18.5 to 22.5) to accommodate sedimentation and channel migration by restoring riparian forests, introducing large woody debris (LWD) to the channel, and retiring existing levees (through either proactive removal, setback, or allowing river processes to erode levees).

2. Restore riparian forests and wood loading to increase sediment storage within response channels and improve instream habitat.

3. Limit land use activities that trigger sediment production in the upper watershed.

Each of these objectives addresses the historical changes in geomorphic processes and the degraded habitat conditions documented by this investigation within the upper Grays River watershed. In order to realize these objectives, the following restoration activities are recommended:

- $\quad$ Establish an unconstrained channel migration zone (CMZ) in the Grays River response reach upstream of State Highway 4 through a program that is sensitive to landowners and the community, and that focuses land acquisition, conservation easements, and levee setback or removal toward areas with high potential for flood and erosion risks and high potential for habitat restoration.

- $\quad$ Construct engineered logjams (ELJs) to create stable forested islands within the channel migration zone of the Grays River response reach (RK 18.5 to 22.5).

- Implement aggressive reforestation of floodplain forests within the response reaches to restore natural, self-sustaining processes that supply 
and recruit functional LWD to the channel (including the Grays River response reach, West Fork Grays River, East Fork Grays River, South Fork Grays River, and tributary response channels).

- Remove structures and related materials from the channel migration zone on the Gorley property that became isolated by the 1999 avulsion.

- Develop a restoration plan for the river and floodplain downstream of the Gorley property, including removal of the right bank levee and floodplain reforestation.

- Limit timber harvest on steep slopes and in areas with soil types that are most susceptible to mass wasting and surface erosion.

- $\quad$ Adhere to forest practices that minimize sediment production and eliminate harvest within channel migration zones and riparian management zones (RMZs).

- Decommission inactive forest roads and restore natural drainage patterns to reduce the potential for debris-flow initiation at road prisms and to reduce surface erosion directly from road surfaces.

- Construct channel-spanning LWD structures throughout the watershed at sites where structures would store sediment, moderate sediment routing, and improve local aquatic habitat (including the West Fork Grays River, East Fork Grays River, South Fork Grays River, and tributary response channels).

A conceptual restoration strategy for the Grays River response reach incorporating a number of these activities is presented in Figure 31. These recommended restoration activities will provide the following habitat benefits to the Grays River main stem response reach:

- $\quad$ Decrease sedimentation leading to channel instability by reducing sediment input from the upper watershed.

- Increase the length of the wetted channel in the Grays River response reach used by salmonids by increasing the number of perennial side channels.

- Decrease water temperature by increasing hyporheic flow, pool frequency, and shade.

- Increase pool frequency.

- Increase side channel hyporheic connectivity and spawning areas. 


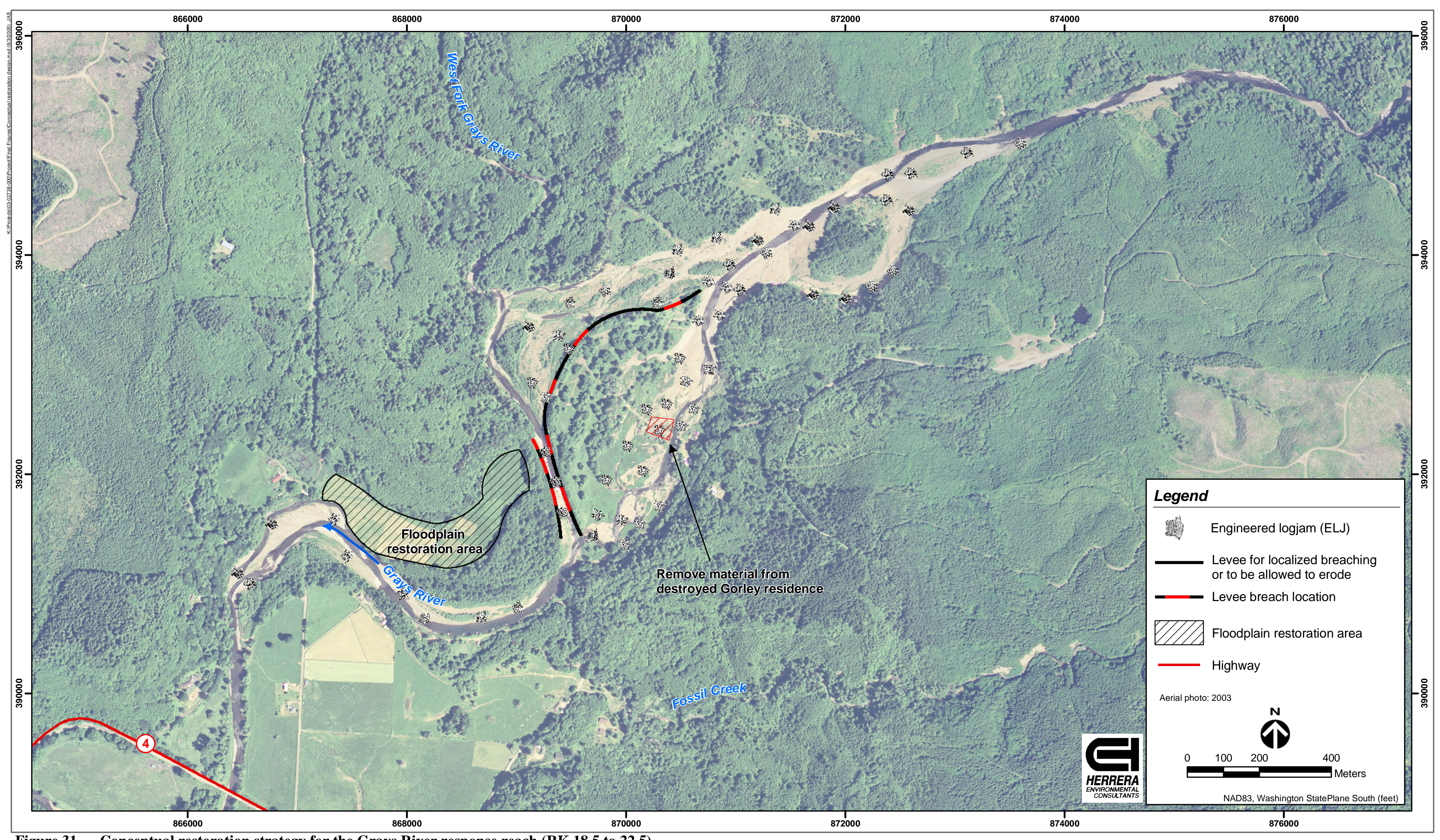

Figure 31. Conceptual restoration strategy for the Grays River response reach (RK 18.5 to 22.5). 

- $\quad$ Reduce the unvegetated channel width.

- Increase shade and cover by increasing the relative area of the channel beneath a forest canopy.

- Increase wood debris recruitment and trap efficiency within the reach.

- Decrease lateral erosion and flood risks to the Grays River below State Highway 4.

Current channel conditions in the upper Grays River watershed present significant opportunities for habitat restoration. However, successful restoration depends on recognizing and accommodating ongoing geomorphic processes such as channel migration and fluctuating sediment loads.

The most direct and immediate actions to restore habitat are the reintroduction of functional wood debris and reestablishment of mature riparian forests. Returning functional LWD to the Grays River response reach would increase sediment storage, increase channel complexity and pool frequency, diffuse flood peaks, and increase channel length. Hard-points within the floodplain created by stable wood debris or engineered logjams would allow islands or riparian forests to mature within the channel migration zone. The placement of stable LWD structures or engineered logjams in probable flow paths would also disperse and bifurcate flow, decreasing the erosive potential of flows while providing the habitat benefits of increased hydraulic complexity where functional wood and recruitment potential is currently lacking. These hard-points also promote the formation of deep channels and pools in place of shallow, braided channels that typically result from increased sediment loading. Intentional placement of engineered logjams would also provide predictability of locations of future flooding and channel changes, such as avulsions, thus improving flood and erosion management. 



\section{References}

Abbe, T.B. 2000. Patterns, Mechanics and Geomorphic Effects of Wood Debris Accumulations in a Forest River System. Doctoral dissertation. University of Washington, Seattle, Washington.

Abbe, T.B. and D.R. Montgomery. 2003. Patterns and Processes of Wood Debris Accumulation in the Queets River Basin, Washington. Geomorphology 51:81-107.

Bagnold, R.A. 1960. Some Aspects of the Shape of River Meanders. U.S. Geological Survey, Professional Paper 282E. p. 135-44.

Bicknell, Bob. 2005. Personal communication (phone conversation with Chris Brummer, Herrera Environmental Consultants, Seattle, Washington, regarding observations of 1999 Grays River channel avulsions). Washington Department of Fish and Wildlife. May 4, 2005.

Brandon, M.T., M.K. Roden-Rice, and J.I. Garver. 1998. Late Cenozoic Exhumation of the Cascadia Accretionary Wedge in the Olympic Mountains, Northwest Washington State. Geological Society of America Bulletin 110(8):985-1009.

Brummer, C.J. and D.R. Montgomery. 2003. Downstream Coarsening in Headwater Channels. Water Resources Research 39(10):1294. doi: 10.1029/2003WR001981.

Bryant, F. 1949. A Survey of the Columbia River and its Tributaries with Special Reference to Its Fishery Resources, 2. Washington Streams from the Mouth of the Columbia River to and Including the Klickitat River (Area I). U.S. Fish and Wildlife Service, Special Scientific Report 62. $51 \mathrm{p}$.

Special Scientific Report 62.

Bunn, J.T. 2003. Patterns of Wood and Sediment Storage along Debris-Flow Impacted Headwater Channels in Old-Growth and Industrial Forests. Master's thesis. University of Washington, Department of Earth and Space Sciences, Seattle, Washington.

Burroughs, E.R., Jr. and J.G. King. 1989. Reduction of Soil Erosion on Forest Roads. General Technical Report INT-264. U.S. Department of Agriculture, Forest Service, Intermountain Research Station, Ogden, Utah.

Collins, B.D. and T. Dunne. 1989. Gravel Transport, Gravel Harvesting, and Channel-Bed Degradation in Rivers Draining the Southern Olympic Mountains, Washington, U.S.A. Environmental Geology and Water Science 13(3):213-224.

Dietrich, W.E. and T. Dunne. 1978. Sediment Budget for a Small Catchment in Mountainous Terrain. Zeitschrift für Geomorphologie 29:191-206. 
Dietrich, W.E., T. Dunne, N.F. Humphrey, and L.M. Reid. 1982. Construction of Sediment Budgets for Drainage Basins. pp. 5-23 in: Workshop on Sediment Budgets and Routing in Forested Drainage Basins: Proceeding. General Technical Report PNW-141.

Dunne, T. and L.B. Leopold. 1978. Water in Environmental Planning. W.H. Freeman, New York.

Furniss, M., F. Leone, and W. Duval. 1991. Water Transportation and Storage of Logs. pp. 297324 in: Influences of Forest and Rangeland Management on Salmonid Fishes and the Habitats. Am. Fish. Soc. Special Publ. 19.

Gilbert, G.K. 1917. Hydraulic Mining Debris in the Sierra Nevada. U.S. Geological Survey, Professional Paper 105. 154 p.

Grant, G.E. and A.L. Wolff. 1991. Long-Term Patterns of Sediment Transport after Timber Harvest, Western Cascade Mountains, Oregon, USA. Sediment and Stream Water Quality in a Changing Environment: Trends and Explanations. IAHS Publ. No. 203, 31-40. International Association of Hydrological Sciences.

Hicks, D.M. and B. Gomez. 2003. Sediment Transport. in: Tools in Fluvial Geomorphology. John Wiley and Sons Ltd, West Sussex, England. 452 p.

Ibbitt, R.P. 1997. Evaluation of Optimal Channel Network and River Basin Heterogeneity Concepts Using Measured Flow and Channel Properties. J. Hydrol. 196:119-138.

Jakob, M. 2000. The Impacts of Logging on Landslide Activity at Clayoquot Sound, British Columbia. Catena (Cremlingen) 38(4):279-300.

Jones, J.A. and G.E. Grant. 1996. Peak Flow Responses to Clear-Cutting and Roads in Small and Large Basins, Western Cascades, Oregon. Water Resources Research 32(4):959-974.

Kelsey, H.M., R.L. Ticknor, J.G. Bockheim, and C.E. Mitchell. 1996. Quaternary Upper Plate Deformation in Coastal Oregon. Geological Society of America Bulletin 108(7):843-860.

Knighton, D. 1998. Fluvial Forms and Processes. Arnold, London. 383 p.

Knighton, D.A. 1999. Downstream Variation in Stream Power. Geomorphology 29:293-306.

Lancaster, S.T., S.K. Hayes, and G.E. Grant. 2001. Modeling Sediment and Wood Storage and Dynamics in Small Mountainous Watersheds. pp. 85-102 in: Geomorphic Processes and Riverine Habitat. Edited by J.B. Dorava, D.R. Montgomery, B. Palcsak, and F. Fitzpatrick. American Geophysical Union, Washington, D.C.

Lane, E.W. 1955. The Importance of Fluvial Morphology in Hydraulic Engineering. American Society of Civil Engineering Proceedings 81, Paper 745:1-17. 
Lecce, S.A. 1997. Nonlinear Downstream Changes in Stream Power on Wisconsin's Blue River. Annals of the Association of American Geographers 87:471-486.

Leopold, L.B. 1994. A View of the River. Harvard University Press, Cambridge, Massachusetts.

Leopold, L.B. and T. Maddock, Jr. 1953. The Hydraulic Geometry of Stream Channels and Some Physiographic Implications. U.S. Geological Survey, Professional Paper 252. 57 p.

Leopold, L.B., M.G. Wolman, and J.P. Miller. 1964. Fluvial Processes in Geomorphology. W.H. Freeman, San Francisco.

Lewis, G.W. and J. Lewin. 1983. Alluvial Cutoffs in Wales and the Borderlands. p. 145-154 in: Modern and Ancient Fluvial Systems. Edited by J.D. Collinson and J. Lewin. International Association of Sedimentologists, Special Publication 6.

Mackin, J.H. 1948. Concept of the Graded River. Bulletin of the Geological Society of America 59(5):463-512.

Madej, M.A. 1982. Sediment Transport and Channel Changes in an Aggrading Stream in the Puget Lowland, Washington. pp. 97-108 in: Workshop on Sediment Budgets and Routing in Forested Drainage Basins, Proceeding. Edited by R.J. Swanson. General Technical Report PNW-141.

Magilligan, F.J. 1992. Thresholds and the Spatial Variability of Flood Power during Extreme Floods. Geomorphology 5:373-390.

Massong, T.M. and D.R. Montgomery. 2000. Influence of Sediment Supply, Lithology, and Wood Debris on the Distribution of Bedrock and Alluvial Channels. Geological Society of America Bulletin 112(5):591-599.

Megahan, W.F. 1991. Erosion and Site Productivity in Western Montane Forest Ecosystems. p. 146-150 in: Proceedings, Management and Productivity of Western Montane Forest Soils. Edited by A.E. Harvey and L.F. Neuenschwander. Gen. Tech. Rep. INT-GTR-280. U.S. Department of Agriculture, Forest Service, Intermountain Research Station, Ogden, Utah.

Megahan, W.F. and W.J. Kidd. 1972. Effects of Logging and Logging Roads on Erosion and Sediment Deposition from Steep Terrain. Journal of Forestry 70:136-141.

Micheli, E.R., J.W. Kirchner, and E.W. Larsen. 2003. Quantifying the Effect of Riparian Forest versus Agricultural Vegetation on River Meander Migration Rates, Central Sacramento River, California, USA. River Research and Applications 19:1-12.

Montgomery, D.R. 1994. Road Surface Drainage, Channel Initiation, and Slope Instability. Water Resources Research 30(6):1925-1932. 
Montgomery, D.R. 1999. Process Domains and the River Continuum. Journal of the American Water Resources Association 35:397-410.

Montgomery, D.R. and E. Foufoula-Georgiou. 1993. Channel Network Source Representation using Digital Elevation Models. Water Resources Research 29:3925-3939.

Montgomery, D.R. and J.M. Buffington. 1997. Channel-Reach Morphology in Mountain Drainage Basins. Geological Society of America Bulletin 109:596-611.

Montgomery, D.R. and J.M. Buffington. 1998. Channel Processes, Classification, and Response. pp. 13-42 in: River Ecology and Management. Edited by R.J. Naimon and R.E. Bilby. SpringerVerlag, New York.

Montgomery, D.R., K.M. Schmidt, H.M. Greenberg, and W.E. Dietrich. 2000. Forest Clearing and Regional Landsliding. Geology 28(4):311-314.

Nanson, G.C. and E.J. Hickin. 1983. Channel Migration and Incision on the Beatton River. Journal of Hydraulic Engineering 109(3):327-337.

Nelson, E.J. and D.B. Booth. 2002. Sediment Sources in an Urbanizing, Mixed Land-Use Watershed. Journal of Hydrology 264:51-68.

NRCS. 2004. Soil Survey Geographic (SSURGO) Database for Grays Harbor County Area, Pacific and Wahkiakum Counties, Washington. U.S. Department of Agriculture, Natural Resources Conservation Service, Fort Worth, Texas.

Parker, Jeremy. 2004. Personal communication (discussion with Chase Barton, Herrera Environmental Consultants, Seattle, Washington, regarding the extent and frequency of dredging of the West Fork Grays River at the Grays River state fish hatchery). Washington Department of Fish and Wildlife, Grays River fish hatchery, Washington. September 22, 2004.

Perkins, S.J. 1989. Interactions of Landslide-Supplied Sediment with Channel Morphology in Forested Watersheds. Master's thesis. University of Washington, Seattle, Washington.

Reid, L.M. and T. Dunne. 1984. Sediment Production from Forest Road Surfaces. Water Resources Research 20(11):1753-1761.

Reid, L.M. and T. Dunne. 1996. Rapid Evaluation of Sediment Budgets. Catena Verlag GMBH, Reiskirchen, Germany. 164 p.

Rice, S. 1998. Which Tributaries Disrupt Downstream Fining Along Gravel-Bed Rivers? Geomorphology 22:39-56.

Richards, K.S. 1982. Rivers: Form and Process in Alluvial Channels. Methuen, London. 
Roberts, R.G. and M. Church. 1986. The Sediment Budget in Severely Disturbed Watersheds, Queen Charlotte Ranges, British Columbia. Can. J. For. Res. 16:1092-1106.

Roler, R. 2001. Draft Grays River Subbasin Summary. Prepared for Northwest Power Planning Council. October 26, 2001. 108 p.

Schmidt, K.M., J.J. Roering, J.D. Stock, W.E. Dietrich, D.R. Montgomery, and T. Schaub. 2001. The Variability of Root Cohesion as an Influence on Shallow Landslide Susceptibility in the Oregon Coast Range. Can. Geotech. J. 38:995-1024.

Schumm, S.A. 1971. Fluvial Geomorphology: Channel Adjustment and River Metamorphism. In: River Mechanics, vol. 1, Chap. 5. Edited by H.W. Shen. 22 p.

Scott, Mark G. 2004. Personal communication (email transmittal to Chase Barton, Herrera Environmental Consultants, Seattle, Washington, containing forest harvest data used in the research paper “Forest Clearing in the Gray’s River Watershed”). Senior GIS analyst, Department of Public Works, Pacific County, Washington. March 9, 2004.

Sedell, J.R. and K.J. Luchessa. 1982. Using the Historical Record as an Aid to Salmon Habitat Enhancement. pp. 210-223 in: Acquisition and Utilization of Aquatic Habitat Inventory Information. Edited by N.B. Armantrout. American Fisheries Society, Western Division.

Selby, M.J. 1993. Hillslope Materials and Processes. $2^{\text {nd }}$ edition. Oxford University Press, Oxford.

Smith, R.B., P.R. Commandeur, and M.W. Ryan. 1983. Natural Revegetation, Soil Development, and Forest Growth on the Queen Charlotte Islands, Progress Report. Fish-Forestry Interaction Program, Working Paper No. 7/83.

Stock, J.D. and W.E. Dietrich. 2003. Valley Incision by Debris Flows: Evidence of a Topographic Signature. Water Resources Research 39(4):1089. 10.1029/2001WR001057.

Stover, S.C. and D.R. Montgomery. 2001. Channel Change and Flooding, Skokomish River, Washington. Journal of Hydrology 243:272-286.

Sullivan, K.O. and S.H. Duncan. 1980. Sediment Yield from Road Surfaces in Response to Truck Traffic and Rainfall. Weyerhaeuser Technical Report 042-4402/80. Weyerhaeuser Company, Technical Center, Tacoma, Washington.

Sutherland, D.G., M. Hansler Ball, S.J. Hilton, and T.E. Lisle. 2002. Evolution of a LandslideInduced Sediment Wave in the Navarro River, California. Geological Society of America Bulletin 114(8):1036-1048.

Swanson, F.J. and C.T. Dyrness. 1975. Impact of Clear-Cutting and Road Construction on Soil Erosion by Landslides in the Western Cascade Range, Oregon. Geology 3(7):393-396. 
Swanson, F.J., R.L. Fredrikson, and F.M. McCorison. 1982. Material Transfer in a Western Oregon Forested Watershed. pp. 223-266 in: Analysis of Coniferous Forest Ecosystems in the Western United States. Edited by R.L. Edmonds. Hutchinson Ross, Stroudsburg, Pennsylvania. .

Swift, L.W., Jr. 1984. Gravel and Grass Surfacing Reduces Soil Loss from Mountain Roads. Forestry Science 30:657-670.

TCG. 2004. Road maps of Grays River watershed. The Campbell Group, LLC.

Walsh, T.J., M.A. Korosec, W.M. Phillips, R.L. Logan, and H.W. Schasse. 1987. Geologic Map of Washington-Southwest Quadrant. Geologic map GM-34. Washington Department of Natural Resources, Division of Geology and Earth Resources.

Washington Conservation Commission. 2001. Water Resource Inventory Area [WRIA] 25 Habitat Limiting Factors Analysis. Draft.

WDFW. 2001. Draft Lower Columbia Chum Stock Inventory. Washington Department of Fish and Wildlife, Olympia, Washington.

WDNR. 1996. Forest Practice Application Reviews System (FPARS) digital forest road coverage. Washington Department of Natural Resources.

WDNR. 1997. Watershed Analysis Manual, Appendix B. Surface Erosion. Washington Department of Natural Resources.

WDNR. 2004. Digital geologic map coverage, 1:100,000 scale; digitized from U.S. Geological Survey maps. Washington Department of Natural Resources.

West Consultants, Inc. 2004. Grays River Hydrology for State Highway No. 4 Crossing and Altoona-Pillar Road Crossing, Wahkiakum County, Washington. Prepared for StreamFix, Oregon City, Oregon, by West Consultants, Inc., Salem, Oregon. January 5, 2004.

Whiting, P.J., J.F. Stamm, D.B. Moog, and R.L. Orndorff. 1999. Sediment Transporting Flows in Headwater Channels. Geol. Soc. Am. Bull. 111:450-466.

Willett, S.D. and M.T. Brandon. 2002. On Steady States in Mountain Belts. Geology 30(2):175178.

Wolman, M.G. 1954. A Method of Sampling Coarse River-Bed Material. Transactions of the Geophysical Union 35:951-956.

WRCC. 2004. Grays River hatchery climate summary data (3/ 17/1962 to 12/31/2004) online. Western Regional Climate Center. Obtained March 16, 2005 from $<$ http://www.wrcc.dri.edu/summary/climsmwa.html>. 
APPENDIX A

Historical Forest Clearing 



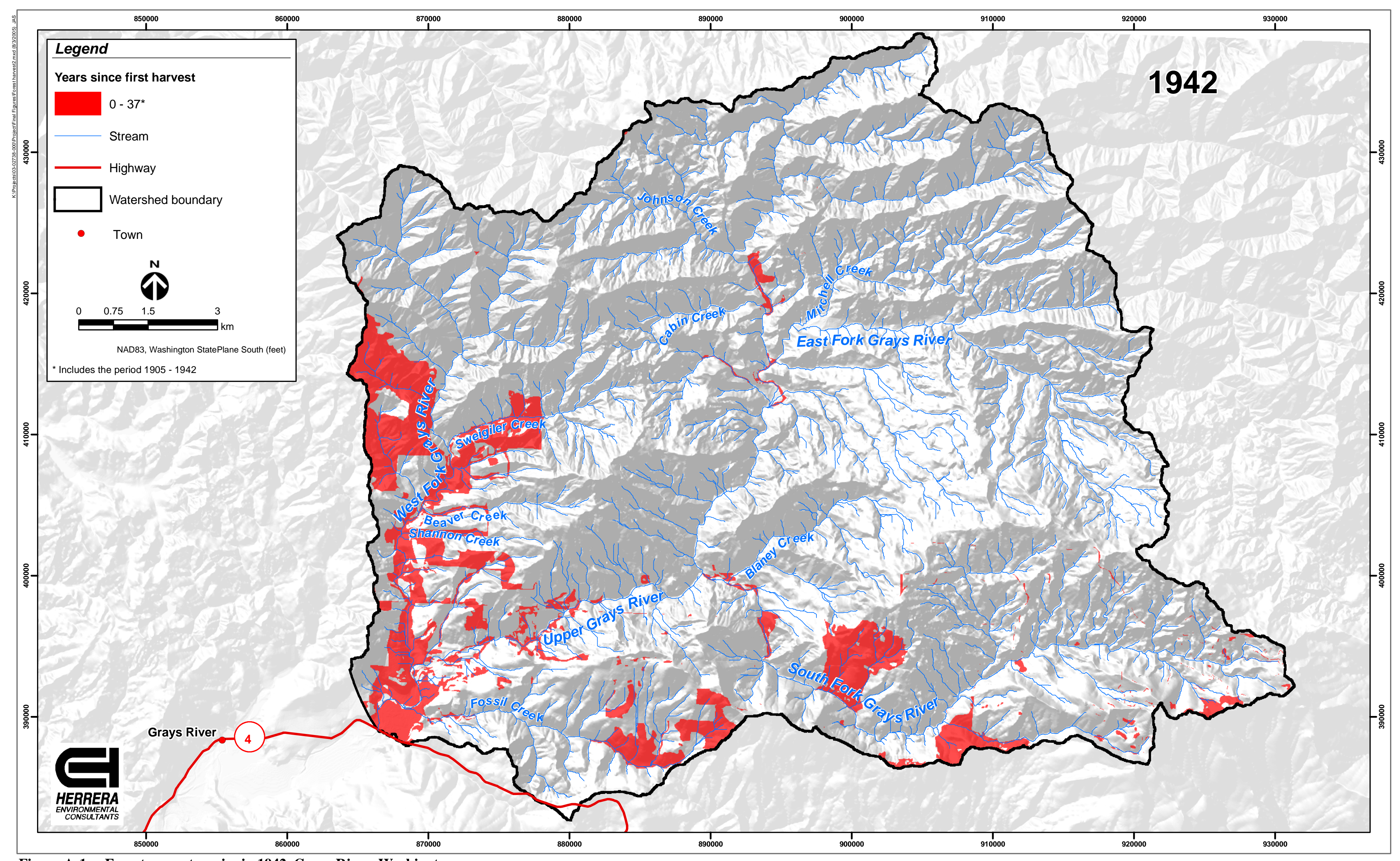

Figure A-1 Forest-age categories in 1942, Grays River, Washington. 



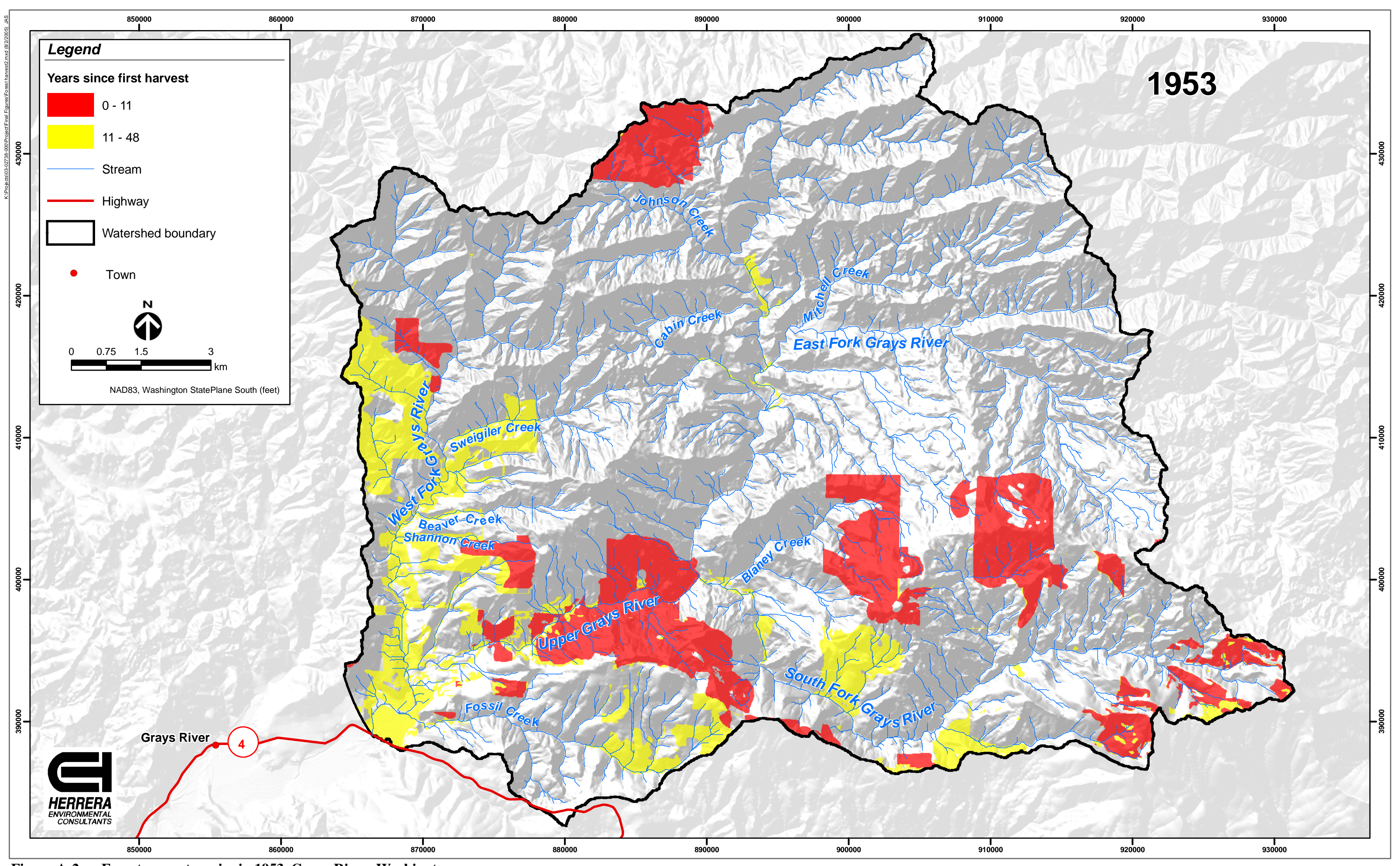

Figure A-2. Forest-age categories in 1953, Grays River, Washington. 



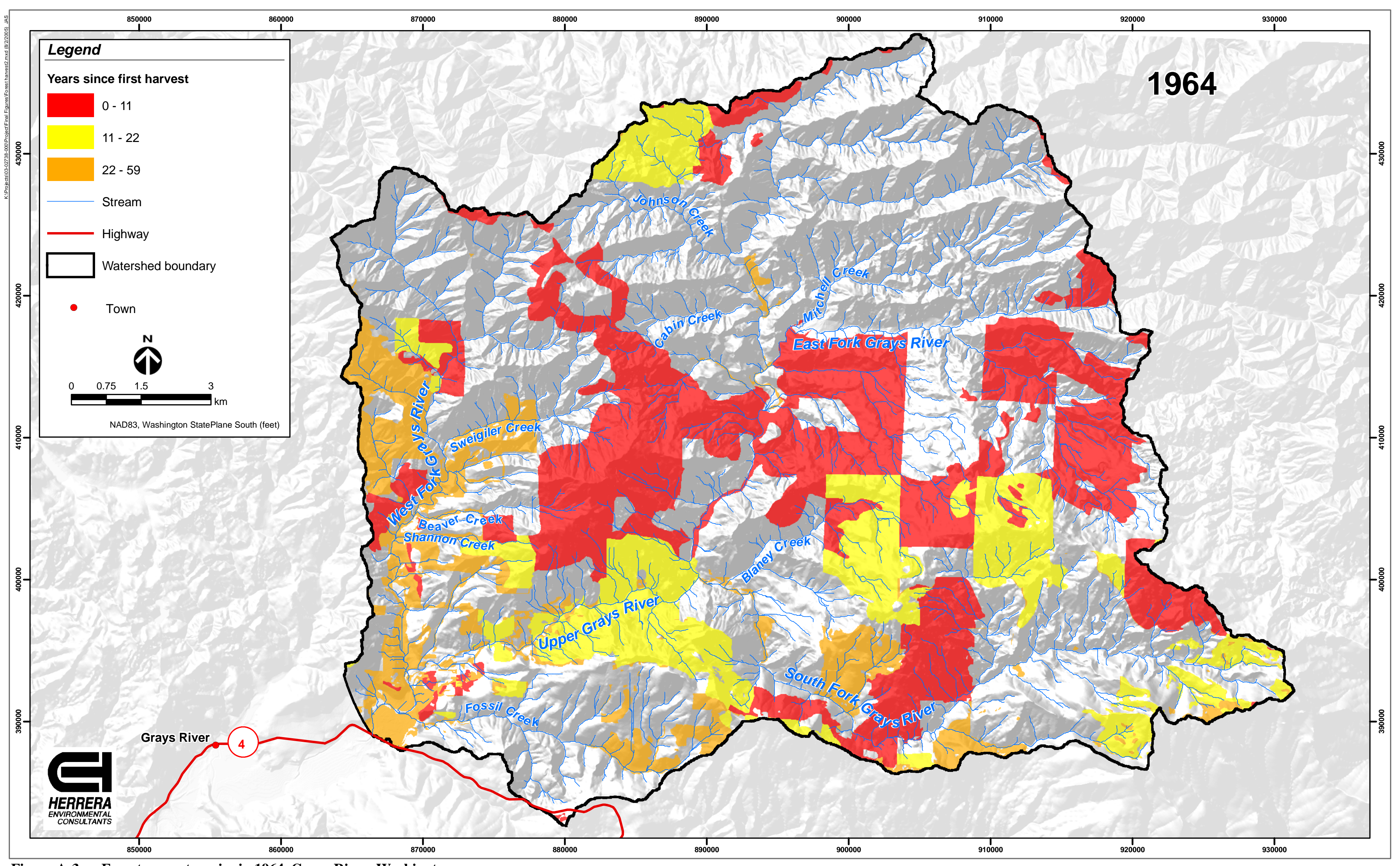

Figure A-3. Forest-age categories in 1964, Grays River, Washington. 



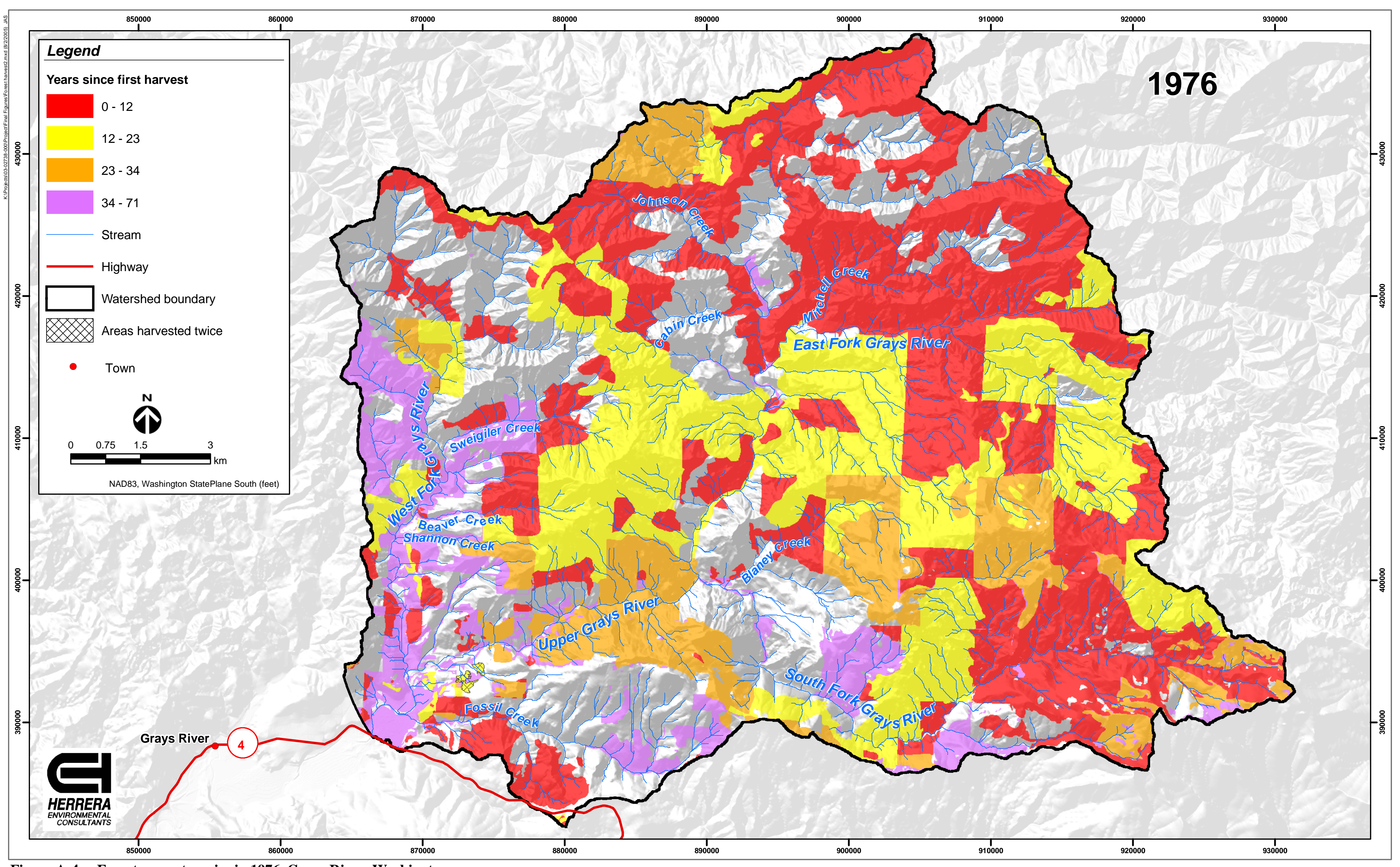

Figure A-4 Forest-age categories in 1976, Grays River, Washington. 



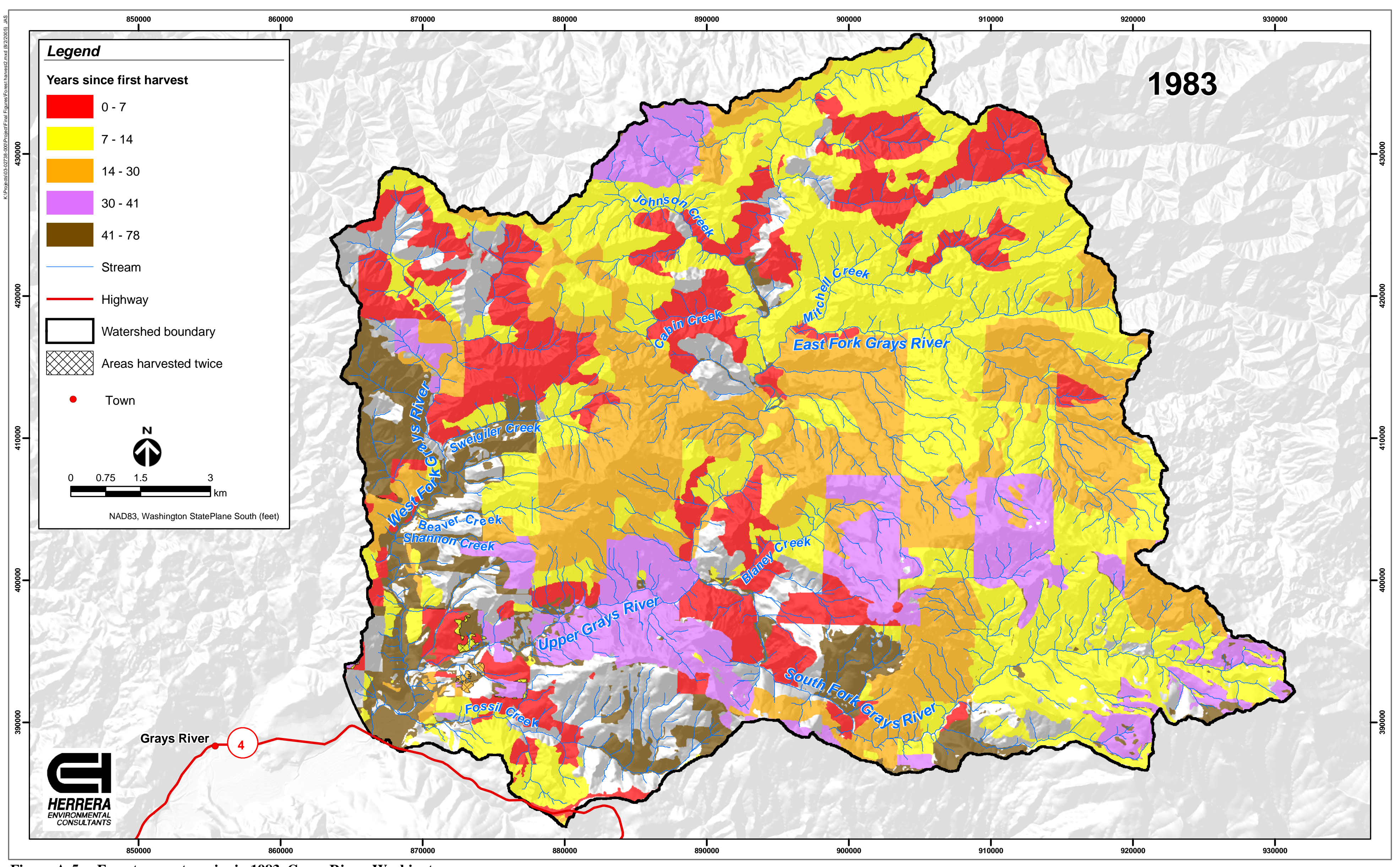

Figure A-5 Forest-age categories in 1983, Grays River, Washington. 



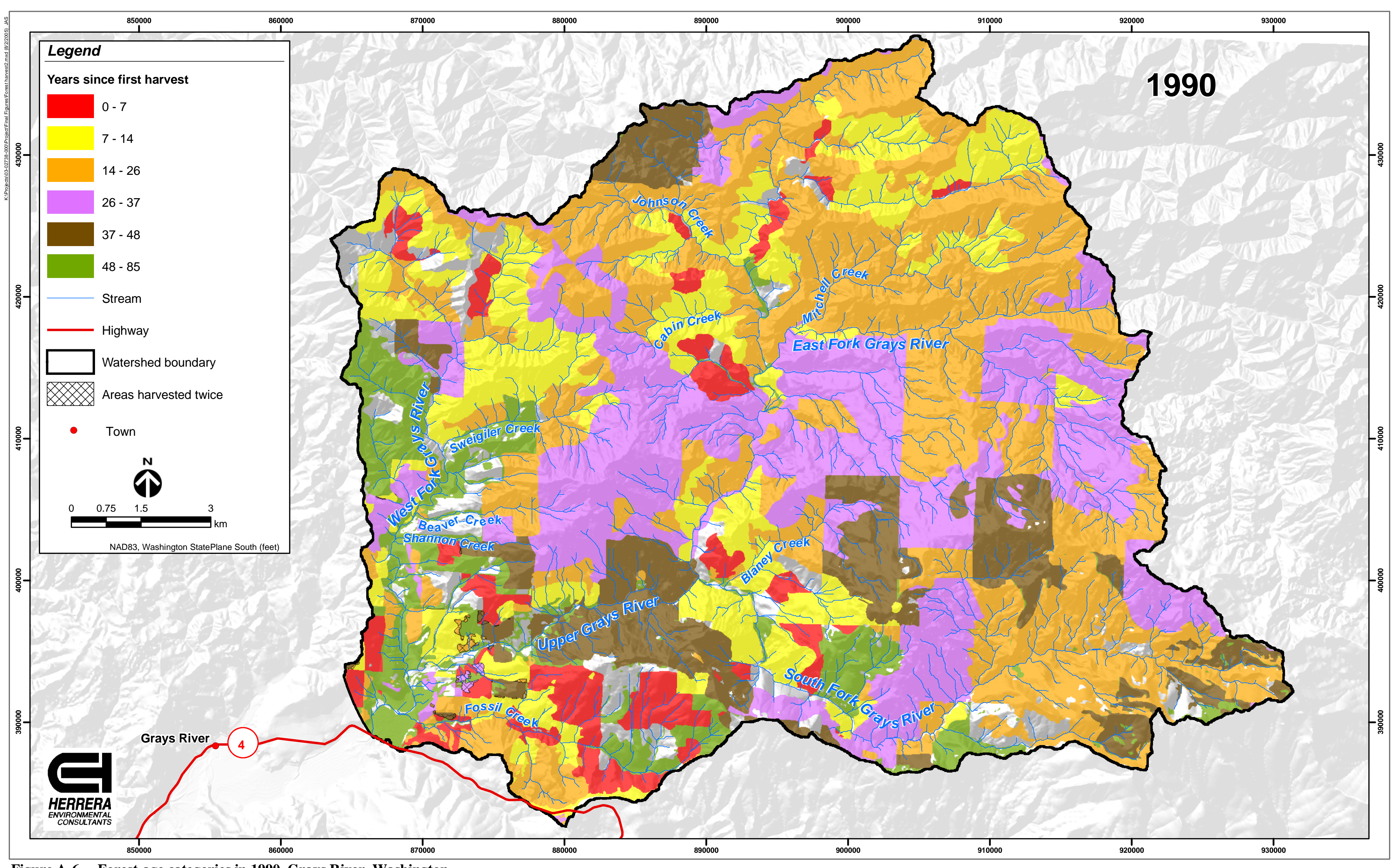

Figure A-6 Forest-age categories in 1990, Grays River, Washington. 



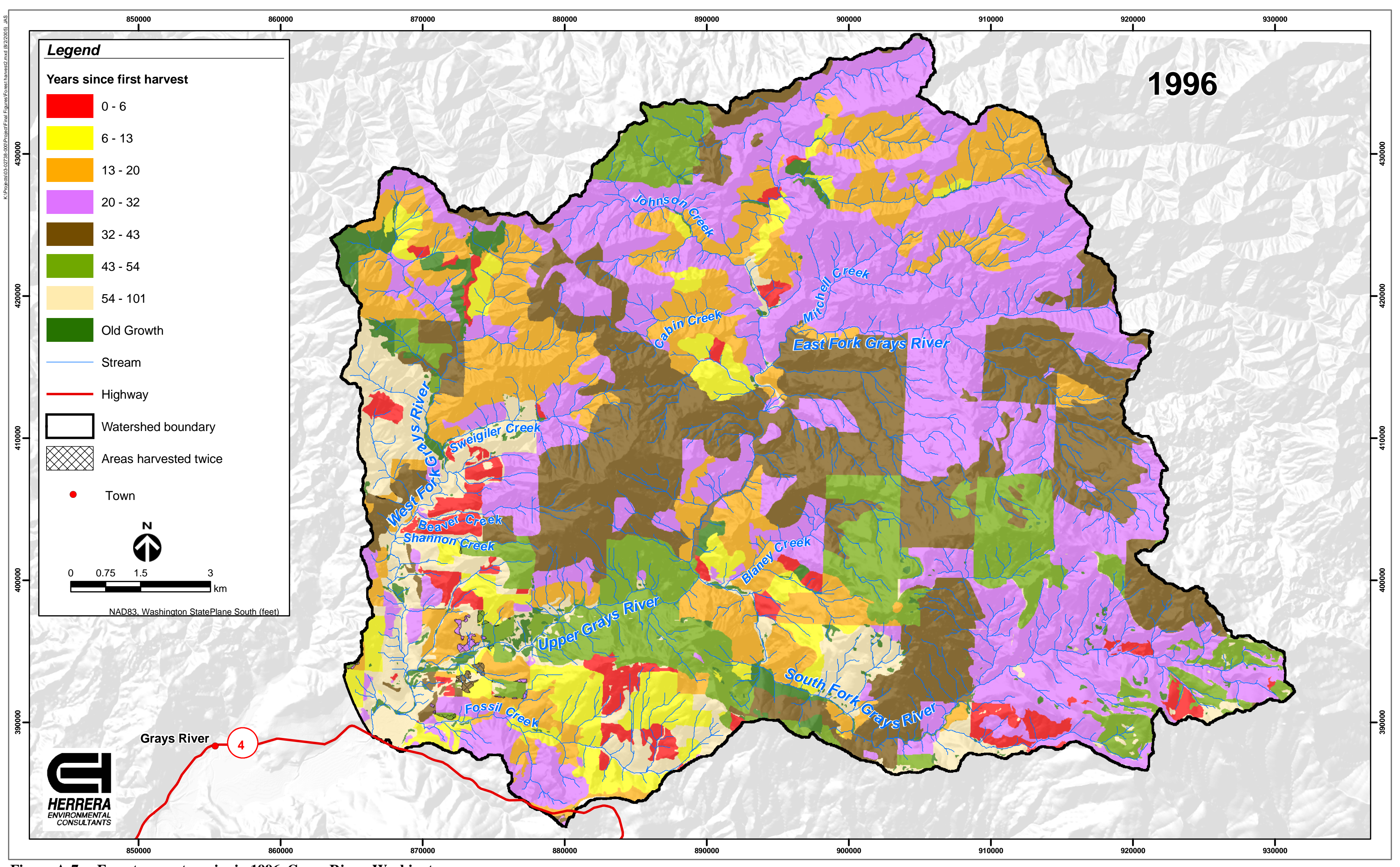

Figure A-7 Forest-age categories in 1996, Grays River, Washington. 

APPENDIX B

\section{Photographic Documentation of \\ Field Reconnaissance}





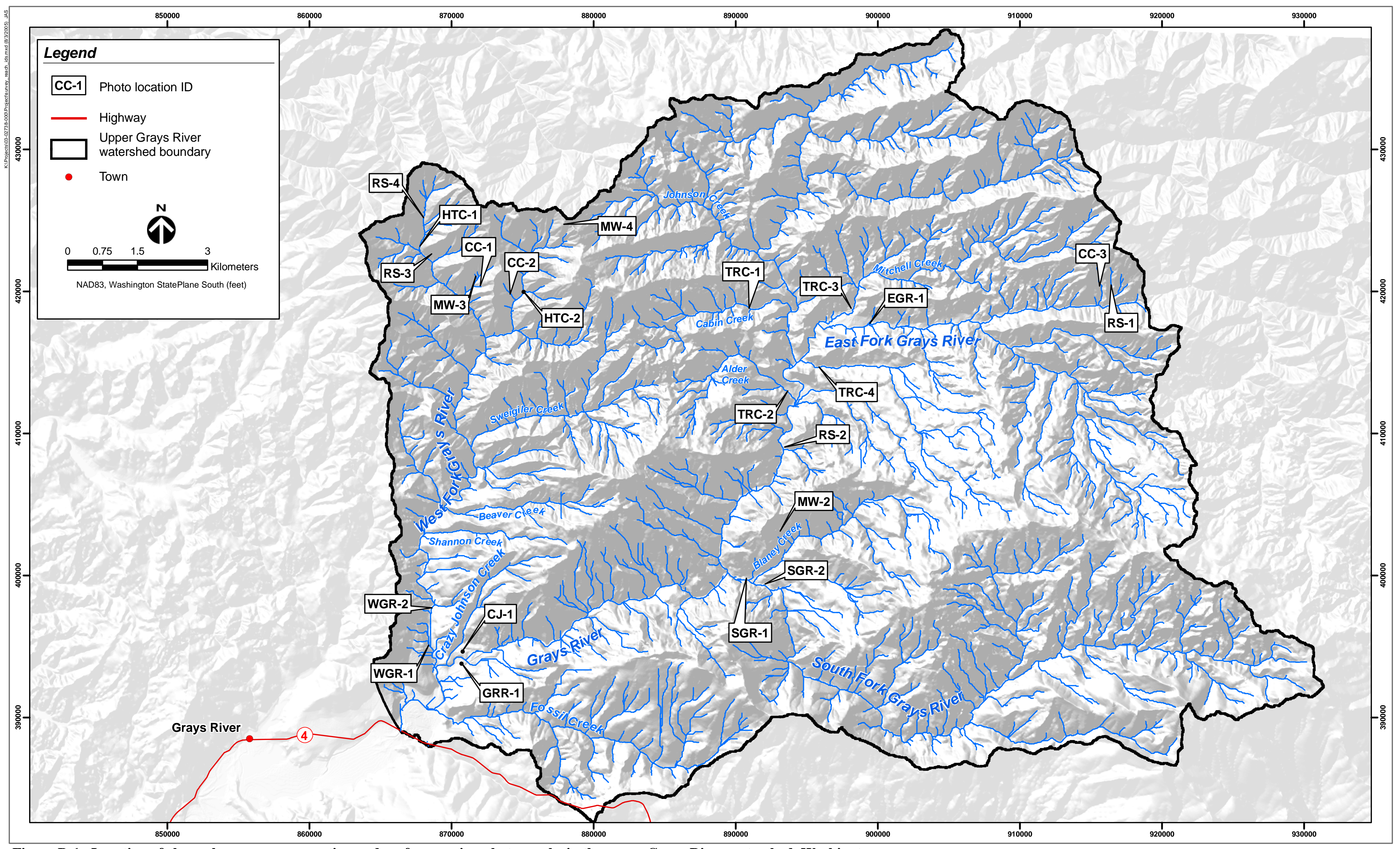

Figure B-1. Location of channel survey, mass wasting and surface erosion photographs in the upper Grays River watershed, Washington. 



\section{Grays River Geomorphic Analysis Photographic Log}

\begin{tabular}{|c|c|}
\hline $\begin{array}{l}\text { Photo } \\
\text { Number }\end{array}$ & Photo Description \\
\hline MW-2-1 & Large rotational landslide above Rd. 7050; note people in center for scale. \\
\hline MW-2-2 & Gulley erosion below large rotational landslide shown in photo MW-2-1. \\
\hline MW-2-3 & Gulley erosion below large rotational landslide shown in photo MW-2-1. \\
\hline MW-2-4 & 1996 aerial photograph of large rotational landslide in photo MW-2-1 and debris flow. \\
\hline MW-2-5 & 2003 aerial photograph of large rotational landslide in photo MW-2-1 and debris flow. \\
\hline MW-3-1 & Debris-flow deposit at Rd. 6200. \\
\hline MW-3-3 & 2003 aerial photograph of debris flow in photo MW-3-1. \\
\hline MW-4-1 & Shallow translational landslides. \\
\hline MW-4-2 & 2003 aerial photograph of shallow translational landslides shown in photo MW-4-1. \\
\hline RS-1-1 & Example of mainline road conditions (Rd. 7000). \\
\hline RS-2-1 & Example of mainline road conditions (Rd. 7000). \\
\hline RS-3-1 & Example of non-active road conditions (Rd. 6200). \\
\hline RS-4-1 & Example of decommissioned road conditions (Rd. 6275). \\
\hline CC-1-1 & Colluvial channel scoured to bedrock from historical debris flow. \\
\hline CC-2-1 & Boulder cascade channel. \\
\hline HTC-1-1 & Confined boulder dominated step-pool channel segment. \\
\hline HTC-1-2 & Relic LWD providing grade control in confined step-pool channel. \\
\hline HTC-2-1 & Confined boulder step-pool channel. \\
\hline TRC-1-1 & Plane-bed of Cabin Creek. \\
\hline TRC-1-2 & Plane-bed reach of Cabin Creek with boulder steps. \\
\hline TRC-2-1 & Moderately confined plane-bed reach of Alder Creek. \\
\hline TRC-3-1 & Moderately confined plane-bed channel of Mitchell Creek. \\
\hline TRC-4-1 & Confined plane-bed reach. \\
\hline EGR-1-1 & Plane-bed morphology in the East Fork Grays River. \\
\hline EGR-1-2 & Looking downstream at plane-bed morphology in the East Fork Grays River. \\
\hline SGR-1-1 & Bifurcated cobble bedded plane-bed channel at the upstream end of the survey reach. \\
\hline
\end{tabular}




\begin{tabular}{|c|c|}
\hline $\begin{array}{l}\text { Photo } \\
\text { Number }\end{array}$ & Photo Description \\
\hline SGR-1-2 & Debris dam with entrained LWD. \\
\hline SGR-1-3 & Foreset beds of sand are evidence of a prograding depositional environment. \\
\hline SGR-1-4 & Coarse grained alluvial sediment visible in the terrace deposit. \\
\hline SGR-2-1 & Valley jam on the South Fork Grays River. \\
\hline SGR-2-2 & Looking downstream over a gravel and cobble bar from the upstream end of the survey reach. \\
\hline WGR-1-1 & Gravel and cobbled bedded plan bed reach of the West Fork Grays River. \\
\hline WGR-2-1 & Gravel bedded pool riffle reach of the West Fork Grays River. \\
\hline WGR-2-2 & Bifurcated gravel bedded pool-riffle reach in the West Fork Grays River. \\
\hline WGR-2-3 & $\begin{array}{l}\text { Erosional scar in the weak marine sedimentary rocks at the left edge of the West Fork Grays River } \\
\text { floodplain. }\end{array}$ \\
\hline CJ-1-1 & $\begin{array}{l}\text { Beaver dam integrated into LWD in gravel and sand bedded low-gradient floodplain channel of } \\
\text { Crazy Johnson Creek. }\end{array}$ \\
\hline GRR-1-1 & Cobble bedded Plan-bed channel of the main stem Grays Rivet. \\
\hline GRR-1-2 & Trees buried in growth position indicate variability in vertical channel elevation. \\
\hline GRR-1-3 & Buried LWD jam exposed in right bank of exiting channel alignment. \\
\hline GRR-1-4 & Looking downstream, the main channel and avulsion path is located to the left of the photo. \\
\hline GRR-1-5a & Eroding hillslope near the head of the avulsion channel alignment. \\
\hline GRR-1-5b & Eroding hillslope at the left margin of the floodplain valley. \\
\hline GRR-1-6 & Looking downstream within the straightened and leveed portion of the main stem Grays River. \\
\hline
\end{tabular}




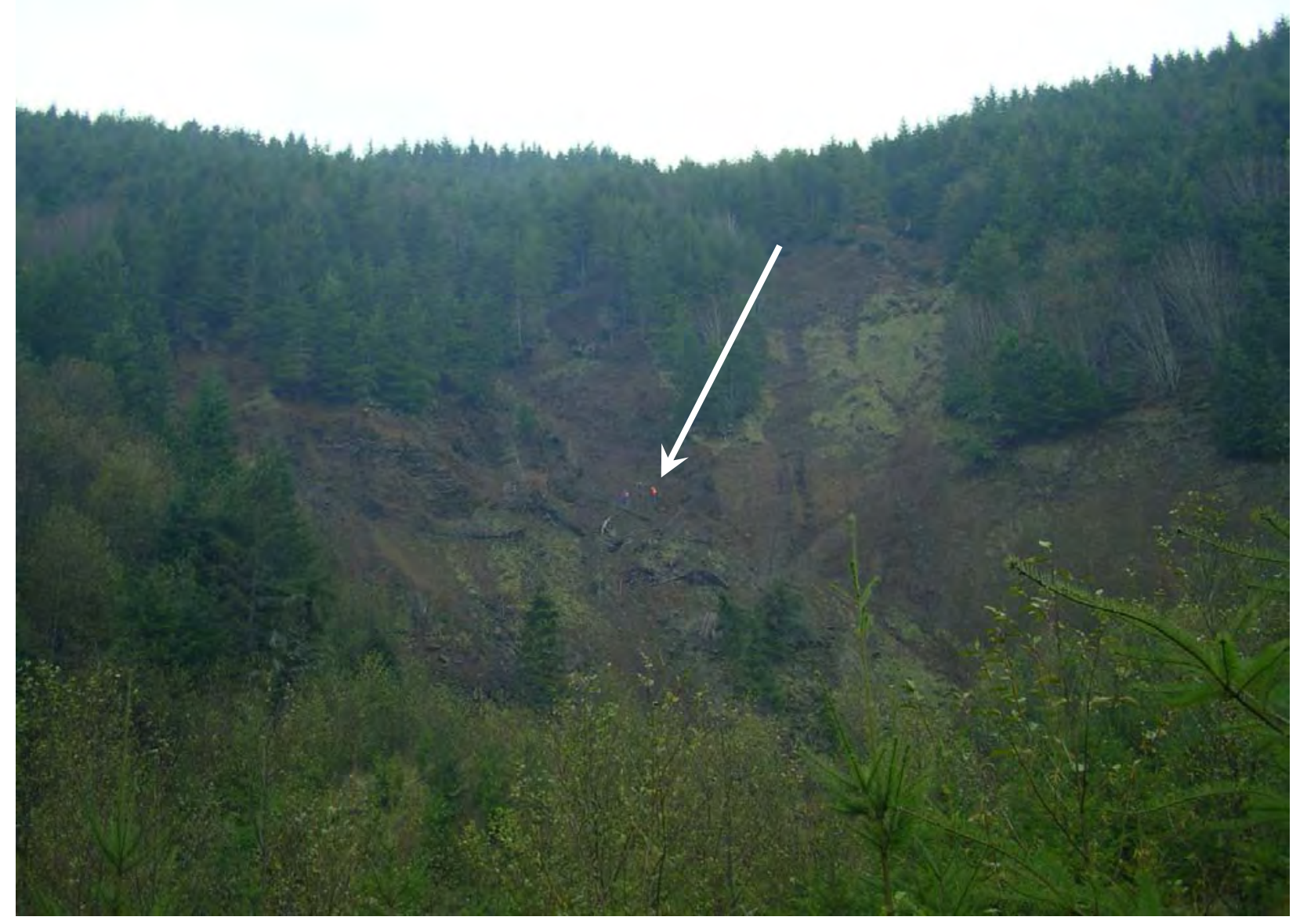

Photo MW-2-1. Survey location MW-2 (October 26, 2004). Looking up from Rd. 7050 (above Blaney Creek) at headscarp of large rotational landslide in basalt. Note people in center for scale (arrow). 



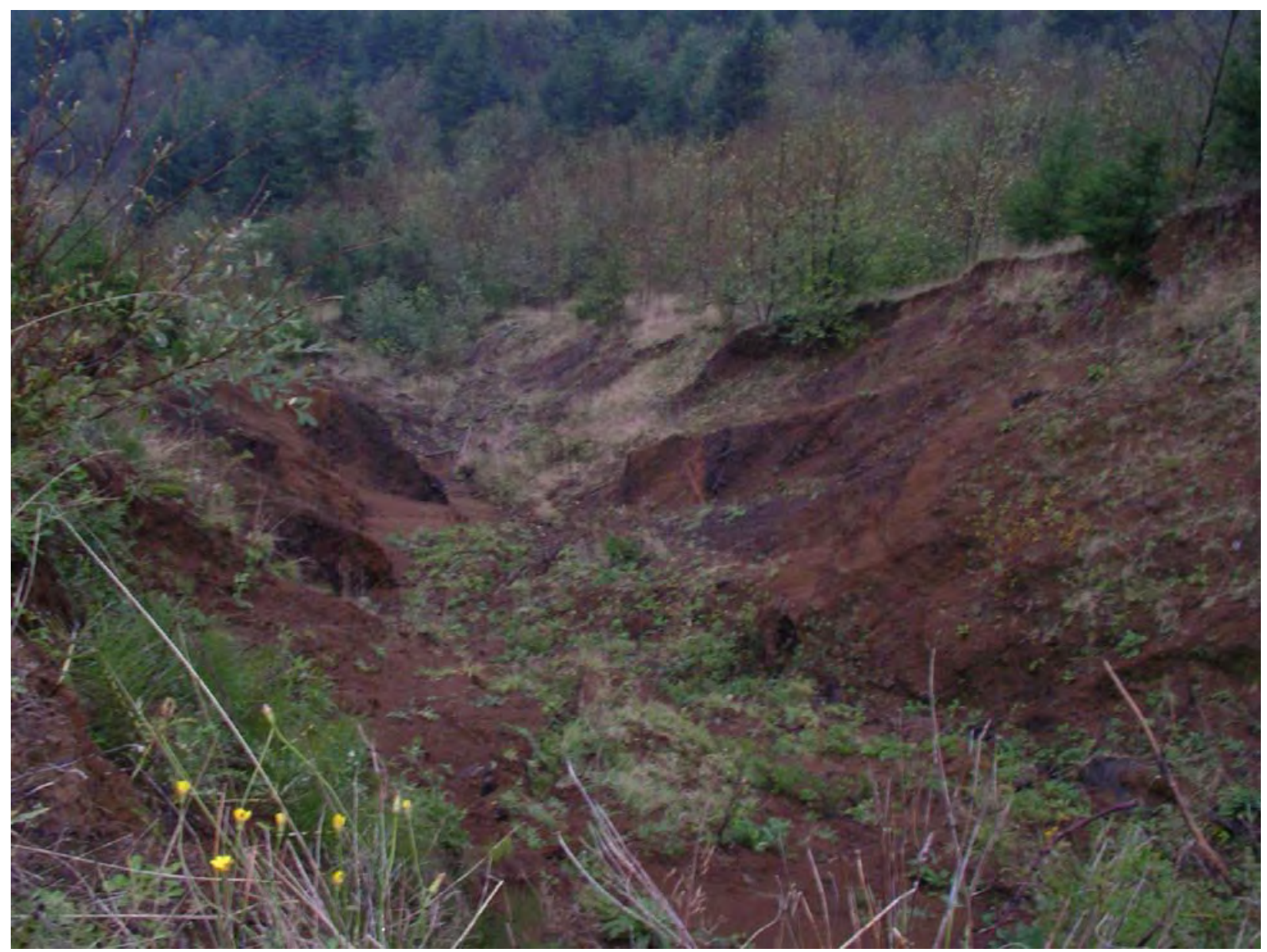

Photo MW-2-2. Survey location MW-2 (October 26, 2004). Looking down westernmost gulley (one of three) below large rotational landslide shown in photo MW-2-1. Gully begins at outlet of culvert beneath Rd. 7050 and has eroded an estimated $3,500 \mathrm{~m}^{3}$ of sediment. 



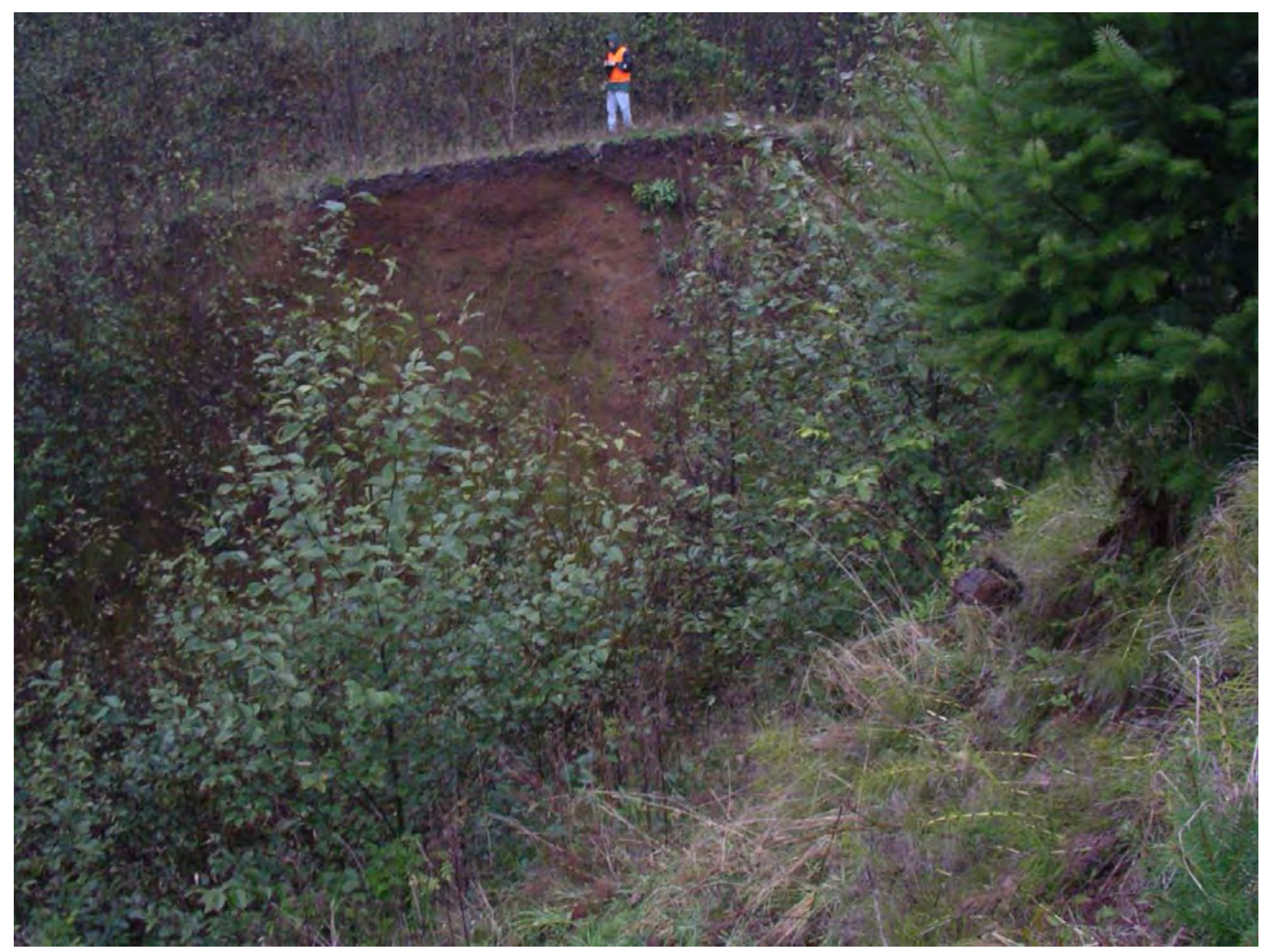

Photo MW-2-3. Survey location MW-2 (October 26, 2004). Looking across the western gulley shown in photo MW-2-2 from below Rd. 7050. Erosion results from concentrated surface water directed by the forest road drainage network. 



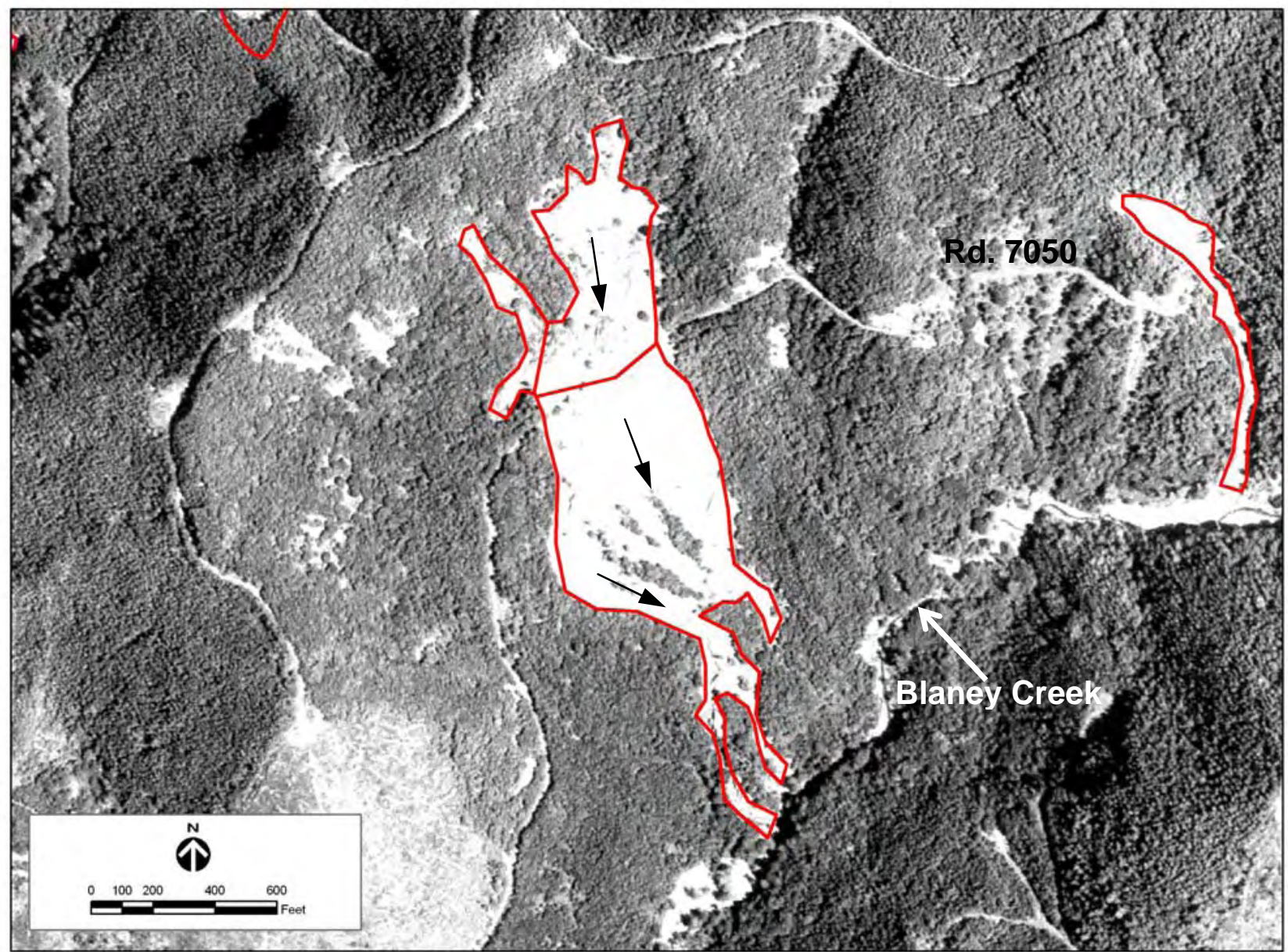

Photo MW-2-4. Survey location MW-2 (1996 aerial photograph). Large rotational landslide and sediment delivery to Blaney Creek. Lack of vegetation indicates failure occurred between 1994 and 1996. Photos MW-2-1 through 3 were taken from $\mathrm{Rd}$. 7050, where the road crosses the landslide. Outline created during landslide inventory. 



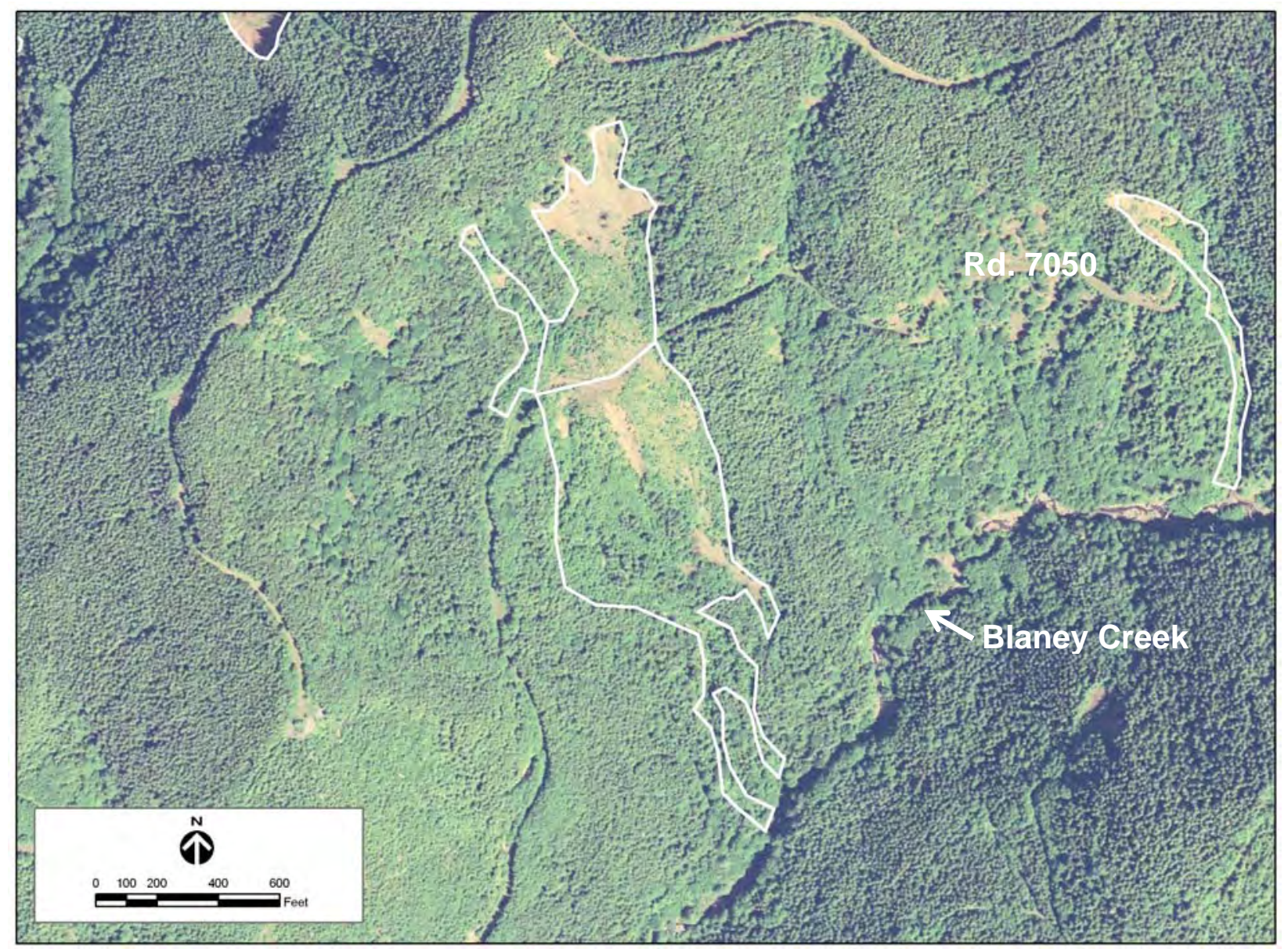

Photo MW-2-5. Survey location MW-2 (2003 aerial photograph). Large rotational landslide showing partial revegetation, except on exposed bedrock headwall and in actively eroding gullies below Rd. 7050. 



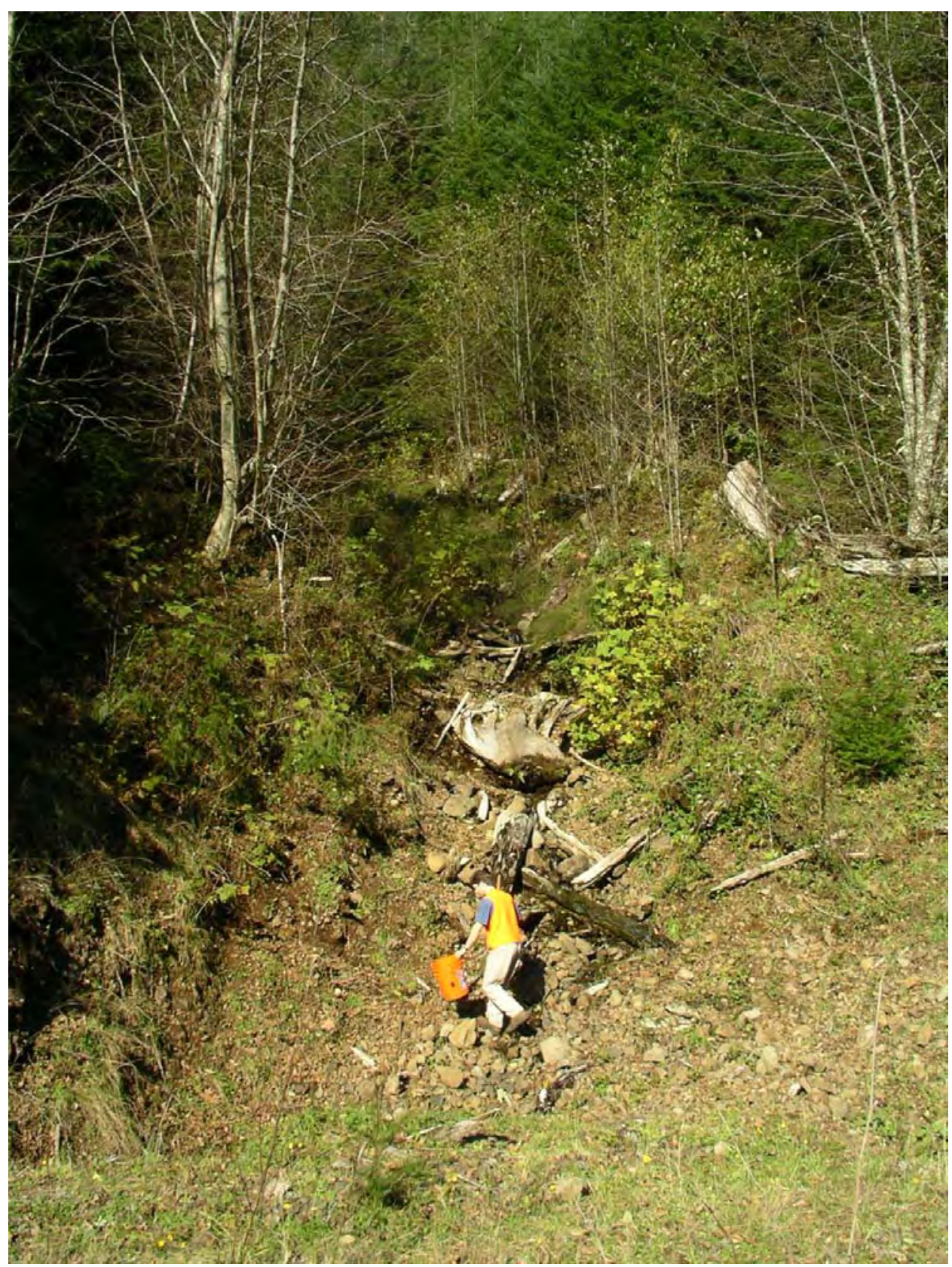

Photo MW-3-1. Survey location MW-3 (October 27, 2004). Sediment and wood accumulation from debris flow in colluvial hollow above Rd. 6200 . 



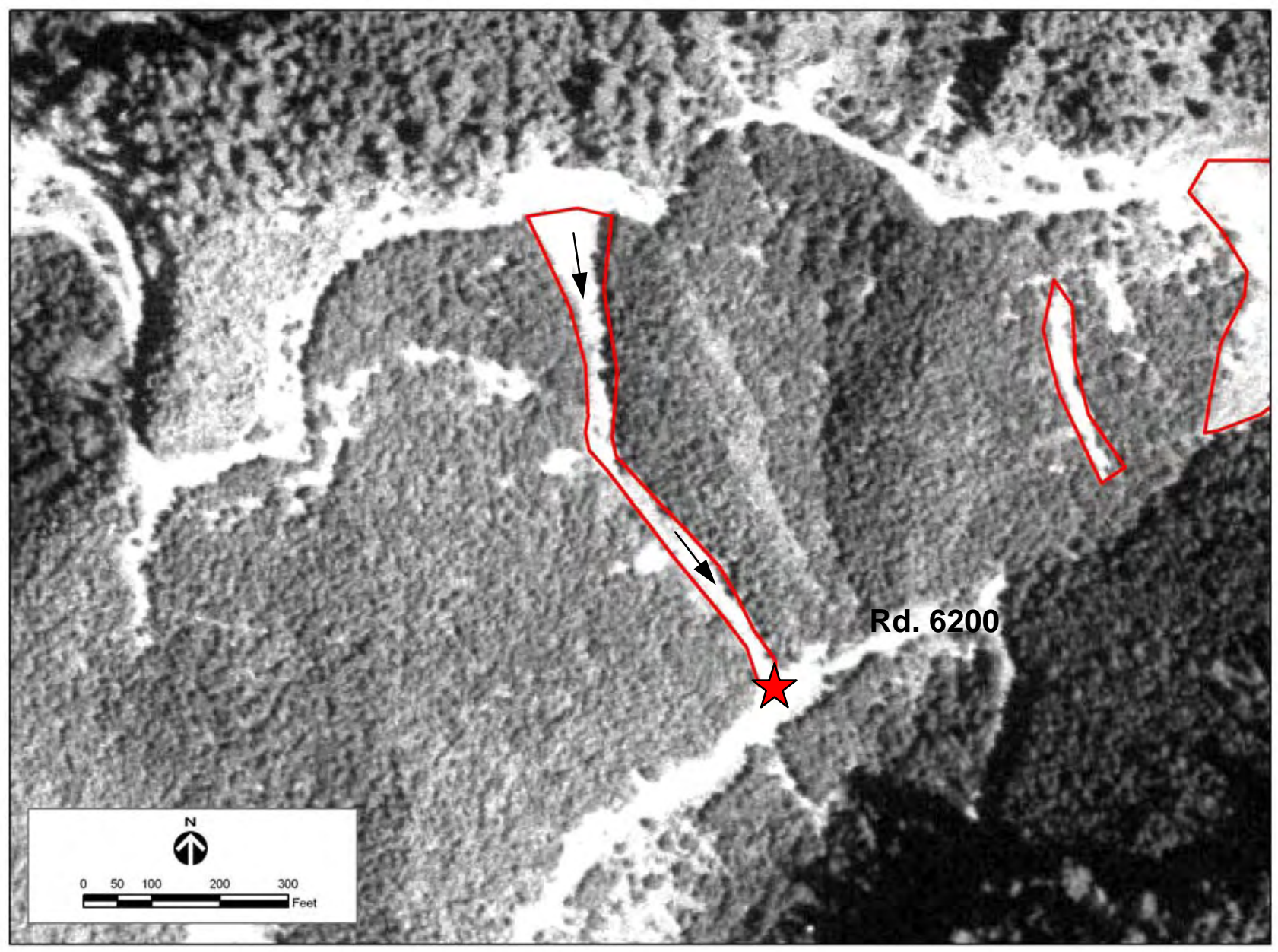

Photo MW-3-3. Survey location MW-3 (1996 aerial photograph). Debris-flow initiation and runout above Rd. 6200. Star denotes location of photos MW-3-1. 



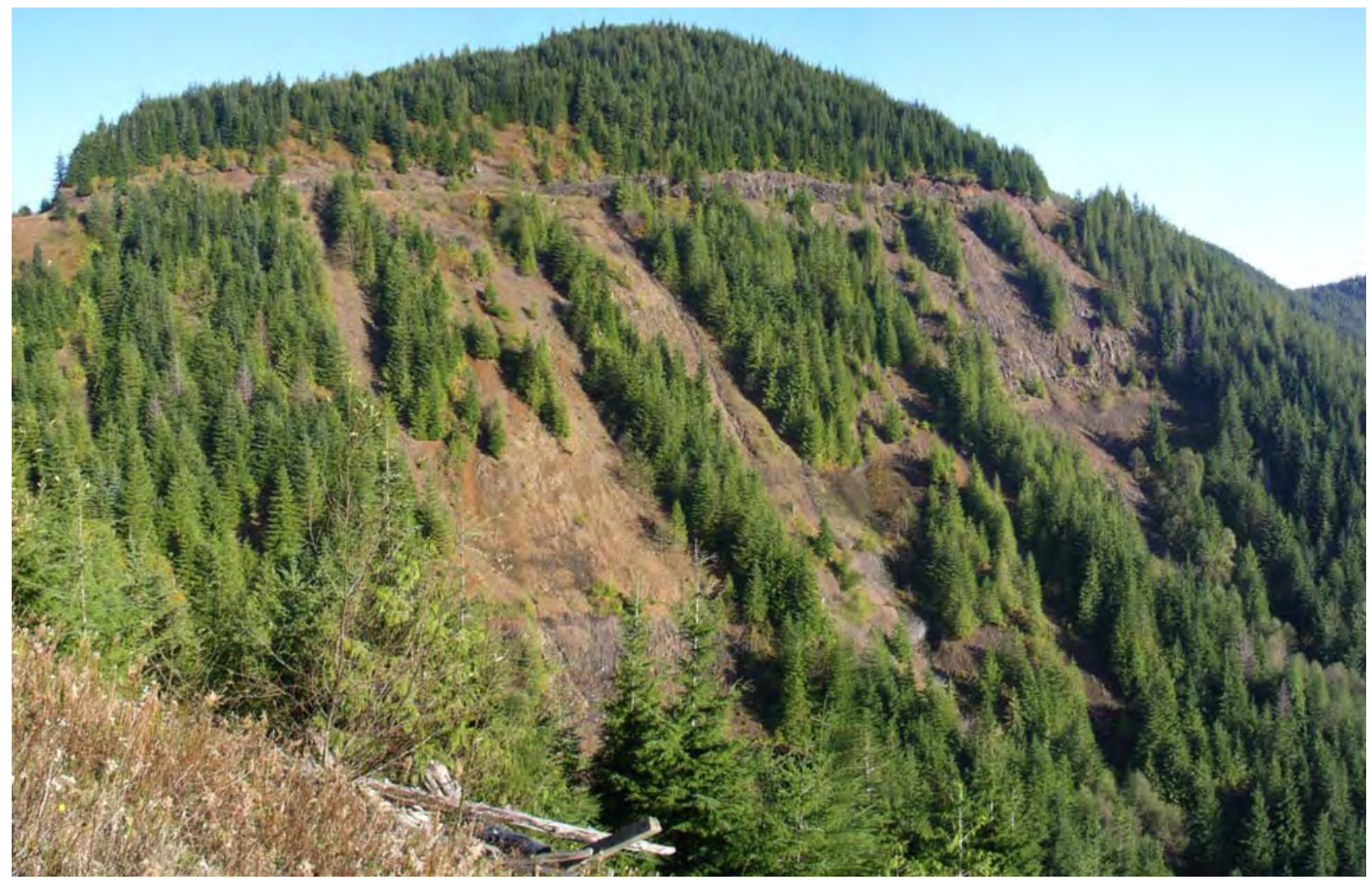

Photo MW-4-1. Survey location MW-4 (October 28, 2004). Translational landslides on steep slopes within the headwaters of the West Fork Grays River. Landsliding has removed the thin $\sim 1$-meter soil horizon down to bedrock of the Crescent Formation (basalt). The visible vertical relief is approximately 500 meters. View is toward the east. 



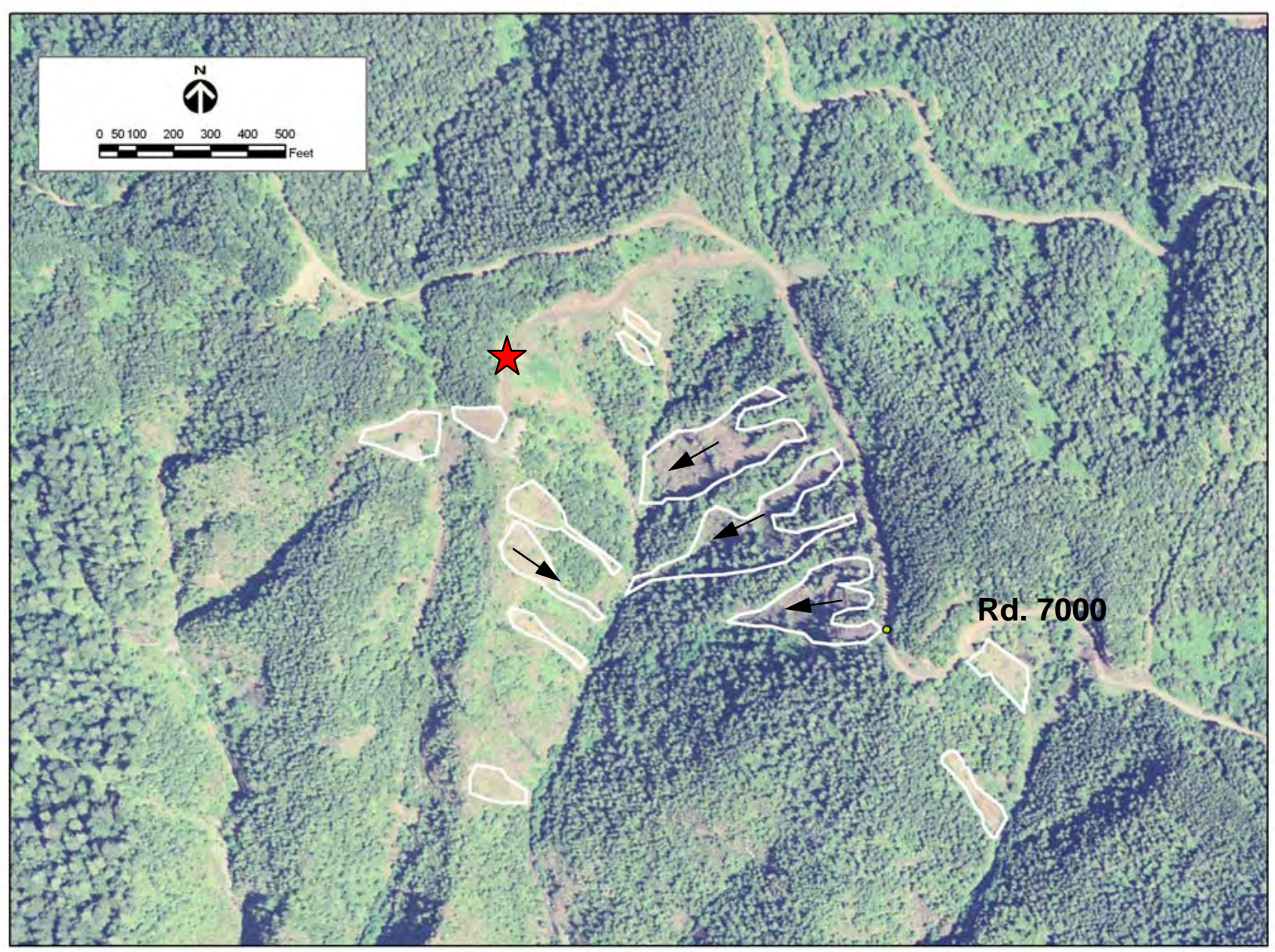

Photo MW-4-2. Survey location MW-4 (2003 aerial photograph). Translational landslides in the headwaters of the West Fork Grays River. Star denotes approximate location of photo-point MW-4-1. 



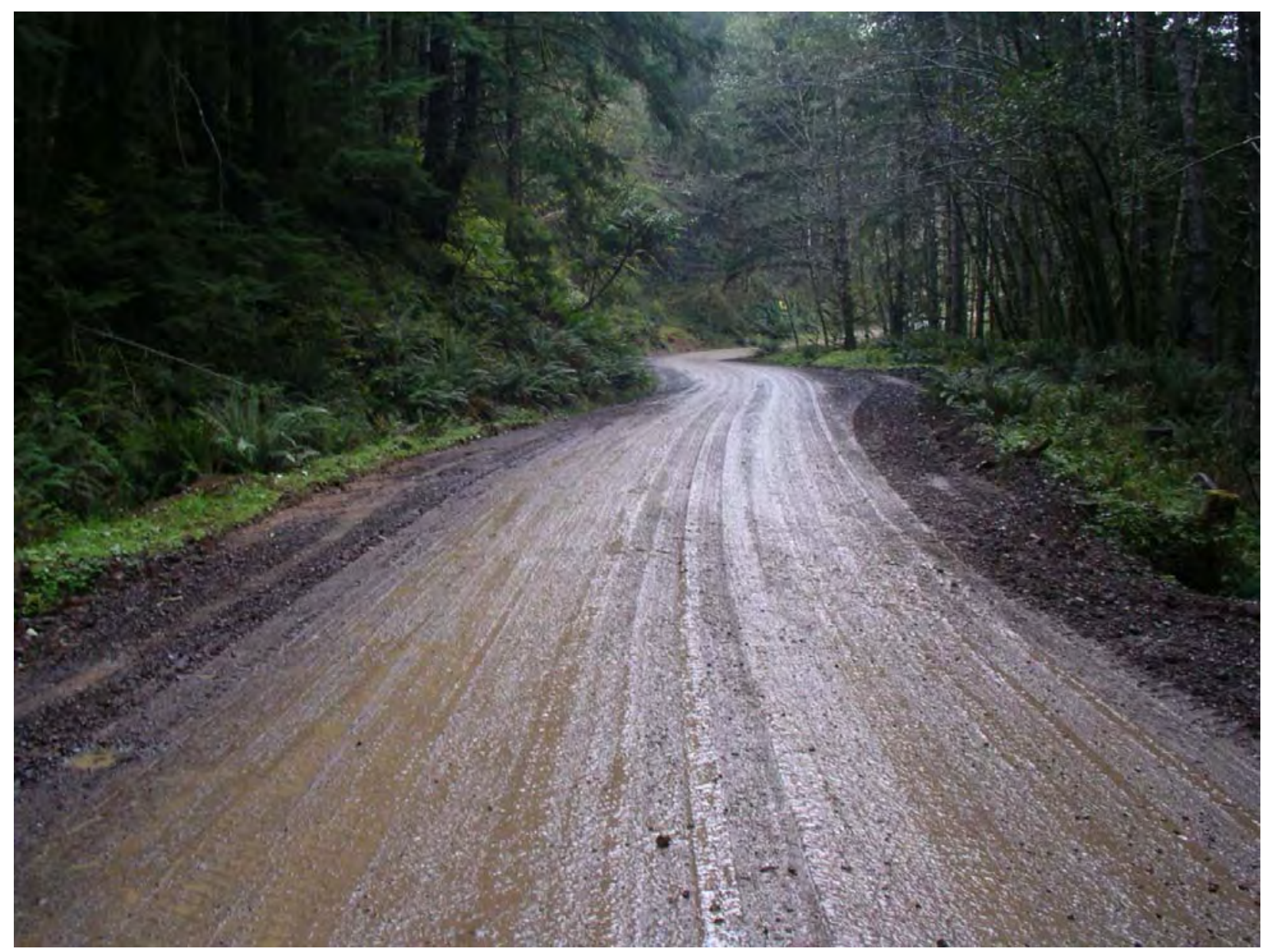

Photo RS-1-1. Survey location RS-1 (October 28, 2004). Example of mainline road conditions (Rd. 7000). 



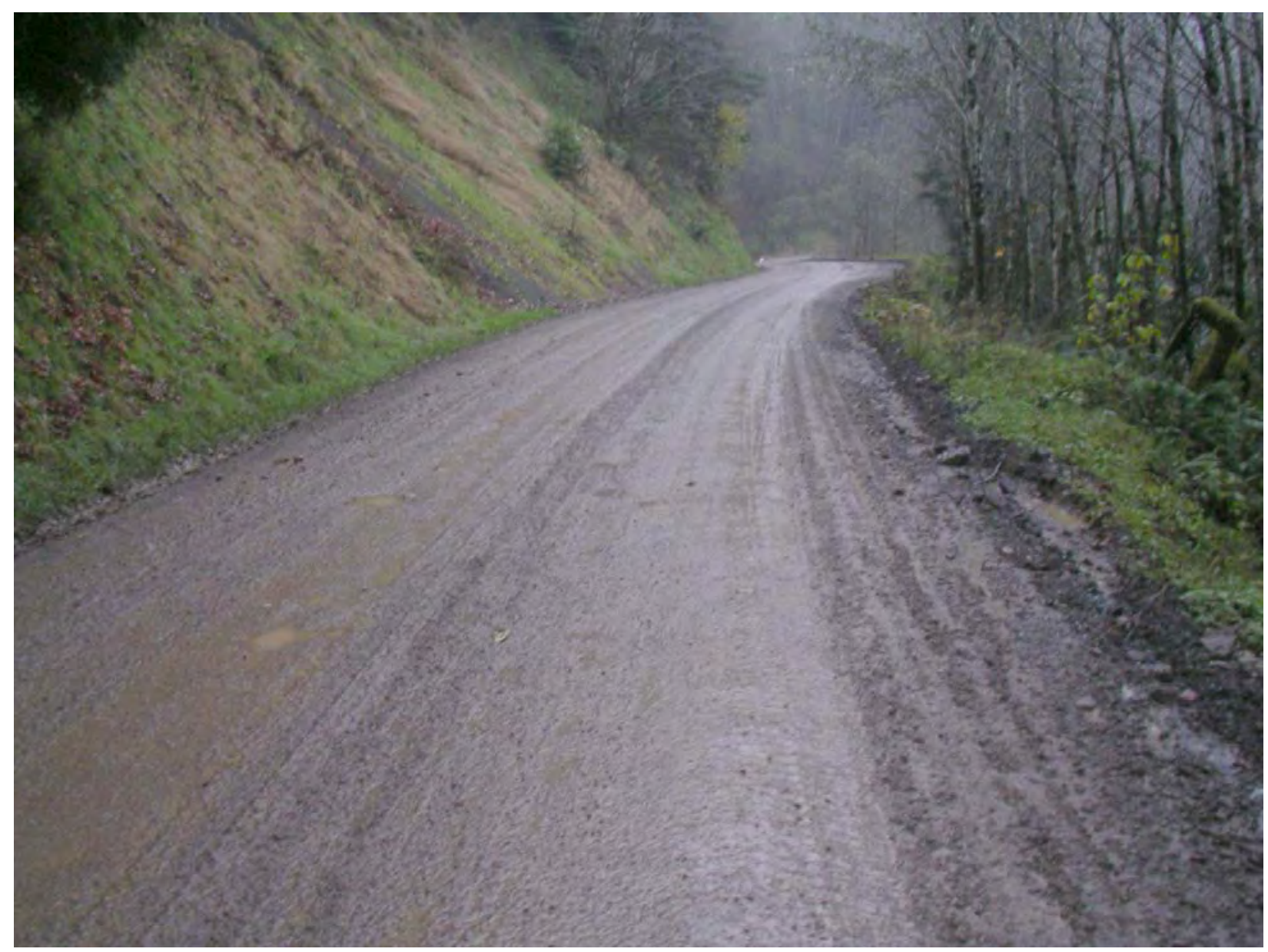

Photo RS-2-1. Survey location RS-2 (October 28, 2004). Example of mainline road conditions (Rd. 7000). 



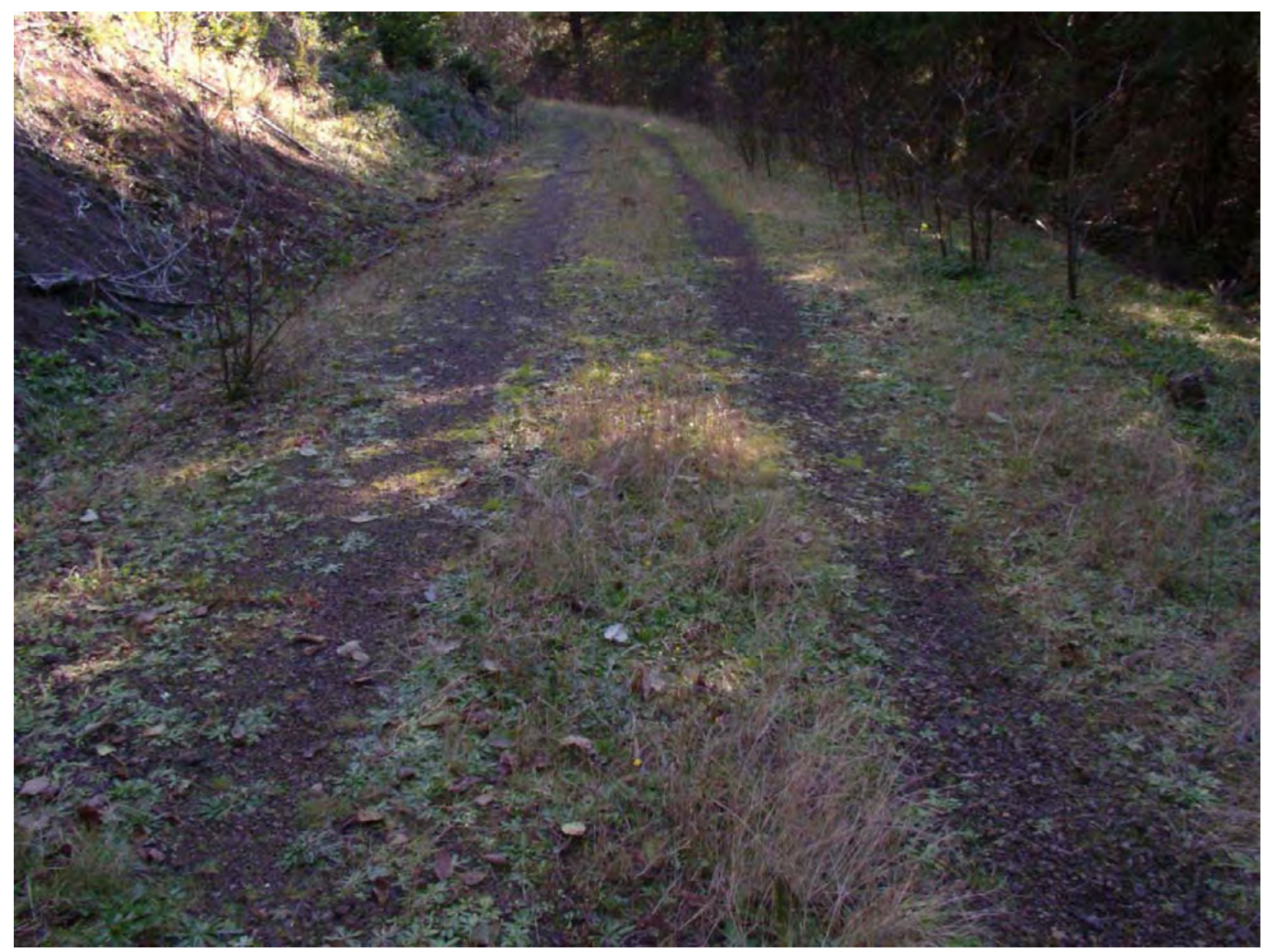

Photo RS-3-1. Survey location RS-3 (October 27, 2004). Example of non-active road conditions (Rd. 6200). 



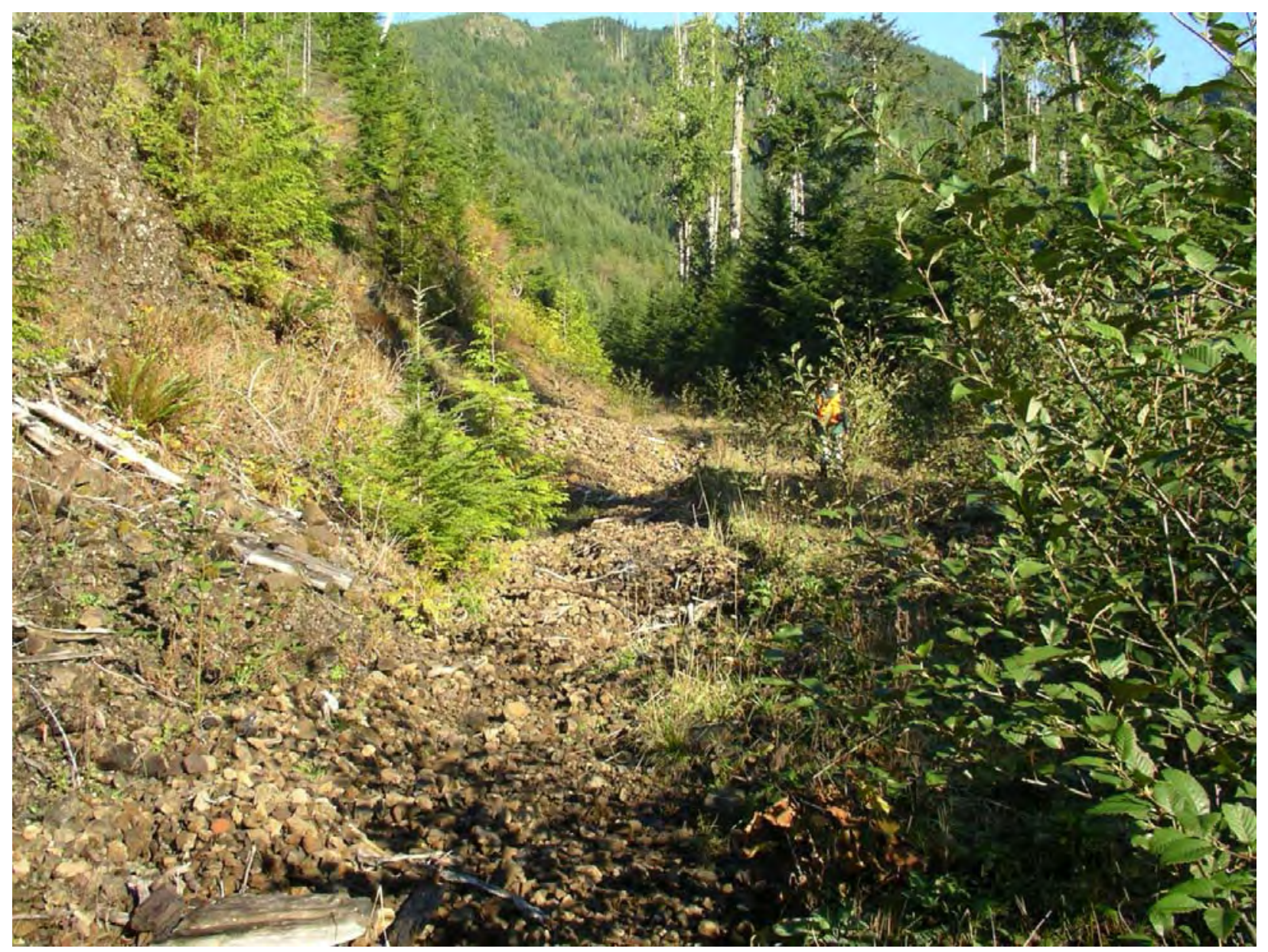

Photo RS-4-1. Survey location RS-4 (October 27, 2004). Example of decommissioned road conditions ( $R d$. 6275). 



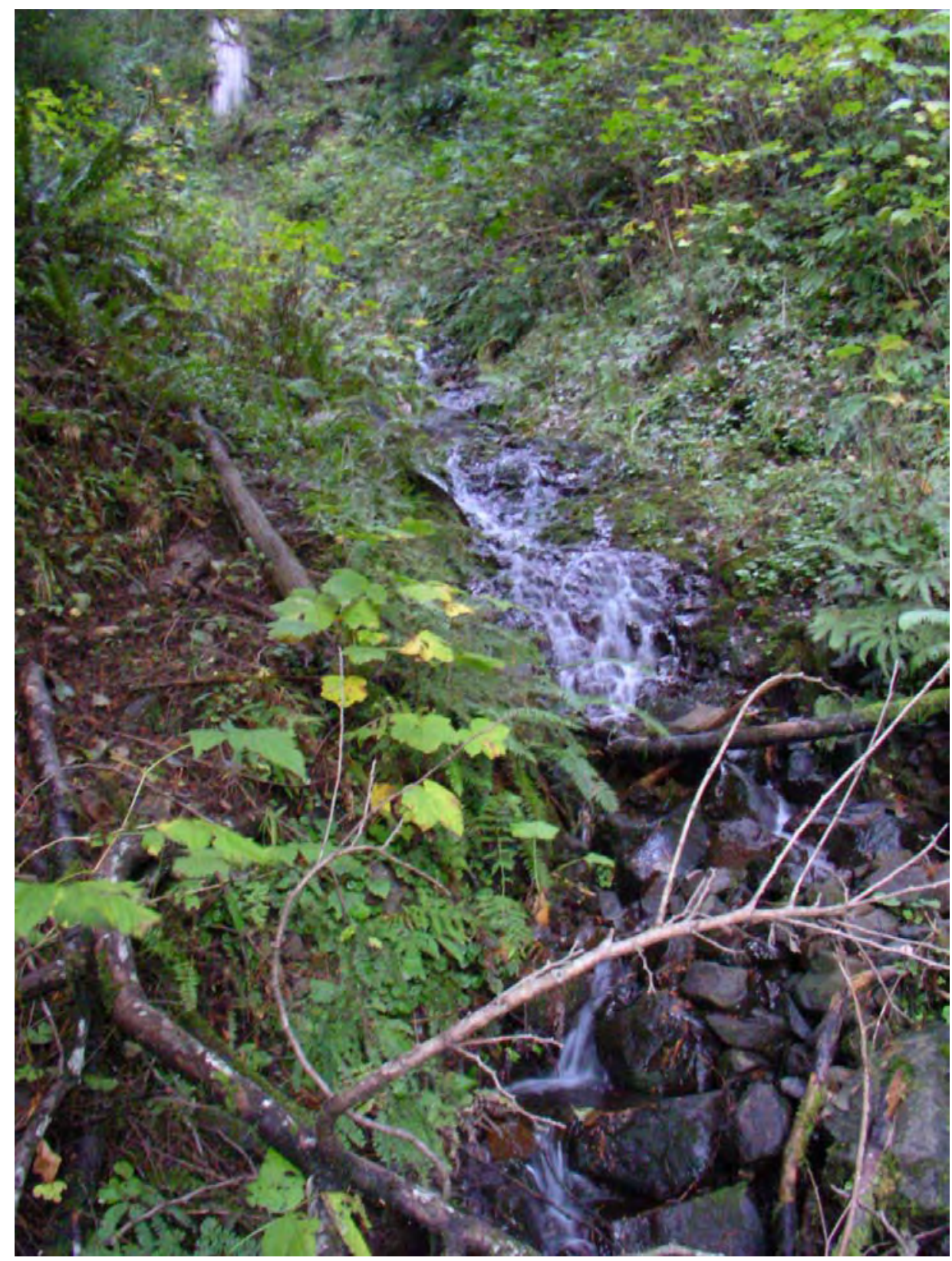

Photo CC-1-1. Survey reach CC-1 (October 27, 2004). Colluvial channel scoured to bedrock from historical debris flow. Angular cobbles form small fan deposit in the lower right part of photo. 



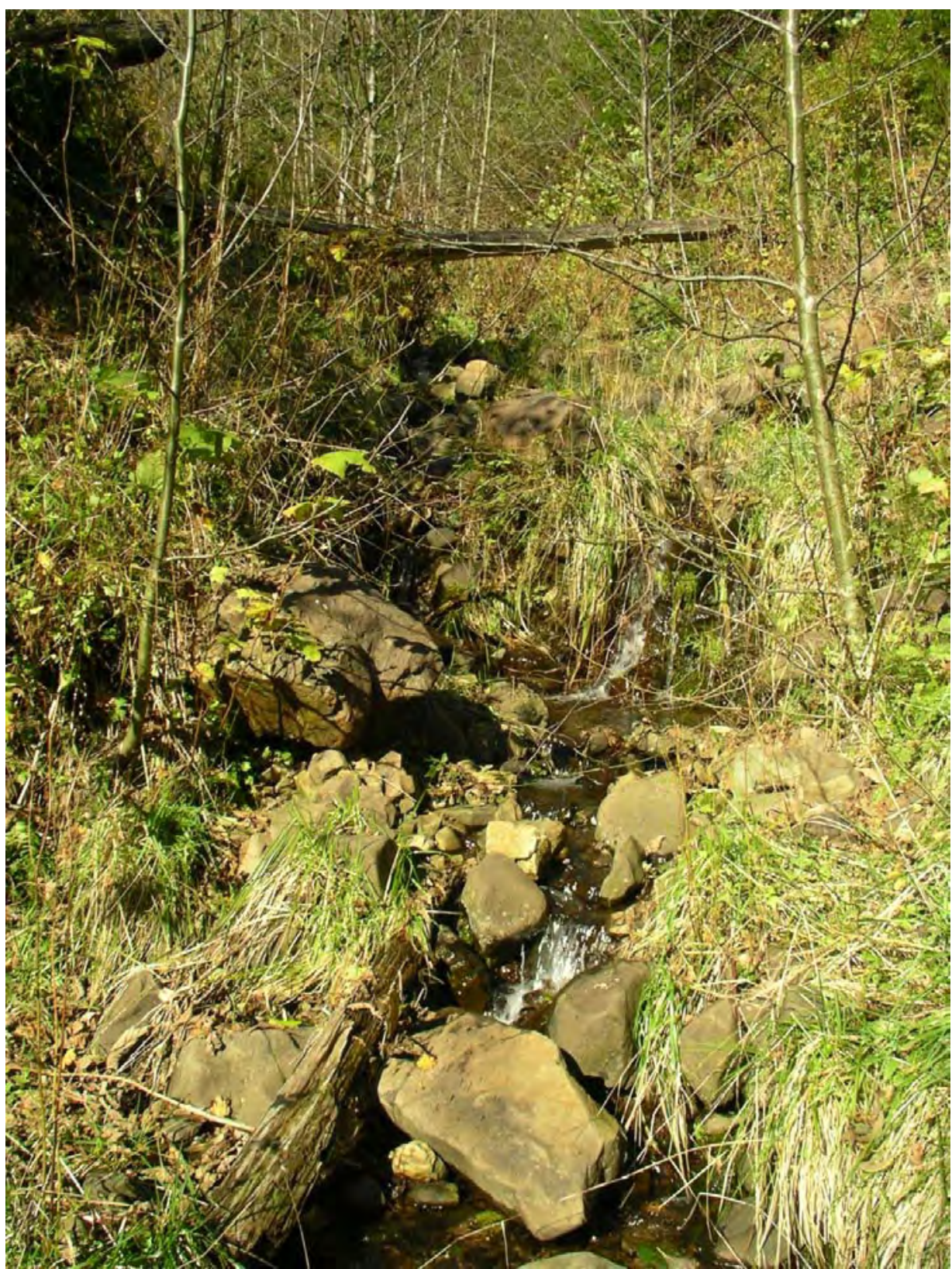

Photo CC-2-1. Survey reach CC-2 (October 27, 2004). Boulder cascade channel is incising into debris flow deposits from upstream. Channel substrate is mixed cobble and gravel between boulders. Stream banks are poorly sorted but little fine sediment is in the active channel indicating this fraction of the sediment load is rapidly transported downstream. 



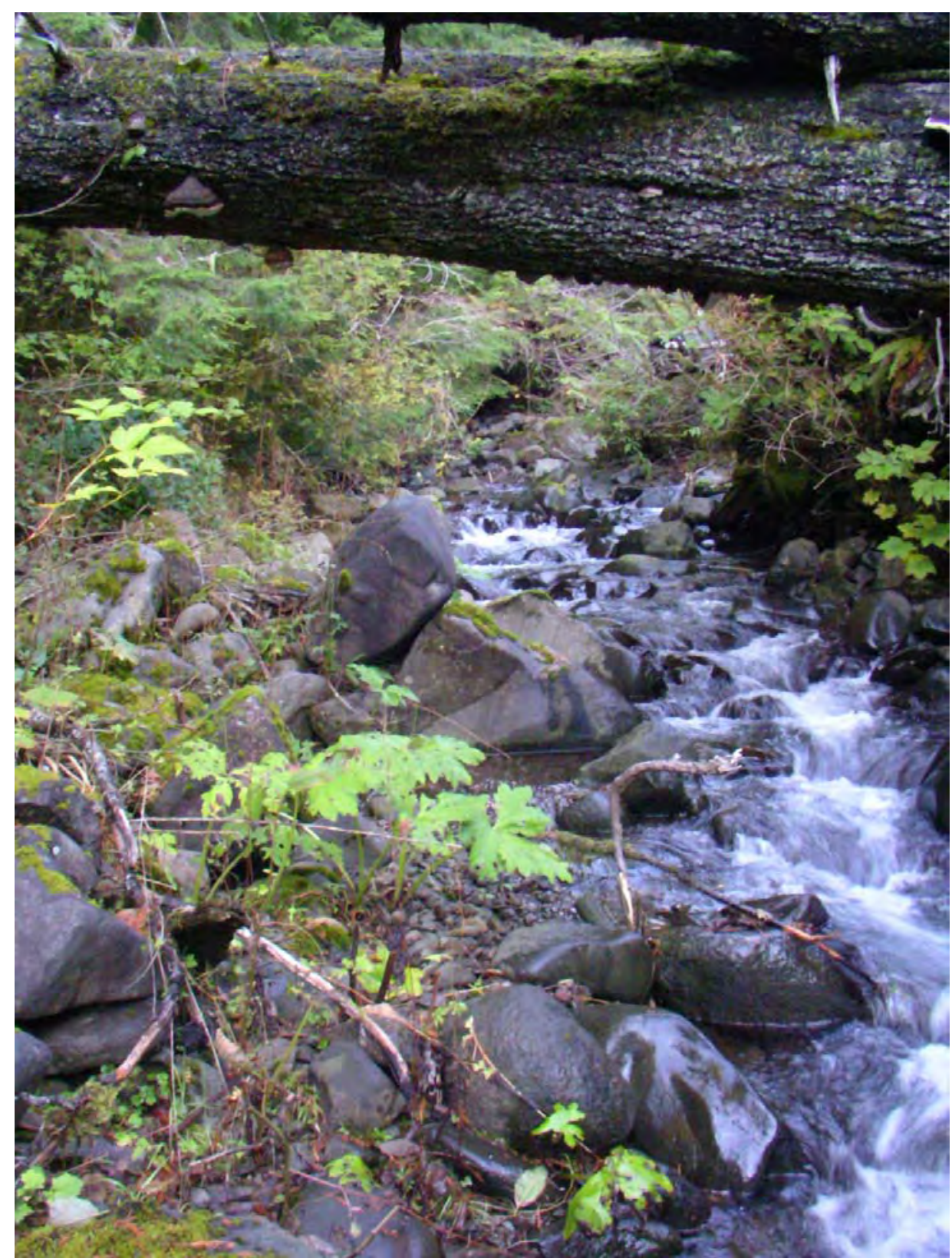

Photo HTC-1-1. Survey reach HTC-1 (October 27, 2004). Confined boulder-dominated, step-pool channel segment. 



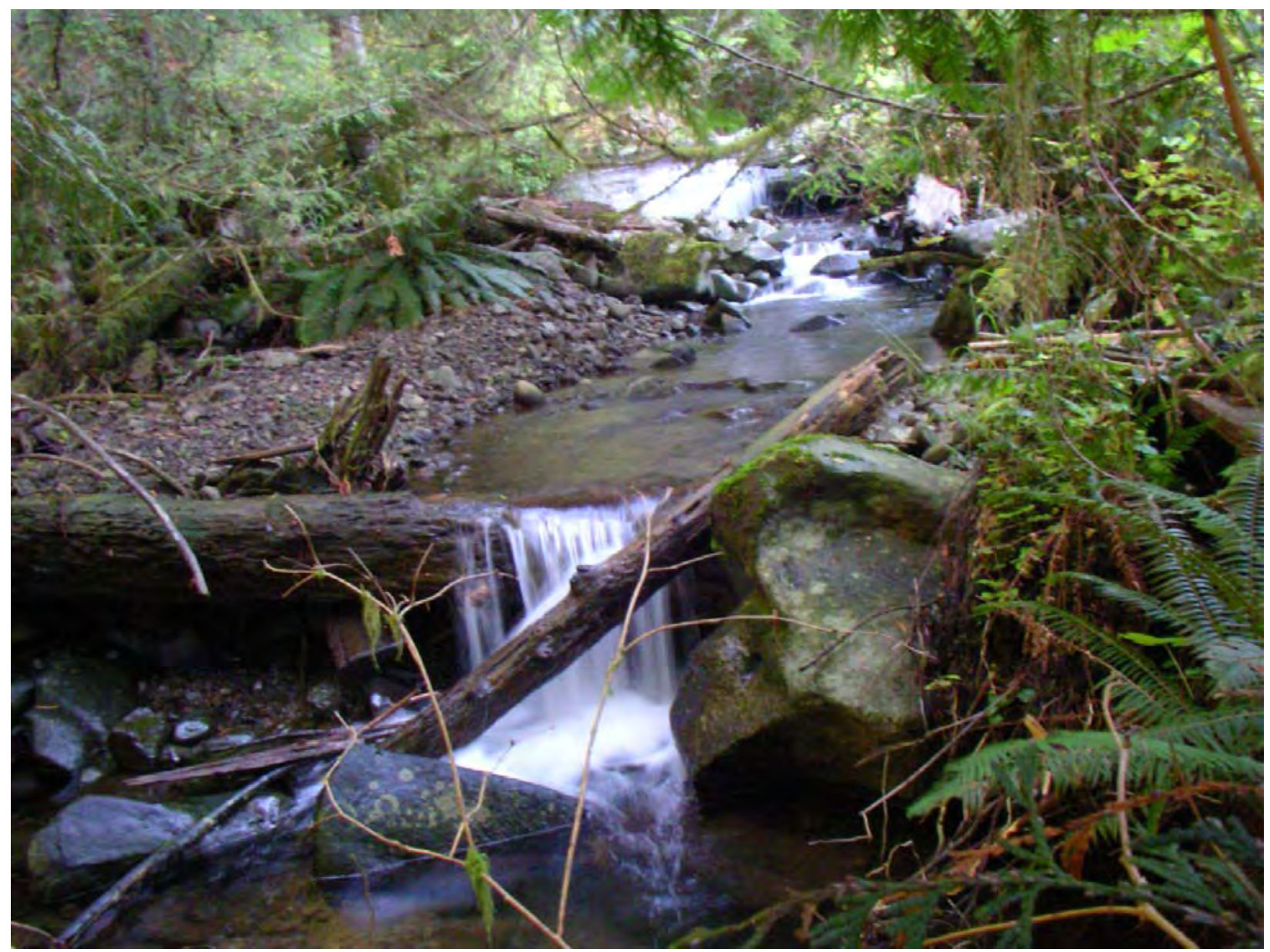

Photo HTC-1-2. Survey reach HTC-1 (October 27, 2004). Relic LWD providing grade control and sediment storage in confined step-pool channel. Extensive lateral bar deposits of cobble, sand and gravel in transport-dominated channel indicate high sediment loading. 



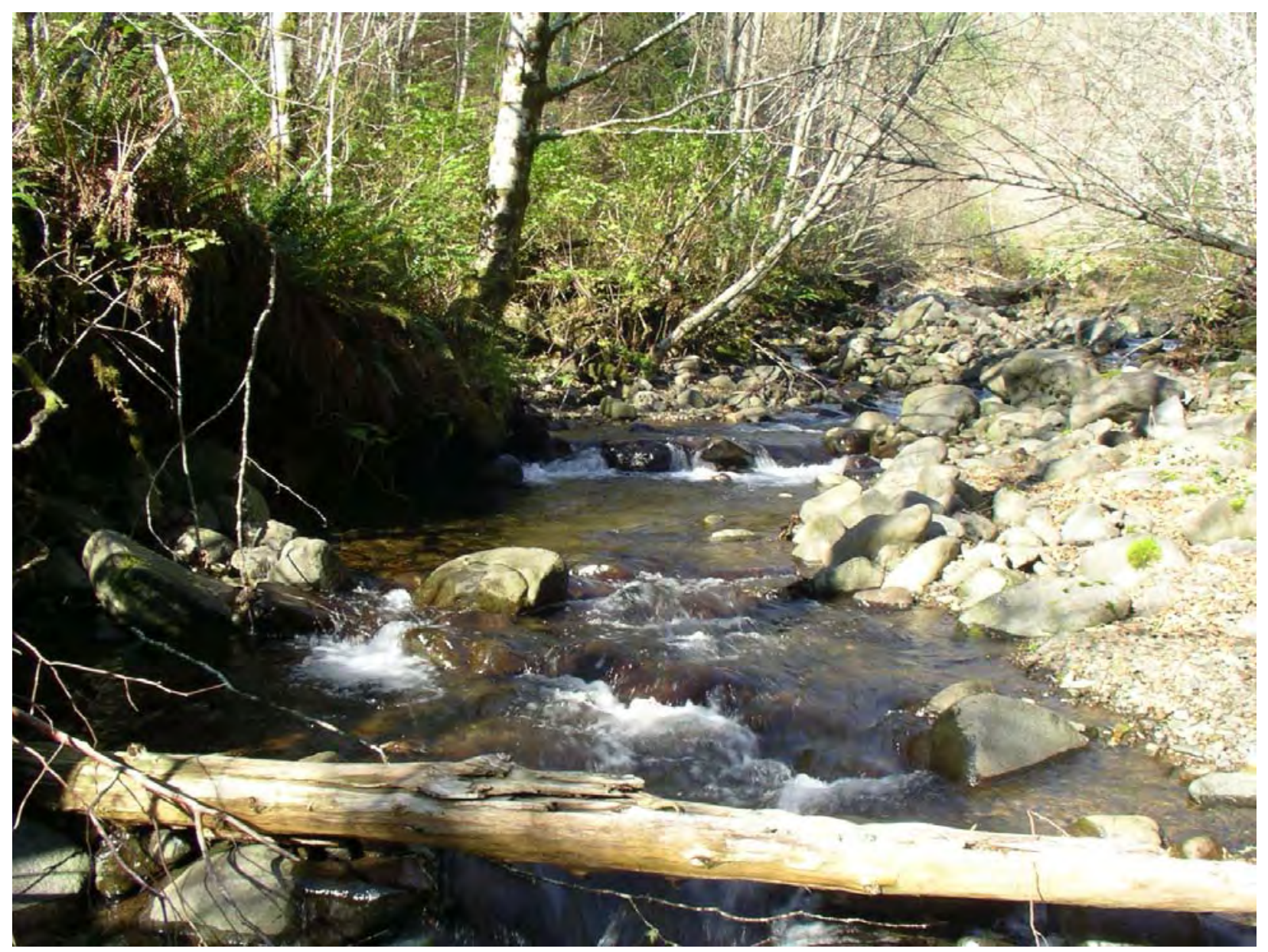

Photo HTC-2-1. Survey reach HTC-2 (October 27, 2004). Confined boulder step-pool channel. Channel substrate is predominantly cobble and boulders. Gravel substrate sediment covers approximately $10 \%$ of the active channel and is visible in a lateral bar deposit behind boulders at the right side of the photo (river left). Functional LWD is lacking in the reach and there is poor recruitment potential from the adjacent riparian forest. 



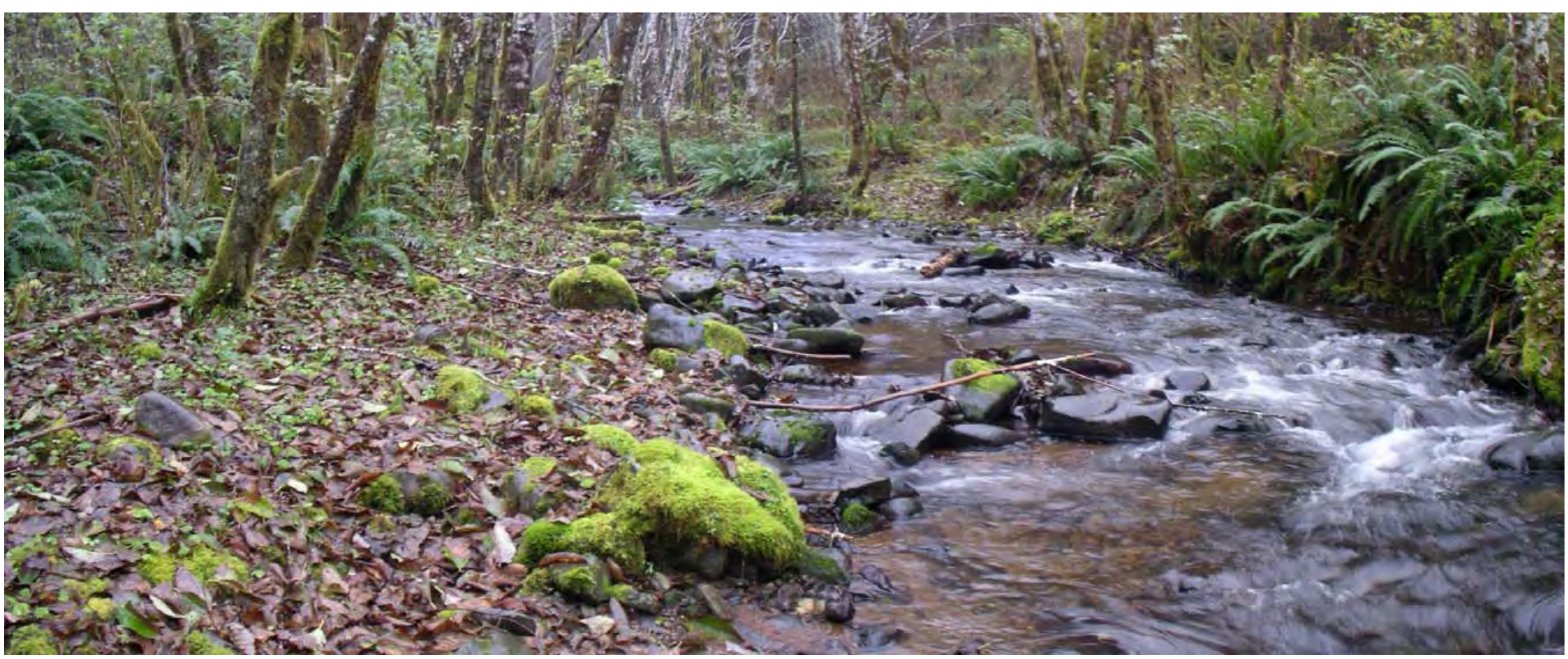

Photo TRC-1-1. Survey reach TRC-1 (October 28, 2004). Plane-bed channel of Cabin Creek. Channel is lacking functional LWD and adjacent riparian community of alders offers poor future recruitment potential. Significant fine sediments (silt to fine gravel) composed of marine siltstone blanket the substrate in this reach and are visible on the channel bed in the front center portion of the photograph. 



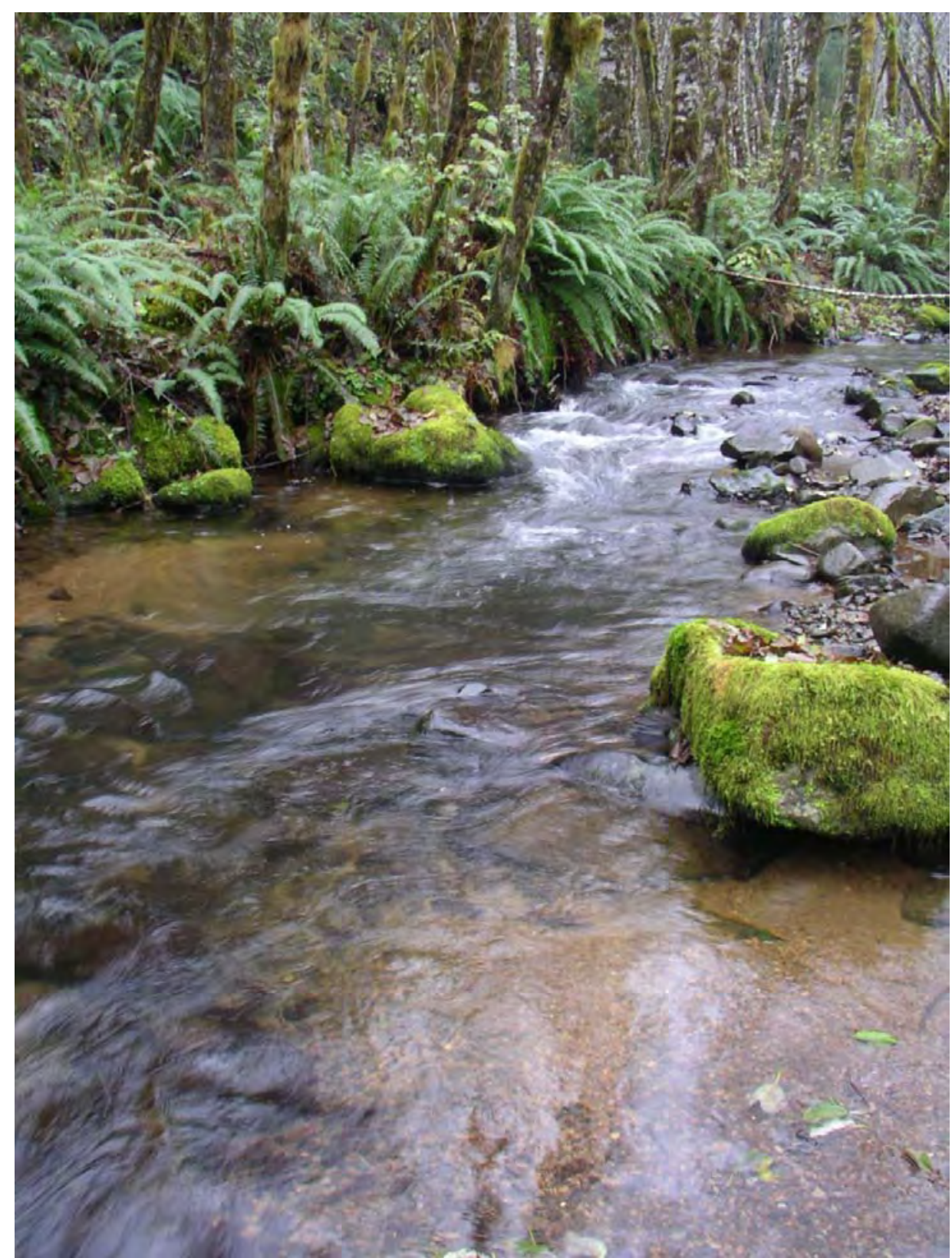

Figure TRC-1-2. Survey reach TRC-1 (October 28, 2004). Plane-bed reach of Cabin Creek with boulder steps. Deposits of loose fine sediments (silt to fine gravel) composed of marine siltstone are visible in lee areas behind boulders. These deposits covered approximately $40 \%$ of the active channel bed and were up to 0.5 meters deep. 



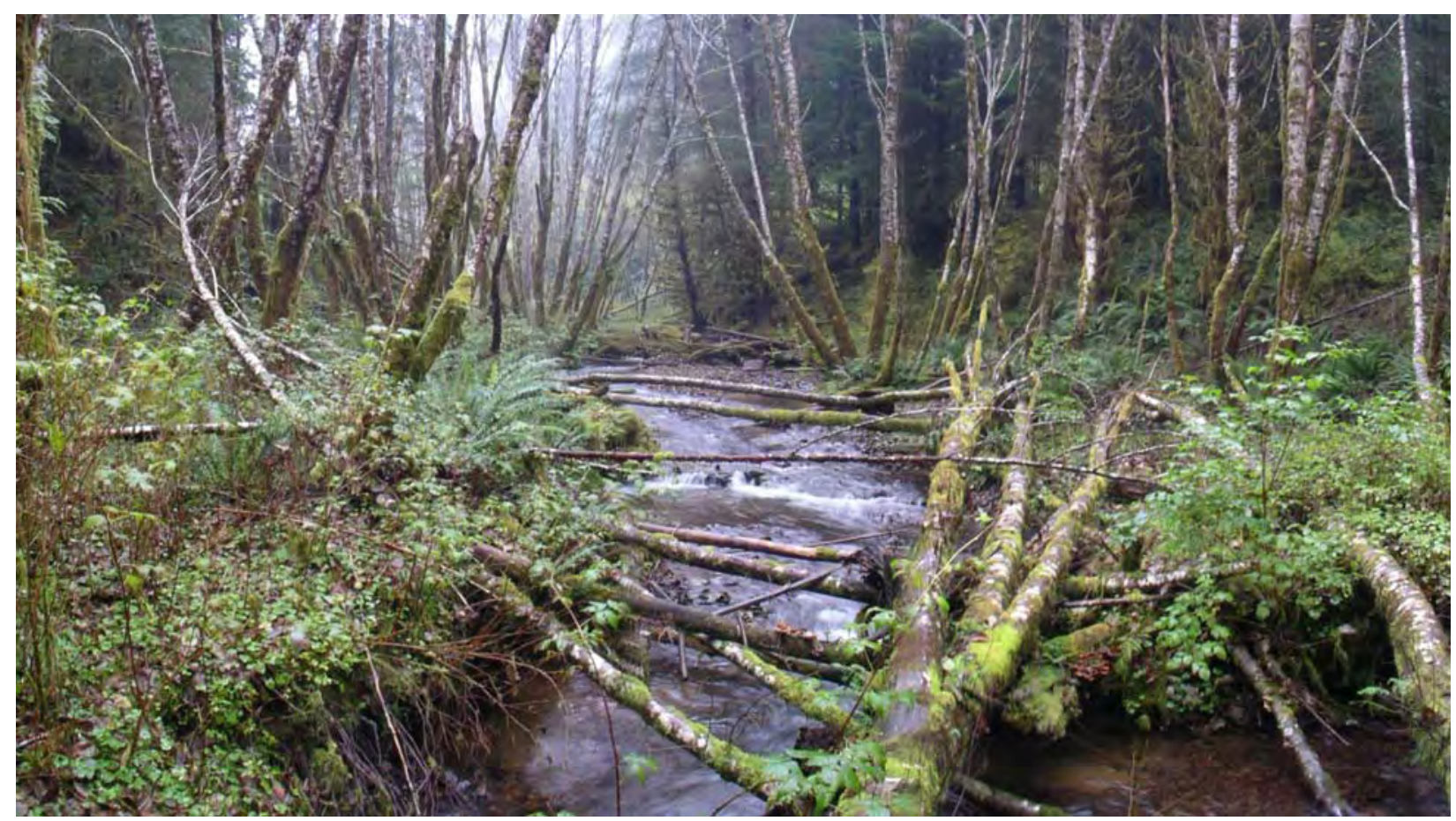

Photo TRC-2-1. Survey reach TRC-2 (October 28, 2004). Moderately confined plane-bed reach of Alder Creek. Channel instability is indicated by extensive vertical eroding banks and frequent recruitment of alders growing adjacent to the channel. The reach contains significant loose deposits of fine grained marine siltstone sediment which forms lateral and midchannel bars and covers approximately $25 \%$ of the active channel bed. 



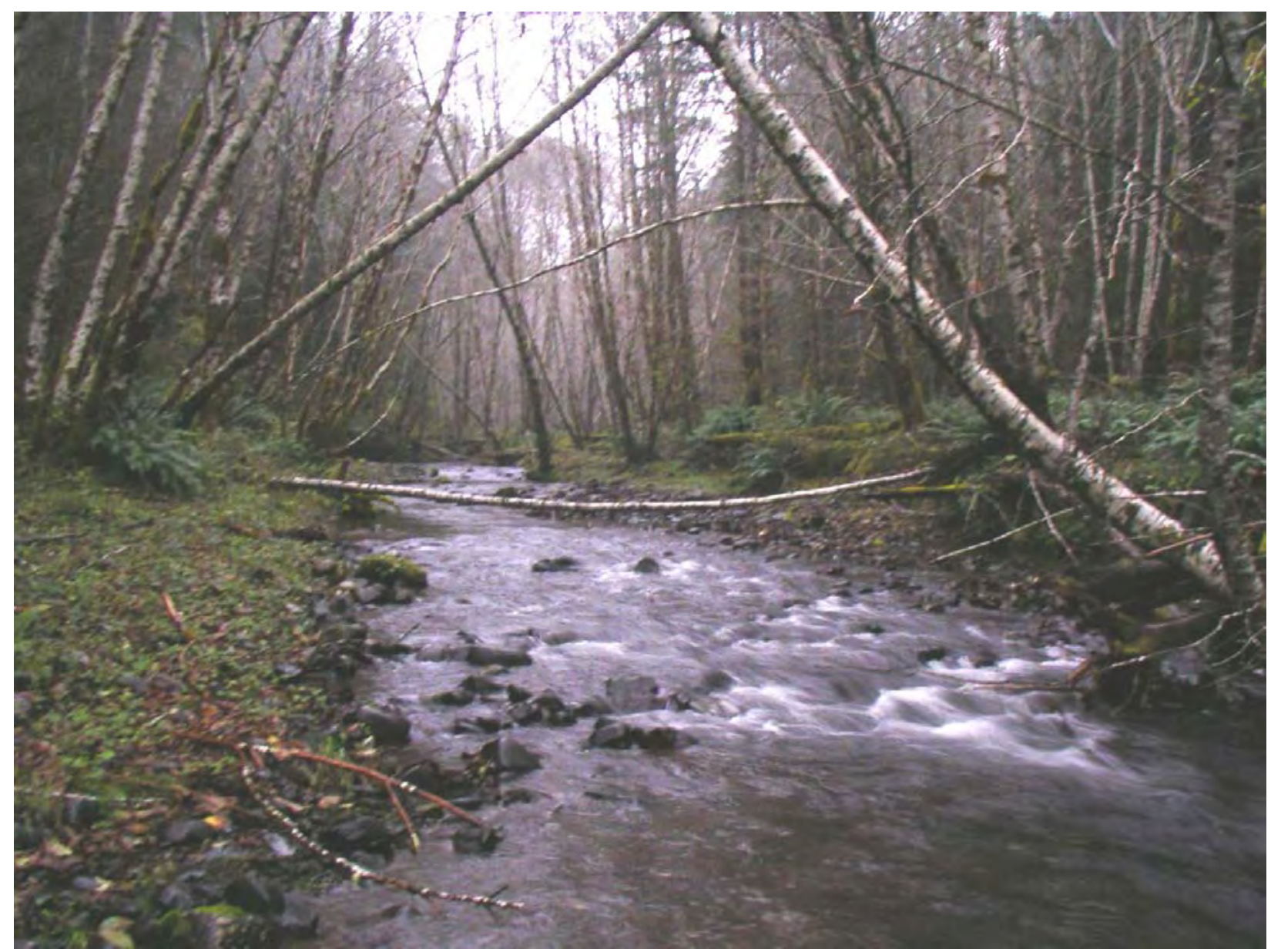

Photo TRC-3-1. Survey reach TRC-3 (October 28, 2004). Moderately confined plane-bed channel of Mitchell Creek. Channel is primarily gravel and cobble bedded. Banks generally appeared stable but undercut alders at the channel margins indicate local erosion and widening. Channel contains little hydraulic complexity and there are few opportunities for sediment storage in the active channel. There was no functional LWD observed in the surveyed reach and the alder-dominated riparian forest provides poor recruitment potential. 



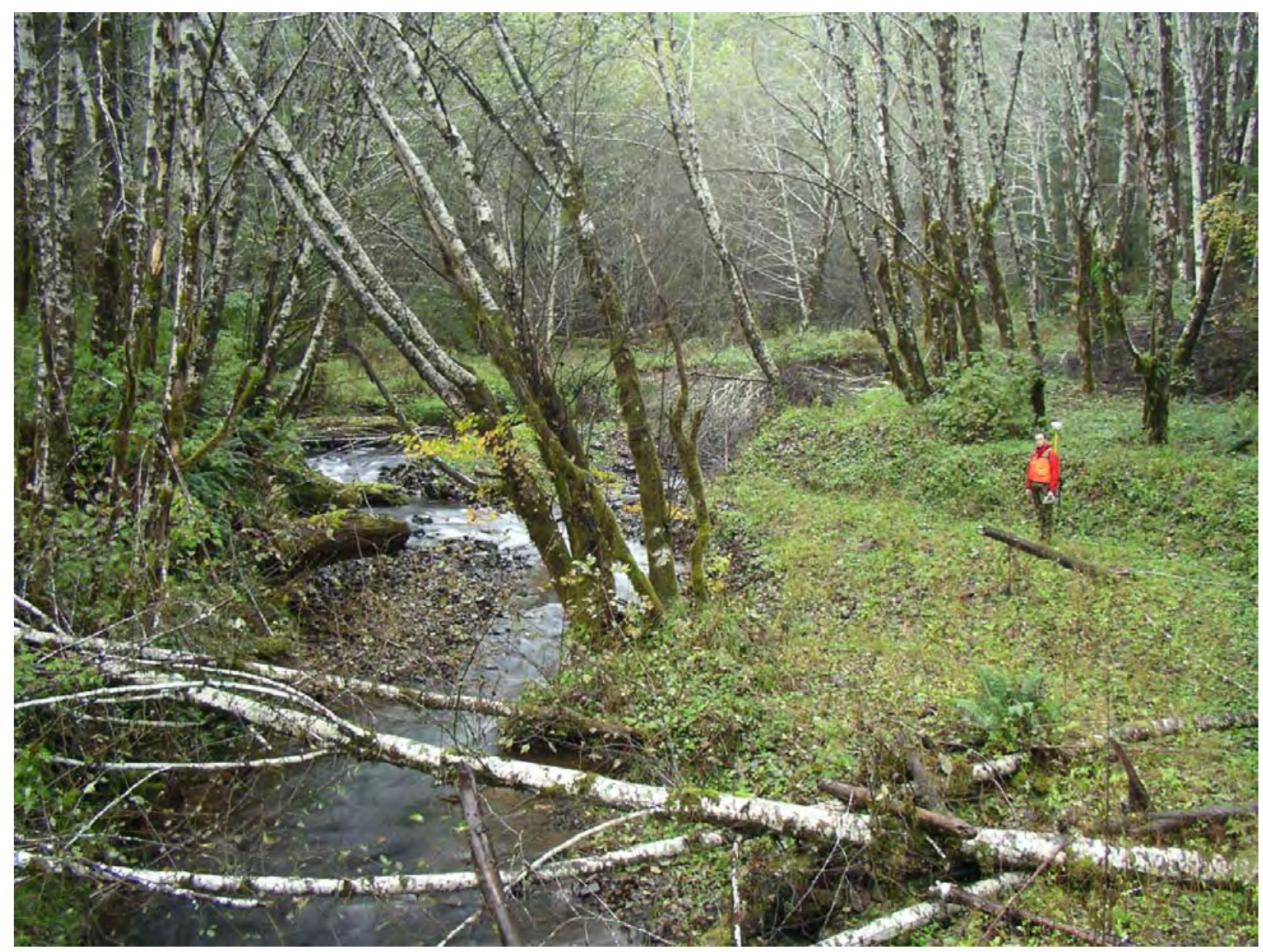

Photo TRC-4-1. Survey reach TRC-4 (October 28, 2004). Confined plane-bed reach. Flow is towards camera. Channel bed is predominantly cobble bedded with gravel and boulders. Inset floodplain surfaces indicate a previous period of channel widening and aggradation. Person at right is standing on inset floodplain surface. Eroding banks, and undercut and locally recruited riparian vegetation indicate continued lateral instability. Vertical instability, and further downcutting, is suggested by exposure of buried relic LWD at the base of the inset floodplain surface. The channel contains large bars and moderate fine sediment loading was apparent in low-energy depositional zones. 



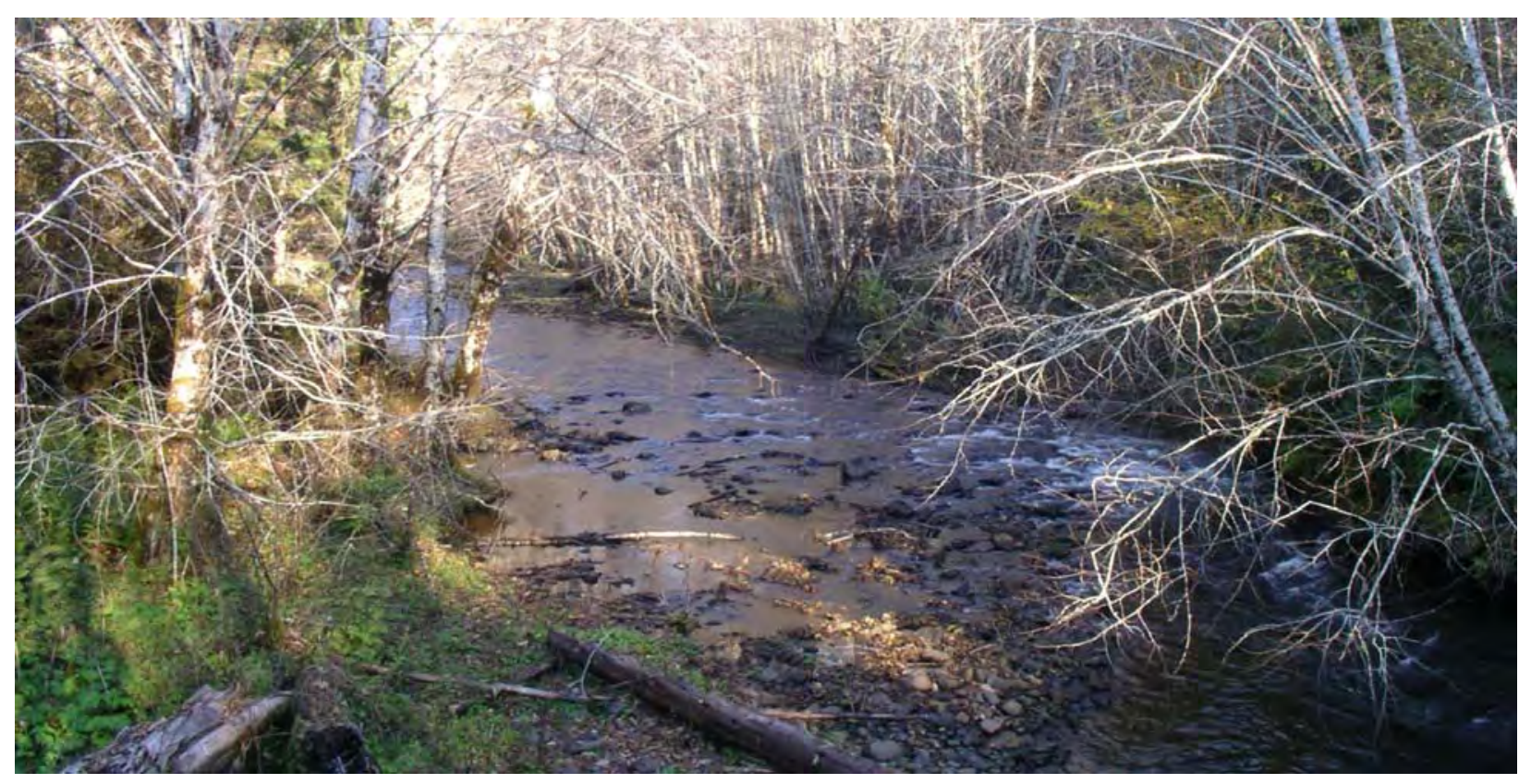

Photo EGR-1-1. Survey reach EGR-1 (October 27, 2004). Plane-bed morphology in the East Fork Grays River. Channel substrate is predominantly gravel and cobble. No functional LWD was encountered in the 500-meter survey reach and there is limited recruitment potential from the adjacent riparian forest. 



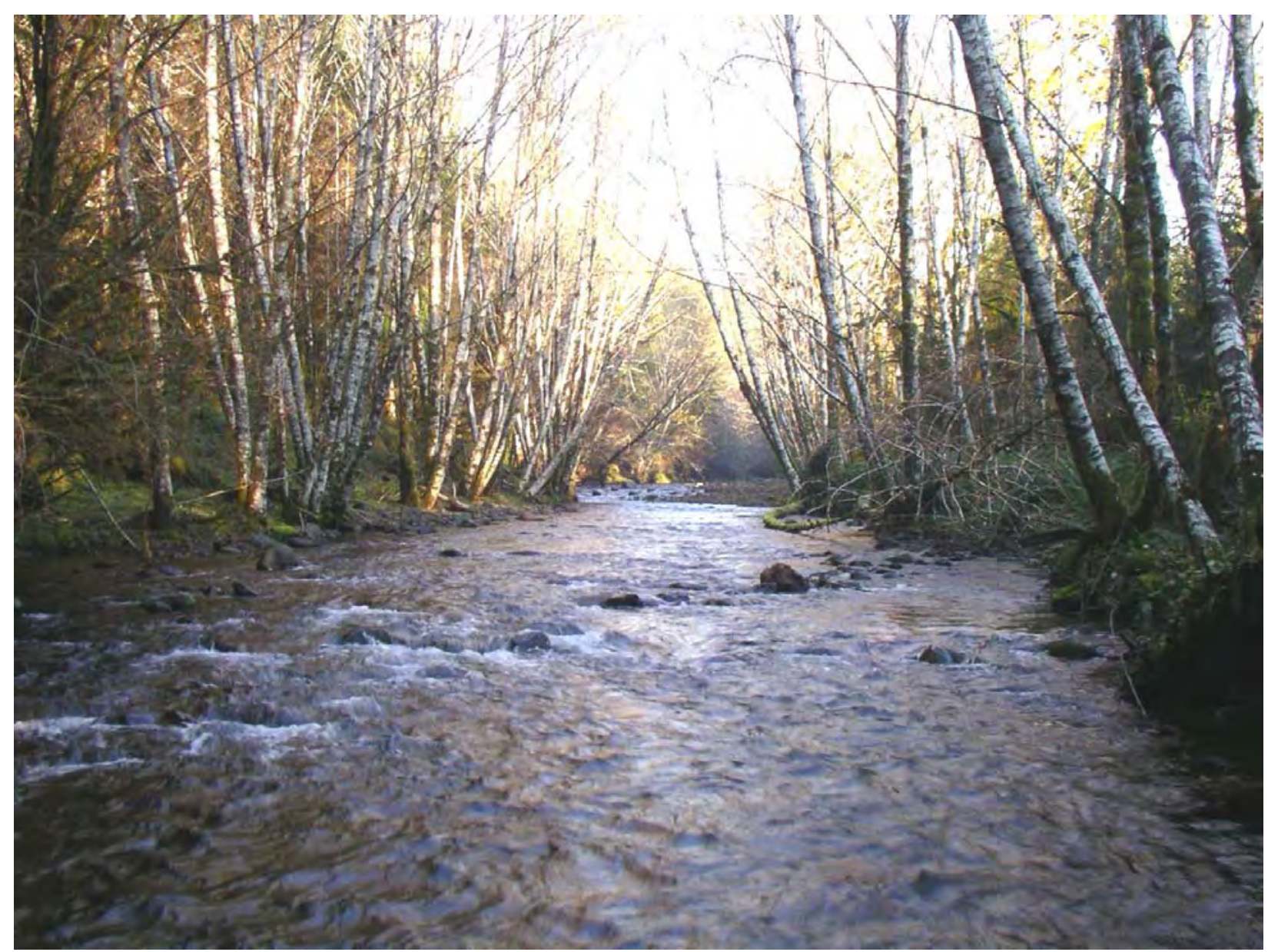

Photo EGR-1-2. Survey reach EGR-1 (October 27, 2004). Looking downstream at planebed morphology in the East Fork Grays River. This photo illustrates the lack of channel complexity and limited recruitment potential from the adjacent riparian forest. 



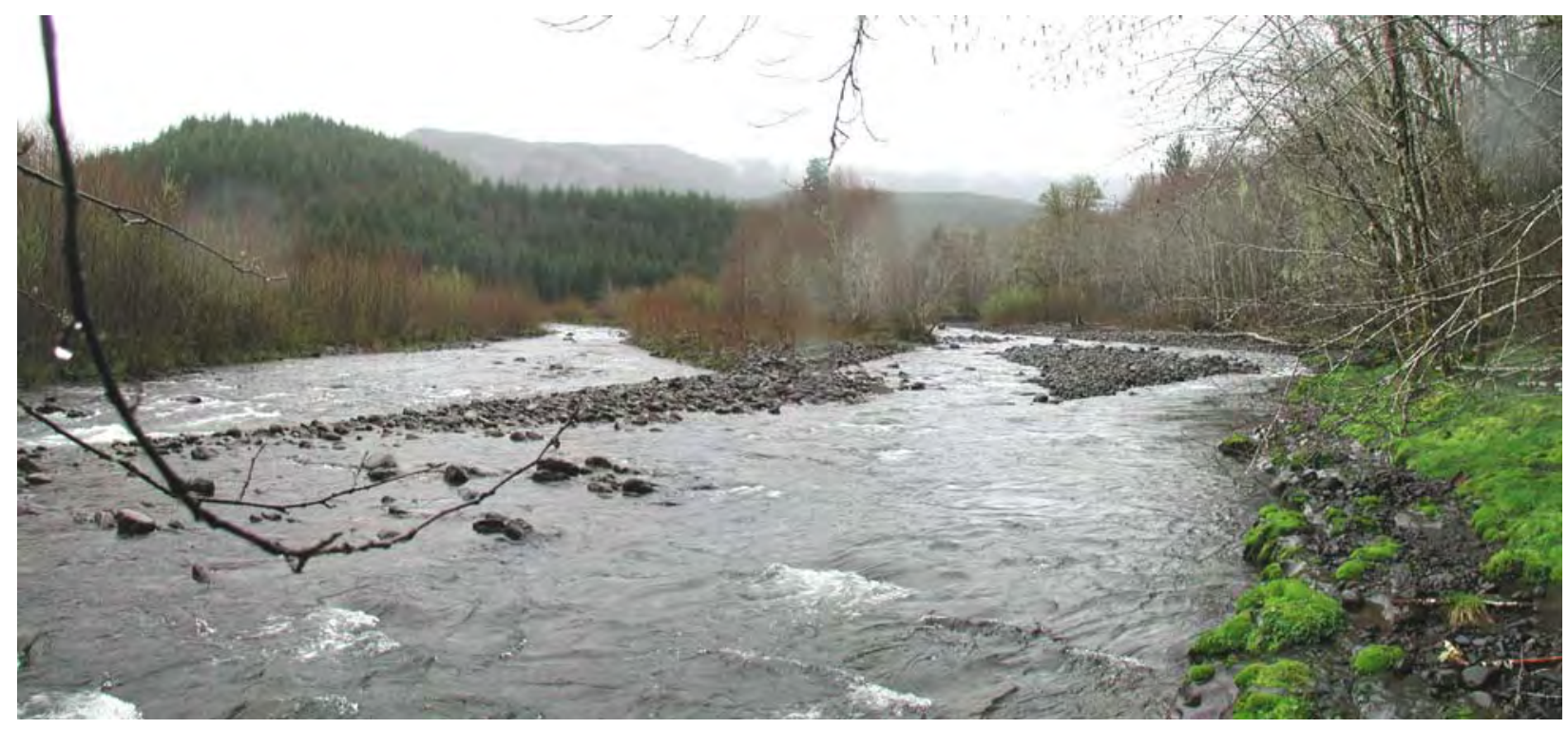

Photo SGR-1-1. Survey reach SGR 1 (March 24, 2004). Bifurcated cobble bedded planebed channel at the upstream end of the survey reach. Little LWD was observed in the reach and the adjacent riparian forest dominated by alders provides little recruitment potential.

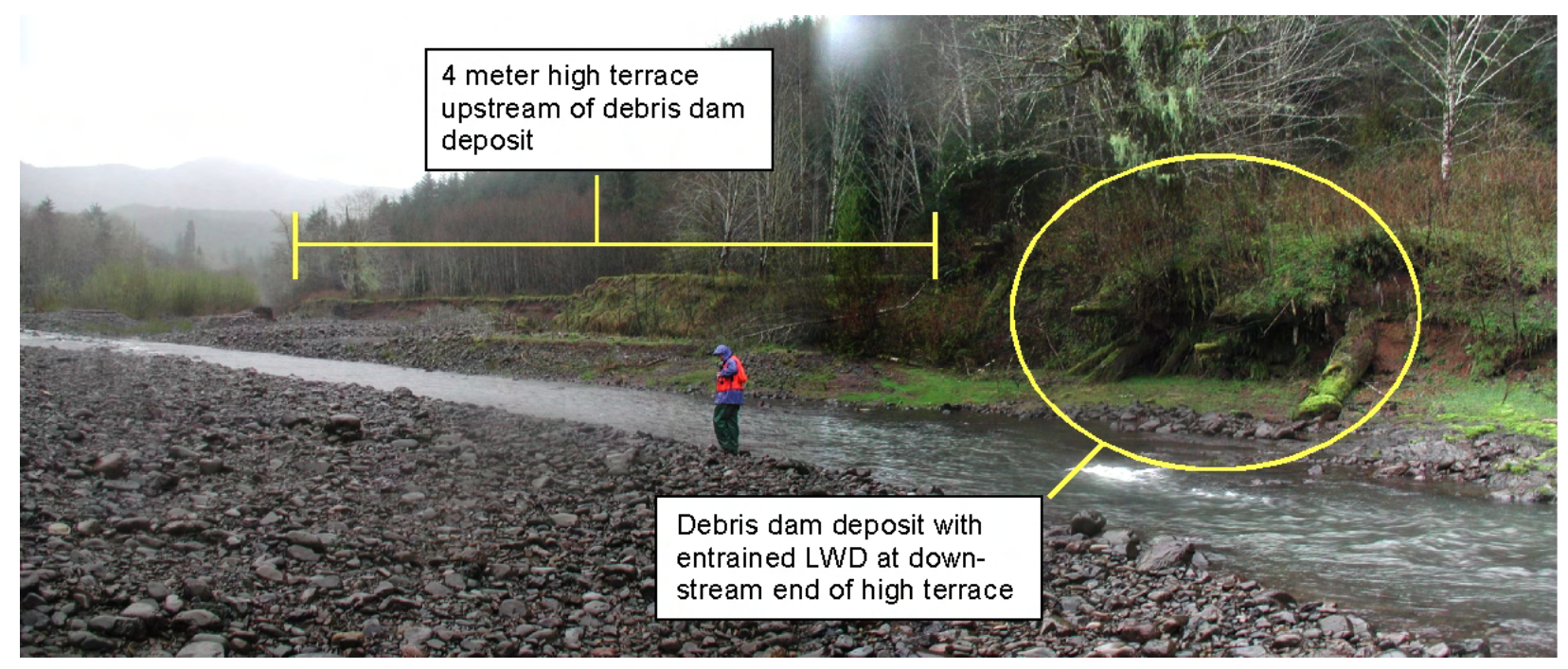

Photo SGR-1-2. Survey reach SGR 1 (March 24, 2004). Remnant of a debris dam with entrained LWD is visible in the lower right portion of the photo. A 4 meter high terrace formed behind the debris dam. Radiocarbon dating of LWD from the debris dam deposit and from wood deposited $1 \mathrm{~m}$ below the top of the terrace surface indicates that the terrace began forming between 215 and 335 years ago (275 years before present $+/-60$ years) and deposition continued through at least 145 and 265 years ago (205 years before present $+/$ - 60 years). 



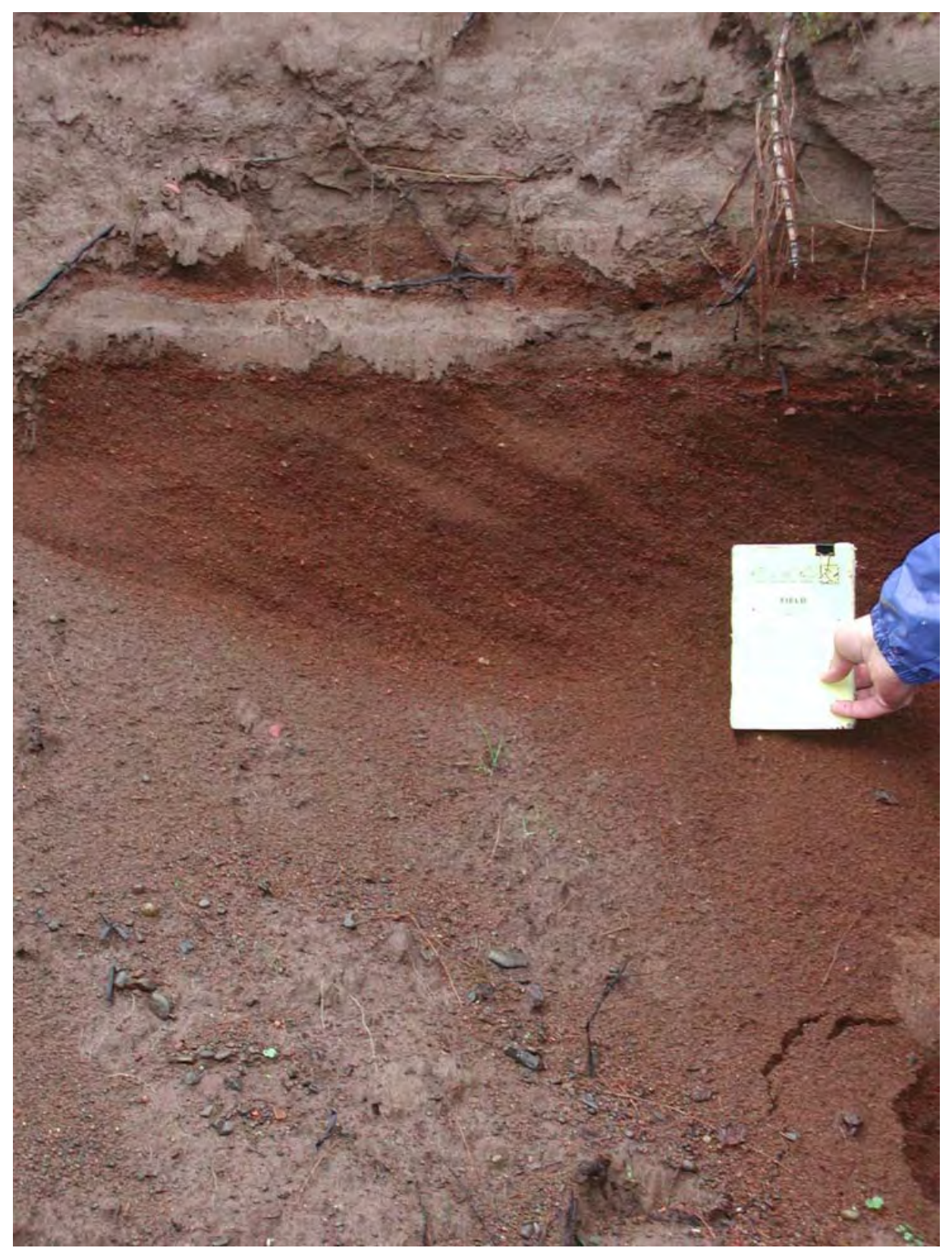

Photo SGR-1-3. Survey reach SGR 1 (March 24, 2004). Foreset beds of sand are evidence of a prograding depositional environment and silt layers indicate periods of low energy deposition. 



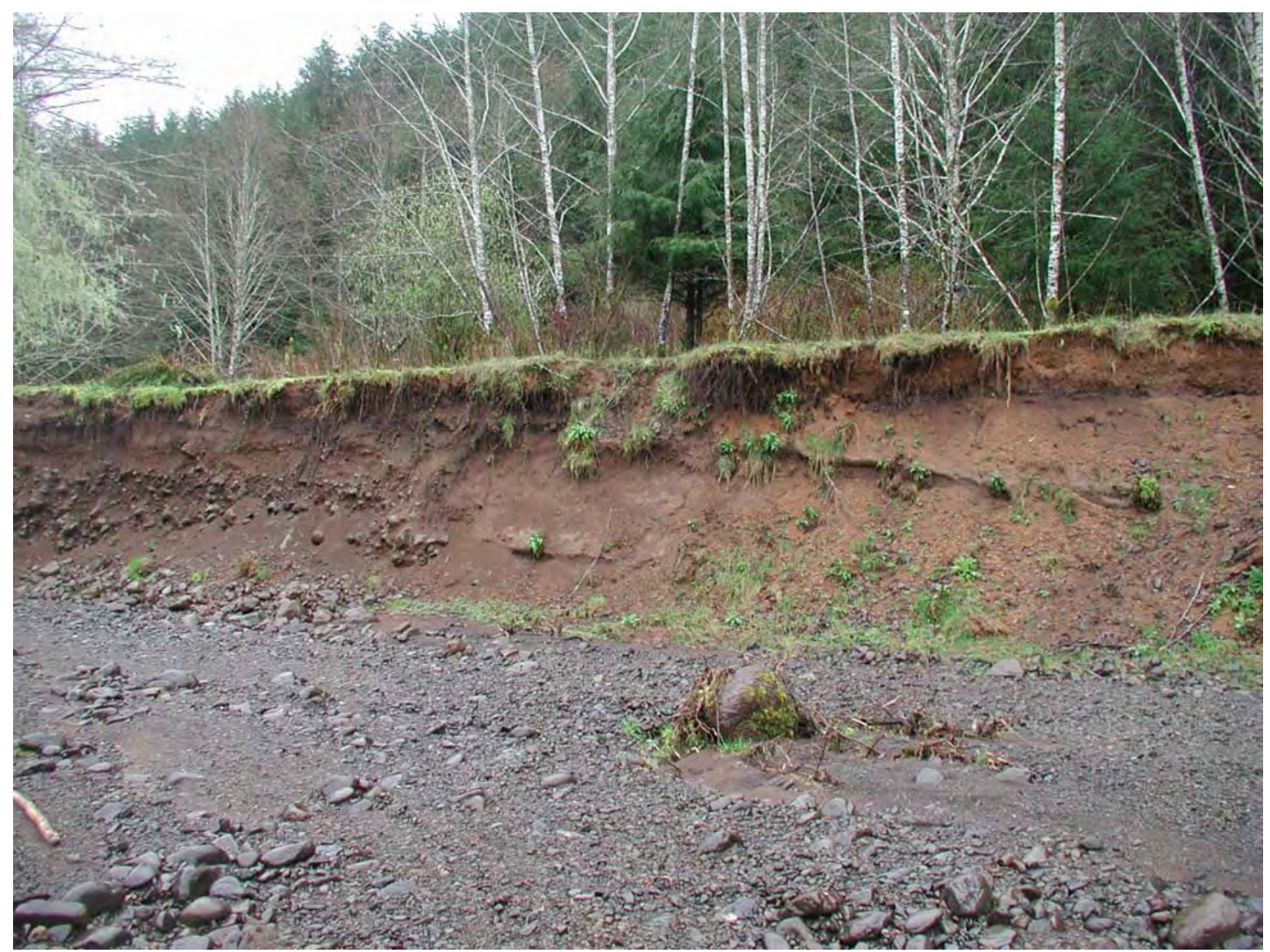

Photo SGR-1-4. Survey reach SGR 1 (March 24, 2004). Coarse grained alluvial sediment visible in the terrace deposit at the right edge of the photo occurs within the upstream portion of the terrace representing a higher energy depositional environment. 



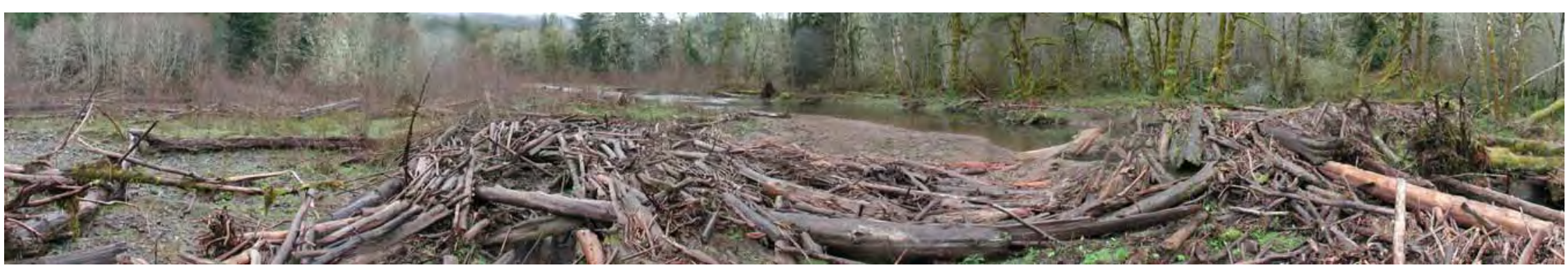

Photo SGR-2-1. Survey reach SGR 2 (March 24, 2004). Valley jam on the South Fork Grays River. Jam is approximately $50 \mathrm{~m}$ wide and creates a $1.5 \mathrm{~m}$ step in the channel profile. Jam provides significant fine and coarse sediment storage and generates a steep hydraulic gradient between main stem channels.

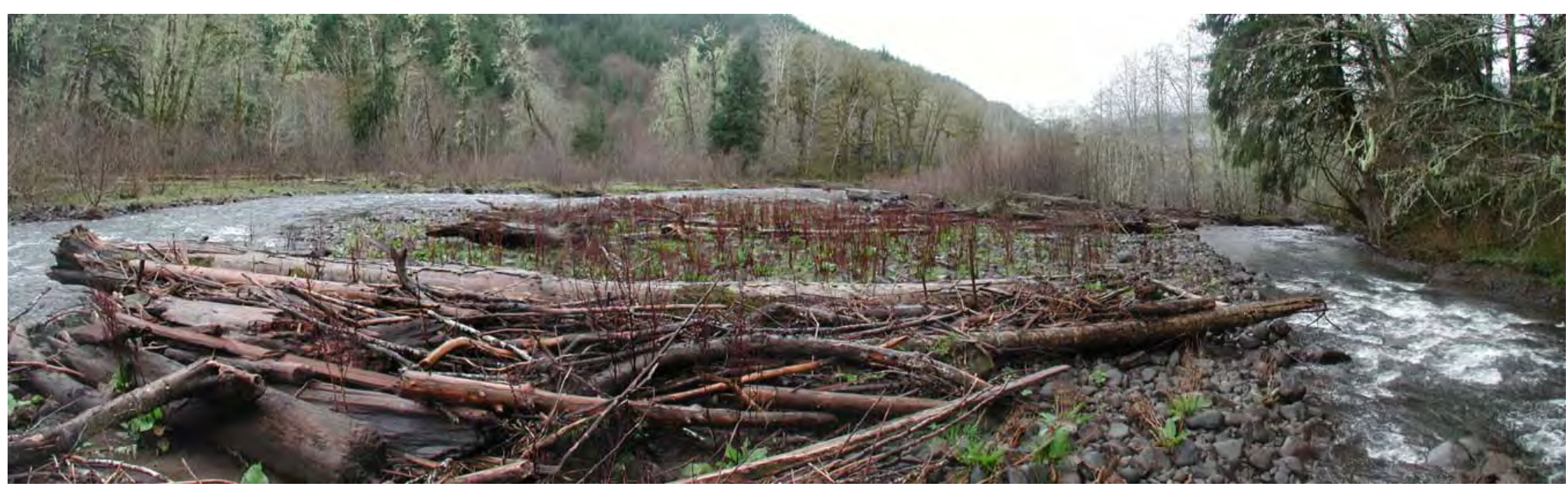

Photo SGR-2-2. Survey reach SGR 2 (March 24, 2004). Looking downstream over a gravel and cobble bar from the upstream end of the survey reach. The gradient of the channel at left is more moderate than the right channel creating a hydraulic gradient, from left to right, across the bar between the channels. 



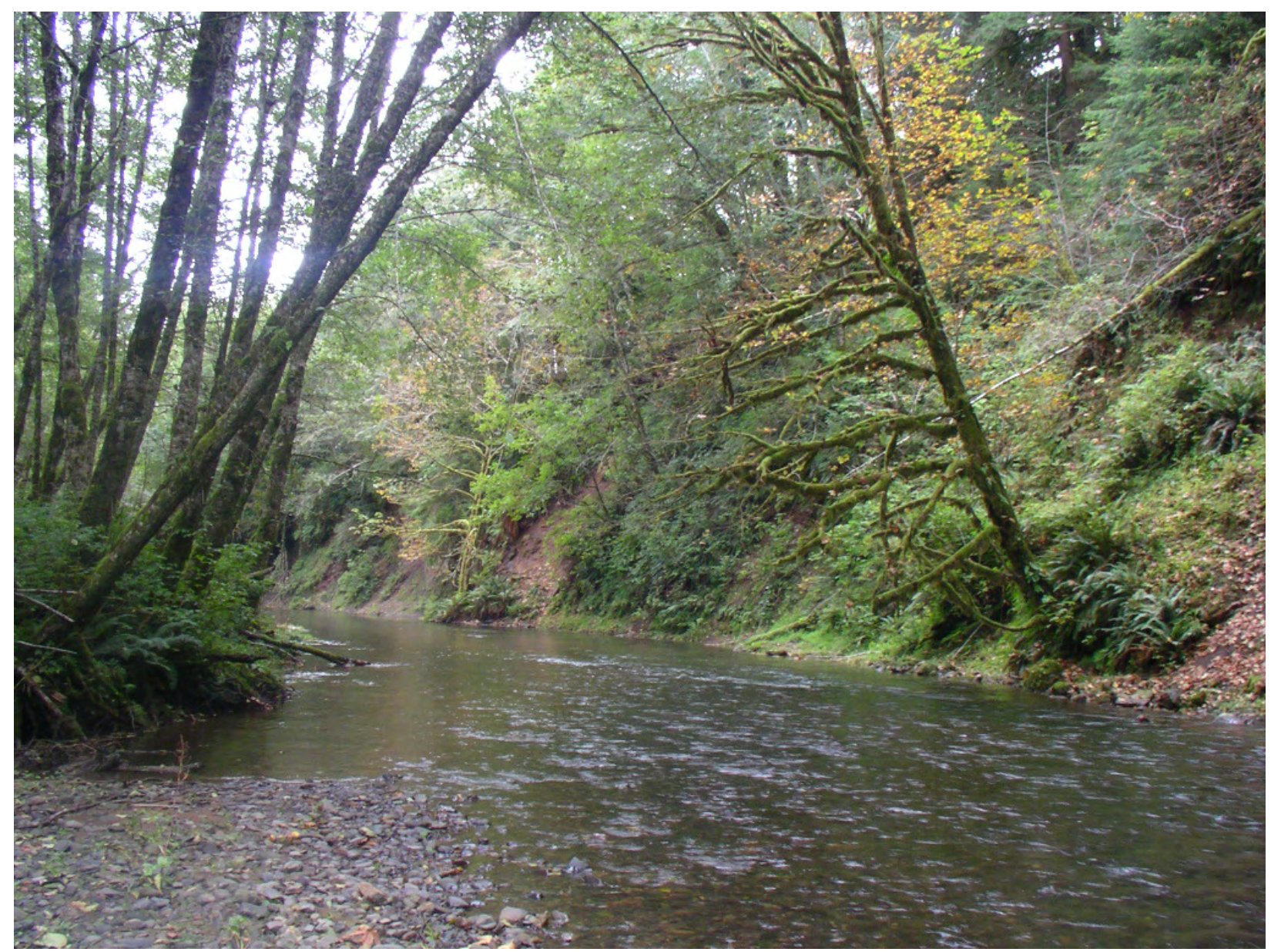

Photo WGR-1-1. Survey reach WGR 1: (September 22, 2004). Gravel and cobbled bedded plane-bed reach of the West Fork Grays River. The lower $1.25 \mathrm{~km}$ of the West Fork contains low wood loading and little channel complexity. The riparian community adjacent to the West Fork is typically alder dominated and provides poor recruitment potential. The channel is confined against marine sedimentary bedrock at the floodplain margin through much of the survey reach. Recruitment potential is locally moderate with occasional mature conifers adjacent to the current channel alignment. The alder dominated forest visible at photo left is typical of the adjacent riparian community. 



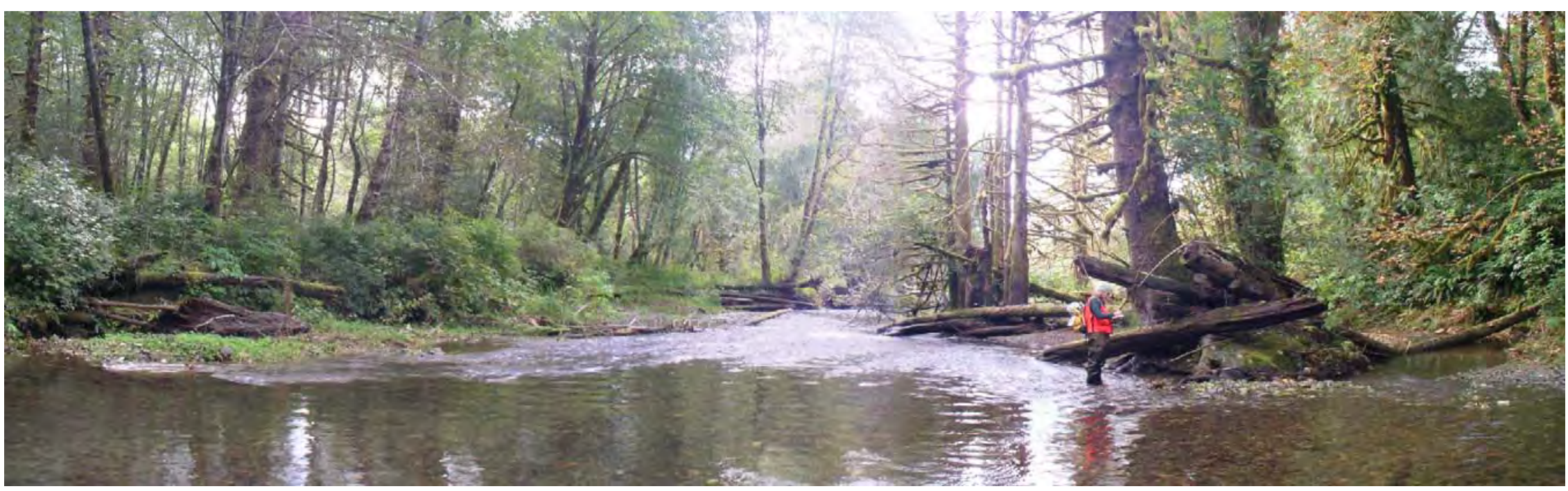

Photo WGR-2-1. Survey reach WGR 2: GPS 44-59 (September 22, 2004). Gravel bedded pool riffle reach of the West Fork Grays River. Recruitment potential is locally moderate with occasional mature conifers adjacent to the current channel alignment. The alder dominated forest visible in the back ground is typical of the adjacent riparian community.

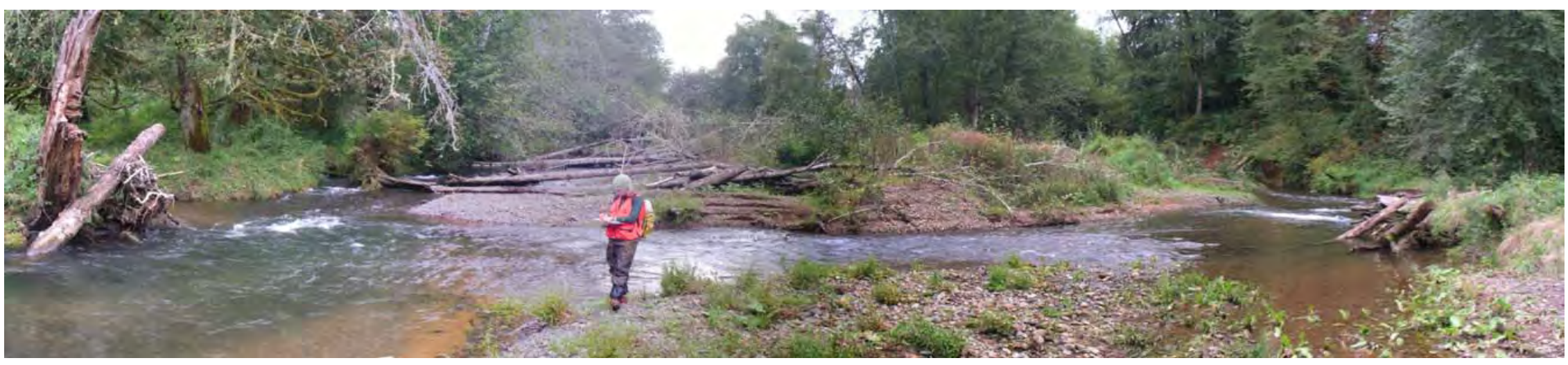

Photo WGR-2-2. Survey reach WGR 2: GPS 44-59 (September 22, 2004). Bifurcated gravel bedded pool-riffle reach in the West Fork Grays River. Moderate LWD loading provides local hydraulic complexity. Riparian forests of alders generally provide low LWD recruitment potential. Visible large mid-channel bars and fine sediment deposition in low-energy zones are indicative of high sediment loading that was observed. 



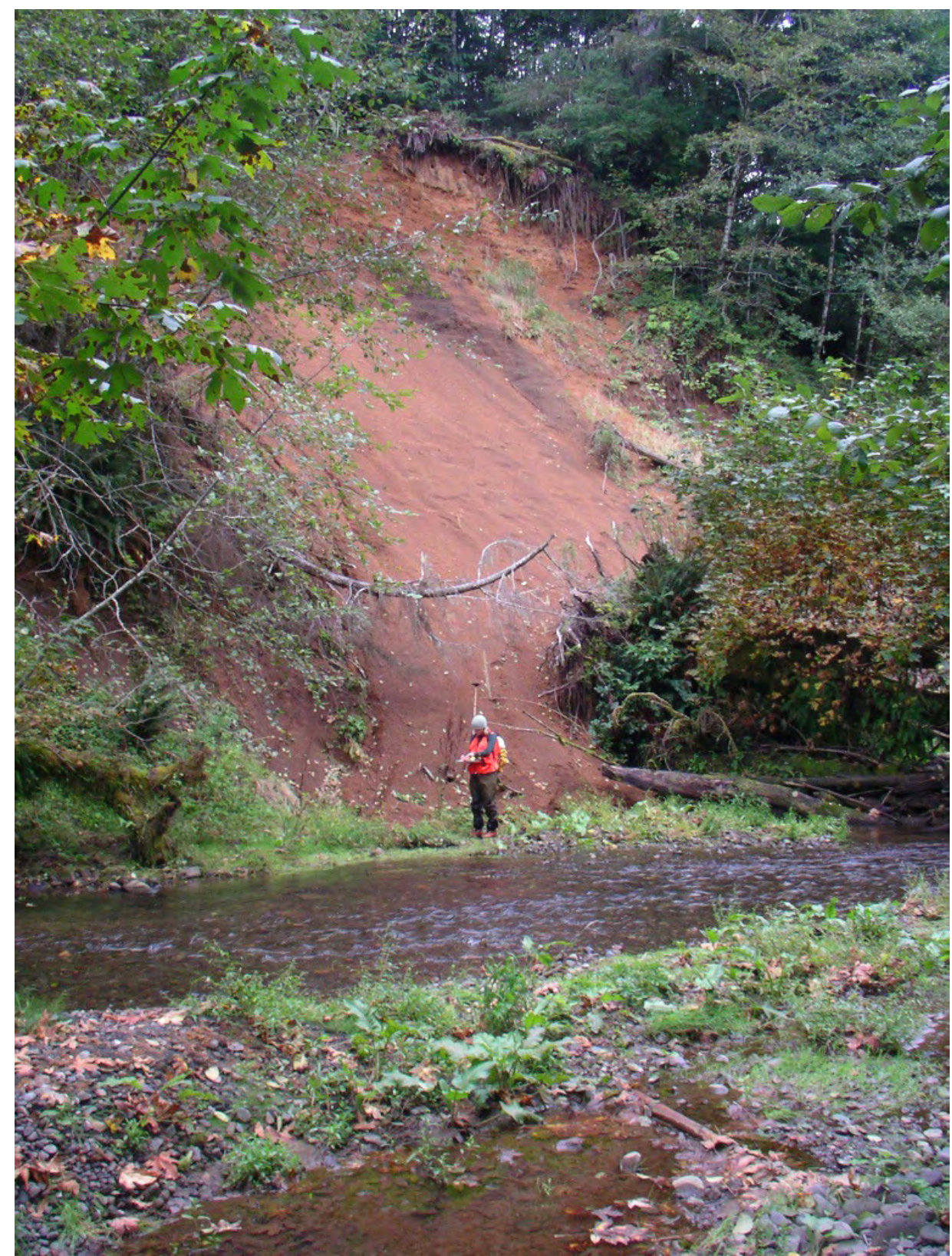

Photo WGR-2-3. Survey reach WFGR 2: GPS 44-59. (September 22, 2004). Erosional scar in weak marine sedimentary rocks at the left edge of the West Fork Grays River floodplain. The lack of mass wasting deposits at the base of the feature indicates total delivery from the sediment source to the channel network. Bedrock erosion at the floodplain margin was observed frequently in the West Fork Grays River. 



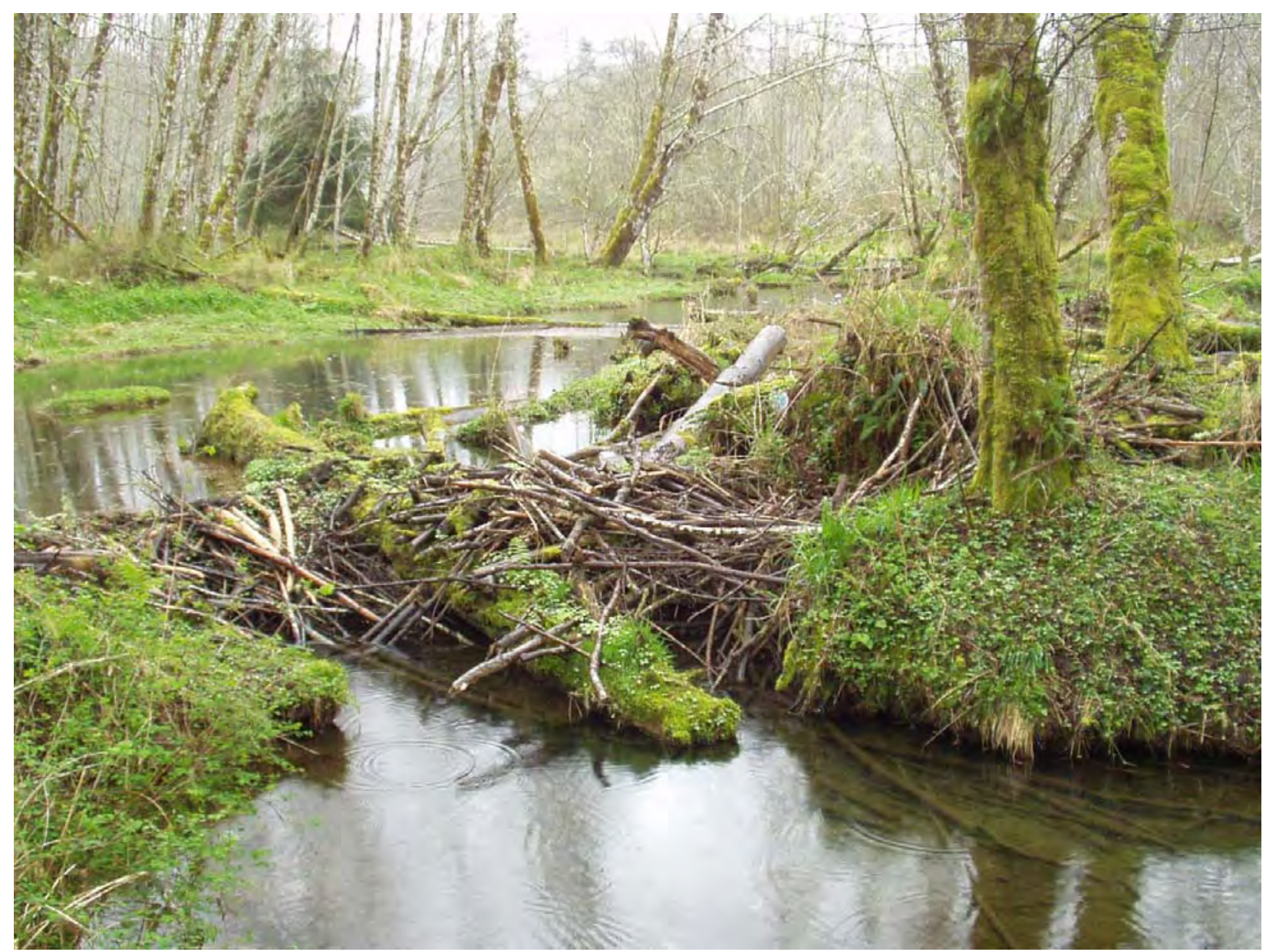

Photo CJ-1-1. Survey reach CJ-1 (March 23, 2004). Beaver dam integrated into LWD in gravel and sand bedded low-gradient floodplain channel of Crazy Johnson Creek. Upwelling was observed in the floodplain channel downstream of similar beaver ponds. 



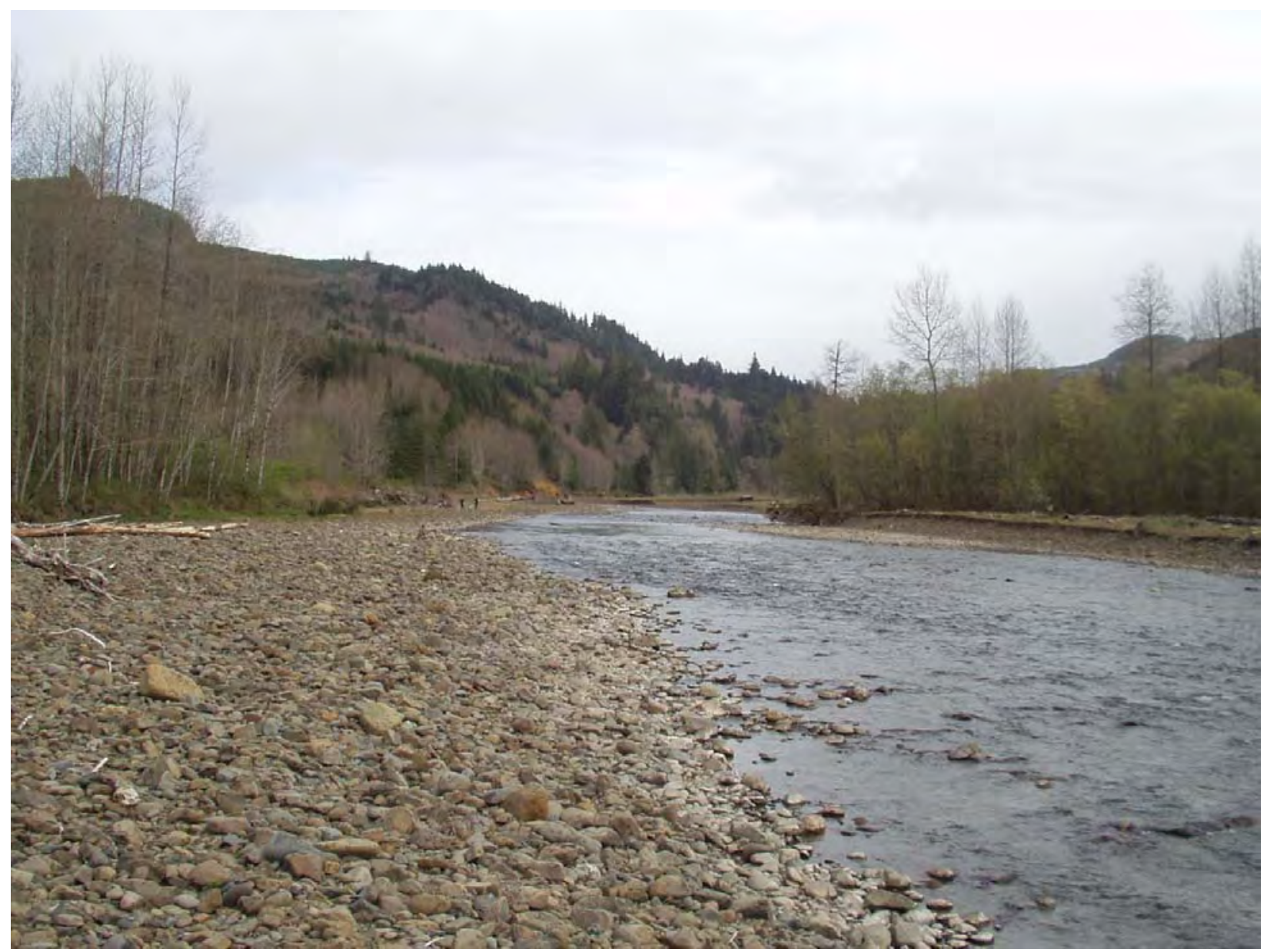

Photo GRR-1-1. Survey reach GRR-1 (March 23, 2004). Cobble bedded plane-bed channel of the main stem Grays River. Flow is towards the camera. The limited LWD and riparian recruitment potential apparent in the photo is typical of the response reach. 



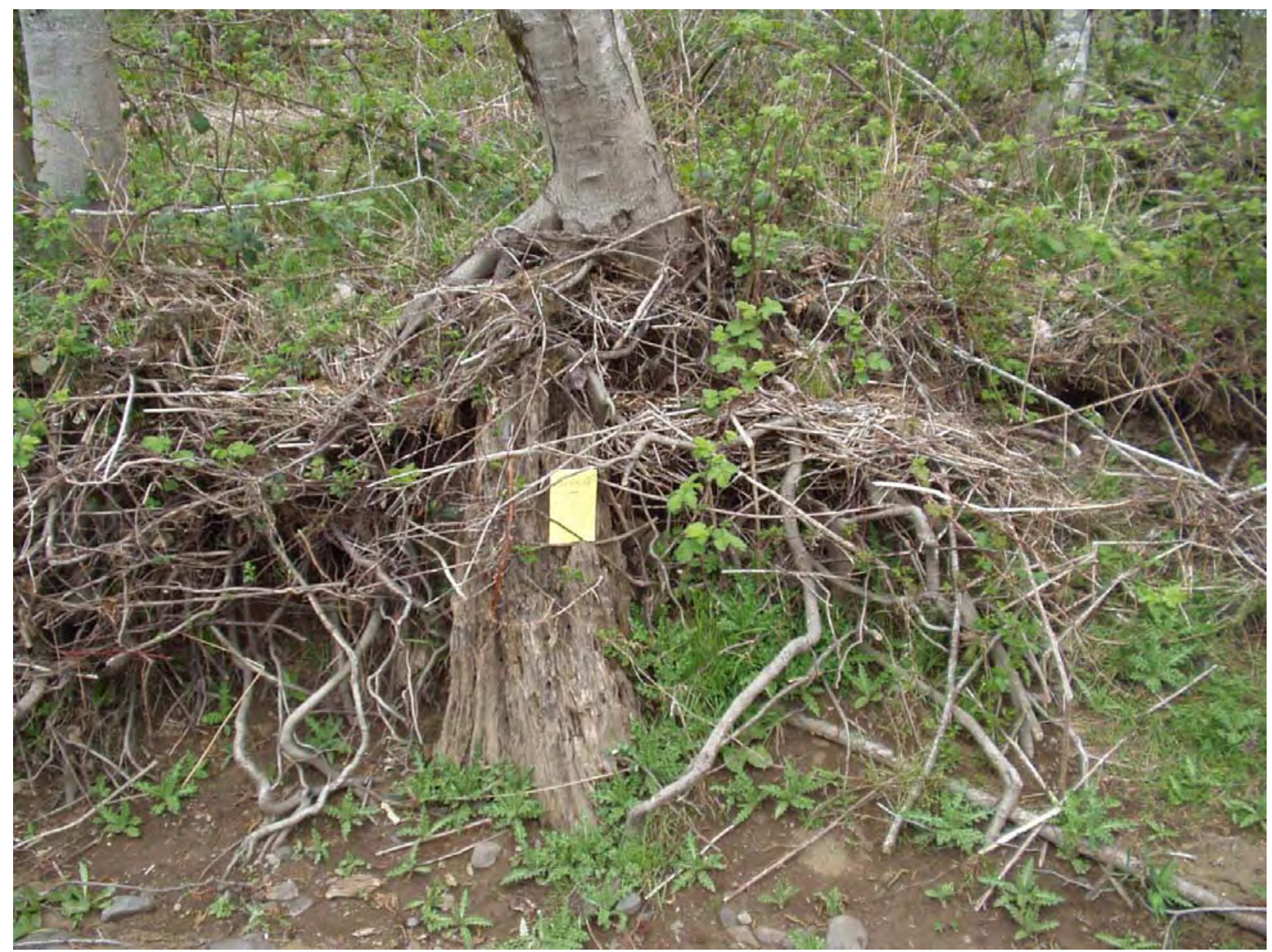

Photo GRR-1-2. Survey reach GRR-1 (March 23, 2004). Trees buried in growth position indicate variability in channel elevations. Alders growing on the floodplain surface are approximately 25 years old. The existing floodplain surface is approximately 1.2 meters above the historical surface. 



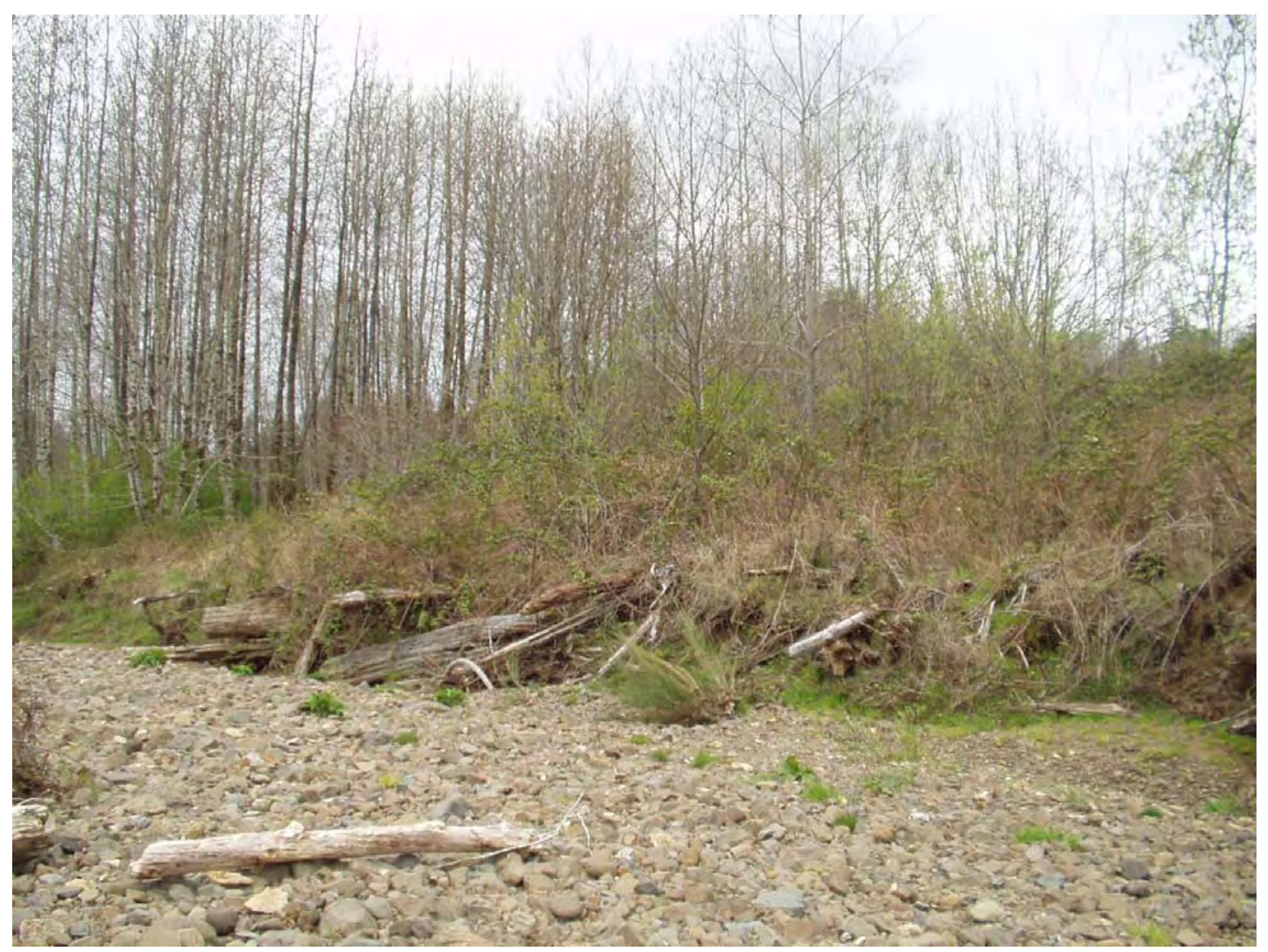

Photo GRR-1-3. Survey reach GRR-1 (March 23, 2004). Buried LWD jam exposed in the right bank of existing channel alignment. Buried jams observed in multiple locations suggests that historical LWD loading conditions were greater in the past. 



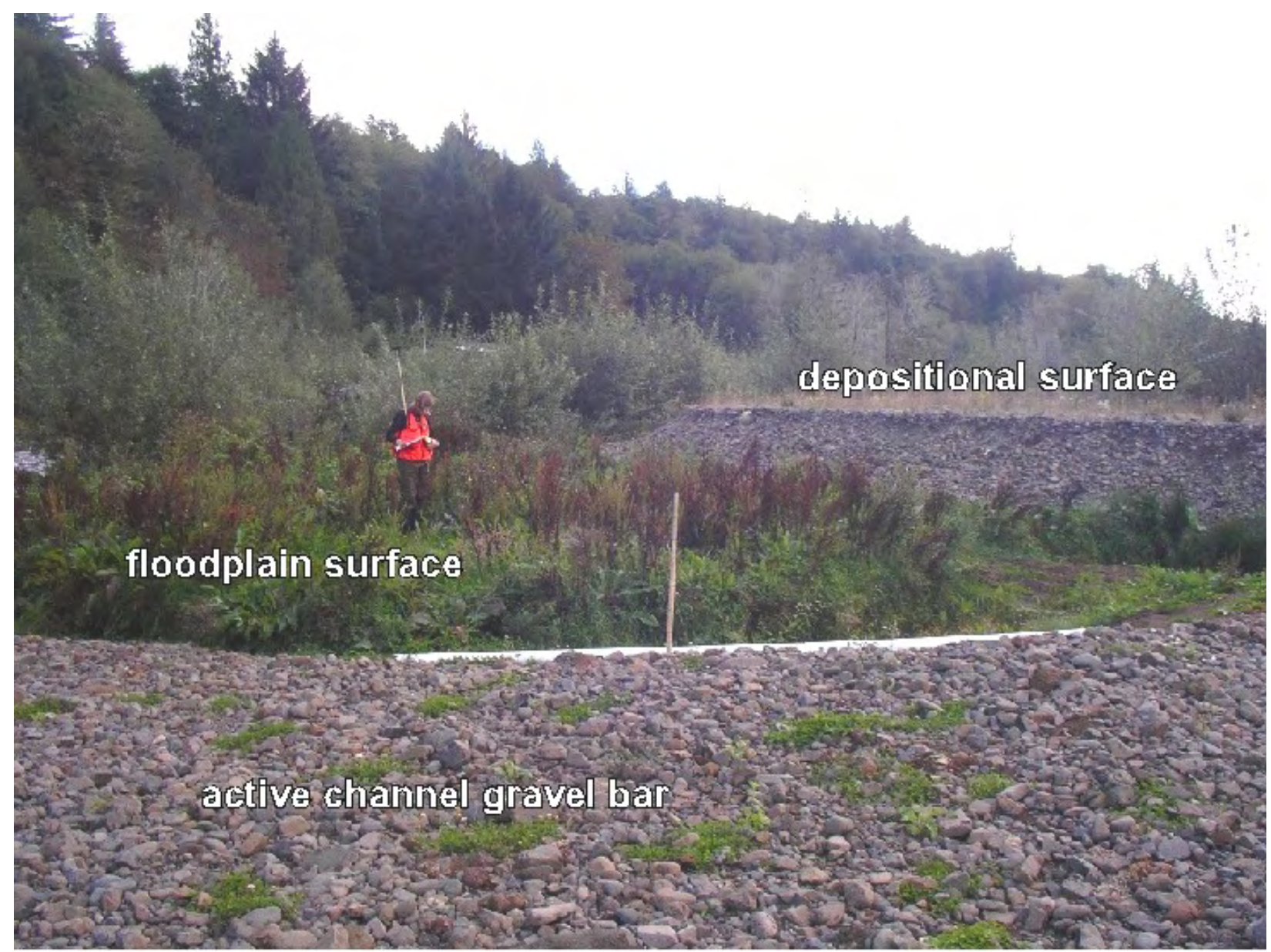

Photo GRR-1-4. Survey reach GRR-1 (September 20, 2004). Looking downstream, the main channel and avulsion path are located to the left of the photo. The depositional surface at right is associated with the avulsion event in December 1999. The vegetated floodplain surface was located behind the levee prior to the avulsion. The depositional surface is approximately $1 \mathrm{~m}$ above the floodplain surface. 


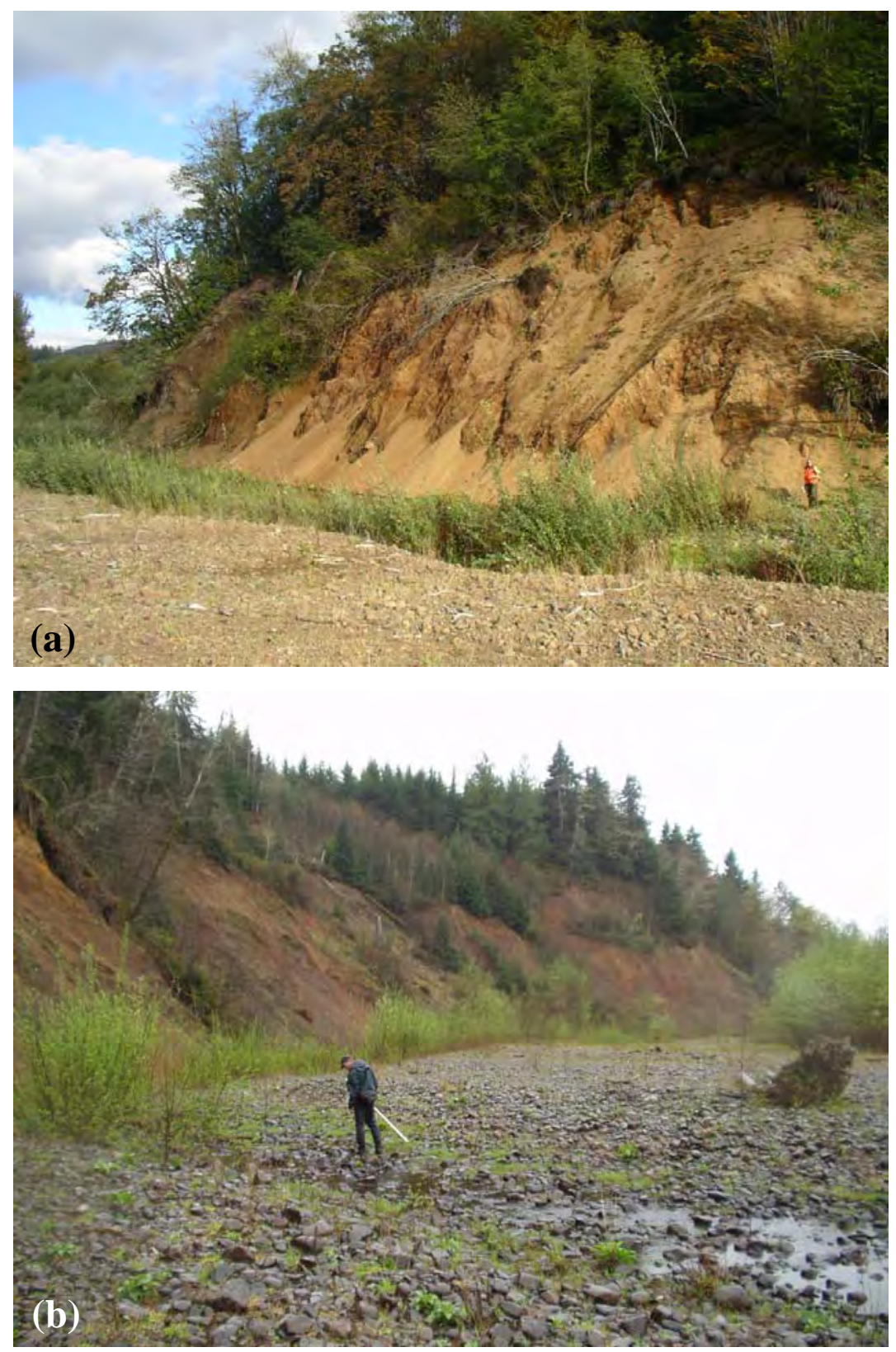

Photo GRR-1-5a and 5b. Survey reach GRR-1 (September 21, 2004). Eroding hillslope (a) and (b) at the left margin of the floodplain valley. Erosion in (a) is occurring near the head of the lower avulsion channel alignment; the height of the exposure is approximately $15 \mathbf{~ m}$. Erosion throughout the meander occupied by the mainstem alignment in 1996 is visible in (b). The unvegetated channel has been at the base of this slope since at least 1939. Landsliding along this slope is visible in the $\mathbf{1 9 9 6}$ aerials photos and indicates a recent increase in the local sediment delivery from this source over the last decade. 



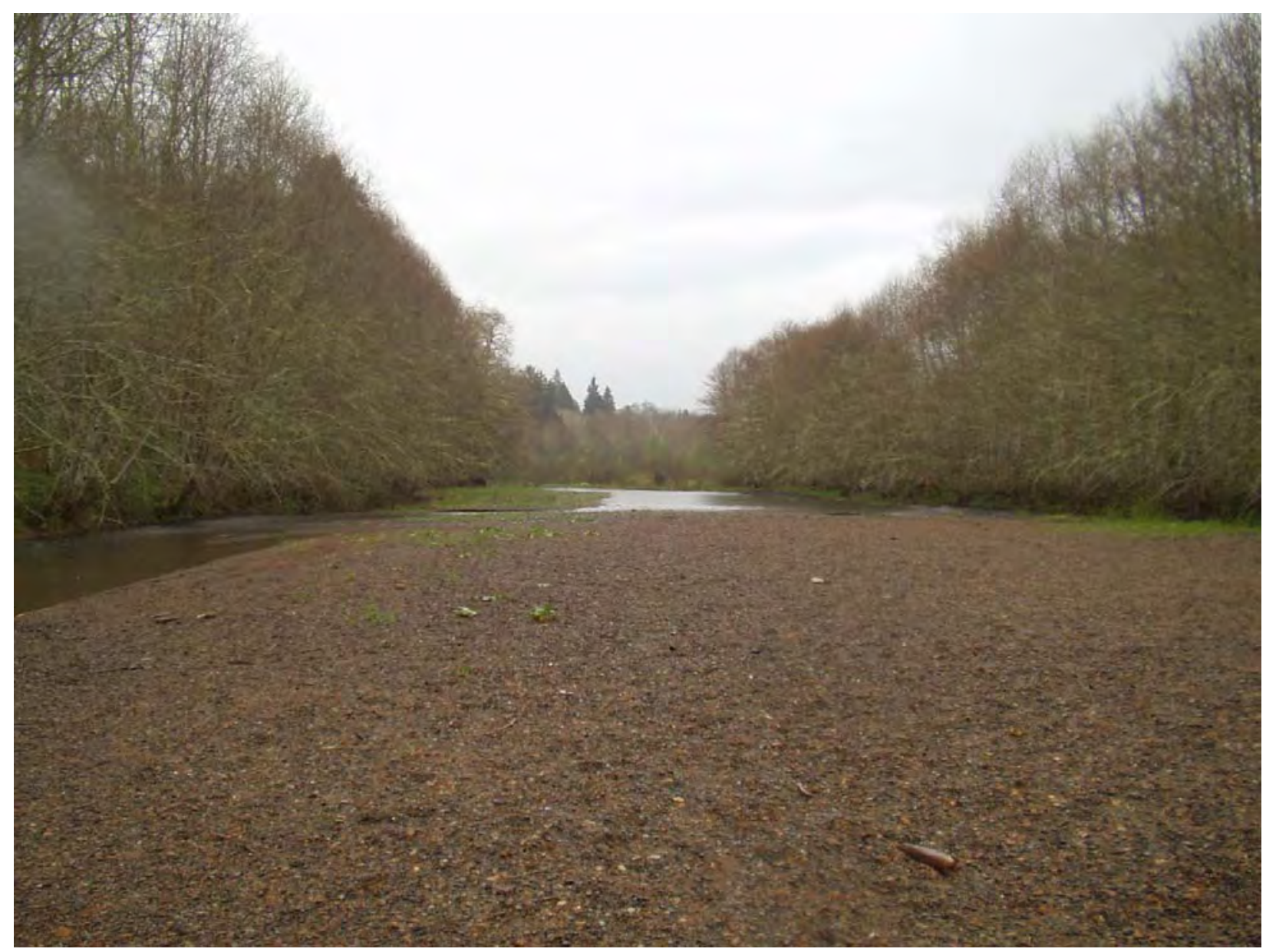

Photo GRR-1-6. Survey reach GRR-1 (March 23, 2004). Looking downstream within the straightened and leveed portion of the Gorley subreach in the Grays River response reach. This reach is located downstream of the preavulsion (December 1999) confluence of the West Fork and main stem Grays River and is now occupied solely by the West Fork. Future aggradation in this reach could increase the probability of an avulsion through the downstream meander (to the photo right) where levees have limited channel migration and isolated floodplain surfaces that were converted to agriculture. 



\section{APPENDIX C}

\section{Channel Survey Field Notes}





\section{Colluvial Channels}

Survey Reach CC-1

Date Surveyed: 10/27/04

Gradient: 45\%

BFW: 2m

Photo: See photo CC-1-1 in Appendix B.

\section{Channel Characteristics:}

Scoured colluvial channel. Channel bed is almost entirely bedrock with some deposits of angular cobbles. Channel has been scoured by a historical debris flow.

Instream Sediment:

Channel bed is almost entirely bedrock with some deposits of angular cobbles. Little other sediment was observed in the channel.

\section{LWD Loading:}

No hydraulic complexity and roughness provided by LWD.

Riparian Recruitment Potential:

Riparian recruitment potential is currently limited as there is little or no mature conifer forest adjacent to the channel. 
Survey Reach CC-2

Gradient: $25 \%$

BFW: 2m

Photo: See photo CC-2-1in Appendix B.

\section{Channel Characteristics:}

Cascade channel is incising into debris flow deposits in the colluvial hollow.

\section{Instream Sediment:}

Channel banks are poorly sorted colluvium with silt to boulder sized particles. Channel substrate is cobble and gravel between boulder steps. The lack of fine sediment in the active channel Stream indicates this fraction of the sediment load is rapidly transported downstream.

\section{LWD Loading:}

No hydraulic complexity and roughness provided by LWD.

\section{Riparian Recruitment Potential:}

Riparian recruitment potential is currently limited as there is little or no mature conifer forest adjacent to the channel. 
Survey Reach CC-3

Date Surveyed: 10/28/04

Gradient: 35\%

BFW: 2m

BFD: $1 \mathrm{~m}$

Photo: NA

Channel Characteristics:

High-gradient cascade channel.

Instream Sediment:

Predominantly angular to subrounded gravel and cobble with some boulders and sand. Finer sediment was not observed in the channel indicating this fraction of the sediment load is readily transport downstream.

\section{LWD Loading:}

High levels of LWD loading provides significant grade control and sediment storage. LWD in channel is relict and composed of pieces significantly larger than those within the adjacent riparian community.

\section{Riparian Recruitment Potential:}

Riparian recruitment potential is currently limited as adjacent riparian community is composed of approximately 20-30 year old conifers. As this community matures the recruitment potential will improve. 


\section{Headwater Transport Channels}

Survey Reach HTC-1

Date Surveyed: 10/27/04

Gradient: 5\%

BFW: 4-6m

Photos: See photos HTC-1-1 and HTC-1-2 in Appendix B.

\section{Channel Characteristics:}

Confined step-pool reach with boulders and LWD forming steps. Stream banks are generally stable though some there is local erosion into historical landslide deposits. Where gradient decreases locally forested island with mature vegetation bifurcate channel alignment. Frequent bar deposits of sand and gravel in lower gradient sections.

\section{Instream Sediment:}

Boulders provide grade-control within the step-pool channel. Boulders are up to $1 \mathrm{~m}$ in diameter with typical boulders ranging between $0.3 \mathrm{~m}$ and $0.5 \mathrm{~m}$. Channel substrate is dominated by cobbles and boulders whereas bar deposits are finer and are composed of sand and gravel. Finer deposits of cobble, sand and gravel are also stored behind roughness elements within the wetted channel. Finer sediment in the bar deposits and wetted channel is loose and appears readily mobile. Extent of bar deposits is high for supply limited channel morphology and is indicative of high sediment loading. Grain-size distribution for surface and subsurface pebble counts of bar deposit material is presented in Appendix B. $\mathrm{D}_{50}$ of surface material is $22 \mathrm{~mm}$; $\mathrm{D}_{50}$ of subsurface material is $10 \mathrm{~mm}$.

\section{LWD Loading:}

LWD loading was fair providing moderate hydraulic complexity and roughness. Relict wood provides the majority of LWD related grade control and sediment storage.

\section{Riparian Recruitment Potential:}

Fair with occasional or limited mature conifer forest adjacent to the channel and within the historical channel migration zone. Cedars and hemlocks up to $1 \mathrm{~m}$ dbh in places on the right bank, however there is no buffer on the left bank and one thread of the channel flows through significant logging slash. 
Survey Reach HTC-2

Date Surveyed: 10/27/04

Gradient: 6\%

BFW: 5-10m

Photo: See photo HTC-2-1 in Appendix B.

\section{Channel Characteristics:}

Confined boulder step-pool channel.

\section{Instream Sediment:}

Channel substrate is predominantly cobble and boulder bedded (est. $\mathrm{D}_{50}$ of $35 \mathrm{~mm}$ ). Approximately $10 \%$ of the active channel is composed of loose gravel deposits. These deposits are predominantly located in lee areas behind instream obstructions and in lateral bars. Grainsize distribution for surface pebble count of gravel substrate sediment is presented in Appendix B. $D_{50}$ of gravel substrate is $21 \mathrm{~mm}$.

\section{LWD Loading:}

Moderate hydraulic complexity and roughness provided by LWD. Relict wood provides the majority of LWD related grade control and sediment storage.

\section{Riparian Recruitment Potential:}

Little or no mature conifer forest was present adjacent to the channel. 


\section{Tributary Response Channels}

\section{Survey Reach TRC-1}

Gradient: 2\%

BFW: 8m

Photo: See photo TRC-1-1, and TRC-1-2 in Appendix B.

\section{Channel Characteristics:}

Moderately confined to confined plane-bed reach of Cabin Creek. Reach transitions towards boulder step-pool at the upstream end of survey reach where the channel gradient increases. Reach is overwhelmed by loose deposits of fine-grained (silt to fine grained gravel) marine siltstone sediment. Banks are eroding locally.

\section{Instream Sediment:}

The channel substrate is predominantly boulder and cobble bedded with silt, sand, and fine gravel deposits in depositional areas of the channel. Cobbles and boulders are typically basaltic in composition and finer sediments are composed of marine siltstone; siltstone gravel particles are easily crushed between fingers. Fine-grained marine siltstone deposits are loose and cover approximately $40 \%$ of the stream bed with deposits of up to $0.5 \mathrm{~m}$ deep in lee areas behind boulders. Cobbles and boulder substrate $\mathrm{D}_{50}$ was visually estimated at $128 \mathrm{~mm}$. The $\mathrm{D}_{50}$ of lateral bars of basaltic gravel was visually estimated at $22 \mathrm{~mm}$. The $\mathrm{D}_{50}$ of loose fine grained siltstone deposits was visually estimated to be $8-11 \mathrm{~mm}$.

\section{LWD Loading:}

There was no functional LWD observed in the surveyed reach (approximately 400m). Numerous pieces of LWD, with rootwads cut off, were located on the adjacent floodplain surfaces and hillslopes but were not engaged within the active channel.

\section{Riparian Recruitment Potential:}

Riparian forest of 30 year old alder provides poor recruitment potential. 
Survey Reach TRC-2

Date Surveyed: 10/27/04

Gradient: 2-3\%

BFW: 5-8m

Photo: See photo TRC-2-1 in Appendix B.

\section{Channel Characteristics:}

Moderately confined to confined plane-bed reach of Alder Creek. The channel appears to be widening as indicated by extensive vertical eroding banks and frequent recruitment of alders growing adjacent to the channel. Lateral instability is further evidenced by erosion into bedrock (basalt) at both valley margins. The reach contains significant loose deposits of fine-grained (predominantly sand and fine grained gravel) marine siltstone sediment. These deposits form large lateral and mid-channel bars and cover approximately $25 \%$ of the active channel stream bed.

\section{Instream Sediment:}

The channel substrate is predominantly cobble and gravel with occasional boulders. Considerable fine-grained (predominantly sand and fine grained gravel) marine siltstone sediment forms large mid-channel and lateral bars and covers approximate $25 \%$ of the stream bed. Substrate cobbles, gravel and boulders are typically basaltic in composition. Well sorted bars of subangular clasts of basalt indicate this sediment has not been transported far from its source. The $\mathrm{D}_{50}$ of these bars was visually estimated at $45 \mathrm{~mm}$. The $\mathrm{D}_{50}$ of substrate material was visually estimated at $64-90 \mathrm{~mm}$ and the $\mathrm{D}_{50}$ of fine grained, loose, marine siltstone sediment was visually estimated at $22 \mathrm{~mm}$.

\section{LWD Loading:}

There was low to moderate functional LWD observed in the survey reach. LWD that did occur in the reach consisted of locally recruited alders up to $0.3 \mathrm{~m}$ in diameter. This wood will decay rapidly and will not provide long term complexity to the channel network.

\section{Riparian Recruitment Potential:}

The riparian forest is dominated by $\sim 30$ year old alder and provides poor recruitment potential. 
Survey Reach TRC-3

Date Surveyed: 10/27/04

Gradient: 2\%

BFW: $15 m$

BFD: $1 \mathrm{~m}$

Photo: See photo TRC-3-1 in Appendix B.

\section{Channel Characteristics:}

Moderately confined plane-bed reach of Mitchell Creek. Channel is primarily gravel and cobble bedded. Banks generally appeared stable but undercut alders at channel margins indicate local erosion and widening. Channel contains little hydraulic complexity and there are few opportunities for sediment storage in the active channel.

\section{Instream Sediment:}

Primarily gravel and cobble bedded channel. Some sand and fine gravel composed of marine siltstone in subsurface sediment. The $\mathrm{D}_{50}$ of the plane-bed channel was visually estimated at $45 \mathrm{~mm}$. Large point bars and frequent lateral bars of sand, cobble and gravel.

\section{LWD Loading:}

There was no functional LWD observed in the surveyed reach.

Riparian Recruitment Potential:

Recruitment potential is poor as the adjacent riparian forest is dominated by alders with very few conifers of any age. 
Survey Reach TRC-4

Date Surveyed: 10/27/04

Gradient: 3\%

BFW: 10m

Photo: See photo TRC-4-1 in Appendix B.

\section{Channel Characteristics:}

Confined plane-bed reach. Channel bed is dominantly cobble bedded with gravel and boulders. Inset floodplain surfaces indicate a previous period of channel widening and aggradation. Eroding banks, and undercut and locally recruited riparian vegetation indicate continued lateral instability. Vertical instability, and further downcutting, is suggested by exposure of buried relict LWD at the base of the inset floodplain surface. Buried jams of relict LWD provide grade control within the reach. Channel contains large bars and moderate fine-sediment loading was apparent in low-energy depositional zones.

\section{Instream Sediment:}

Channel bed is dominantly cobble bedded with gravel and boulders. The $\mathrm{D}_{50}$ of substrate material was visually estimated at $45 \mathrm{~mm}$ Occasional steps in the channel profile were composed of boulders. Large bars consist of subangular gravel and cobble. Moderate loading of finer sediment (consisting of sand and fine-grained sediment composed of marine siltstone) was apparent in low-energy depositional zones.

\section{LWD Loading:}

Moderate complexity provided by LWD. Relict LWD provides grade control within the reach. Additional locally recruited alder LWD provides additional complexity.

\section{Riparian Recruitment Potential:}

The alder dominated riparian forest provides poor recruitment potential. 


\section{East Fork Grays River}

Survey Reach EGR-1

Date Surveyed: 10/27/04

Gradient: 2\%

BFW: 20m

BFD: $1 \mathrm{~m}$

Photo: See photos EGR-1-1 and EGR-1-2 in Appendix B.

\section{Channel Characteristics:}

The East Fork Grays River exhibits plane-bed morphology through the surveyed reach. The channel is moderately confined with a small side-channel running along the left (south) edge of the floodplain. During the survey there was no surface connection to the floodplain margin side channel and was being fed by hyporheic flows. The active floodplain surface is populated primarily by alders (approximately 30 years old). Occasional Sitka spruce are growing on the floodplain but do not appear healthy.

\section{Instream Sediment:}

The channel is predominantly gravel and cobble bedded with occasional boulders. Sand and fine gravel deposits were found in lateral bars at the wetted channel margin. Sand deposits were found on the active floodplain surface. Grain-size distributions for surface and subsurface pebble counts of lateral bar deposit sediment that approximates gravel and cobble substrate is presented in Appendix B. $\mathrm{D}_{50}$ of surface material is $54 \mathrm{~mm}$; $\mathrm{D}_{50}$ of subsurface material is $14 \mathrm{~mm}$.

\section{LWD Loading:}

There was no functional LWD in the 500 m survey reach.

\section{Riparian Recruitment Potential:}

Poor recruitment potential with little or no mature conifer forest adjacent to the channel. 


\section{South Fork Grays River}

Two reaches with distinct character were surveyed between the confluence of the South Fork and main stem Grays River and South Fork RK 1.2.

\section{Survey Reach SGR-1}

Date Surveyed: 3/24/04 and 9/23/04

Gradient: 1\%

BFW: 30m

BFD: 1.5

Photo: See photos SGR-1-1, SGR-1-2, SGR-1-3, and SGR-1-4 in Appendix B.

\section{Channel Characteristics:}

The South Fork Grays River was observed to be a moderately confined predominantly cobble bedded plane-bed reach between RK 0.3 and 0.7 . The channel had limited complexity in the active channel. Adjacent floodplain surfaces and terraces range up to $3 \mathrm{~m}$ above the current bankfull stage indicating historical vertical variability. Portions of a $4 \mathrm{~m}$ high terrace (3m above bankfull stage) that formed behind a debris dam at the downstream end of the survey reach remain at the left margin and central part of the floodplain valley. Radiocarbon dating of LWD from the debris dam deposit at the downstream end of the terrace formation and from wood deposited at $2 \mathrm{~m}$ above current bank full stage ( $1 \mathrm{~m}$ below the top of the terrace surface) indicate that the terrace began forming between 210 and 330 years ago (270 years before present +/- 60 years) and deposition continued through at least 130 and 250 years ago (200 years before present +/- 60 years). Stratigraphy within the terrace is typical of a prograding deltaic deposit with clayey silt deposits, foreset beds of sand, and coarser alluvial deposits. The depositional rate behind the debris jam was estimated at approximately 1,440 m3/year (2,450 tons/year) from the observed extent of the remaining portions of the terrace surface, the dimensions of the floodplain valley, and assuming 100 years of terrace growth (based on the radiocarbon dates).

\section{Instream Sediment:}

Substrate sediment is predominantly gravel and cobble bedded. The $\mathrm{D}_{50}$ of the plane-bed substrate was visually estimated to be $\sim 64-90 \mathrm{~mm}$. Boulders are common in locally steeper segments. Large bars of gravel and cobble occupy much of the unvegetated channel, some of which are unvegetated and some of which have immature alder growth indicating relative stability over the last 3-5 years. 


\section{LWD Loading:}

LWD loading was low within the survey reach and provided little hydraulic complexity or opportunities for sediment storage.

\section{Riparian Recruitment Potential:}

Adjacent riparian forests are primarily alder dominated and offer poor recruitment potential. 
Survey Reach SGR-2

Date Surveyed: 3/24/04

Gradient: 1\%

BFW: NA due to multiple thread channel network. Floodplain width is approximately 80m.

Photo: See photo SGR-2-1 and SGR-2-2 in Appendix B.

\section{Channel Characteristics:}

Complex multiple threaded pool-riffle channel network. The surveyed reach was moderately confined and dominated by forested islands, mid-channel bars, buried jams and high levels of LWD loading. A wall-based channel was observed at the left edge of floodplain valley. Channel erosion at the right edge of the floodplain valley has eroded the riparian buffer and is eroding into managed forest and recruiting immature conifers.

\section{Instream Sediment:}

Significant sediment storage was provided by LWD jams. Where jams decrease, the effective channel gradient deposits consisted of coarse and fine sediment. Locally steeper channel units were cobble bedded.

\section{LWD Loading:}

LWD loading was high in the survey reach. Complex jams created steps in the channel profile and steep transverse hydraulic gradients between channels across the floodplain. Jam steps were up to $1.5 \mathrm{~m}$ in height and extended almost the full valley width in some locations (up to $50 \mathrm{~m}$ in width). Much of the wood was in a partial or significant state of decay.

\section{Riparian Recruitment Potential:}

Recruitment potential is low because of a limited riparian buffer adjacent to the channel. The current channel alignment is eroding into managed forest with immature conifers. 


\section{West Fork Grays River}

Two reaches with distinct character were surveyed between the confluence of the West Fork and main stem Grays River and the Grays River State Fish Hatchery at RK 2.0.

\section{Survey Reach WGR-1}

Date Surveyed: 9/22/04

Gradient: $0.5 \%$

BFW: 25

BFD: $1.5 \mathrm{~m}$

Photo: See photo WGR-1-1 in Appendix B.

\section{Channel Characteristics:}

The West Fork Grays River was observed to be a moderately confined predominantly straight plane-bed channel with little channel complexity between its confluence with the main stem Grays River and RK 1.25. Much of the reach is aligned against bedrock at the floodplain valley margin. These bedrock outcrops deliver sediment and limit scour depths. Sediment is also delivered from steep tributary channels from the right bank. The left bank floodplain surface is likely accessed at high flows but seems somewhat disconnected.

\section{Instream Sediment:}

The stream bed substrate material was generally loose and composed of sub-angular to rounded cobble and gravel with some sand. Lateral bars consist of solely fine-grained sediment as well as well graded silt to gravel sediment deposits. Sediment storage opportunities in the reach are limited.

\section{LWD Loading:}

LWD loading in the reach was generally low. Jams imparting hydraulic complexity on the active channel were located almost exclusively at tight radius meander bends.

\section{Riparian Recruitment Potential:}

Recruitment potential from the adjacent, alder-dominated, riparian forest was poor. 
Grays River Watershed-Geomorphic Analysis

Survey Reach WGR-2

Date Surveyed: 9/22/04

Gradient: $0.5 \%$

BFW: 25

BFD: 1.5

Photo: See photos WGR-2-1, WGR-2-2, and WGR-2-3 in Appendix B.

Channel Characteristics:

The West Fork Grays River was observed to be a moderately confined gravel bedded pool-riffle reach between West Fork RK (river kilometer) 1.25 and 2.0 (at the Grays River State Fish Hatchery). Lateral channel instability was evidenced through undercut riparian vegetation and bank erosion into floodplain valley margins. High bank erosion where the channel is eroding into the valley margins provides fine and coarse sediment in the West Fork. The channel was typically moderately confined but was unconfined in some locations and appears able to reach its floodplain during large flow events. The 1986 USGS topo map shows the channel adjacent to the left valley margin in the upper $0.5 \mathrm{~km}$; however, the current channel alignment is further towards the right margin of the valley. A large LWD jam was observed filling the upstream end of the historic alignment. Within the current alignment the channel position appears to be variable as a result of the combination of locally recruited LWD and high sediment loads. There was evidence of recent adjustment and the channel was observed to have avulsed and occupied a new channel alignment through an area of moderate to low LWD recruitment potential. Buried logjams are commonly evident in eroding alluvial banks.

\section{Instream Sediment:}

High sediment loading was observed downstream of the Grays River State Fish Hatchery. Dredging of the main channel at the bridge to the Grays River State Fish Hatchery indicates that bedload sediment deposition in this reach has been on the magnitude of $2500 \mathrm{~m}^{3} /$ year (4300 tons/year) annually from 1999 to 2003 (Parker 2004 personal communication). The stream bed substrate material was generally loose and composed of sub-angular to rounded cobble and gravel with some sand. The $\mathrm{D}_{50}$ of the substrate material was visually estimated to be $32 \mathrm{~mm}$. Mid-channel and lateral bar deposits are frequent in the reach. The $\mathrm{D}_{50}$ of sediment in bar deposits was estimated at $11-16 \mathrm{~mm}$. Significant deposits of very loose marine siltstone sand and gravel fill pools in many locations.

\section{LWD Loading:}

LWD loading in the reach was moderate to high and jams frequently imparted significant hydraulic complexity and provided considerable sediment storage in the active channel. Much of the LWD was either relict or composed of large deciduous trees. LWD composed of large deciduous trees was frequently in moderate to extreme states of decay. 


\section{Riparian Recruitment Potential:}

Conditions of riparian recruitment potential were locally variable but typically moderate to low. In the upstream $200 \mathrm{~m}$ of the survey reach (which appears to correspond with the extent of state land dedicated to the fish hatchery), occasional mature conifers on floodplain surfaces provide moderate recruitment potential. Downstream of this, the floodplain forest provides low recruitment potential as it is dominated by alders and there are limited conifers of any age. 


\section{Lower Crazy Johnson Creek}

\section{Survey Reach CJ-1}

\section{Date Surveyed: 3/23/04}

Gradient: $<1 \%$

BFW: 2-3m

Photo: See photo CJ-1-1 in Appendix B.

\section{Channel Characteristics:}

Gravel and sand bedded low-gradient floodplain channel of Crazy Johnson Creek. Banks are typically vertical and were locally unstable. Banks were typically composed of alluvium indicating historical deposition in this area from the main stem Grays River. Beaver ponds create backwater environments and are often correlated with occurrences of LWD. The ponds create hydraulic gradients across the floodplain and upwelling was clearly observed in one location.

\section{Instream Sediment:}

Local sediment inputs to the channel appear limited primarily to bank erosion. Channel substrate was composed of loose sand and gravel with some cobble. Deposits of fine sediments are concentrated locally.

\section{LWD Loading:}

LWD loading was moderate but pieces in the channel provided steps in the channel profile and were often associated with beaver ponds.

\section{Riparian Recruitment Potential:}

Recruitment potential of LWD is limited. Mature alders sparsely populate the floodplain and conifers of any age are limited in occurrence. 


\section{Grays River Response Reach}

Survey Reach GRR-1

Gradient: 1\%

BFW: 50m
Date Surveyed: 3/23/04, 9/20/04, and 9/21/04

Photo: See photos GRR-1-1, GRR-1-2, GRR-1-3, GRR-1-4, GRR-1-5, and GRR-1-6 in Appendix B.

\section{Channel Characteristics:}

Predominantly a cobble bedded plane-bed reach with little hydraulic complexity. The reach extends from the bedrock canyon to the present confluence of the main stem and West Fork Grays River, at the downstream end of the 1999 avulsion path. It is moderately confined throughout the survey reach and erosion into bedrock at the floodplain margin occurs in a number of locations. Further widespread bank erosion and channel adjustment were evident through the channel alignment occupied since the 1999 avulsion events. Floodplain surfaces at a wide range of elevations throughout the survey reach, and trees buried in growth position, indicate variability in vertical channel elevations. Buried logjams were also evident in eroding banks suggesting that historical LWD loading conditions were greater than at present.

\section{Instream Sediment:}

The plane-bed channel is primarily cobble bedded. Large and widespread mid-channel and lateral bar deposits consist of sand, gravel and cobble and indicate large sediment loading. The $\mathrm{D}_{50}$ of the plane bedded channel was visually estimated at $45-64 \mathrm{~mm}$. Substrate sediment was progressively coarser farther upstream in the survey reach; occasional boulders were observed just downstream from the downstream extent of the canyon. Local inputs of sediment include bank/ hillslope erosion along the left margin of the floodplain valley and local erosion of alluvial banks at other locations along the main stem alignment. Bedrock consisting of marine sedimentary rocks was exposed locally in the avulsion path channel alignment. In many areas gravel and cobble particles consist of weak marine sedimentary rock. These clasts appear to degrade rapidly when not inundated.

\section{LWD Loading:}

Very few pieces of functional LWD were observed within the study reach and none were engaged in the active channel alignment. Buried jams that extended to the top of floodplain surfaces were observed to have acquired additional racked material on the floodplain surface. Limited pieces of LWD were deposited on bar tops and most appeared readily mobile at high flow stages. Buried LWD jams were observed in eroding banks in multiple locations suggesting that historical LWD loading conditions were greater than at present. 


\section{Riparian Recruitment Potential:}

Limited potential recruitment of functional LWD from adjacent riparian forests primarily dominated by alders. Some forested islands contain maturing conifers that may become functional pieces if allowed to grow for another $\sim 50$ years. 



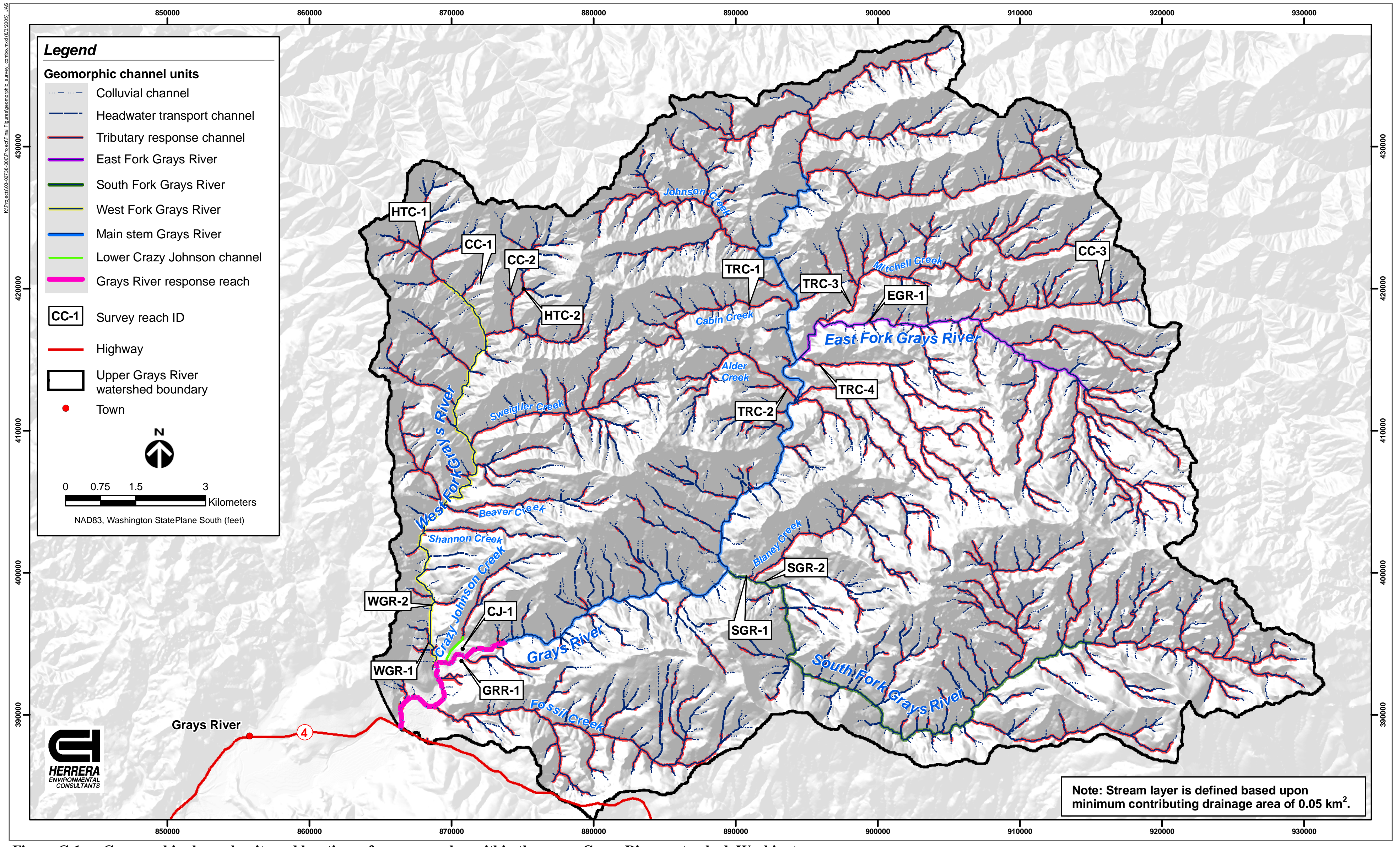

Figure C-1. Geomorphic channel units and locations of survey reaches within the upper Grays River watershed, Washington. 



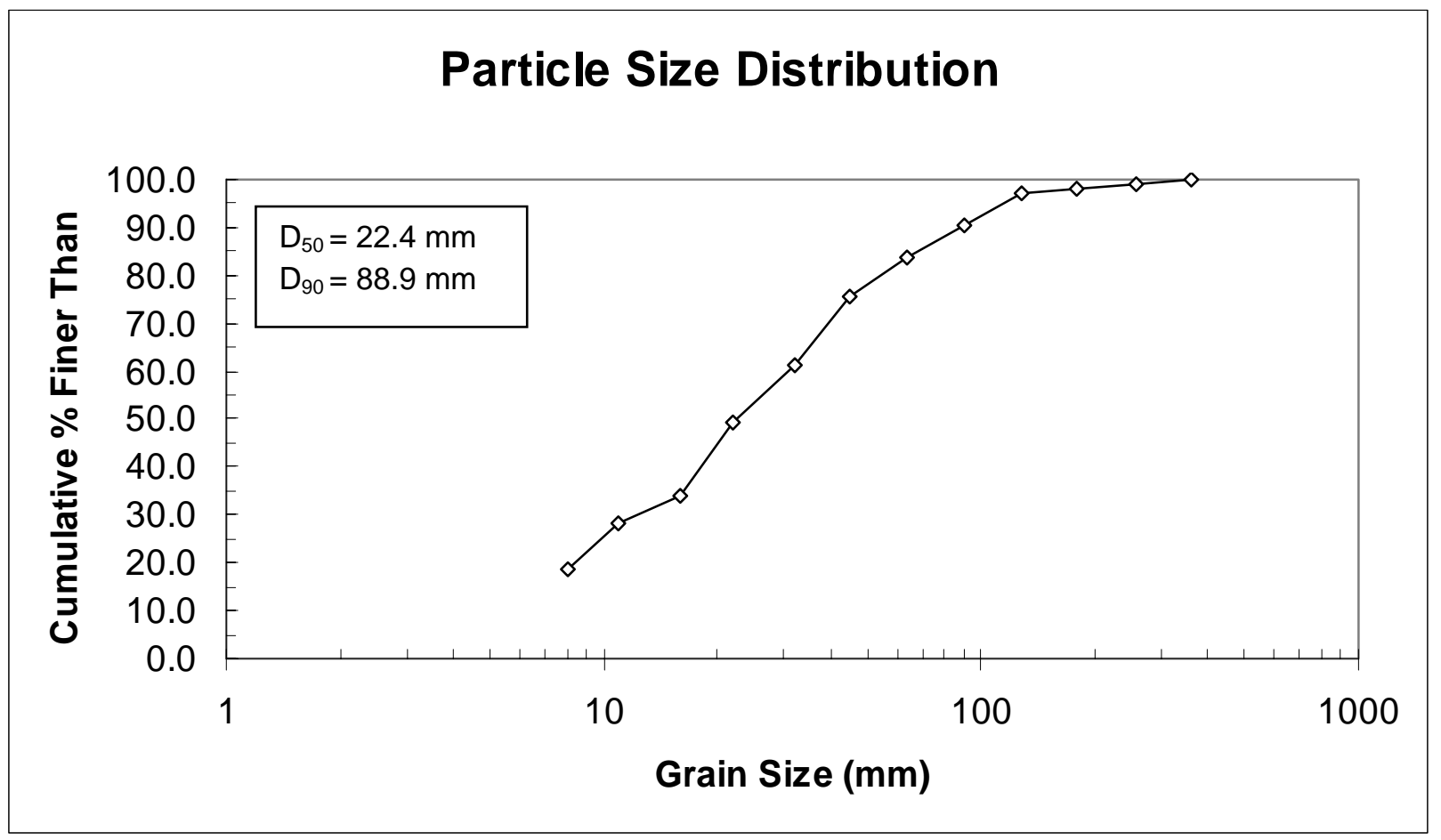

Figure C-2. Particle-size distribution of surface sediment in Survey Reach HTC-1.

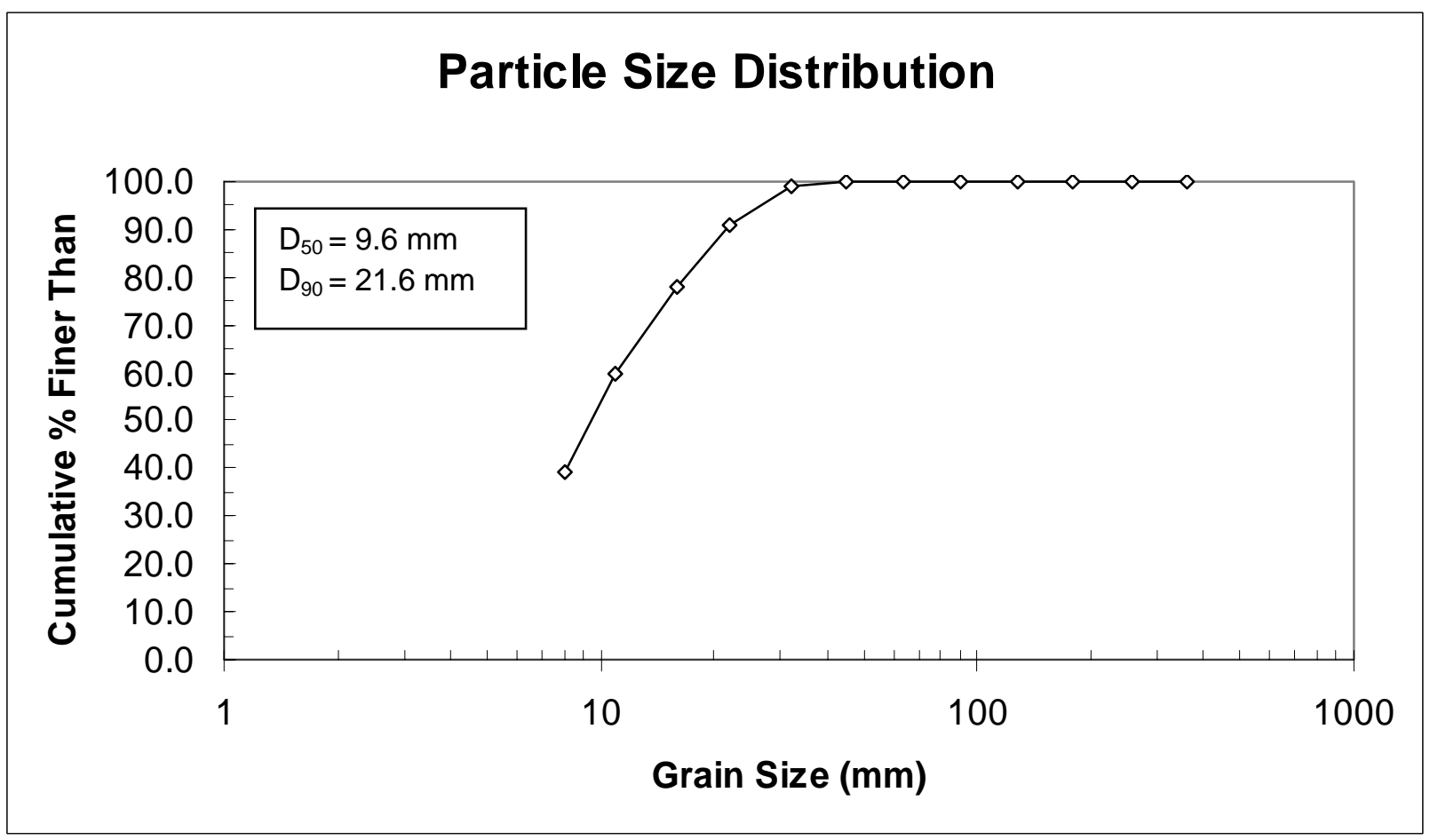

Figure C-3. Particle-size distribution of subsurface sediment in Survey Reach HTC-1. 


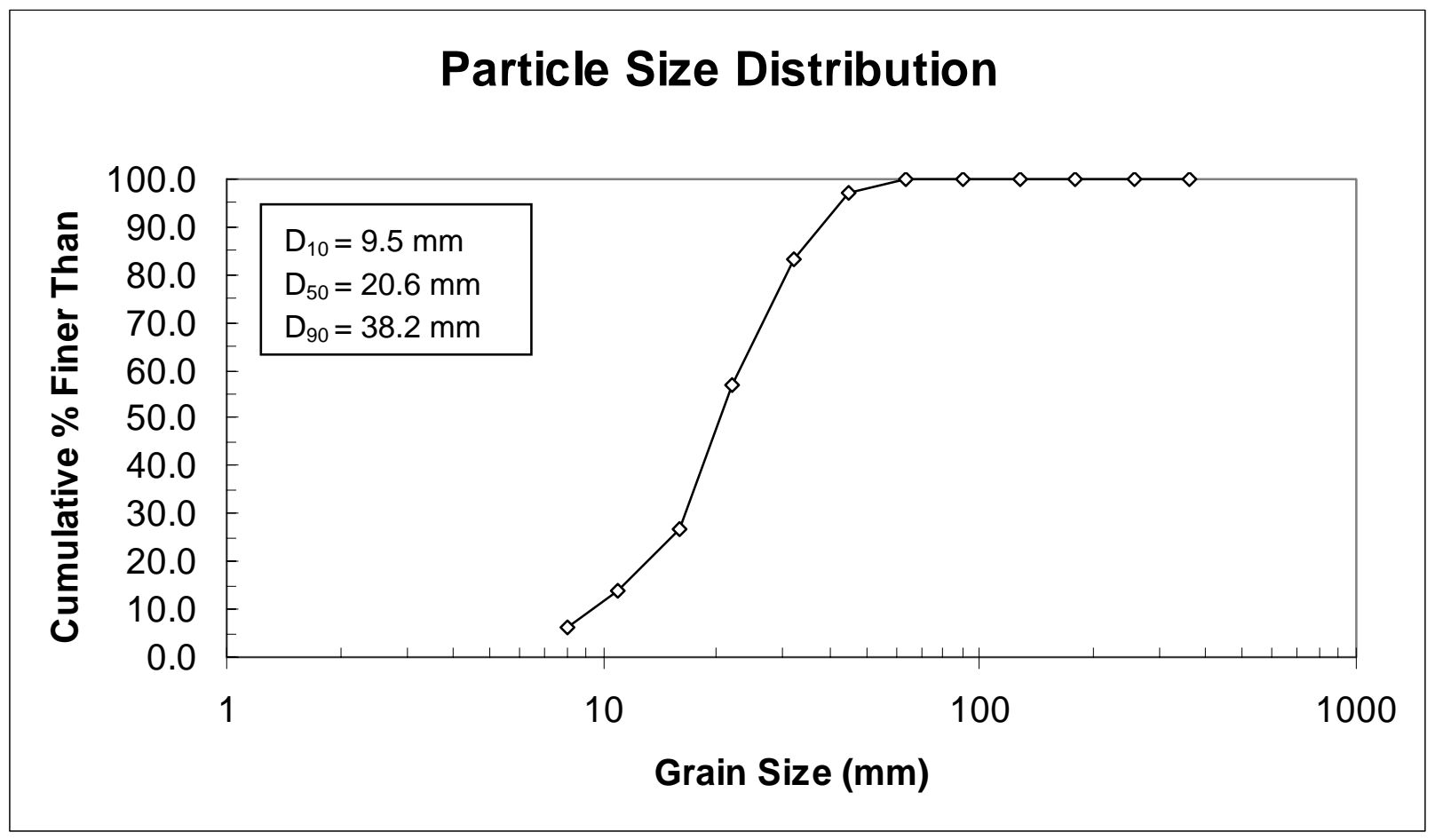

Figure C-4. Particle-size distribution of readily mobile gravel deposits in Survey Reach HTC-2.

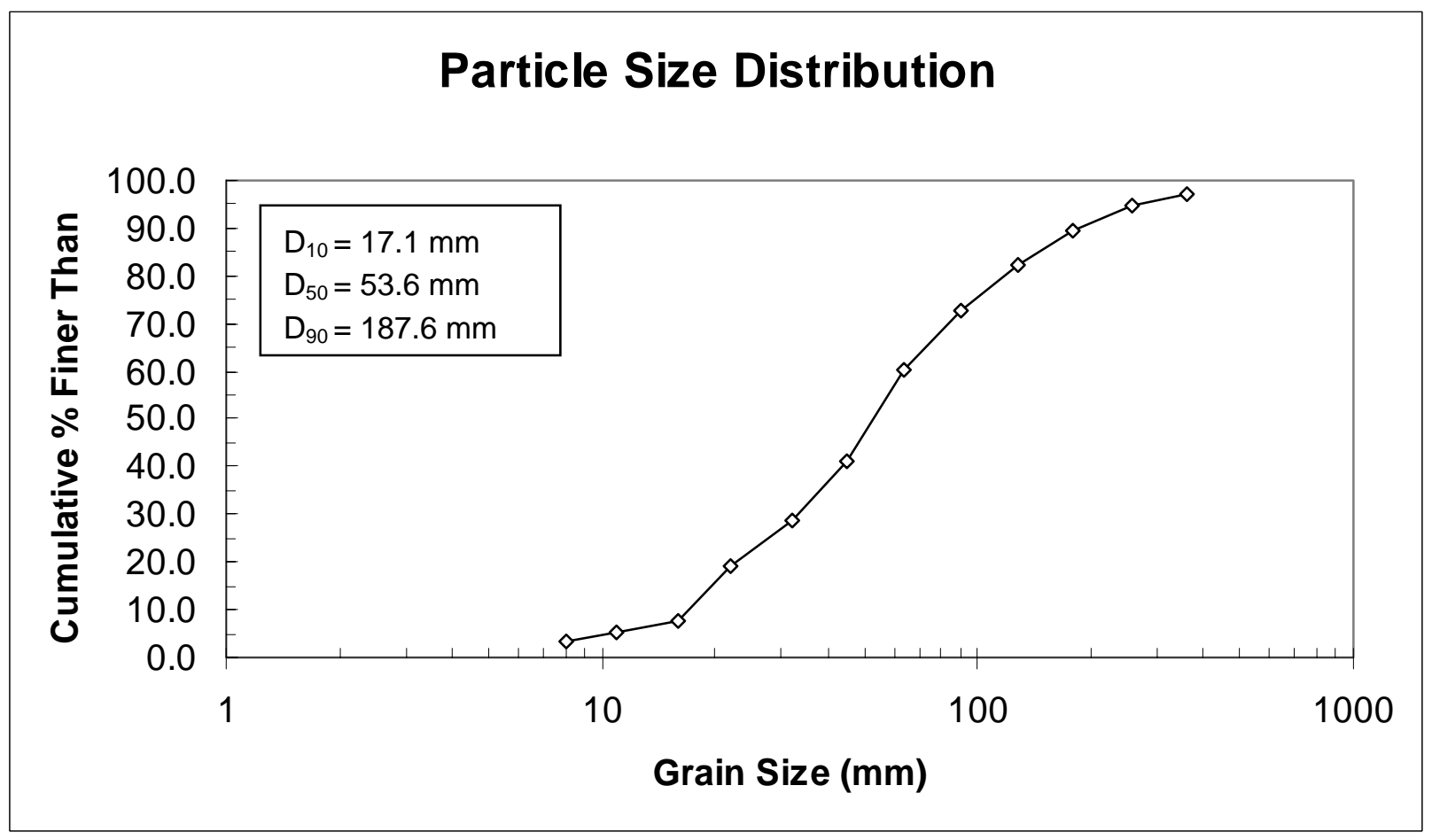

Figure C-5. Particle-size distribution of lateral bar surface sediment in Survey Reach EGR-1. 


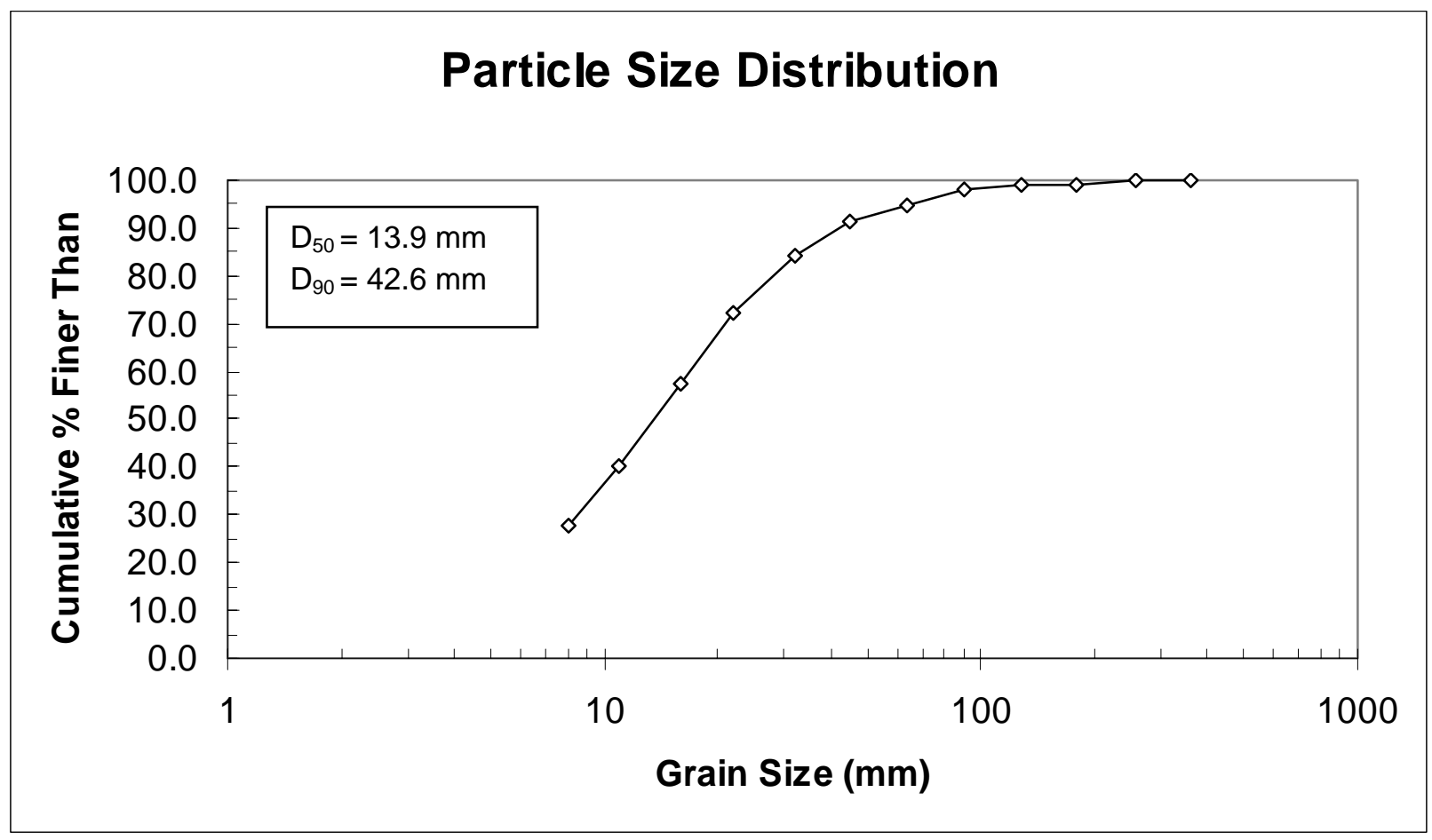

Figure C-6. Particle-size distribution of lateral bar subsurface sediment in Survey Reach EGR-1. 



\section{APPENDIX D}

\section{Laboratory Results}





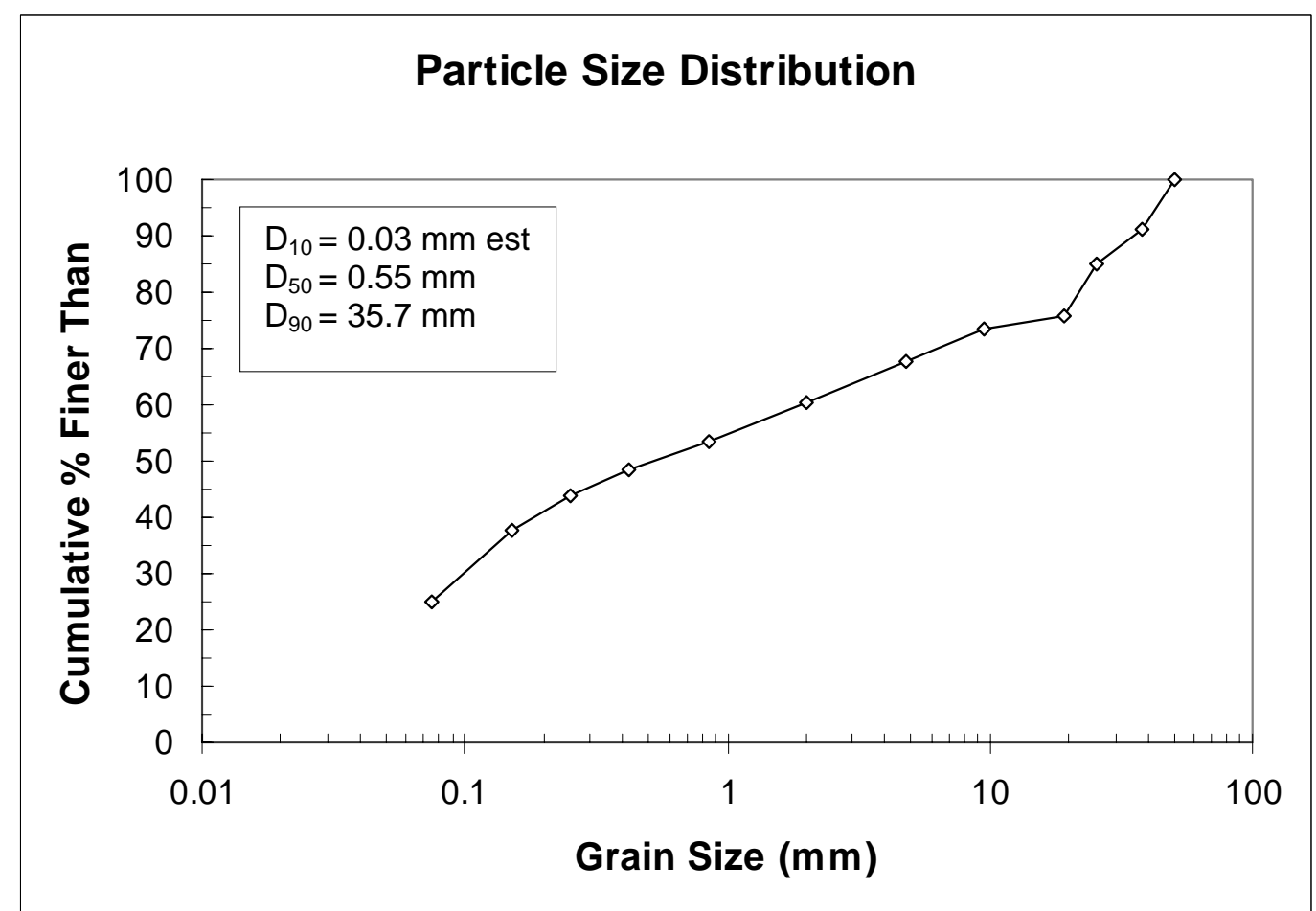

Figure D-1. Particle-size distribution of sample Grays 1; basalt lithology.

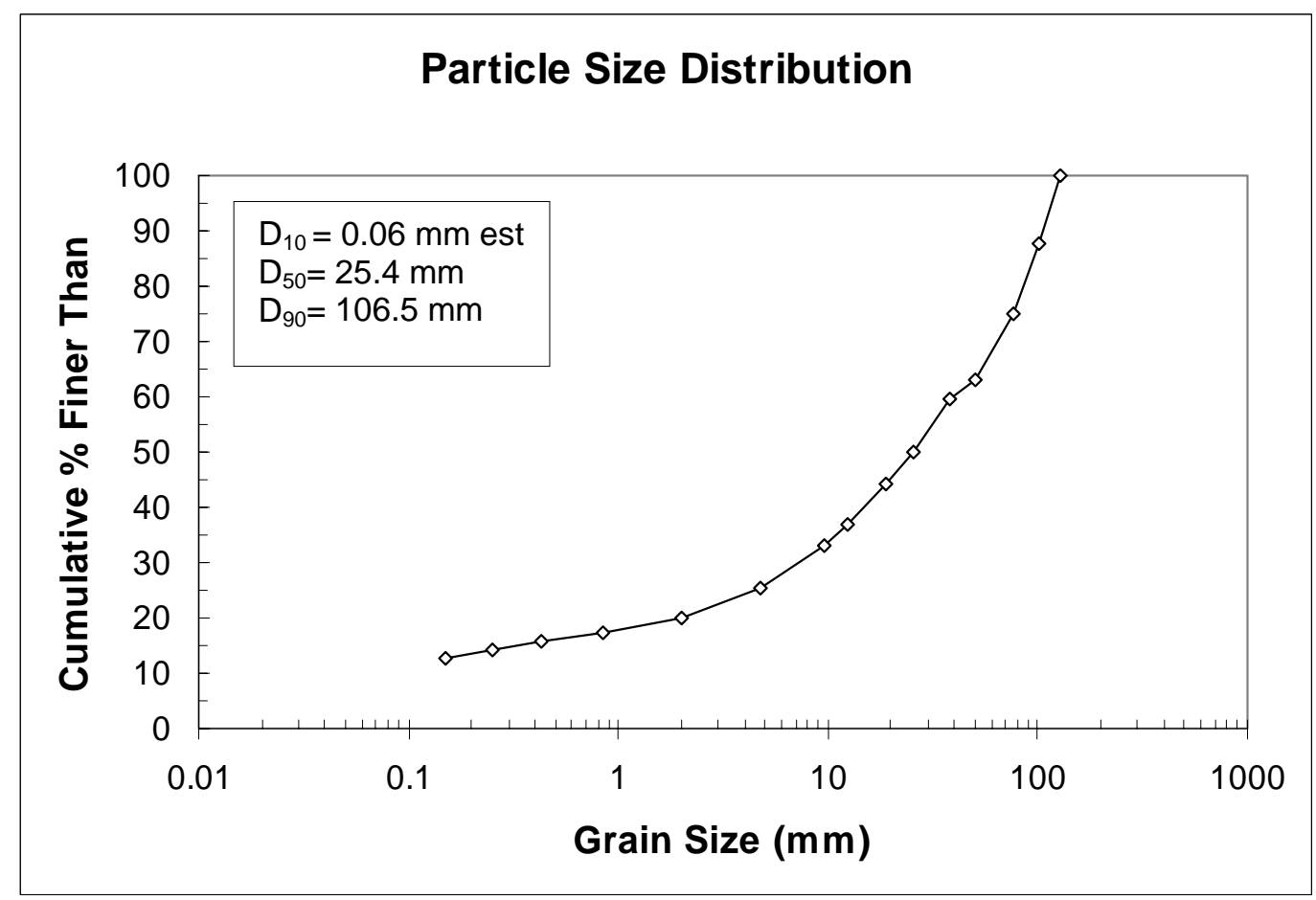

Figure D-2. Particle-size distribution of sample Grays 2; basalt lithology. 


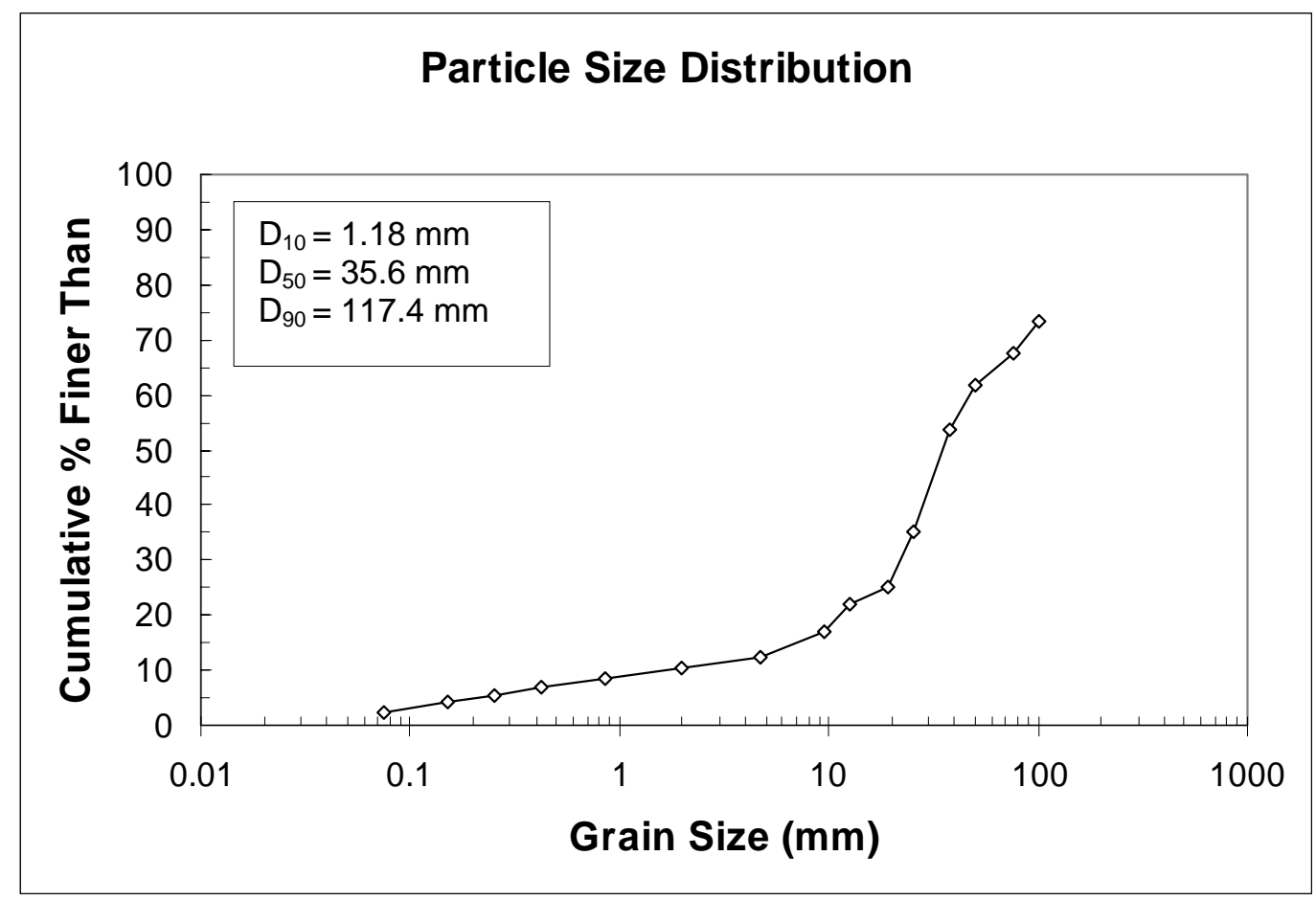

Figure D-3. Particle-size distribution of sample Grays 3; basalt lithology.

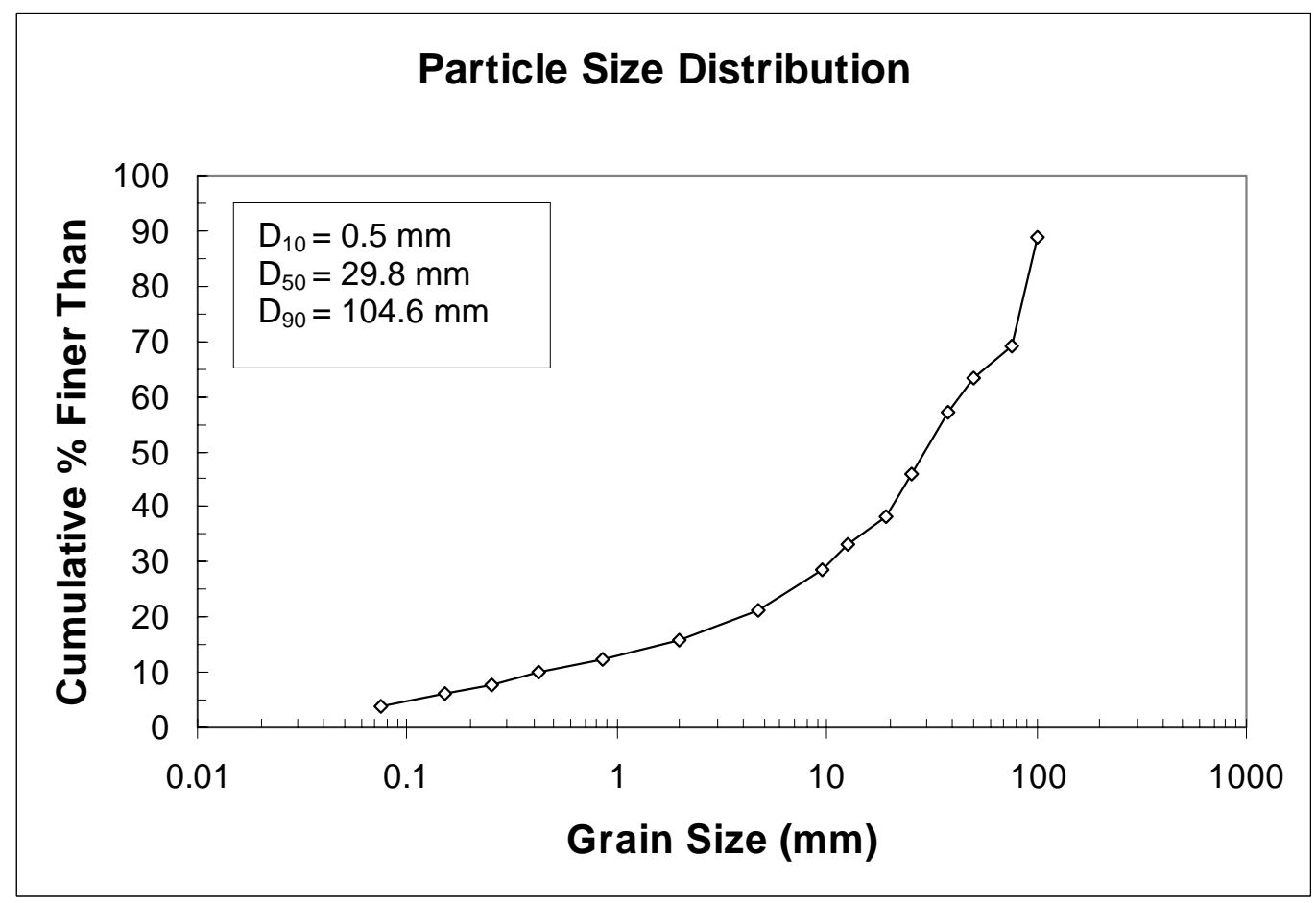

Figure D-4. Particle-size distribution of sample Grays 4; basalt lithology. 


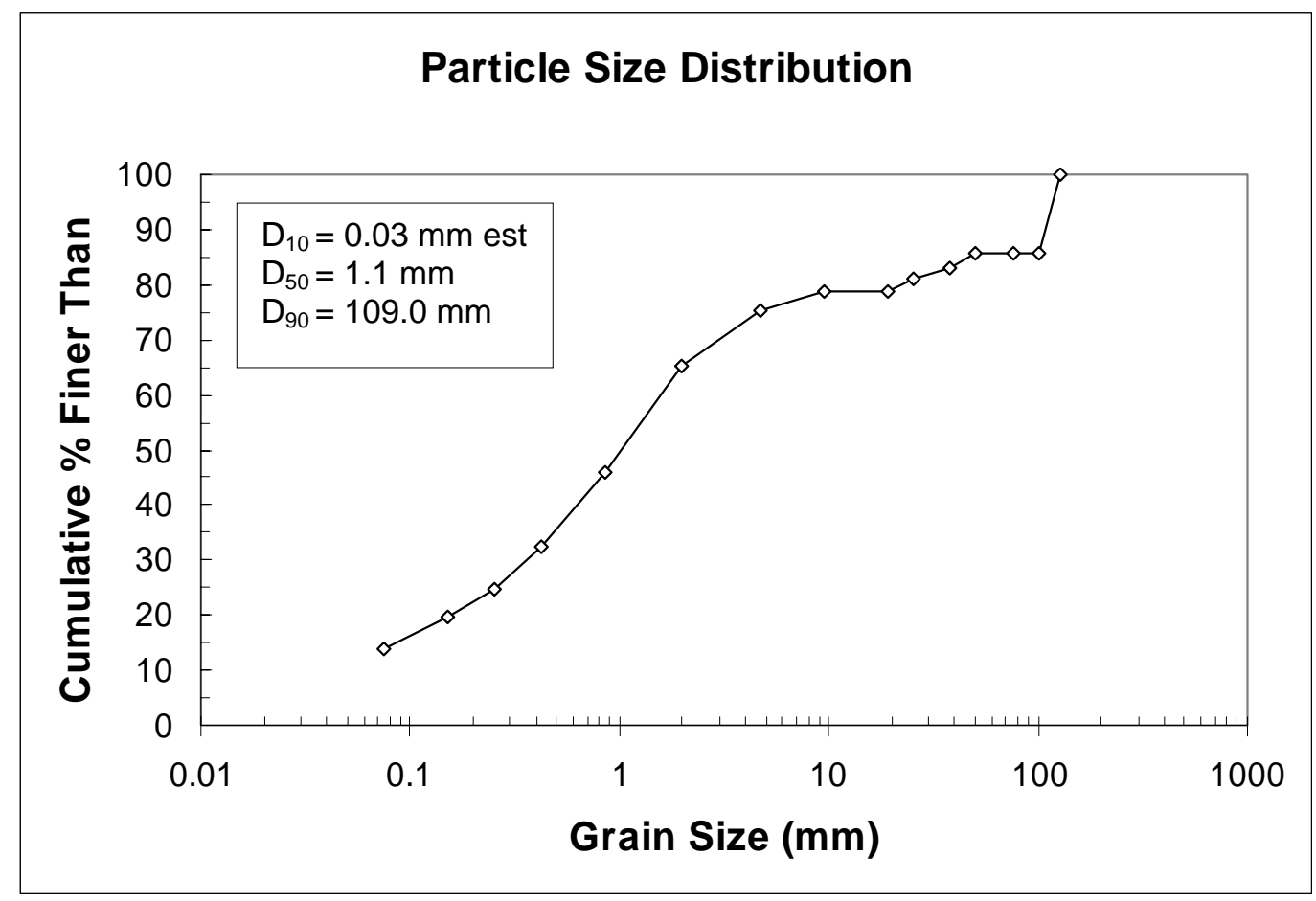

Figure D-5. Particle-size distribution of sample Grays 5; basic intrusive rock lithology.

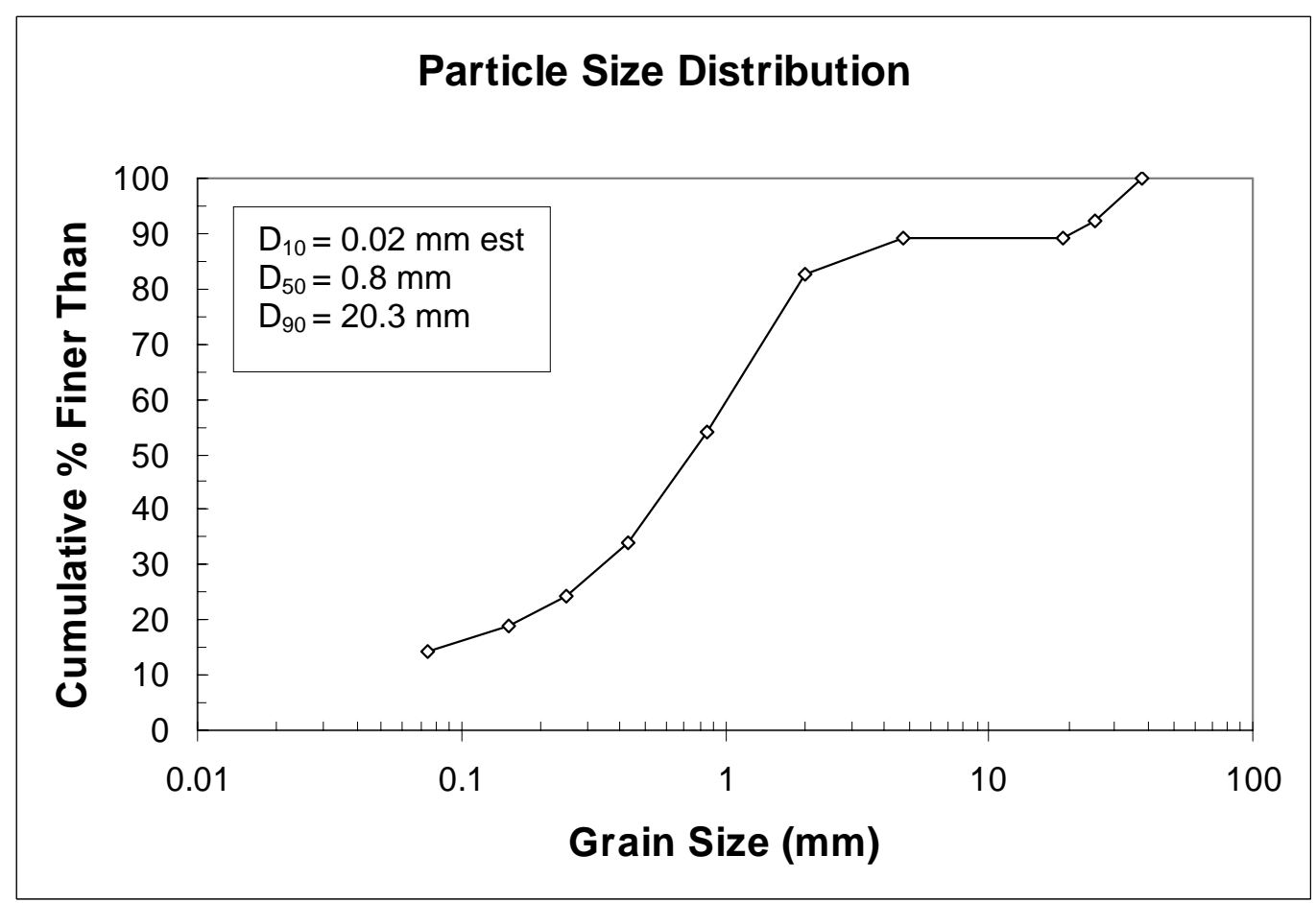

Figure D-6. Particle-size distribution of sample Grays 6; marine sedimentary lithology. 


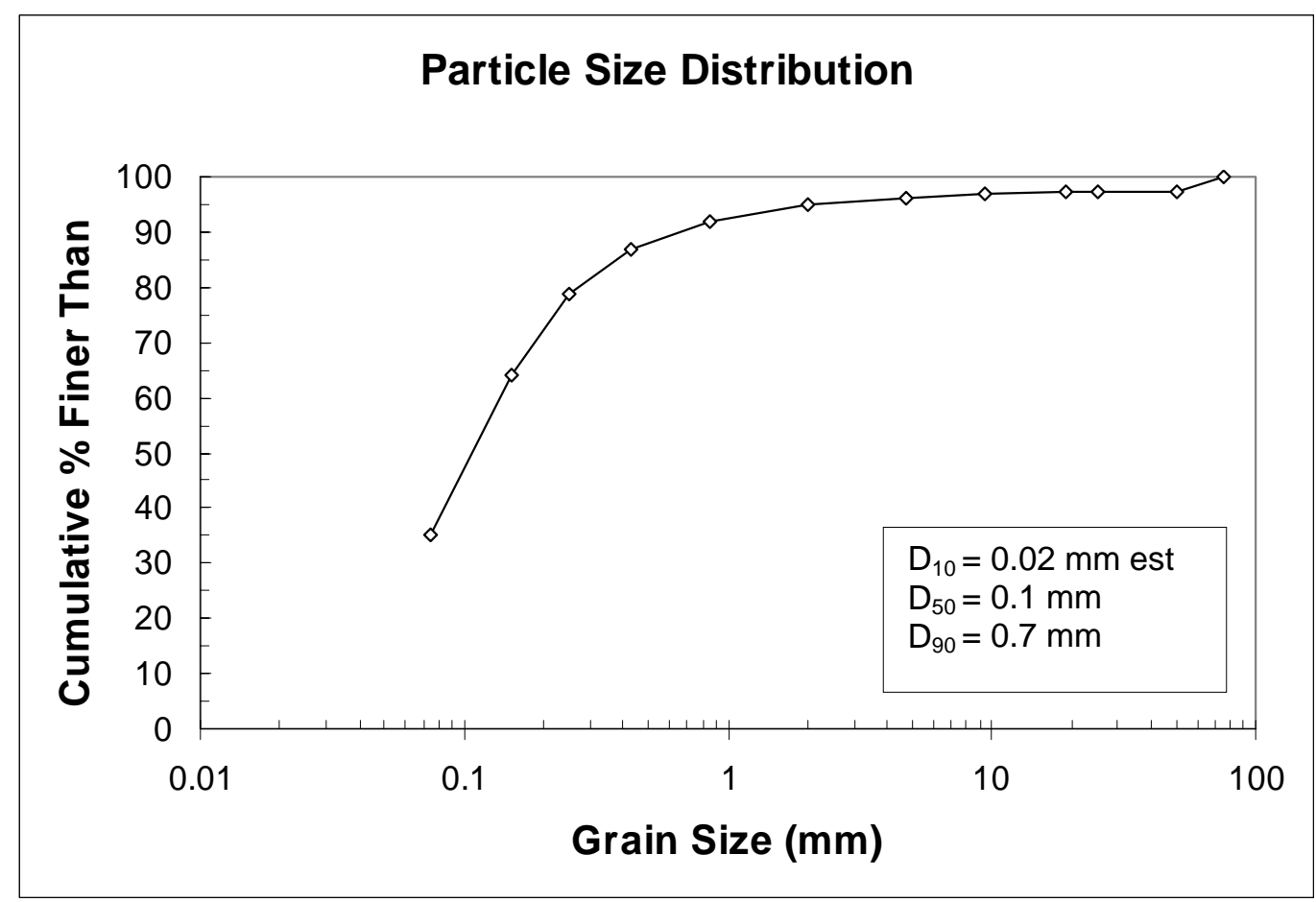

Figure D-7. Particle-size distribution sample Grays 7; tuffs / breccia lithology.

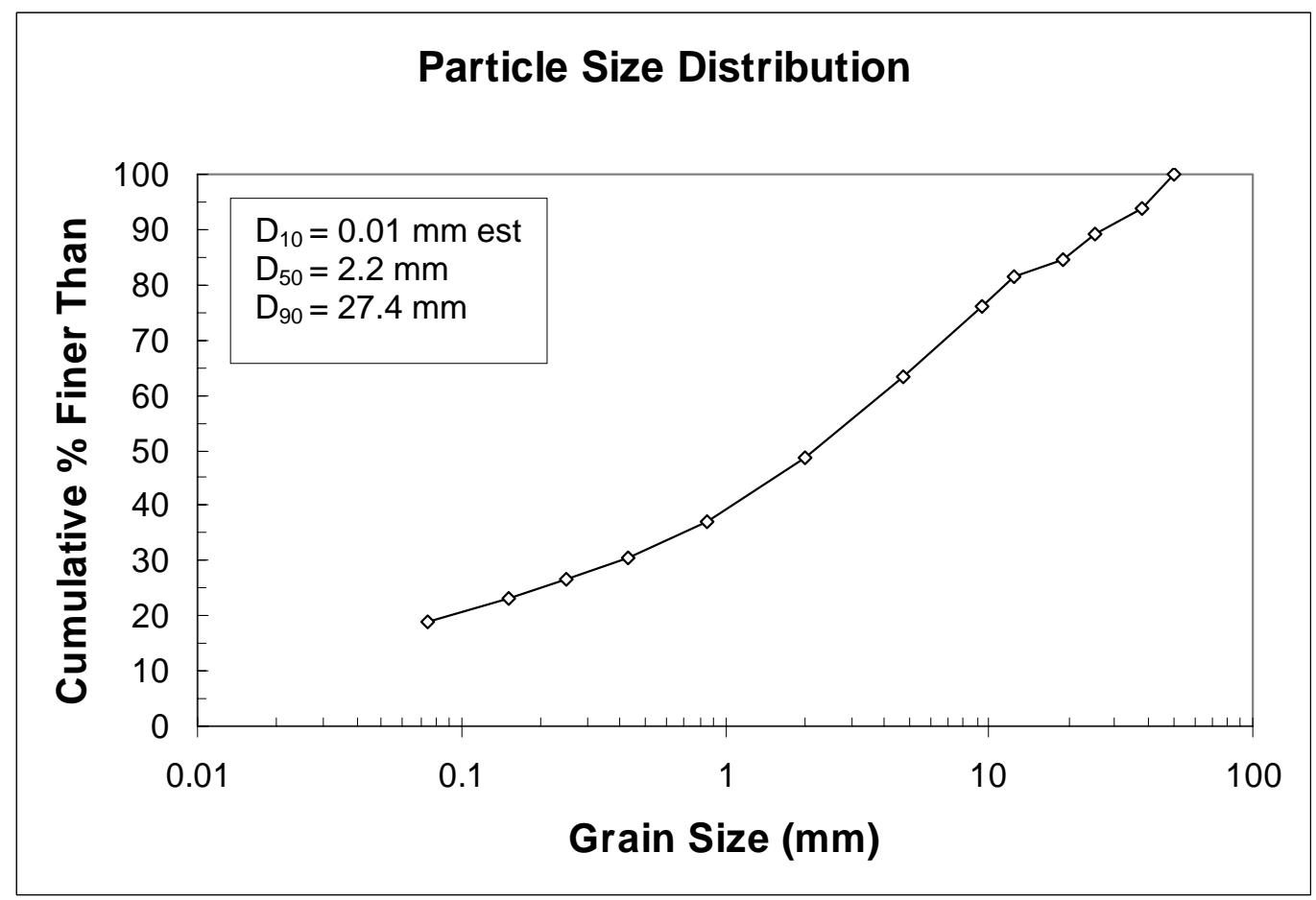

Figure D-8. Particle-size distribution of sample Grays 8; basic intrusive rock lithology. 


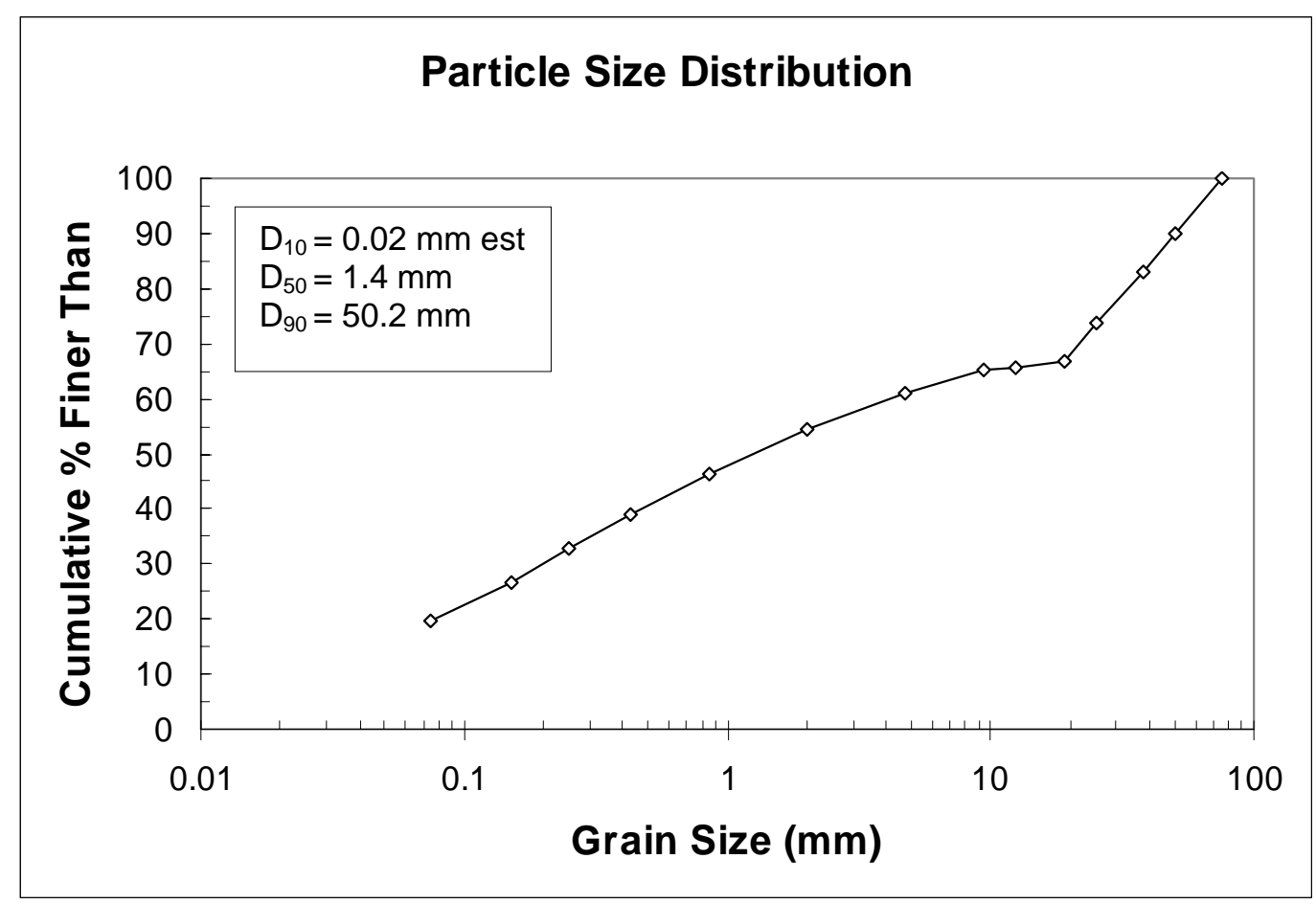

Figure D-9. Particle-size distribution of sample Grays 9; tuff / breccia lithology.

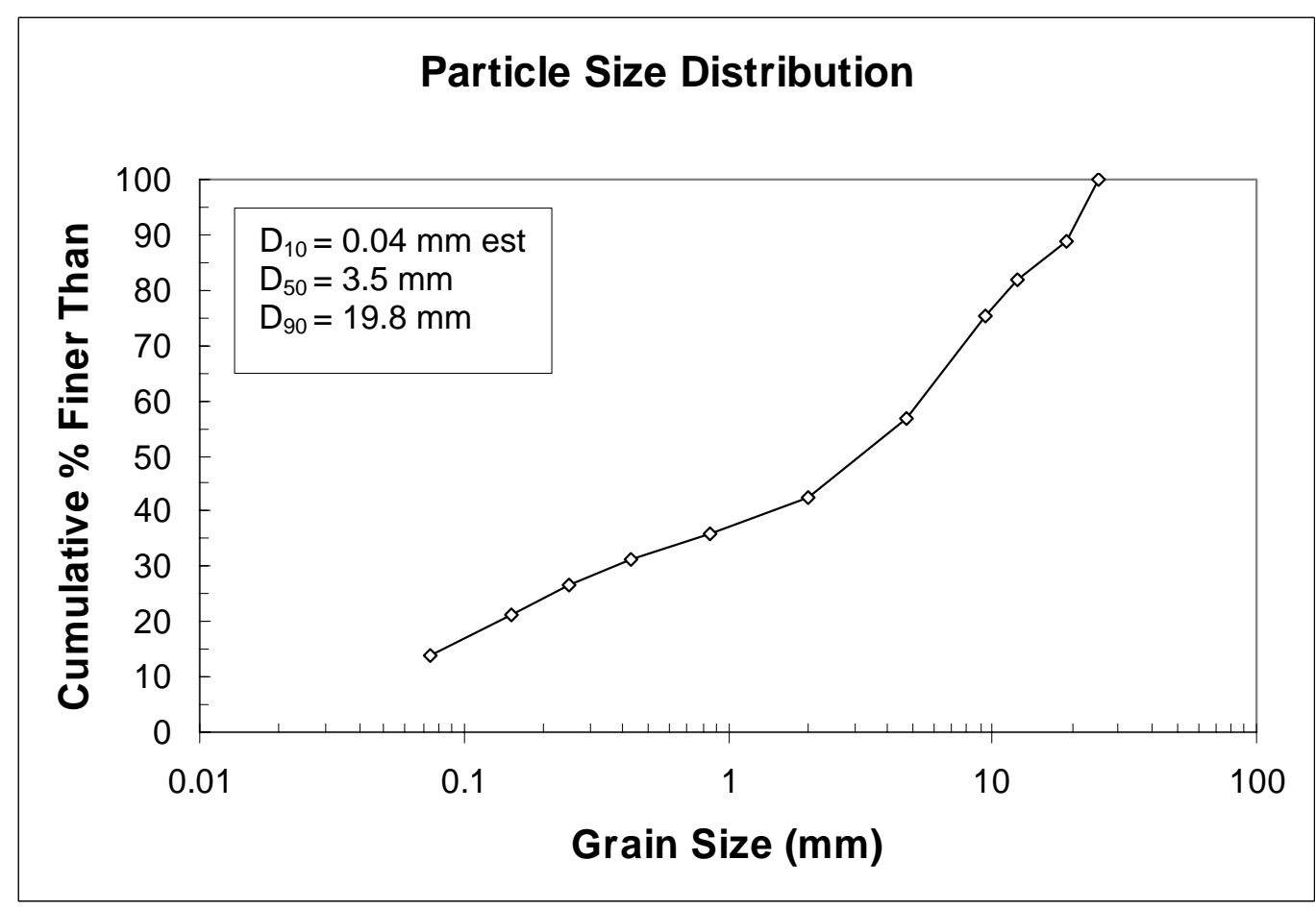

Figure D-10. Particle-size distribution of sample Grays 10; marine sedimentary lithology. 



\section{BETA ANALYTIC INC.}

\section{DR. M.A. TAMERS and MR. D.G. HOOD}

UNIVERSITY BRANCH

4985 S.W. 74 COURT

MAMI, FLORIDA, USA 33155

PH: 305/667-5167 FAX: 305/663-0964

E-MAll: beta@radiocarbon.com

\section{REPORT OF RADIOCARBON DATING ANALYSES}

Mr. Chase Barton

Report Date: 11/24/2004

Herrera Environmental Consultants, Inc.

Material Received: 11/3/2004

Sample Data

\author{
Measured \\ Radiocarbon Age
}

$13 \mathrm{C} / 12 \mathrm{C}$

Ratio
Conventional

Radiocarbon Age $\left(^{*}\right)$

Beta - 197561

$230+/-60 \mathrm{BP}$

-25.6 o/oo

$220+/-60$ BP

SAMPLE : GRAYS RC1

ANALYSIS : Radiometric-Standard delivery

MATERIAL/PRETREATMENT : (wood): acid/alkali/acid

2 SIGMA CALIBRATION :

Cal AD 1520 to 1590 (Cal BP 430 to 360) AND Cal AD 1620 to 1710 (Cal BP 330 to 240)

Cal AD 1720 to 1880 (Cal BP 230 to 70) AND Cal AD 1910 to 1950 (Cal BP 40 to 0)

Beta - 197562

$180+/-60 \mathrm{BP}$

$-27.6 \mathrm{o} / \mathrm{oo}$

$140+/-60 \mathrm{BP}$

SAMPLE : GRAYS RC2

ANALYSIS : Radiometric-Standard delivery

MATERIAL/PRETREATMENT : (wood): acid/alkali/acid

2 SIGMA CALIBRATION : $\quad$ Cal AD 1650 to 1950 (Cal BP 300 to 0)

Dates are reported as RCYBP (radiocarbon years before present, "present" = 1950A.D.). By International convention, the modern reference standard was $95 \%$ of the $\mathrm{C} 14$ content of the National Bureau of Standards' Oxalic Acid \& calculated using the Libby C14 half life (5568 years). Quoted errors represent 1 standard deviation statistics ( $68 \%$ probability) \& are based on combined measurements of the sample, background, and modern reference standards.
Measured $\mathrm{C} 13 / \mathrm{C} 12$ ratios were calculated relative to the PDB-1 international standard and the RCYBP ages were normalized to -25 per mil. If the ratio and age are accompanied by an $\left({ }^{\star}\right)$, then the C13/C12 value was estimated, based on values typical of the material type. The quoted results are NOT calibrated to calendar years. Calibration to calendar years should be calculated using the Conventional $\mathrm{C} 14$ age. 


\section{CALIBRATION OF RADIOCARBON AGE TO CALENDAR YEARS}

(Variables: $\mathrm{C} 13 / \mathrm{C} 12=-25 \cdot 6:$ lab. $\mathrm{mult}=1$ )

Laboratory number: Beta-197561

Conventional radiocarbon age: $220 \pm 60 \mathrm{BP}$

2 Sigma calibrated results: Cal AD 1520 to 1590 (Cal BP 430 to 360 ) and

(95\% probability) Cal AD 1620 to 1710 (Cal BP 330 to 240) and

Cal AD 1720 to 1880 (Cal BP 230 to 70) and

Cal AD 1910 to 1950 (Cal BP 40 to 0)

Intercept data

Intercept of radiocarbon age

with calibration curve:

Cal AD 1660 (Cal BP 290)

1 Sigma calibrated results:

Cal AD 1640 to 1680 (Cal BP 310 to 270) and

(68\% probability)

Cal AD 1740 to 1800 (Cal BP 200 to 150 ) and

Cal AD 1930 to 1950 (Cal BP 20 to 0 )

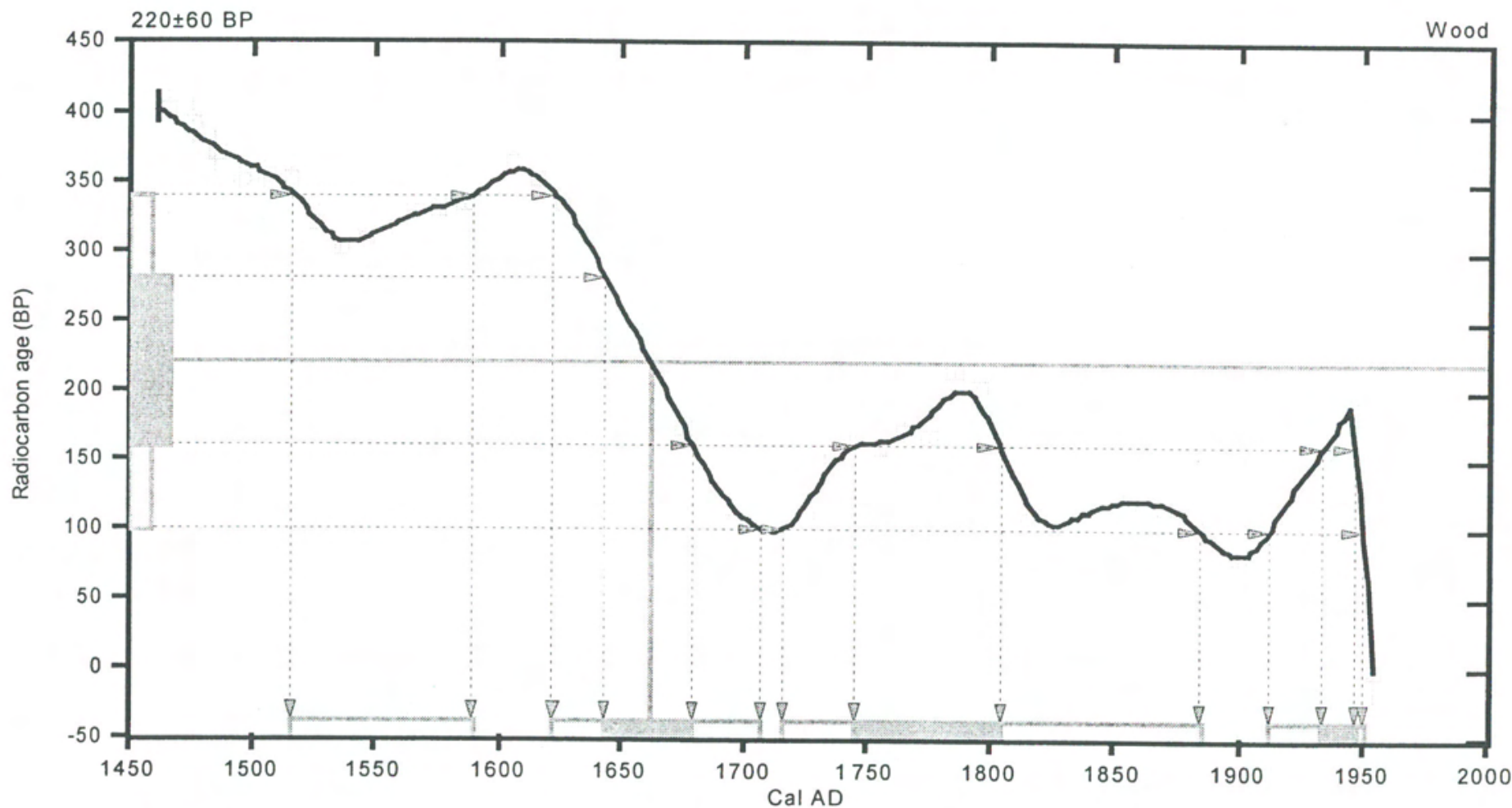

References:

Database used In tcal98

Calibration Database

Editorial Comment

Stuiver, M., van der Plicht, H., 1998, Radiocarbon 40(3), pxii-xiii

INTCAL 98 Radiocarbon Age Calibration

Stuiver, M., et al., 1998, Radio carbon 40(3), p1 041-1083

Math ematics

A Simplified Approach to Calibrating C14 Dates

Talma, A. S., Vogel, J. C., 1993, Radiocarb on 35(2), p317-322 


\section{CALIBRATION OF RADIOCARBON AGE TO CALENDAR YEARS}

(Variables: C13/C 12=-27.6:lab. mult $=1$ )

Laboratory number: Beta-197562

Conventional radiocarbon age: $140 \pm 60 \mathrm{BP}$

2 Sigma calibrated result: Cal AD 1650 to 1950 (Cal BP 300 to 0)

(95\% probability)

Intercept data

Intercepts of radiocarbon age

with calibration curve:

Cal AD 1680 (Cal BP 260) and

Cal AD 1730 (Cal BP 220) and

Cal AD 1810 (Cal BP 140) and

Cal AD 1930 (Cal BP 20) and

Cal AD 1950 (Cal BP 0)

1 Sigma calibrated result: Cal AD 1670 to 1950 (Cal BP 280 to 0)

(68\% probability)

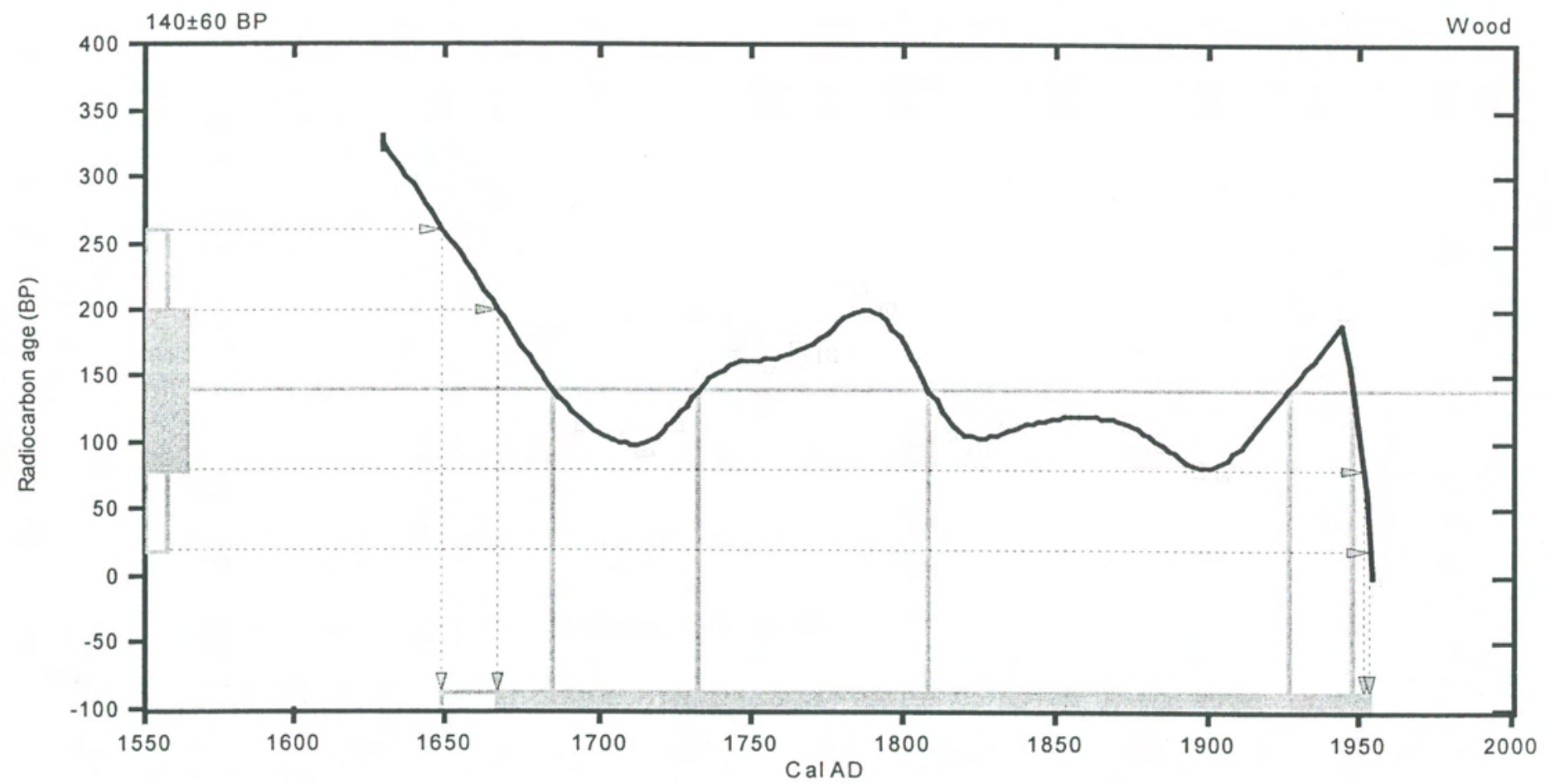

References:

Database used Intcal98

Calibration Database

Editorial Comment

Stuiver, M., van der Plicht, H., 1998, Radiocarbon 40(3), pxii-xiii

INTCAL98 Radiocarbon Age Calibration

Stuiver, M., et al., 1998, Rad io carbon 40(3), p1 041-1083

Math ematics

A Simplified Approach to Calib rating C1 4 Dates

Talma, A. S., Vogel, J. C., 1993, Radiocarb on 35(2), p317-322 



\section{APPENDIX E}

\section{Landslide Inventory}



Table E-1. Inventory of historical landslides. Landslide type refers to rotational (rot), translational (t), and debris flow (df). Estimated volumes are based on assumed depth and delivery ratio described in text. Mass wasting map units refer to geology, harvest age, and slope categories described in text.

\begin{tabular}{|c|c|c|c|c|c|c|c|}
\hline $\begin{array}{l}\text { Landslide } \\
\text { ID }\end{array}$ & Type & Subbasin & $\begin{array}{l}\text { Area } \\
\left(\mathrm{m}^{2}\right)\end{array}$ & $\begin{array}{c}\text { Estimated Volume } \\
\qquad\left(\mathrm{m}^{3}\right)\end{array}$ & $\begin{array}{c}\text { Road } \\
\text { Intersection }\end{array}$ & $\begin{array}{l}\text { Year Last } \\
\text { Harvested }\end{array}$ & $\begin{array}{c}\text { Mass } \\
\text { Wasting Map } \\
\text { Unit }\end{array}$ \\
\hline 0 & rot & 12 & 9,705 & 902 & $\mathrm{~N}$ & 1976 & 223 \\
\hline 1 & $\mathrm{df}$ & 12 & 22,118 & 2,231 & $\mathrm{Y}$ & 1990 & 223 \\
\hline 2 & $\mathrm{t}$ & 12 & 7,651 & 900 & $\mathrm{~N}$ & 1990 & 223 \\
\hline 3 & $\mathrm{t}$ & 12 & 12,631 & 1,592 & $\mathrm{Y}$ & 1990 & 223 \\
\hline 4 & $\mathrm{t}$ & 12 & 15,554 & 1,681 & $\mathrm{Y}$ & 1990 & 223 \\
\hline 5 & $\mathrm{df}$ & 12 & 60 & 270 & $\mathrm{~N}$ & 1990 & 223 \\
\hline 6 & $\mathrm{t}$ & 12 & 26,484 & 3,081 & $\mathrm{Y}$ & 1983 & 223 \\
\hline 7 & $\mathrm{t}$ & 12 & 23,233 & 2,158 & $\mathrm{Y}$ & 1983 & 223 \\
\hline 8 & rot & 12 & 4,883 & 454 & $\mathrm{~N}$ & 1990 & 223 \\
\hline 9 & $\mathrm{t}$ & 12 & 24,941 & 2,366 & $\mathrm{Y}$ & 1976 & 223 \\
\hline 10 & $\mathrm{df}$ & 12 & 6,317 & 587 & $\mathrm{Y}$ & 1976 & 223 \\
\hline 11 & $\mathrm{df}$ & 12 & 14,073 & 1,625 & $\mathrm{Y}$ & 1976 & 223 \\
\hline 12 & $\mathrm{df}$ & 12 & 13,033 & 1,211 & $\mathrm{Y}$ & 1976 & 223 \\
\hline 13 & $\mathrm{t}$ & 12 & 19,572 & 1,900 & $\mathrm{Y}$ & 1976 & 223 \\
\hline 14 & $\mathrm{t}$ & 12 & 41,022 & 6,174 & $\mathrm{Y}$ & 1976 & 223 \\
\hline 15 & $\mathrm{df}$ & 17 & 9,811 & 1,024 & $\mathrm{Y}$ & 1983 & 223 \\
\hline 16 & $\mathrm{t}$ & 20 & 29,117 & 2,779 & $\mathrm{Y}$ & 1976 & 223 \\
\hline 17 & rot & 20 & 2,877 & 267 & $\mathrm{~N}$ & 1983 & 223 \\
\hline 18 & $\mathrm{t}$ & 66 & 6,508 & 616 & $\mathrm{Y}$ & 1990 & 122 \\
\hline 19 & $\mathrm{t}$ & 61 & 5,436 & 2,378 & $\mathrm{~N}$ & 1983 & 121 \\
\hline 20 & $\mathrm{t}$ & 16 & 21,260 & 5,427 & $\mathrm{Y}$ & 1983 & 123 \\
\hline 21 & $\mathrm{t}$ & 16 & 18,418 & 2,532 & $\mathrm{Y}$ & 1000 & 143 \\
\hline 22 & $\mathrm{t}$ & 16 & 7,947 & 738 & $\mathrm{Y}$ & 1000 & 143 \\
\hline 23 & $\mathrm{t}$ & 16 & 9,586 & 1,794 & $\mathrm{Y}$ & 1990 & 123 \\
\hline 24 & $\mathrm{t}$ & 16 & 3,192 & 301 & $\mathrm{Y}$ & 1990 & 123 \\
\hline 25 & $\mathrm{t}$ & 20 & 13,102 & 1,444 & $\mathrm{Y}$ & 1976 & 223 \\
\hline 26 & $\mathrm{t}$ & 22 & 468 & 2,034 & $\mathrm{~N}$ & 1983 & 223 \\
\hline 27 & $\mathrm{df}$ & 61 & 1,570 & 1,480 & $\mathrm{~N}$ & 1990 & 121 \\
\hline 28 & $\mathrm{t}$ & 81 & 2,001 & 768 & $\mathrm{~N}$ & 1983 & 121 \\
\hline 29 & $\mathrm{t}$ & 81 & 6 & 1,255 & $\mathrm{~N}$ & 1976 & 121 \\
\hline 30 & $\mathrm{t}$ & 81 & 1,311 & 231 & $\mathrm{~N}$ & 1983 & 122 \\
\hline 31 & $\mathrm{df}$ & 16 & 4,414 & 790 & $\mathrm{Y}$ & 1976 & 123 \\
\hline 32 & $\mathrm{t}$ & 16 & 9,191 & 1,688 & $\mathrm{~N}$ & 1976 & 123 \\
\hline 33 & $\mathrm{t}$ & 16 & 7,519 & 699 & $\mathrm{~N}$ & 1983 & 123 \\
\hline
\end{tabular}




\begin{tabular}{|c|c|c|c|c|c|c|c|}
\hline $\begin{array}{l}\text { Landslide } \\
\text { ID }\end{array}$ & Type & Subbasin & $\begin{array}{l}\text { Area } \\
\left(\mathrm{m}^{2}\right)\end{array}$ & $\begin{array}{l}\text { Estimated Volume } \\
\qquad\left(\mathrm{m}^{3}\right)\end{array}$ & $\begin{array}{c}\text { Road } \\
\text { Intersection }\end{array}$ & $\begin{array}{l}\text { Year Last } \\
\text { Harvested }\end{array}$ & $\begin{array}{c}\text { Mass } \\
\text { Wasting Map } \\
\text { Unit }\end{array}$ \\
\hline 34 & $\mathrm{t}$ & 16 & 12,647 & 1,177 & $\mathrm{~N}$ & 1983 & 123 \\
\hline 35 & $\mathrm{t}$ & 16 & 7,145 & 744 & $\mathrm{~N}$ & 1983 & 123 \\
\hline 36 & $\mathrm{t}$ & 16 & 8,708 & 809 & $\mathrm{~N}$ & 1983 & 223 \\
\hline 37 & $\mathrm{t}$ & 16 & 5,832 & 542 & $\mathrm{~N}$ & 1983 & 223 \\
\hline 38 & $\mathrm{df}$ & 16 & 9,003 & 879 & $\mathrm{~N}$ & 1983 & 223 \\
\hline 39 & $\mathrm{t}$ & 16 & 23,103 & 2,242 & $\mathrm{~N}$ & 1983 & 223 \\
\hline 40 & $\mathrm{t}$ & 16 & 10,636 & 992 & $\mathrm{~N}$ & 1983 & 223 \\
\hline 41 & $\mathrm{df}$ & 16 & 32 & 735 & $\mathrm{~N}$ & 1976 & 223 \\
\hline 42 & $\mathrm{t}$ & 16 & 17,982 & 1,672 & $\mathrm{~N}$ & 1976 & 223 \\
\hline 43 & $\mathrm{df}$ & 16 & 15,345 & 1,434 & $\mathrm{~N}$ & 1976 & 223 \\
\hline 44 & $\mathrm{t}$ & 16 & 3,237 & 325 & $\mathrm{Y}$ & 1976 & 223 \\
\hline 45 & $\mathrm{df}$ & 16 & 1,685 & 287 & $\mathrm{Y}$ & 1976 & 223 \\
\hline 46 & $\mathrm{t}$ & 16 & 54,143 & 5,745 & $\mathrm{Y}$ & 1976 & 223 \\
\hline 47 & $\mathrm{df}$ & 16 & 61,745 & 6,050 & $\mathrm{Y}$ & 1976 & 223 \\
\hline 48 & $\mathrm{df}$ & 16 & 39,090 & 4,348 & $\mathrm{Y}$ & 1976 & 223 \\
\hline 49 & $\mathrm{df}$ & 16 & 11,234 & 1,044 & $\mathrm{~N}$ & 1976 & 223 \\
\hline 50 & $\mathrm{t}$ & 16 & 5,011 & 1,301 & $\mathrm{Y}$ & 1976 & 223 \\
\hline 51 & $\mathrm{t}$ & 16 & 21,070 & 1,957 & $\mathrm{~N}$ & 1983 & 223 \\
\hline 52 & $\mathrm{t}$ & 16 & 3,861 & 359 & $\mathrm{~N}$ & 1983 & 223 \\
\hline 53 & $\mathrm{df}$ & 16 & 12,036 & 1,189 & $\mathrm{Y}$ & 1983 & 223 \\
\hline 54 & $\mathrm{t}$ & 16 & 90,533 & 13,110 & $\mathrm{Y}$ & 1983 & 223 \\
\hline 55 & $\mathrm{df}$ & 36 & 2,203 & 1,042 & $\mathrm{~N}$ & 1983 & 222 \\
\hline 56 & $\mathrm{df}$ & 54 & 25,300 & 2,482 & $\mathrm{Y}$ & 1976 & 223 \\
\hline 61 & $\mathrm{df}$ & 70 & 3,515 & 4,623 & $\mathrm{~N}$ & 1976 & 222 \\
\hline 62 & $\mathrm{t}$ & 70 & 57,056 & 6,269 & $\mathrm{~N}$ & 1976 & 222 \\
\hline 63 & $\mathrm{df}$ & 7 & 2,173 & 5,458 & $\mathrm{Y}$ & 1976 & 122 \\
\hline 64 & $\mathrm{t}$ & 7 & 31,373 & 3,019 & $\mathrm{Y}$ & 1983 & 123 \\
\hline 65 & $\mathrm{df}$ & 7 & 46,610 & 4,517 & $\mathrm{Y}$ & 1983 & 123 \\
\hline 66 & $\mathrm{df}$ & 7 & 43,780 & 4,554 & $\mathrm{Y}$ & 1983 & 123 \\
\hline 67 & $\mathrm{t}$ & 7 & 10,841 & 1,008 & $\mathrm{~N}$ & 1983 & 123 \\
\hline 68 & $\mathrm{t}$ & 7 & 8,783 & 816 & $\mathrm{~N}$ & 1976 & 223 \\
\hline 69 & $\mathrm{t}$ & 7 & 15,467 & 1,479 & $\mathrm{~N}$ & 1983 & 223 \\
\hline 70 & $\mathrm{t}$ & 7 & 35,109 & 3,262 & $\mathrm{~N}$ & 1983 & 223 \\
\hline 71 & $\mathrm{t}$ & 7 & 47,229 & 4,388 & $\mathrm{Y}$ & 1983 & 223 \\
\hline 72 & $\mathrm{t}$ & 7 & 35,086 & 3,260 & $\mathrm{Y}$ & 1983 & 223 \\
\hline 73 & $\mathrm{t}$ & 7 & 5,292 & 566 & $\mathrm{Y}$ & 1983 & 223 \\
\hline 74 & $\mathrm{df}$ & 6 & 21,322 & 2,679 & $\mathrm{Y}$ & 1976 & 123 \\
\hline 75 & $\mathrm{df}$ & 18 & 19,830 & 1,879 & $\mathrm{Y}$ & 1983 & 123 \\
\hline 76 & $\mathrm{t}$ & 12 & 4,003 & 603 & $\mathrm{~N}$ & 1983 & 223 \\
\hline
\end{tabular}


Grays River Watershed-Geomorphic Analysis

\begin{tabular}{|c|c|c|c|c|c|c|c|}
\hline $\begin{array}{l}\text { Landslide } \\
\text { ID }\end{array}$ & Type & Subbasin & $\begin{array}{l}\text { Area } \\
\left(m^{2}\right)\end{array}$ & $\begin{array}{l}\text { Estimated Volume } \\
\qquad\left(\mathrm{m}^{3}\right)\end{array}$ & $\begin{array}{c}\text { Road } \\
\text { Intersection }\end{array}$ & $\begin{array}{l}\text { Year Last } \\
\text { Harvested }\end{array}$ & $\begin{array}{c}\text { Mass } \\
\text { Wasting Map } \\
\text { Unit }\end{array}$ \\
\hline 77 & $\mathrm{df}$ & 12 & 9,930 & 923 & $\mathrm{~N}$ & 1983 & 223 \\
\hline 78 & $\mathrm{df}$ & 12 & 24,351 & 2,338 & $\mathrm{~N}$ & 1983 & 223 \\
\hline 79 & $\mathrm{t}$ & 12 & 18,949 & 2,449 & $\mathrm{~N}$ & 1983 & 222 \\
\hline 80 & $\mathrm{df}$ & 22 & 9,212 & 2,967 & $\mathrm{Y}$ & 1983 & 223 \\
\hline 81 & rot & 44 & 24,169 & 2,426 & $\mathrm{~N}$ & 1942 & 132 \\
\hline 82 & $\mathrm{df}$ & 44 & 806 & 4,956 & $\mathrm{Y}$ & 1964 & 132 \\
\hline 83 & $\mathrm{df}$ & 66 & 331 & 1,631 & $\mathrm{~N}$ & 1964 & 132 \\
\hline 84 & $\mathrm{t}$ & 66 & 16,219 & 3,084 & $\mathrm{~N}$ & 1942 & 132 \\
\hline 85 & $\mathrm{t}$ & 12 & 221 & 3,339 & $\mathrm{Y}$ & 1976 & 223 \\
\hline 86 & $\mathrm{t}$ & 17 & 7,799 & 1,368 & $\mathrm{Y}$ & 1983 & 223 \\
\hline 87 & $\mathrm{df}$ & 17 & 568 & 1,099 & $\mathrm{~N}$ & 1990 & 223 \\
\hline 88 & $\mathrm{df}$ & 20 & 21,748 & 3,259 & $\mathrm{Y}$ & 1983 & 223 \\
\hline 89 & $\mathrm{df}$ & 20 & 6,353 & 920 & $\mathrm{Y}$ & 1983 & 223 \\
\hline 90 & $\mathrm{t}$ & 20 & 27,517 & 4,683 & $\mathrm{Y}$ & 1983 & 223 \\
\hline 91 & $\mathrm{df}$ & 36 & 13,923 & 3,683 & $\mathrm{Y}$ & 1983 & 222 \\
\hline 92 & rot & 54 & 9,073 & 90,385 & $\mathrm{~N}$ & 1942 & 131 \\
\hline 93 & rot & 16 & 25,518 & 2,604 & $\mathrm{~N}$ & 1983 & 223 \\
\hline 94 & rot & 16 & 51,899 & 5,140 & $\mathrm{~N}$ & 1983 & 223 \\
\hline 95 & $\mathrm{t}$ & 16 & 27,104 & 3,327 & $\mathrm{Y}$ & 1990 & 223 \\
\hline 96 & $\mathrm{df}$ & 16 & 15,091 & 1,859 & $\mathrm{Y}$ & 1990 & 223 \\
\hline 97 & $\mathrm{t}$ & 16 & 9,483 & 1,896 & $\mathrm{Y}$ & 1990 & 223 \\
\hline 98 & rot & 16 & 60,784 & 5,647 & $\mathrm{~N}$ & 1983 & 223 \\
\hline 99 & $\mathrm{df}$ & 16 & 30,134 & 4,335 & $\mathrm{Y}$ & 1976 & 223 \\
\hline 100 & $\mathrm{df}$ & 16 & 54,431 & 5,995 & $\mathrm{Y}$ & 1983 & 223 \\
\hline 101 & rot & 61 & 69,791 & 34,276 & $\mathrm{~N}$ & 1953 & 131 \\
\hline 102 & $\mathrm{df}$ & 16 & 47,245 & 4,389 & $\mathrm{Y}$ & 1976 & 223 \\
\hline 103 & $\mathrm{df}$ & 16 & 22,455 & 2,086 & $\mathrm{~N}$ & 1976 & 223 \\
\hline 107 & $\mathrm{df}$ & 16 & 9,942 & 1,051 & $\mathrm{~N}$ & 1983 & 223 \\
\hline 108 & $\mathrm{df}$ & 16 & 174 & 3,326 & $\mathrm{Y}$ & 1983 & 222 \\
\hline 111 & $\mathrm{df}$ & 16 & 12,681 & 2,349 & $\mathrm{Y}$ & 1983 & 223 \\
\hline 112 & df & 16 & 12,088 & 1,688 & $\mathrm{Y}$ & 1983 & 223 \\
\hline 113 & $\mathrm{df}$ & 16 & 1,894 & 5,010 & $\mathrm{Y}$ & 1983 & 223 \\
\hline 114 & $\mathrm{df}$ & 16 & 8,517 & 2,895 & $\mathrm{Y}$ & 1976 & 223 \\
\hline 115 & $\mathrm{t}$ & 16 & 12,294 & 1,451 & $\mathrm{Y}$ & 1983 & 223 \\
\hline 119 & $\mathrm{t}$ & 61 & 6,445 & 9,057 & $\mathrm{Y}$ & 1983 & 222 \\
\hline 123 & $\mathrm{t}$ & 84 & 105 & 1,647 & $\mathrm{~N}$ & 1976 & 122 \\
\hline 124 & rot & 8 & 45 & 1,344 & $\mathrm{Y}$ & 1953 & 132 \\
\hline 125 & $\mathrm{t}$ & 8 & 21,061 & 2,907 & $\mathrm{Y}$ & 1976 & 123 \\
\hline 126 & rot & 14 & 20,296 & 1,886 & $\mathrm{~N}$ & 1976 & 223 \\
\hline
\end{tabular}




\begin{tabular}{|c|c|c|c|c|c|c|c|}
\hline $\begin{array}{l}\text { Landslide } \\
\text { ID }\end{array}$ & Type & Subbasin & $\begin{array}{l}\text { Area } \\
\left(m^{2}\right)\end{array}$ & $\begin{array}{c}\text { Estimated Volume } \\
\left(\mathrm{m}^{3}\right)\end{array}$ & $\begin{array}{c}\text { Road } \\
\text { Intersection }\end{array}$ & $\begin{array}{l}\text { Year Last } \\
\text { Harvested }\end{array}$ & $\begin{array}{c}\text { Mass } \\
\text { Wasting Map } \\
\text { Unit }\end{array}$ \\
\hline 127 & $\mathrm{t}$ & 14 & 9,316 & 928 & $\mathrm{~N}$ & 1976 & 223 \\
\hline 128 & $\mathrm{t}$ & 32 & 12,371 & 1,205 & $\mathrm{~N}$ & 1964 & 132 \\
\hline 136 & $\mathrm{df}$ & 61 & 62,176 & 12,415 & $\mathrm{~N}$ & 1964 & 232 \\
\hline 137 & $\mathrm{t}$ & 61 & 61,030 & 5,741 & $\mathrm{~N}$ & 1964 & 233 \\
\hline 142 & $\mathrm{df}$ & 82 & 18,270 & 2,429 & $\mathrm{~N}$ & 1990 & 122 \\
\hline 145 & $\mathrm{df}$ & 8 & 20,087 & 3,502 & $\mathrm{Y}$ & 1976 & 222 \\
\hline 146 & $\mathrm{df}$ & 8 & 7,313 & 1,741 & $\mathrm{Y}$ & 1976 & 222 \\
\hline 147 & $\mathrm{t}$ & 18 & 4,765 & 3,939 & $\mathrm{Y}$ & 1976 & 122 \\
\hline 148 & $\mathrm{df}$ & 18 & 27,167 & 3,490 & $\mathrm{Y}$ & 1976 & 123 \\
\hline 149 & df & 18 & 12,567 & 1,167 & $\mathrm{Y}$ & 1976 & 123 \\
\hline 150 & $\mathrm{df}$ & 18 & 8,563 & 1,214 & $\mathrm{~N}$ & 1983 & 123 \\
\hline 151 & df & 18 & 36,204 & 5,270 & $\mathrm{Y}$ & 1976 & 122 \\
\hline 152 & df & 83 & 3,590 & 1,109 & $\mathrm{Y}$ & 1990 & 121 \\
\hline 153 & df & 82 & 19,350 & 3,200 & $\mathrm{Y}$ & 1990 & 121 \\
\hline 154 & $\mathrm{t}$ & 18 & 39,976 & 4,125 & $\mathrm{Y}$ & 1983 & 123 \\
\hline 155 & $\mathrm{t}$ & 18 & 20,080 & 1,867 & $\mathrm{Y}$ & 1983 & 222 \\
\hline 161 & $\mathrm{t}$ & 49 & 26,919 & 2,743 & $\mathrm{~N}$ & 1976 & 223 \\
\hline 162 & df & 49 & 24,208 & 12,194 & $\mathrm{Y}$ & 1976 & 221 \\
\hline 163 & $\mathrm{df}$ & 49 & 1,470 & 3,801 & $\mathrm{Y}$ & 1983 & 222 \\
\hline 164 & rot & 49 & 27,782 & 5,950 & $\mathrm{Y}$ & 1983 & 222 \\
\hline 165 & $\mathrm{df}$ & 56 & 8,680 & 5,022 & $\mathrm{~N}$ & 1964 & 231 \\
\hline 166 & $\mathrm{t}$ & 56 & 227 & 90,793 & $\mathrm{~N}$ & 1964 & 231 \\
\hline 167 & rot & 67 & 12,815 & 3,765 & $\mathrm{~N}$ & 1983 & 222 \\
\hline 168 & $\mathrm{t}$ & 67 & 40 & 744 & $\mathrm{~N}$ & 1942 & 231 \\
\hline 170 & $\mathrm{t}$ & 67 & 212 & 300 & $\mathrm{~N}$ & 1983 & 223 \\
\hline 174 & $\mathrm{t}$ & 83 & 38,429 & 3,570 & $\mathrm{Y}$ & 1990 & 121 \\
\hline 175 & $\mathrm{t}$ & 83 & 17,283 & 2,952 & $\mathrm{Y}$ & 1990 & 121 \\
\hline 176 & $\mathrm{t}$ & 2 & 7,679 & 3,826 & $\mathrm{Y}$ & 1976 & 222 \\
\hline 178 & $\mathrm{df}$ & 2 & 163 & 1,451 & $\mathrm{Y}$ & 1976 & 222 \\
\hline 179 & $\mathrm{df}$ & 2 & 13,568 & 1,964 & $\mathrm{Y}$ & 1976 & 222 \\
\hline 180 & $\mathrm{df}$ & 7 & 18,391 & 2,092 & $\mathrm{~N}$ & 1976 & 223 \\
\hline 181 & $\mathrm{df}$ & 7 & 15,783 & 1,816 & $\mathrm{Y}$ & 1976 & 223 \\
\hline 182 & $\mathrm{t}$ & 7 & 20,464 & 1,901 & $\mathrm{~N}$ & 1983 & 223 \\
\hline 183 & $\mathrm{df}$ & 7 & 7,912 & 742 & $\mathrm{~N}$ & 1983 & 223 \\
\hline 184 & $\mathrm{df}$ & 13 & 958 & 5,340 & $\mathrm{~N}$ & 1976 & 122 \\
\hline 185 & rot & 13 & 17,558 & 2,024 & $\mathrm{~N}$ & 1990 & 223 \\
\hline 186 & $\mathrm{df}$ & 13 & 7,038 & 1,744 & $\mathrm{Y}$ & 1990 & 223 \\
\hline 187 & $\mathrm{df}$ & 18 & 9,213 & 1,045 & $\mathrm{Y}$ & 1983 & 223 \\
\hline 188 & $\mathrm{df}$ & 18 & 10,402 & 2,422 & Y & 1983 & 222 \\
\hline
\end{tabular}


Grays River Watershed-Geomorphic Analysis

\begin{tabular}{|c|c|c|c|c|c|c|c|}
\hline $\begin{array}{l}\text { Landslide } \\
\text { ID }\end{array}$ & Type & Subbasin & $\begin{array}{l}\text { Area } \\
\left(\mathrm{m}^{2}\right)\end{array}$ & $\begin{array}{l}\text { Estimated Volume } \\
\qquad\left(\mathrm{m}^{3}\right)\end{array}$ & $\begin{array}{c}\text { Road } \\
\text { Intersection }\end{array}$ & $\begin{array}{l}\text { Year Last } \\
\text { Harvested }\end{array}$ & $\begin{array}{c}\text { Mass } \\
\text { Wasting Map } \\
\text { Unit }\end{array}$ \\
\hline 191 & $\mathrm{t}$ & 30 & 11,170 & 1,346 & $\mathrm{~N}$ & 1983 & 122 \\
\hline 198 & $\mathrm{t}$ & 68 & 7,488 & 7,466 & $\mathrm{~N}$ & 1983 & 222 \\
\hline 199 & $\mathrm{t}$ & 68 & 91,842 & 24,982 & $\mathrm{Y}$ & 1983 & 222 \\
\hline 203 & $\mathrm{t}$ & 2 & 7,532 & 3,681 & $\mathrm{Y}$ & 1976 & 222 \\
\hline 204 & $\mathrm{t}$ & 2 & 45,575 & 4,411 & $\mathrm{Y}$ & 1976 & 223 \\
\hline 205 & $\mathrm{df}$ & 2 & 24,877 & 3,787 & $\mathrm{Y}$ & 1976 & 223 \\
\hline 206 & $\mathrm{t}$ & 7 & 16,039 & 2,646 & $\mathrm{Y}$ & 1976 & 223 \\
\hline 208 & rot & 45 & 15,005 & 2,638 & $\mathrm{~N}$ & 1976 & 122 \\
\hline 211 & $\mathrm{df}$ & 59 & 26,118 & 4,758 & $\mathrm{Y}$ & 1983 & 222 \\
\hline 212 & $\mathrm{df}$ & 59 & 21,565 & 3,285 & $\mathrm{Y}$ & 1983 & 222 \\
\hline 213 & $\mathrm{df}$ & 6 & 8,773 & 2,089 & $\mathrm{Y}$ & 1983 & 123 \\
\hline 214 & $\mathrm{df}$ & 6 & 14,358 & 1,874 & $\mathrm{Y}$ & 1983 & 123 \\
\hline 215 & $\mathrm{df}$ & 6 & 8,119 & 1,646 & $\mathrm{Y}$ & 1983 & 123 \\
\hline 216 & $\mathrm{df}$ & 6 & 19,209 & 1,976 & $\mathrm{Y}$ & 1983 & 122 \\
\hline 217 & $\mathrm{df}$ & 6 & 548 & 2,158 & $\mathrm{~N}$ & 1976 & 122 \\
\hline 218 & df & 6 & 1,698 & 1,398 & $\mathrm{Y}$ & 1983 & 122 \\
\hline 219 & $\mathrm{t}$ & 7 & 9,691 & 1,195 & $\mathrm{Y}$ & 1976 & 223 \\
\hline 220 & $\mathrm{df}$ & 7 & 37,410 & 4,102 & $\mathrm{Y}$ & 1983 & 223 \\
\hline 221 & $\mathrm{df}$ & 7 & 27,341 & 2,901 & $\mathrm{Y}$ & 1983 & 223 \\
\hline 222 & $\mathrm{df}$ & 7 & 4,800 & 458 & $\mathrm{Y}$ & 1983 & 223 \\
\hline 223 & $\mathrm{df}$ & 7 & 7,191 & 773 & $\mathrm{Y}$ & 1983 & 223 \\
\hline 224 & $\mathrm{df}$ & 7 & 6,361 & 658 & $\mathrm{Y}$ & 1983 & 223 \\
\hline 225 & $\mathrm{t}$ & 15 & 3,337 & 1,423 & $\mathrm{Y}$ & 1976 & 122 \\
\hline 226 & $\mathrm{t}$ & 15 & 4,668 & 967 & $\mathrm{Y}$ & 1976 & 122 \\
\hline 227 & rot & 15 & 6,415 & 1,931 & $\mathrm{~N}$ & 1976 & 122 \\
\hline 228 & rot & 15 & 1,653 & 867 & $\mathrm{~N}$ & 1976 & 121 \\
\hline 229 & $\mathrm{t}$ & 15 & 2,762 & 1,479 & $\mathrm{Y}$ & 1976 & 121 \\
\hline 230 & $\mathrm{df}$ & 15 & 515 & 1,267 & $\mathrm{Y}$ & 1976 & 121 \\
\hline 231 & $\mathrm{df}$ & 15 & 12,747 & 1,907 & $\mathrm{Y}$ & 1976 & 122 \\
\hline 233 & $\mathrm{df}$ & 76 & 30,920 & 2,934 & $\mathrm{Y}$ & 1964 & 231 \\
\hline 234 & $\mathrm{df}$ & 6 & 13,592 & 2,613 & $\mathrm{Y}$ & 1976 & 122 \\
\hline 235 & rot & 6 & 7,717 & 1,182 & $\mathrm{~N}$ & 1976 & 223 \\
\hline 236 & $\mathrm{df}$ & 6 & 10,705 & 1,170 & $\mathrm{Y}$ & 1983 & 222 \\
\hline 237 & $\mathrm{df}$ & 6 & 4,903 & 5,868 & $\mathrm{Y}$ & 1976 & 222 \\
\hline 238 & $\mathrm{df}$ & 6 & 5,878 & 1,463 & $\mathrm{Y}$ & 1983 & 222 \\
\hline 239 & rot & 6 & 3,812 & 3,032 & $\mathrm{~N}$ & 1983 & 222 \\
\hline 240 & $\mathrm{df}$ & 6 & 18,981 & 3,853 & $\mathrm{Y}$ & 1983 & 222 \\
\hline 241 & $\mathrm{t}$ & 7 & 9,339 & 1,093 & $\mathrm{~N}$ & 1983 & 223 \\
\hline 242 & $\mathrm{t}$ & 7 & 1,256 & 3,154 & $\mathrm{Y}$ & 1976 & 222 \\
\hline
\end{tabular}




\begin{tabular}{|c|c|c|c|c|c|c|c||}
\hline $\begin{array}{c}\text { Landslide } \\
\text { ID }\end{array}$ & Type & Subbasin & $\begin{array}{c}\text { Area } \\
\left(\mathrm{m}^{2}\right)\end{array}$ & $\begin{array}{c}\text { Estimated Volume } \\
\left(\mathrm{m}^{3}\right)\end{array}$ & $\begin{array}{c}\text { Road } \\
\text { Intersection }\end{array}$ & $\begin{array}{c}\text { Year Last } \\
\text { Harvested }\end{array}$ & $\begin{array}{c}\text { Mass } \\
\text { Unit }\end{array}$ \\
\hline \hline 244 & df & 15 & 401 & 3,320 & $\mathrm{Y}$ & 1976 & 121 \\
\hline 245 & $\mathrm{df}$ & 15 & 24,007 & 2,357 & $\mathrm{Y}$ & 1976 & 221 \\
\hline 246 & rot & 15 & 2,310 & 1,449 & $\mathrm{~N}$ & 1976 & 221 \\
\hline 248 & rot & 7 & 27,057 & 2,516 & $\mathrm{Y}$ & 1983 & 223 \\
\hline 249 & rot & 7 & 2,951 & 1,786 & $\mathrm{Y}$ & 1976 & 223 \\
\hline 250 & $\mathrm{t}$ & 7 & 28,240 & 4,844 & $\mathrm{Y}$ & 1976 & 223 \\
\hline 251 & rot & 7 & 6,244 & 2,327 & $\mathrm{Y}$ & 1976 & 222 \\
\hline 252 & $\mathrm{t}$ & 15 & 3,125 & 1,150 & $\mathrm{Y}$ & 1976 & 222 \\
\hline 253 & $\mathrm{df}$ & 15 & 655 & 1,229 & $\mathrm{~N}$ & 1976 & 222 \\
\hline 254 & $\mathrm{df}$ & 15 & 632 & 2,029 & $\mathrm{Y}$ & 1976 & 222 \\
\hline 256 & $\mathrm{df}$ & 15 & 33,794 & 6,153 & $\mathrm{Y}$ & 1976 & 221 \\
\hline 257 & $\mathrm{df}$ & 19 & 10,367 & 1,174 & $\mathrm{Y}$ & 1976 & 121 \\
\hline 258 & rot & 19 & 4,632 & 2,750 & $\mathrm{Y}$ & 1976 & 122 \\
\hline 260 & rot & 64 & 15,303 & 1,620 & $\mathrm{~N}$ & 1976 & 222 \\
\hline 261 & $\mathrm{df}$ & 7 & 10,776 & 2,107 & $\mathrm{Y}$ & 1983 & 222 \\
\hline 262 & $\mathrm{t}$ & 15 & 25,040 & 4,374 & $\mathrm{~N}$ & 1976 & 222 \\
\hline 263 & $\mathrm{df}$ & 33 & 19,040 & 2,318 & $\mathrm{Y}$ & 1964 & 232 \\
\hline 264 & $\mathrm{df}$ & 33 & 17,178 & 2,629 & $\mathrm{Y}$ & 1964 & 232 \\
\hline 265 & $\mathrm{t}$ & 15 & 4,809 & 1,759 & $\mathrm{Y}$ & 1976 & 222 \\
\hline 266 & $\mathrm{t}$ & 15 & 26,446 & 10,423 & $\mathrm{Y}$ & 1976 & 222 \\
\hline 267 & $\mathrm{df}$ & 19 & 81,239 & 14,036 & $\mathrm{Y}$ & 1964 & 232 \\
\hline 268 & $\mathrm{df}$ & 19 & 19,605 & 3,292 & $\mathrm{Y}$ & 1976 & 222 \\
\hline 269 & $\mathrm{t}$ & 25 & 7,103 & 1,329 & $\mathrm{Y}$ & 1976 & 123 \\
\hline 272 & $\mathrm{rot}$ & 61 & 91 & 10,315 & $\mathrm{~N}$ & 1942 & 231 \\
\hline 273 & $\mathrm{df}$ & 20 & 13,386 & 2,351 & $\mathrm{Y}$ & 1976 & 223 \\
\hline 274 & $\mathrm{t}$ & 59 & 126,670 & 98,435 & $\mathrm{Y}$ & 1976 & 222 \\
\hline & & & & & & & \\
\hline
\end{tabular}




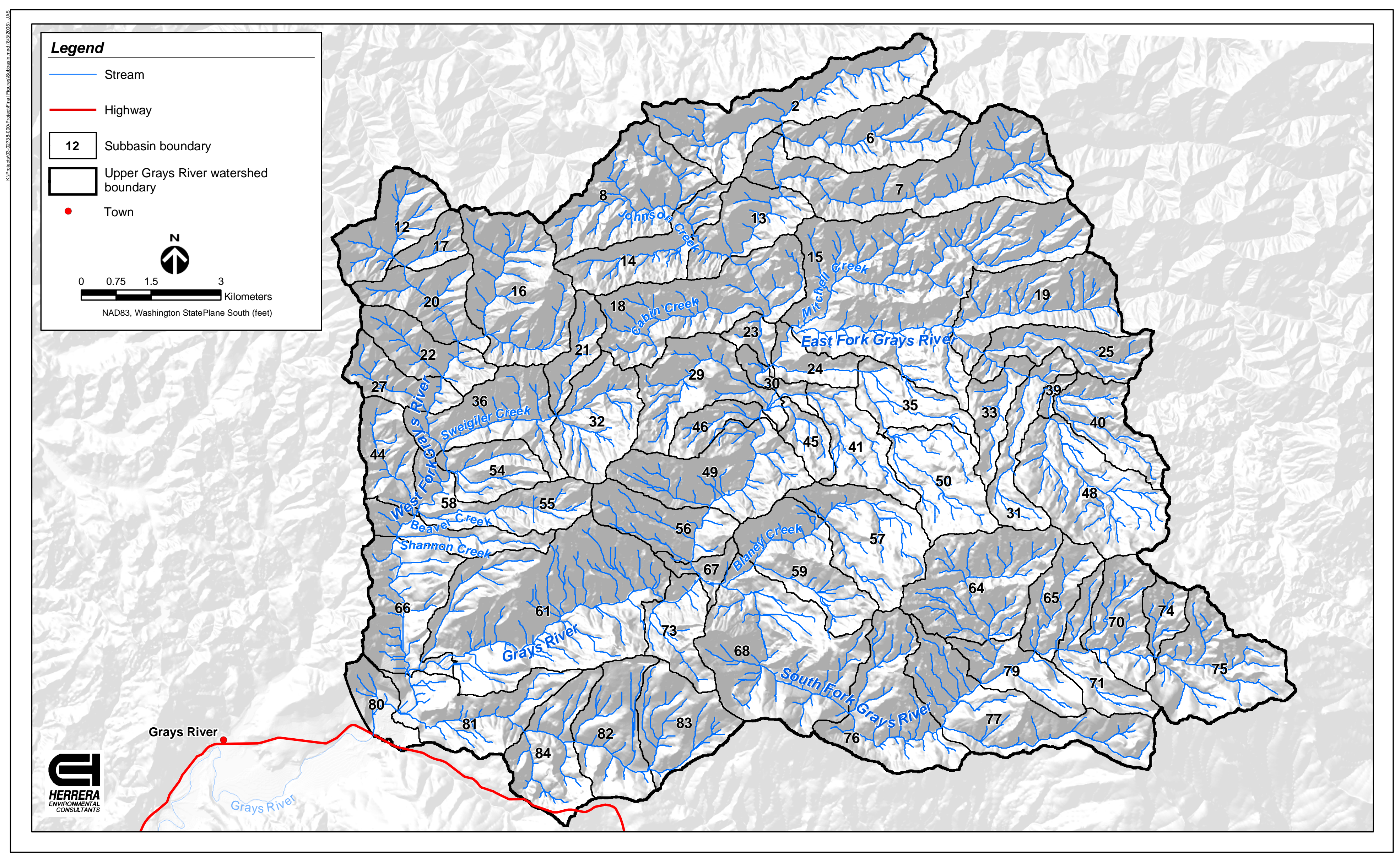

Figure E-1. Subbasins used for analysis of mass wasting and road surface erosion sediment production. 



\section{APPENDIX F}

Analysis of Surface Erosion from Roads 



\section{Analysis of Surface Erosion from Roads}

A road density analysis was performed to account for additional roads construction in the harvested areas shown on 2003 photos since preparation of the 1996 GIS coverage. Results of the analysis were used to calibrate the 1996 GIS road coverage to current (2004) conditions.

Seven of the 60 subbasins within the upper Grays River basin were chosen at random for the road density analysis (Figure F-1). Roads represented in the WDNR road layer within each of these subbasins were compared to the roads on the TCG (2004) maps. Roads present in the TCG (2004) map but not in the WDNR road layer were digitized in GIS and labeled as "added roads." A subset of the added roads were labeled as "added harvest roads" if they were associated with harvest operations identified in the 1996 and 2003 aerial photos. Roads present in the 1996 WDNR coverage, but absent from the 2004 TCG maps (and which did not appear to be active in the 2003 aerial photos) were digitized and labeled as "decommissioned roads." Subbasin and road density information for the sampled subbasin are presented in Table F-1.

Table F-1. Road densities for seven sample subbasins in Grays River watershed, from 1996 and 2003.

\begin{tabular}{|c|c|c|c|c|c|c|c|}
\hline $\begin{array}{c}\text { Subbasin } \\
\#\end{array}$ & $\begin{array}{c}\text { Subbasin } \\
\text { Drainage } \\
\text { Area } \\
\left(\mathrm{km}^{2}\right)\end{array}$ & $\begin{array}{c}\text { Percent of } \\
\text { Subbasin } \\
\text { Harvested } \\
\text { between } 1996 \\
\text { and } 2003\end{array}$ & $\begin{array}{c}1996 \text { Road } \\
\text { Density } \\
\left(\mathrm{m}^{-1}\right) \times 10^{4}\end{array}$ & $\begin{array}{c}2003 \text { Road } \\
\text { Density } \\
\left(\mathrm{m}^{-1}\right) \times 10^{3}\end{array}$ & $\begin{array}{l}\text { Added Road } \\
\text { Density } \\
\left(\mathrm{m}^{-1}\right) \times 10^{3}\end{array}$ & $\begin{array}{l}\text { Added Harvest } \\
\text { Road Density } \\
\left(\mathrm{m}^{-1}\right) \times 10^{3}\end{array}$ & $\begin{array}{l}\text { Decommissioned } \\
\text { Road Density } \\
\left(\mathrm{m}^{-1}\right) \times 10^{3}\end{array}$ \\
\hline 8 & 5.53 & 6.6 & 3.75 & 4.03 & 0.33 & 0.14 & 0.05 \\
\hline 15 & 15.24 & 0 & 4.29 & 4.45 & 0.20 & 0.00 & 0.04 \\
\hline 32 & 3.69 & 0 & 3.65 & 3.95 & 0.30 & 0.00 & 0.00 \\
\hline 45 & 1.19 & 10 & 2.86 & 3.60 & 0.74 & 0.51 & 0.00 \\
\hline 64 & 5.95 & 36 & 1.78 & 3.55 & 1.83 & 1.58 & 0.06 \\
\hline 65 & 2.30 & 47 & 3.13 & 4.13 & 1.17 & 0.96 & 0.17 \\
\hline 79 & 2.51 & 27 & 2.79 & 3.29 & 0.50 & 0.38 & 0.01 \\
\hline 82 & - & - & - & - & - & - & 0.00 \\
\hline 35 & - & - & - & - & - & - & 0.20 \\
\hline
\end{tabular}

Road density computed as road length per basin area.

An empirical relationship was derived for the added road density as a function of the percent of the subbasin that had been harvested between 1993 and 2003. The linear regression of road density and harvest data explains 56 percent of the variability in road density within the sampled subbasins (Figure F-2).

The empirical relationship used to adjust the 1996 WDNR road coverage is given by:

$$
L_{h}=(2.59 p+0.272) A_{d} / 1000
$$


where: $p=$ percent basin harvested between 1996 and 2003

$A_{d}=$ subbasin drainage area $\left(\mathrm{km}^{2}\right)$

$L_{h}=$ length of additional road in harvested subbasin (m).

The road length for the non-harvested basins delineated in the 1996 road coverage was not adjusted. Abandoned/decommissioned road lengths for the remaining harvested and nonharvested subbasins were characterized using the average decommissioned road densities of the 7 sample subbasins and 2 additional subbasins. The relationship for estimating decommissioned road length is given by:

$$
L_{d}=\left(6.81 \times 10^{-5}\right) A_{d}
$$

where: $A_{d}=$ subbasin drainage area $\left(\mathrm{km}^{2}\right)$

$L_{d}=$ Length of decommissioned roads (m).

\section{Erosion Potential}

The erosion potential of road surfaces and adjacent slopes and ditches within the road corridor (i.e., the road prism) was estimated by applying several adjustment factors to a baseline erosion rate. The factors represent empirical relationships between characteristics of the road prism and the difference in erosion rates relative to reference conditions. The characteristics of the reference road include (WDNR 1997):

- Insloped with ditch

- $\quad$ Native surface road tread and ditch

- General use traffic (passenger vehicles)

- $\quad$ Cutslope 1:1 and fillslope gradient 1.5:1

- Initial ground cover density of zero on cut and fill slopes

- $\quad$ Sustained grade of 5-7 percent

- $\quad$ Average cross-drain spacing of 500 feet.

\section{Reference Erosion Rate}

The reference erosion rate from roads for the upper Grays River basin was developed from 10 representative subbasins $(8,15,32,35,45,64,65,79,82$, and 84$)$. Road maps, aerial photographs, and field observations of road conditions were used to classify roads within the sample basins into four groups based on traffic use:

- $\quad$ Mainline: Active logging traffic

- $\quad$ Secondary: Roads that are present on 1996 road layer and TCG maps, and easily visible from aerial photographs

- $\quad$ Non-active: Roads that are present on 1996 road layer and TCG maps, but not highly visible from aerial photographs

- $\quad$ Decommissioned: Roads that are present on the 1996 road layer, but not on TCG maps, and not visible in aerial photographs. 


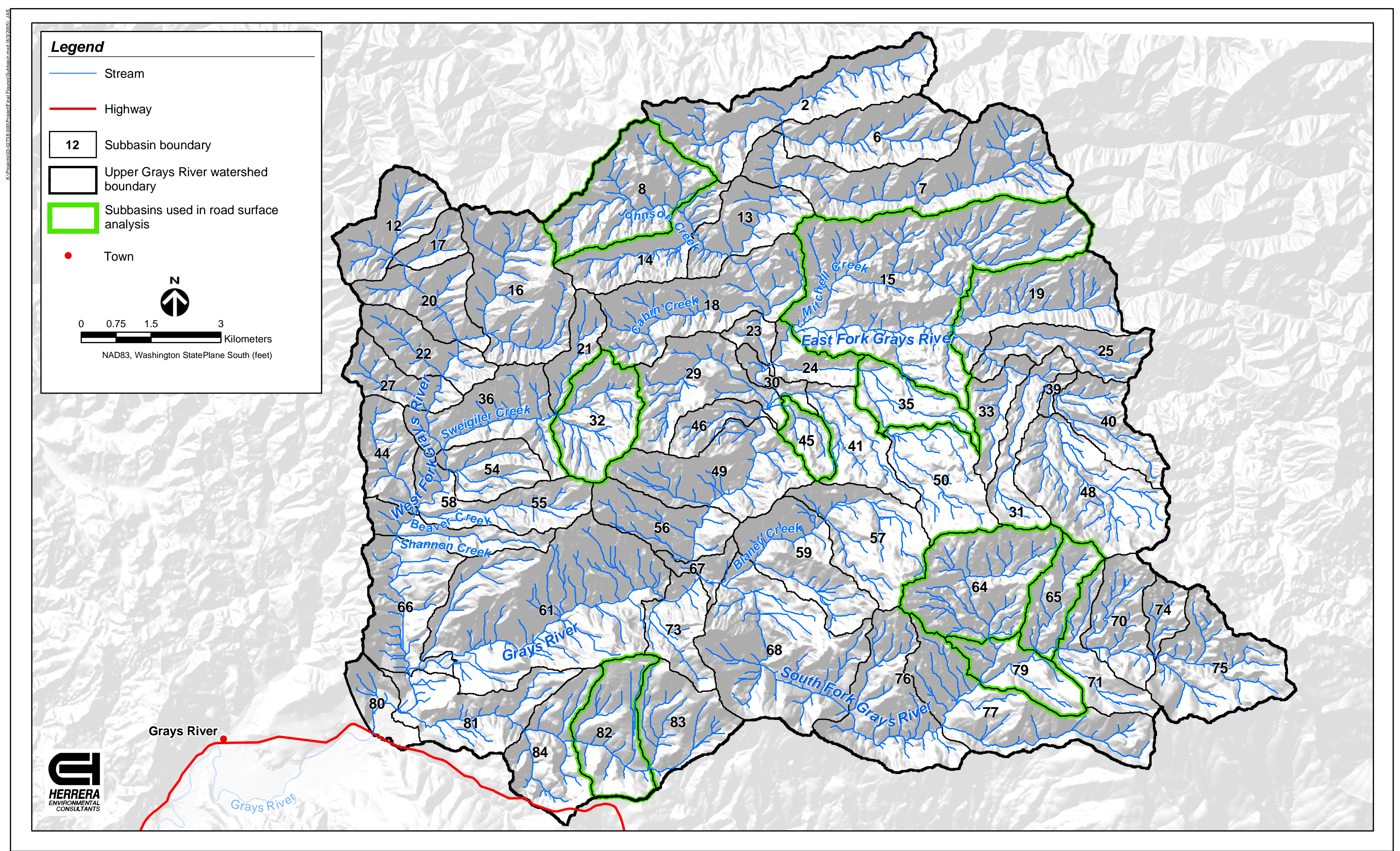

Figure F-1. Subbasins used for analysis of road surface erosion sediment production. 



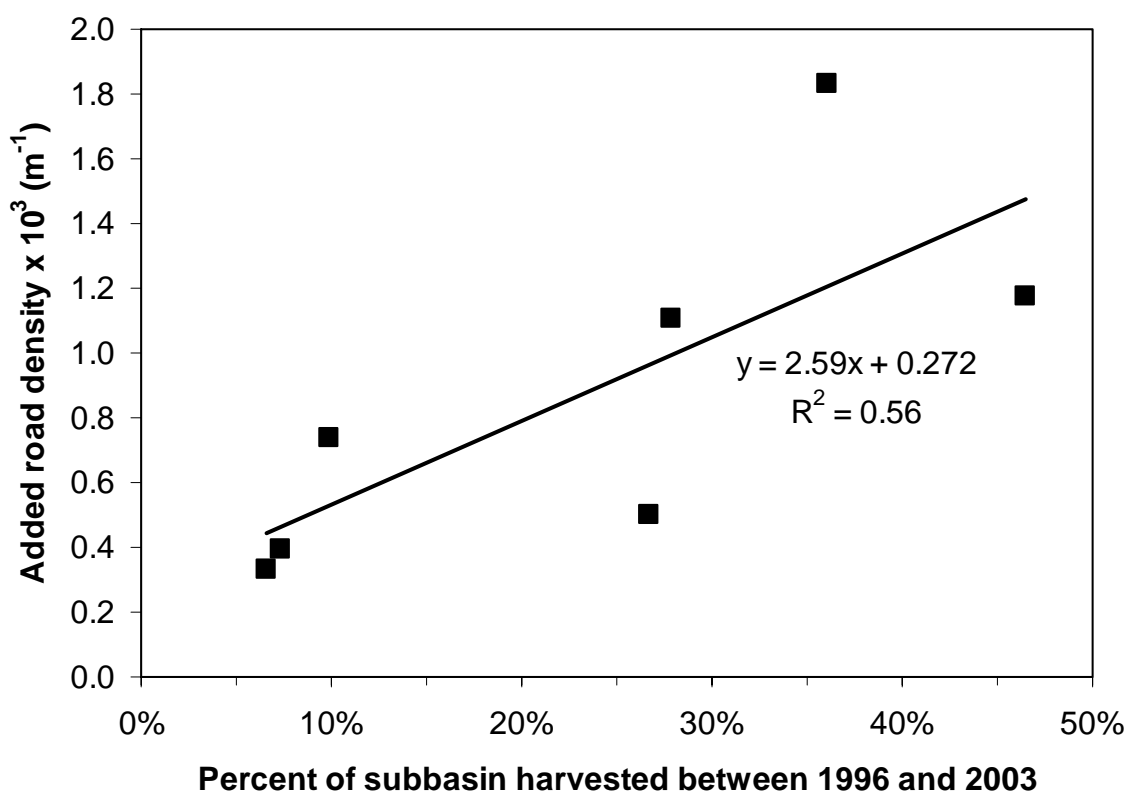

Figure F-2. Linear regression for 2003 added road densities associated with harvesting between 1996 and 2003.

Because there are few mainline roads in the basin, the length of mainline roads was delineated throughout the entire upper Grays River basin from the 1996 GIS coverage. Field observations, personal communications with TCG, and comparison with 2003 photos and the 2004 road map indicated that no significant mainline road lengths were added between 1996 and 2004. Approximately 2 percent of roads in the upper Grays River basin are mainline roads. Secondary and non-active roads were only delineated in the 10 representative subbasins. Of the remaining 98 percent of active roads in the 10 subbasins, 85 percent were classified as secondary and 15 percent as non-active roads. The proportion of secondary and non-active roads delineated in the 10 subbasins was applied to all subbasins in the upper Grays River basin. The length of decommissioned roads in each subbasin was calculated from Equation F-1.

The total area of road surface in each subbasin was calculated from the delineated road length and the average width of road types measured during the field investigation. Average road widths measured in the field are given in Table F-2. The width of decommissioned roads was characterized using the average width of the non-active roads.

Table F-2. Average road width measured in the field.

\begin{tabular}{lc}
\hline \hline \multicolumn{1}{c}{ Road Category } & $\begin{array}{c}\text { Average Road Width } \\
(\mathrm{m})\end{array}$ \\
\hline Mainline & 8.1 \\
Secondary & 6.1 \\
Non-active & 5.4 \\
Decommissioned & 5.4 \\
\hline \hline
\end{tabular}


Reference erosion rates were calculated for each road type and for each component of the road prism using the proportions given in Table F-3. The baseline erosion rate is given by:

$$
E_{b l}=F_{r p} L_{r} W_{r} E_{r e f}
$$

where: $E_{b l}=$ baseline erosion rate for each component of each road type (tons/year)

$F_{r p}=$ road prism factor (Table F-4)

$L_{r}=$ road length $(\mathrm{m})$

$W_{r}=$ road width $(\mathrm{m})$

$E_{r e f}=$ reference erosion rate (tons/acre).

Table F-3. Reference erosion rates of road prism per year by road age and parent material, based on reference road conditions.

\begin{tabular}{llcc}
\hline \hline \multirow{2}{*}{ General Category } & \multicolumn{2}{c}{ Erosion Rates (tons/acre) of Road Prism per Year } \\
\cline { 3 - 4 } High & \multicolumn{1}{c}{ Parent Material } & \multicolumn{2}{c}{ Road Age } \\
\cline { 3 - 4 } High/Moderate & $\begin{array}{l}\text { Mica schist } \\
\text { Volcanic ash } \\
\text { Highly weathered sedimentary } \\
\text { Quartzite } \\
\text { Course-grained granite } \\
\text { Fine-grained granite } \\
\text { Moderately weathered rock } \\
\text { Sedimentary rocks } \\
\text { Competent granite } \\
\text { Basalt } \\
\text { Metamorphic rocks } \\
\text { Relatively unweathered rocks }\end{array}$ & 60 & 30 \\
\hline \hline
\end{tabular}

Source: WDNR (1997).

The reference erosion rate selected for the analysis was based on erosion criteria for sediment production (i.e., low, moderate, and high) the parent material, and road age (Table F-3). A reference erosion rate of 30 tons/acre/year was used for the road analysis.

Table F-4. Proportions of total long-term average road erosion rates attributed to the components of the standard road prism.

\begin{tabular}{lc}
\hline \hline $\begin{array}{c}\text { Component of } \\
\text { Standard Road Prism }\end{array}$ & $\begin{array}{c}\text { Proportion of Total Long Term } \\
\text { Average Road Erosion Rates }\end{array}$ \\
\hline Tread & $40 \%$ \\
Cutslope/ditch & $40 \%$ \\
Fillslope & $20 \%$ \\
\hline \hline
\end{tabular}

Sources: Swift (1984); Burroughs and King (1989); Sullivan and Duncan (1980); Megahan (unpublished data), cited in WDNR (1997). 
Baseline erosion rates for each road type and prism component were then adjusted for vegetative cover, surface material, traffic use, and precipitation. Each factor is described in detail in the following sections.

\section{Cover Factor}

Cover factors for cut and fill slopes refer to all surfaces other than bare soil (e.g., vegetation, rock, slash, and erosion control materials). Since reference road conditions are defined with unvegetated cut and fill slopes, cover protecting these slopes will tend to reduce the baseline erosion rate. Correction factors for different ground cover densities are shown in Table F-5. Average ground cover densities measured during field road surveys are summarized for each road prism component in Table F-6.

Table F-5. Correction factors for ground cover density $\left(F_{g c}\right)$ on cut and fill slopes.

\begin{tabular}{cc}
\hline \hline Ground Cover Density & $F_{r t}$ Factor \\
\hline$>80 \%$ & 0.18 \\
$50 \%$ & 0.37 \\
$30 \%$ & 0.53 \\
$20 \%$ & 0.63 \\
$10 \%$ & 0.77 \\
$0 \%$ & 1.00 \\
\hline \hline
\end{tabular}

Sources: Megahan (1991); Burroughs and King (1989); Megahan (unpublished data), cited in WDNR (1997).

Table F-6. Average ground cover densities $\left(F_{g c}\right)$ measured from road surveys performed in the Grays River watershed in October 2004.

\begin{tabular}{lccc}
\hline \hline \multirow{2}{*}{ Road Category } & \multicolumn{3}{c}{ Average Ground Cover Density, $F_{g c}(\%)$} \\
\cline { 2 - 4 } & Road Tread & Cutslope/Ditch & Fillslope \\
\hline Mainline & 0 & 92 & 81 \\
Secondary & 20 & 68 & 84 \\
Non-active & 60 & 45 & 85 \\
Decommissioned & $>80$ & $>80$ & $>80$ \\
\hline \hline
\end{tabular}

\section{Surface Material Factor}

The reference erosion rate is based on a road surface of native material. Therefore, improvements to the road surface material will reduce erosion from the road surface relative to the baseline erosion rate. Correction factors for different surface materials are shown in Table F-7. The surface material of most roads in the Grays River watershed are made up of gravel greater than 6 inches deep; therefore, a correction factor of 0.20 was applied to Equation F-3. 
Table F-7. Road tread correction factors $\left(F_{r t}\right)$ for road surface materials.

\begin{tabular}{lc}
\hline \hline \multicolumn{1}{c}{ Surfacing Material } & $F_{r t}$ Factor \\
\hline Paved & 0.03 \\
Dust-oil & 0.15 \\
Gravel, >6” deep & 0.2 \\
Gravel, 2"-6” deep & 0.5 \\
Native soil/rock & 1.00 \\
\hline \hline
\end{tabular}

\section{Traffic Use and Precipitation Factor}

Traffic use is one of the greatest factors affecting the generation of sediment from road surfaces (Reid and Dunne 1984; Sullivan and Duncan unpublished). Traffic can grind the road surface material into smaller particles, which can be transported more easily by rainfall runoff. While traffic rate determines the quantity of sediment available for transport, precipitation determines the transport capacity. Correction factors for traffic use by annual precipitation categories are presented in Table F-8. Annual precipitation in the Grays River watershed is approximately $2790 \mathrm{~mm} /$ year (WRCC 2004). The traffic-precipitation factors used in the analysis are those for annual precipitation of 1,200 to 3,000mm in Table F-8.

\section{Table F-8. Traffic and precipitation factors (Ftp) for traffic use by annual precipitation categories.}

\begin{tabular}{llll}
\hline \hline \multirow{2}{*}{ Traffic Use/Road Category } & \multicolumn{3}{c}{ Annual Precipitation and $F_{t p}$ factor } \\
\cline { 2 - 4 } & $<1,200 \mathrm{~mm}$ & $1,200 \mathrm{~mm}-3,000 \mathrm{~mm}$ & $>3,000 \mathrm{~mm}$ \\
\hline Heavy Traffic/ Active Mainline & 20 & 50 & 120 \\
Moderate Traffic/Active Secondary & 2 & 4 & 10 \\
Light Traffic/ Non-Active & 1 & 1 & 1 \\
No Traffic/ Decommissioned & 0.02 & 0.05 & 0.1 \\
\hline \hline
\end{tabular}

Sources: Reid and Dunne (1984); Sullivan and Duncan (unpublished), cited in WDNR (1997).

The ground cover, road tread, and traffic-precipitation factors specified for the road network were applied to the reference erosion rate to calculate the adjusted erosion rate for the road prism. The adjusted erosion rate of the tread component of the road prism is given by:

$$
E_{a d j}=E_{r e f} F_{g c} F_{r t} F_{t p}
$$

where: $E_{a d j}=$ adjusted erosion rate for the road tread (tons/year)

$E_{\text {ref }}=$ reference erosion rate (tons/acre)

$F_{g c}=$ ground cover density factor

$F_{r t}=$ road tread surface factor

$F_{t p}=$ traffic and precipitation factor. 
Grays River Watershed-Geomorphic Analysis

The adjusted erosion rates for the cutslope/ditch and fillslope components were calculated using Equation F-4 without the $F_{r t}$ and $F_{t p}$ factors. The adjusted erosion rates calculated from Equation F-4 represents the average sediment production rate from all roads within the upper Grays River basin. The adjusted erosion rate for each road type was divided by the total road length to calculate an average sediment production rate per length of road prism (tons/m/year).

\section{Sediment Yield from Roads}

Sediment generated from the road prism is delivered to the stream network by water flowing in roadside ditches, gullies, culverts, or on surfaces as shallow overland flow. Only a portion of the sediment produced from the road network reaches the stream network. The portion of sediment delivered to the stream system is highly dependent on drainage characteristics of the road prism. The two main characteristics of the road prism are the cross-sectional shape and the connection of ditches to stream channels. The cross-sectional shape of the road prism can be broken up into four types:
- Insloped with ditch
- $\quad$ Crowned with ditch
- $\quad$ Outsloped with ditch
- Outsloped- no ditch.

Road surveys from the October 2004 field investigation indicate approximately 39 percent of roads are insloped (both with and without a ditch), 38 percent are crowned with a ditch, and 24 percent are outsloped with a ditch. Results indicate approximately half of the road surfaces drain into the slope and concentrate water along a ditch or swale at the toe of the cutslope.

Sediment yield to the channel network depends on the relative degree of connectivity of road ditches and culverts to the stream network. Roadside ditches that drain directly to a stream can deliver 100 percent of their sediment load to the channel network. Work by Ketcheson and Megahan (unpublished, cited in WADNR 1997) found that only 10 percent of sediment discharge from the road prism to within $200 \mathrm{ft}(60 \mathrm{~m})$ of a stream channel is delivered to the channel network. Sediment yield to the channel network was calculated using the following delivery ratios:
- $\quad 1.0$ if road drains directly to a stream channel via ditch or gully
- $\quad 0.10$ if road drains onto hillslope within 200 feet of a stream
- $\quad 0.0$ if road drains onto hillslope more than 200 feet from stream.

A GIS comparison of road and stream coverages indicates, on average, 80 percent of roads in the Grays River basin are located within $200 \mathrm{ft}(60 \mathrm{~m})$ of a stream channel. Field observations indicate drainage from roughly half of the roads within $200 \mathrm{ft}(60 \mathrm{~m})$ of a stream drain to the stream channel. Based on these observations, half of the roads within $200 \mathrm{ft}(60 \mathrm{~m})$ of a stream were assigned a delivery ratio of 1.0 and the other half were assigned a delivery ratio of 0.1 . Therefore, the combined delivery ratio for roads within $200 \mathrm{ft}(60 \mathrm{~m})$ of a stream channel is 0.55 . The average sediment yield (tons/year) from roads was then calculated for each subbasin using 
the lengths of road types for each subbasin. The average sediment yield from roads for each subbasin is given by:

$$
S_{r}=0.55\left(\frac{L_{R 200}}{L_{R}}\right)\left(E_{a d j-m} L_{m}+E_{a d j-s} L_{s}+E_{a d j-n} L_{n}+E_{a d j-d} L_{d}\right)
$$

where: $S_{r}=$ average sediment yield from all roads in each subbasin (tons/year)

$L_{R 200}=$ length of roads within $200 \mathrm{ft}(60 \mathrm{~m})$ of the channel network $(\mathrm{m})$

$L_{R}=$ total length of roads in the subbasin (m)

$E_{a d j-m}=$ adjusted sediment production rate per length of road prism for mainline $(m)$, secondary $(s)$, non-active $(n)$, and decommissioned $(d)$ roads (tons/m/year)

$L_{-m}=$ road length for each road type (m).

A summary of data used in the analysis of surface erosion from roads, as well as results of the analysis, is presented in Table F-9.

Table F-9. Summary of surface erosion factors and rates for roads.

\begin{tabular}{|c|c|c|c|c|c|c|c|c|}
\hline Road Type & $\begin{array}{c}2003 \\
\text { Road } \\
\text { Length } \\
(\mathrm{m})\end{array}$ & $\begin{array}{c}\text { Road } \\
\text { Width } \\
\text { (m) }\end{array}$ & $\begin{array}{l}\text { Baseline } \\
\text { Erosion } \\
\text { Rate } \\
\text { (tons/year) }\end{array}$ & $\begin{array}{l}\text { Ground } \\
\text { Cover } \\
\text { Density } \\
\text { Factor } \\
\left(F_{g c}\right)\end{array}$ & $\begin{array}{c}\text { Road } \\
\text { Tread } \\
\text { Factor } \\
\left(F_{r t}\right)\end{array}$ & $\begin{array}{c}\text { Traffic/ } \\
\text { ppt } \\
\text { Factor } \\
\left(F_{t p}\right)\end{array}$ & $\begin{array}{l}\text { Adjusted } \\
\text { Erosion } \\
\text { Rate } \\
\text { (tons/year) }\end{array}$ & $\begin{array}{c}\text { Normalized } \\
\text { Sediment } \\
\text { Production } \\
\text { Rate } \\
\text { (tons/km/year) }\end{array}$ \\
\hline Mainline & 42,011 & 8.1 & & & & & 10,334 & 246 \\
\hline Tread & & & 1,006 & 1.00 & 0.2 & 50 & 10,062 & \\
\hline Cutslope & & & 1,006 & 0.18 & & & 181 & \\
\hline Fillslope & & & 503 & 0.18 & & & 91 & \\
\hline Active Secondary & 717,073 & 6.1 & & & & & 12,495 & 17.4 \\
\hline Tread & & & 12,962 & 0.63 & 0.2 & 4 & 6,533 & \\
\hline Cutslope & & & 12,962 & 0.37 & & & 4,796 & \\
\hline Fillslope & & & 6,481 & 0.18 & & & 1,167 & \\
\hline Non-Active & 126,542 & 5.4 & & & & & 1,413 & 11.2 \\
\hline Tread & & & 2,036 & 0.37 & 0.2 & 1 & 151 & \\
\hline Cutslope & & & 2,036 & 0.53 & & & 1,079 & \\
\hline Fillslope & & & 1,018 & 0.18 & & & 183 & \\
\hline Decommissioned & 15,737 & 5.4 & & & & & 69 & 4.37 \\
\hline Tread & & & 253 & 0.18 & 0.2 & 0.05 & 0 & \\
\hline Cutslope & & & 253 & 0.18 & & & 46 & \\
\hline Fillslope & & & 127 & 0.18 & & & 23 & \\
\hline Basin Totals & 901,364 & & 40,010 & & & & 24,311 & 27.0 \\
\hline
\end{tabular}




\section{APPENDIX G}

\section{Reconstruction of Historical Sediment Yield}





\section{2}

\begin{tabular}{|c|c|c|c|c|c|c|c|c|}
\hline \multirow[b]{2}{*}{ Subbasin Group } & \multicolumn{4}{|c|}{ Sediment Yield (tons/year) } & \multicolumn{4}{|c|}{ Sediment Yield (tons $/ \mathrm{km}^{2} /$ year) } \\
\hline & $\begin{array}{c}\text { Mass } \\
\text { Wasting }\end{array}$ & Roads & Creep & Total & $\begin{array}{c}\text { Mass } \\
\text { Wasting }\end{array}$ & Roads & Creep & Total \\
\hline Upper Main Stem & 1,148 & 0.6 & 1,048 & 2,196 & 30 & 0 & 27 & 57 \\
\hline East Fork & 1,338 & 178 & 1,209 & 2,724 & 30 & 4 & 27 & 61 \\
\hline Middle Main Stem & 613 & 61 & 513 & 1,186 & 30 & 3 & 25 & 58 \\
\hline South Fork & 1,560 & 213 & 1,244 & 3,017 & 30 & 4 & 24 & 58 \\
\hline Lower Main Stem & 461 & 5 & 336 & 802 & 30 & 0 & 22 & 52 \\
\hline West Fork & 1,278 & 31 & 1,258 & 2,566 & 30 & 1 & 30 & 60 \\
\hline Fossil Creek & 535 & 68 & 375 & 977 & 30 & 4 & 21 & 55 \\
\hline Total Basin & 6,932 & 556 & 5,982 & 13,469 & 30 & 2 & 26 & 58 \\
\hline
\end{tabular}

\section{3}

\begin{tabular}{|c|c|c|c|c|c|c|c|c|}
\hline \multirow[b]{2}{*}{ Subbasin Group } & \multicolumn{4}{|c|}{ Sediment Yield (tons/year) } & \multicolumn{4}{|c|}{ Sediment Yield (tons/km²/year) } \\
\hline & $\begin{array}{c}\text { Mass } \\
\text { Wasting }\end{array}$ & Roads & Creep & Total & $\begin{array}{c}\text { Mass } \\
\text { Wasting }\end{array}$ & Roads & Creep & Total \\
\hline Upper Main Stem & 1,148 & 123.1 & 1,048 & 2,319 & 30 & 3 & 27 & 61 \\
\hline East Fork & 1,338 & 113 & 1,209 & 2,660 & 30 & 3 & 27 & 60 \\
\hline Middle Main Stem & 613 & 49 & 513 & 1,175 & 30 & 2 & 25 & 57 \\
\hline South Fork & 1,701 & 623 & 1,244 & 3,568 & 33 & 12 & 24 & 69 \\
\hline Lower Main Stem & 996 & 515 & 336 & 1,847 & 65 & 33 & 22 & 120 \\
\hline West Fork & 1,278 & 198 & 1,258 & 2,734 & 30 & 5 & 30 & 64 \\
\hline Fossil Creek & 570 & 117 & 375 & 1,061 & 32 & 7 & 21 & 59 \\
\hline Total Basin & 7,643 & 1,739 & 5,982 & 15,363 & 33 & 8 & 26 & 66 \\
\hline
\end{tabular}

1964

\begin{tabular}{|c|c|c|c|c|c|c|c|c|}
\hline \multirow[b]{2}{*}{ Subbasin Group } & \multicolumn{4}{|c|}{ Sediment Yield (tons/year) } & \multicolumn{4}{|c|}{ Sediment Yield (tons $/ \mathrm{km}^{2} /$ year) } \\
\hline & $\begin{array}{c}\text { Mass } \\
\text { Wasting }\end{array}$ & Roads & Creep & Total & $\begin{array}{c}\text { Mass } \\
\text { Wasting }\end{array}$ & Roads & Creep & Total \\
\hline Upper Main Stem & 1,148 & 259.0 & 1,048 & 2,455 & 30 & 7 & 27 & 64 \\
\hline East Fork & 1,669 & 779 & 1,209 & 3,656 & 37 & 17 & 27 & 82 \\
\hline Middle Main Stem & 613 & 735 & 513 & 1,860 & 30 & 36 & 25 & 91 \\
\hline South Fork & 1,701 & 1,185 & 1,244 & 4,130 & 33 & 23 & 24 & 79 \\
\hline Lower Main Stem & 1,029 & 597 & 336 & 1,963 & 67 & 39 & 22 & 128 \\
\hline West Fork & 1,367 & 503 & 1,258 & 3,128 & 32 & 12 & 30 & 73 \\
\hline Fossil Creek & 578 & 128 & 375 & 1,081 & 32 & 7 & 21 & 61 \\
\hline Total Basin & 8,105 & 4,186 & 5,982 & 18,273 & 35 & 18 & 26 & 79 \\
\hline
\end{tabular}




\section{6}

\begin{tabular}{|c|c|c|c|c|c|c|c|c|}
\hline \multirow[b]{2}{*}{ Subbasin Group } & \multicolumn{4}{|c|}{ Sediment Yield (tons/year) } & \multicolumn{4}{|c|}{ Sediment Yield (tons $/ \mathrm{km}^{2} /$ year) } \\
\hline & $\begin{array}{c}\text { Mass } \\
\text { Wasting }\end{array}$ & Roads & Creep & Total & $\begin{array}{c}\text { Mass } \\
\text { Wasting }\end{array}$ & Roads & Creep & Total \\
\hline Upper Main Stem & 25,222 & 939.5 & 1,048 & 27,210 & 659 & 25 & 27 & 711 \\
\hline East Fork & 14,269 & 1,735 & 1,209 & 17,212 & 320 & 39 & 27 & 386 \\
\hline Middle Main Stem & 5,635 & 964 & 513 & 7,111 & 276 & 47 & 25 & 348 \\
\hline South Fork & 11,050 & 1,656 & 1,244 & 13,950 & 212 & 32 & 24 & 268 \\
\hline Lower Main Stem & 1,658 & 640 & 336 & 2,635 & 108 & 42 & 22 & 171 \\
\hline West Fork & 14,499 & 809 & 1,258 & 16,565 & 340 & 19 & 30 & 389 \\
\hline Fossil Creek & 1,367 & 244 & 375 & 1,985 & 77 & 14 & 21 & 111 \\
\hline Total Basin & 73,699 & 6,986 & 5,982 & 86,668 & 319 & 30 & 26 & 375 \\
\hline
\end{tabular}

\section{3}

\begin{tabular}{|c|c|c|c|c|c|c|c|c|}
\hline \multirow[b]{2}{*}{ Subbasin Group } & \multicolumn{4}{|c|}{ Sediment Yield (tons/year) } & \multicolumn{4}{|c|}{ Sediment Yield (tons/km²/year) } \\
\hline & $\begin{array}{c}\text { Mass } \\
\text { Wasting }\end{array}$ & Roads & Creep & Total & $\begin{array}{c}\text { Mass } \\
\text { Wasting }\end{array}$ & Roads & Creep & Total \\
\hline Upper Main Stem & 45,139 & $1,379.3$ & 1,048 & 47,566 & 1,179 & 36 & 27 & 1,242 \\
\hline East Fork & 15,605 & 1,811 & 1,209 & 18,625 & 350 & 41 & 27 & 417 \\
\hline Middle Main Stem & 11,176 & 1,133 & 513 & 12,822 & 547 & 55 & 25 & 627 \\
\hline South Fork & 17,154 & 1,814 & 1,244 & 20,213 & 330 & 35 & 24 & 389 \\
\hline Lower Main Stem & 3,884 & 782 & 336 & 5,002 & 252 & 51 & 22 & 325 \\
\hline West Fork & 41,595 & 1,328 & 1,258 & 44,180 & 976 & 31 & 30 & 1,037 \\
\hline Fossil Creek & 1,849 & 311 & 375 & 2,535 & 104 & 17 & 21 & 142 \\
\hline Total Basin & 136,403 & 8,559 & 5,982 & 150,943 & 590 & 37 & 26 & 653 \\
\hline
\end{tabular}

\section{0}

\begin{tabular}{|c|c|c|c|c|c|c|c|c|}
\hline \multirow[b]{2}{*}{ Subbasin Group } & \multicolumn{4}{|c|}{ Sediment Yield (tons/year) } & \multicolumn{4}{|c|}{ Sediment Yield (tons/km²/year) } \\
\hline & $\begin{array}{c}\text { Mass } \\
\text { Wasting }\end{array}$ & Roads & Creep & Total & $\begin{array}{c}\text { Mass } \\
\text { Wasting }\end{array}$ & Roads & Creep & Total \\
\hline Upper Main Stem & 48,656 & $1,428.8$ & 1,048 & 51,133 & 1,271 & 37 & 27 & 1,336 \\
\hline East Fork & 15,605 & 1,811 & 1,209 & 18,625 & 350 & 41 & 27 & 417 \\
\hline Middle Main Stem & 12,889 & 1,242 & 513 & 14,643 & 631 & 61 & 25 & 717 \\
\hline South Fork & 18,096 & 1,846 & 1,244 & 21,186 & 348 & 35 & 24 & 407 \\
\hline Lower Main Stem & 4,655 & 842 & 336 & 5,833 & 303 & 55 & 22 & 379 \\
\hline West Fork & 47,561 & 1,409 & 1,258 & 50,227 & 1,116 & 33 & 30 & 1,179 \\
\hline Fossil Creek & 3,240 & 459 & 375 & 4,073 & 182 & 26 & 21 & 228 \\
\hline Total Basin & 150,700 & 9,038 & 5,982 & 165,720 & 652 & 39 & 26 & 717 \\
\hline
\end{tabular}


1996

\begin{tabular}{|c|c|c|c|c|c|c|c|c|}
\hline \multirow[b]{2}{*}{ Subbasin Group } & \multicolumn{4}{|c|}{ Sediment Yield (tons/year) } & \multicolumn{4}{|c|}{ Sediment Yield (tons $/ \mathrm{km}^{2} /$ year) } \\
\hline & $\begin{array}{c}\text { Mass } \\
\text { Wasting }\end{array}$ & Roads & Creep & Total & $\begin{array}{c}\text { Mass } \\
\text { Wasting }\end{array}$ & Roads & Creep & Total \\
\hline Upper Main Stem & 50,722 & $1,449.4$ & 1,048 & 53,220 & 1,325 & 38 & 27 & 1,390 \\
\hline East Fork & 15,605 & 1,811 & 1,209 & 18,625 & 350 & 41 & 27 & 417 \\
\hline Middle Main Stem & 13,727 & 1,256 & 513 & 15,496 & 672 & 61 & 25 & 758 \\
\hline South Fork & 23,945 & 1,914 & 1,244 & 27,103 & 460 & 37 & 24 & 521 \\
\hline Lower Main Stem & 6,289 & 875 & 336 & 7,501 & 409 & 57 & 22 & 488 \\
\hline West Fork & 56,220 & 1,472 & 1,258 & 58,950 & 1,319 & 35 & 30 & 1,383 \\
\hline Fossil Creek & 6,683 & 495 & 375 & 7,553 & 375 & 28 & 21 & 424 \\
\hline Total Basin & 173,192 & 9,274 & 5,982 & 188,447 & 749 & 40 & 26 & 815 \\
\hline
\end{tabular}

2003

\begin{tabular}{|c|c|c|c|c|c|c|c|c|}
\hline \multirow[b]{2}{*}{ Subbasin Group } & \multicolumn{4}{|c|}{ Sediment Yield (tons/year) } & \multicolumn{4}{|c|}{ Sediment Yield (tons $/ \mathrm{km}^{2} /$ year) } \\
\hline & $\begin{array}{c}\text { Mass } \\
\text { Wasting }\end{array}$ & Roads & Creep & Total & $\begin{array}{c}\text { Mass } \\
\text { Wasting }\end{array}$ & Roads & Creep & Total \\
\hline Upper Main Stem & 40,722 & $1,471.5$ & 1,048 & 43,241 & 1,064 & 38 & 27 & 1,129 \\
\hline East Fork & 17,259 & 1,820 & 1,209 & 20,288 & 387 & 41 & 27 & 455 \\
\hline Middle Main Stem & 9,929 & 1,273 & 513 & 11,715 & 486 & 62 & 25 & 573 \\
\hline South Fork & 54,591 & 1,975 & 1,244 & 57,811 & 1,049 & 38 & 24 & 1,111 \\
\hline Lower Main Stem & 25,814 & 902 & 336 & 27,053 & 1,678 & 59 & 22 & 1,759 \\
\hline West Fork & 86,388 & 1,569 & 1,258 & 89,215 & 2,027 & 37 & 30 & 2,093 \\
\hline Fossil Creek & 3,782 & 503 & 375 & 4,660 & 212 & 28 & 21 & 261 \\
\hline Total Basin & 238,487 & 9,515 & 5,982 & 253,983 & 1,032 & 41 & 26 & 1,099 \\
\hline
\end{tabular}

Total Sediment Yield (tons/year)

\begin{tabular}{||l|c|c|c|c|c|c|c|c||}
\hline \hline Subbasin Group & 1942 & 1953 & 1964 & 1976 & 1983 & 1990 & 1996 & 2003 \\
\hline \hline Upper Main Stem & 2,196 & 2,319 & 2,455 & 27,210 & 47,566 & 51,133 & 53,220 & 43,241 \\
\hline East Fork & 2,724 & 2,660 & 3,656 & 17,212 & 18,625 & 18,625 & 18,625 & 20,288 \\
\hline Middle Main Stem & 1,186 & 1,175 & 1,860 & 7,111 & 12,822 & 14,643 & 15,496 & 11,715 \\
\hline South Fork & 3,017 & 3,568 & 4,130 & 13,950 & 20,213 & 21,186 & 27,103 & 57,811 \\
\hline Lower Main Stem & 802 & 1,847 & 1,963 & 2,635 & 5,002 & 5,833 & 7,501 & 27,053 \\
\hline West Fork & 2,566 & 2,734 & 3,128 & 16,565 & 44,180 & 50,227 & 58,950 & 89,215 \\
\hline Fossil Creek & 977 & 1,061 & 1,081 & 1,985 & 2,535 & 4,073 & 7,553 & 4,660 \\
\hline Total Basin & 13,469 & 15,363 & 18,273 & 86,668 & 150,943 & 165,720 & 188,447 & 253,983 \\
\hline
\end{tabular}





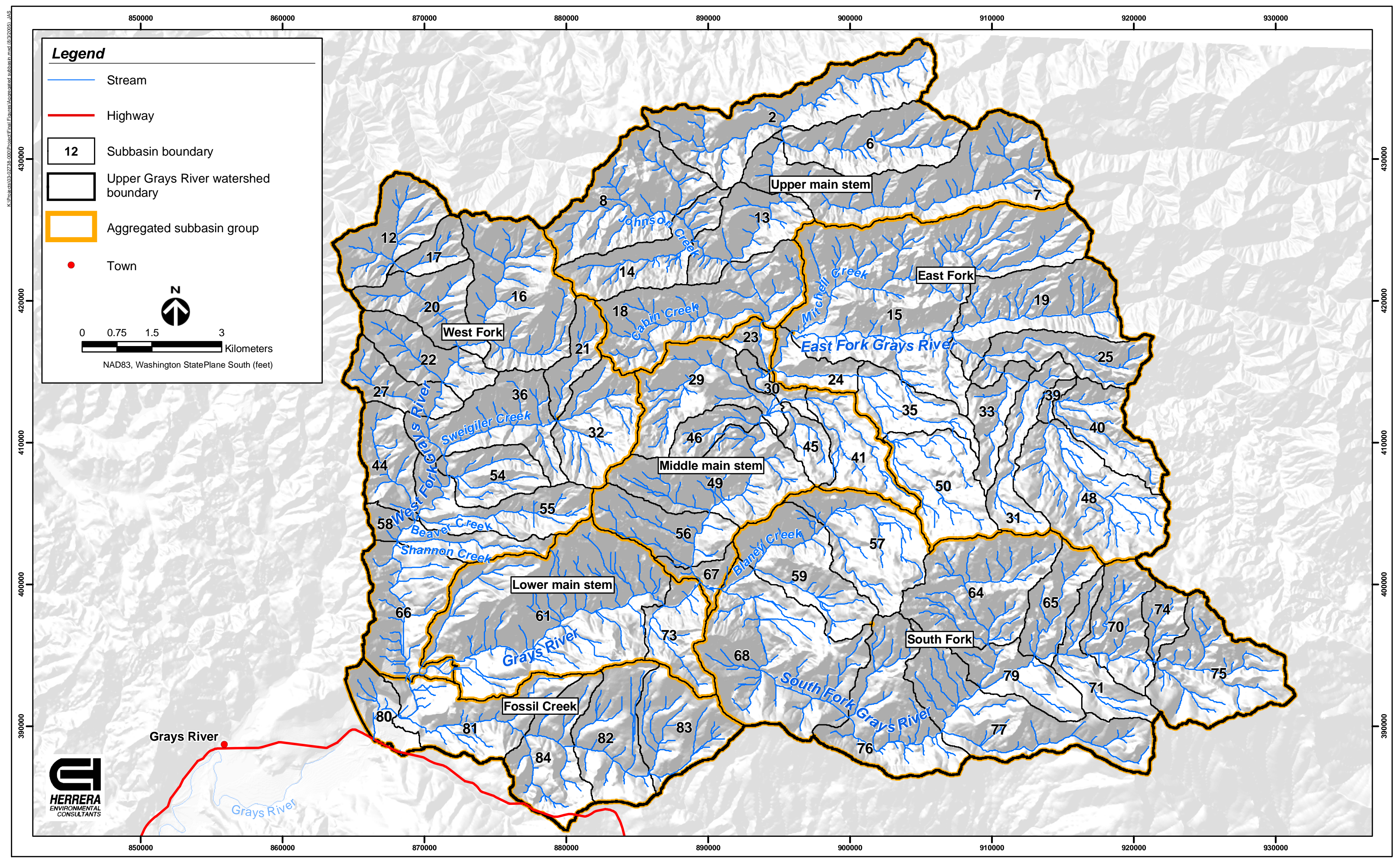

Figure G-1. Aggregated subbasin groups for sediment budget construction. 

Slope $\mathbf{0 - 3 0 \%}$

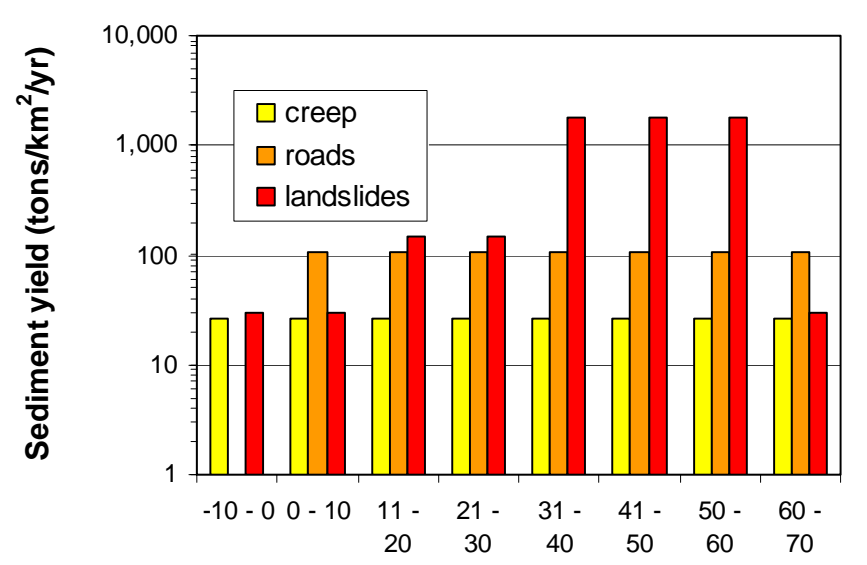

Time since harvest (years)

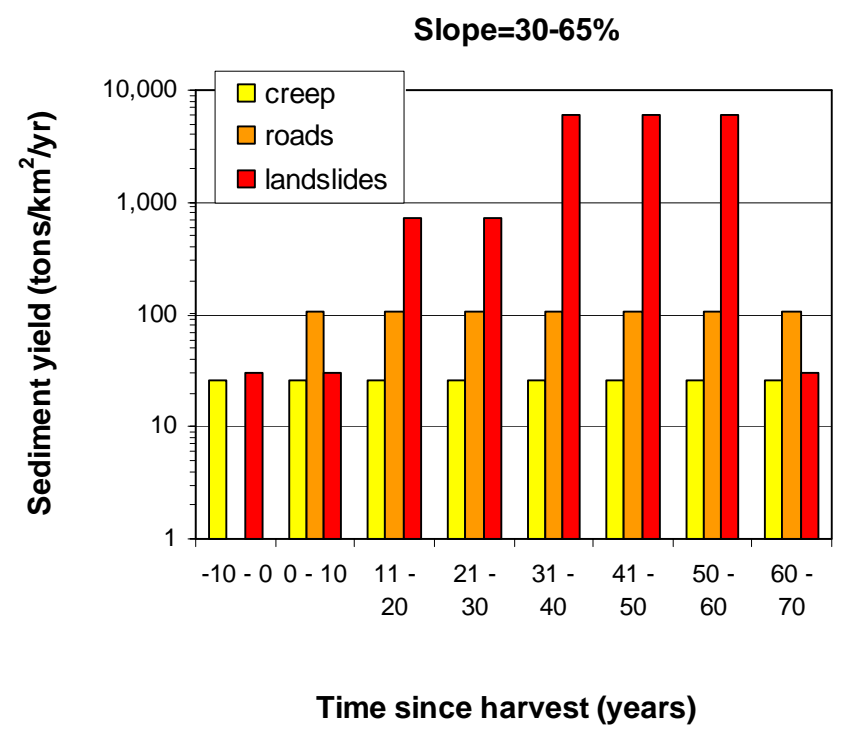

Slope $>65 \%$

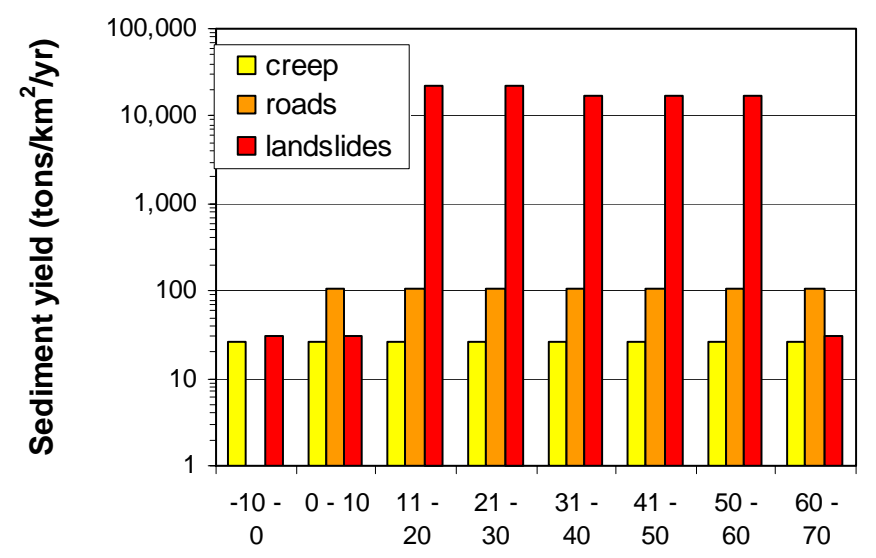

Time since harvest (years)

Figure G-2. Reconstructed sediment yield from soil creep, roads, and landslides as a function of time since last harvest. The three plots illustrate the range in sediment yield for the three slope categories. 

APPENDIX H

Channel Locations and Radii of Curvature for Each Photo Year 



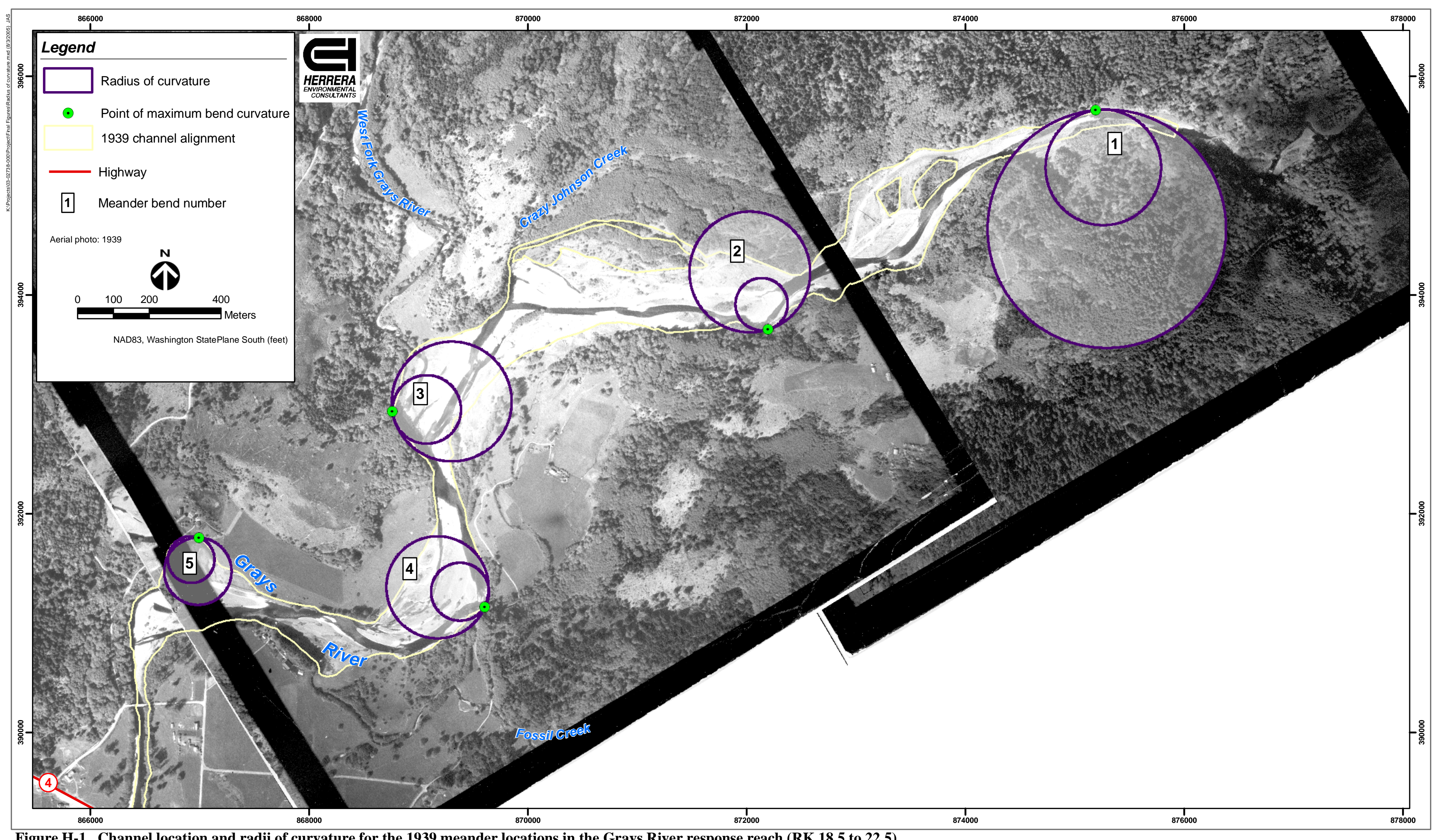

Figure H-1. Channel location and radii of curvature for the 1939 meander locations in the Grays River response reach (RK 18.5 to 22.5$)$. 



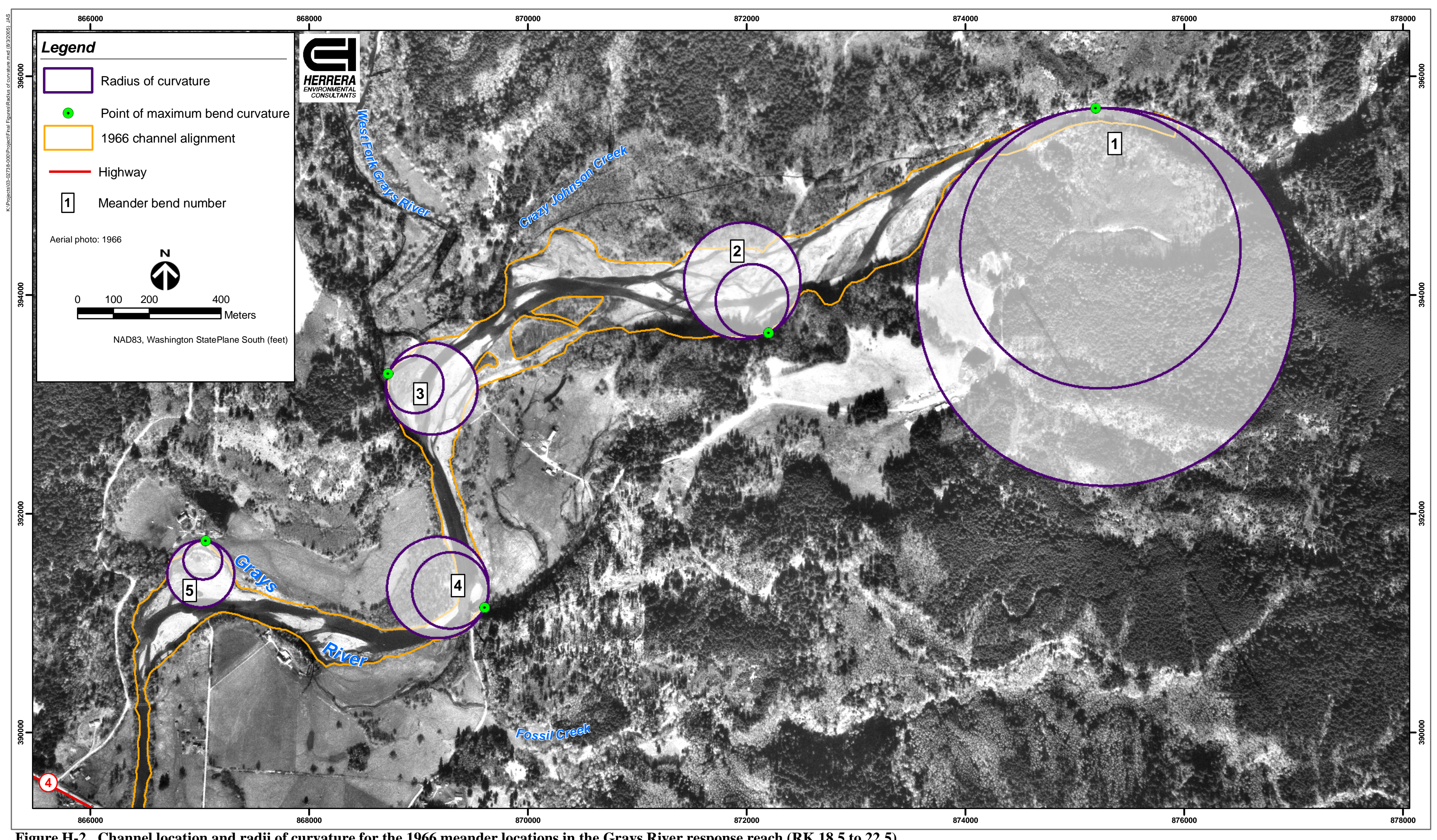

Figure H-2. Channel location and radii of curvature for the 1966 meander locations in the Grays River response reach (RK 18.5 to 22.5). 



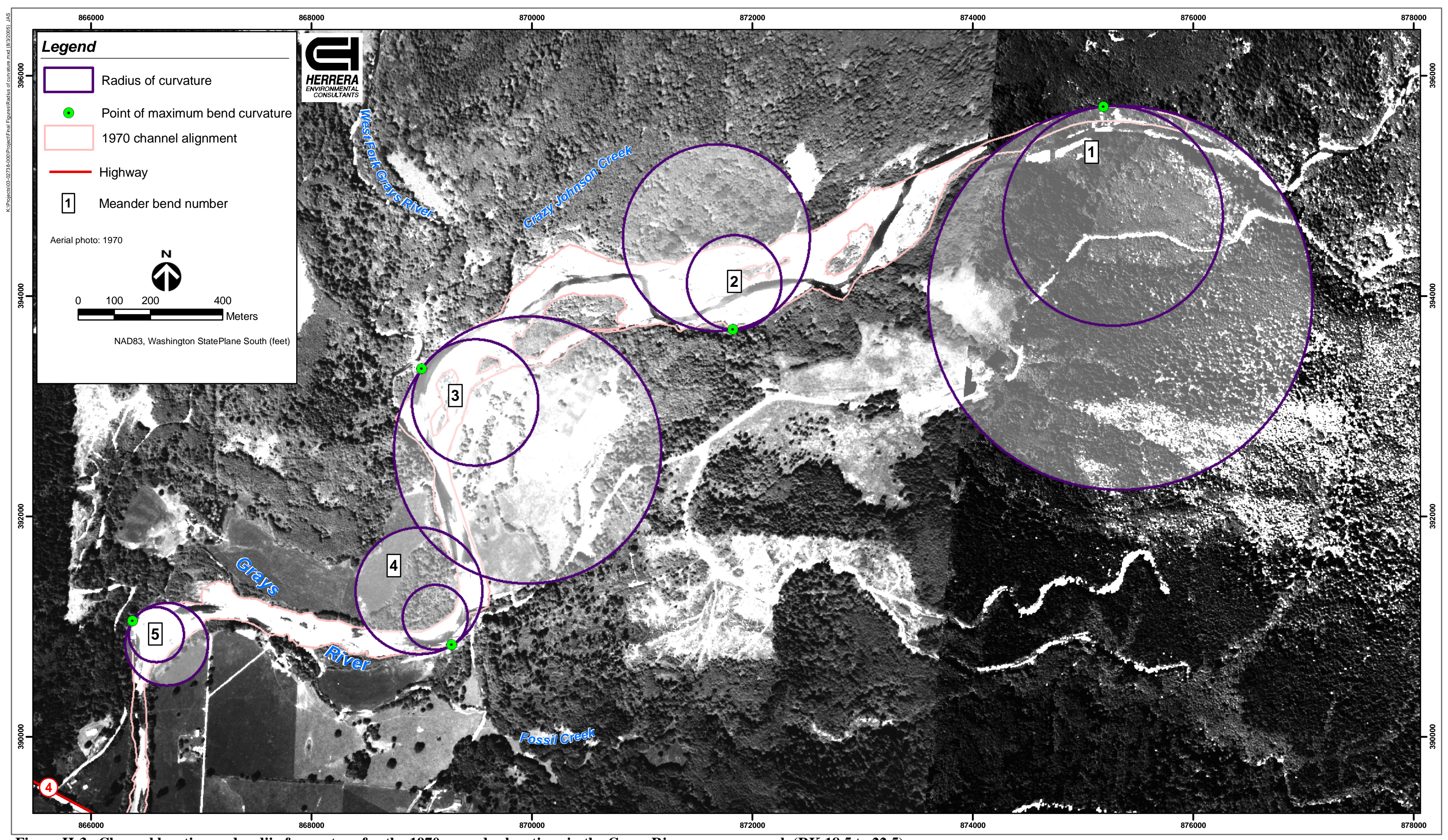

Figure H-3. Channel location and radii of curvature for the 1970 meander locations in the Grays River response reach (RK 18.5 to 22.5). 



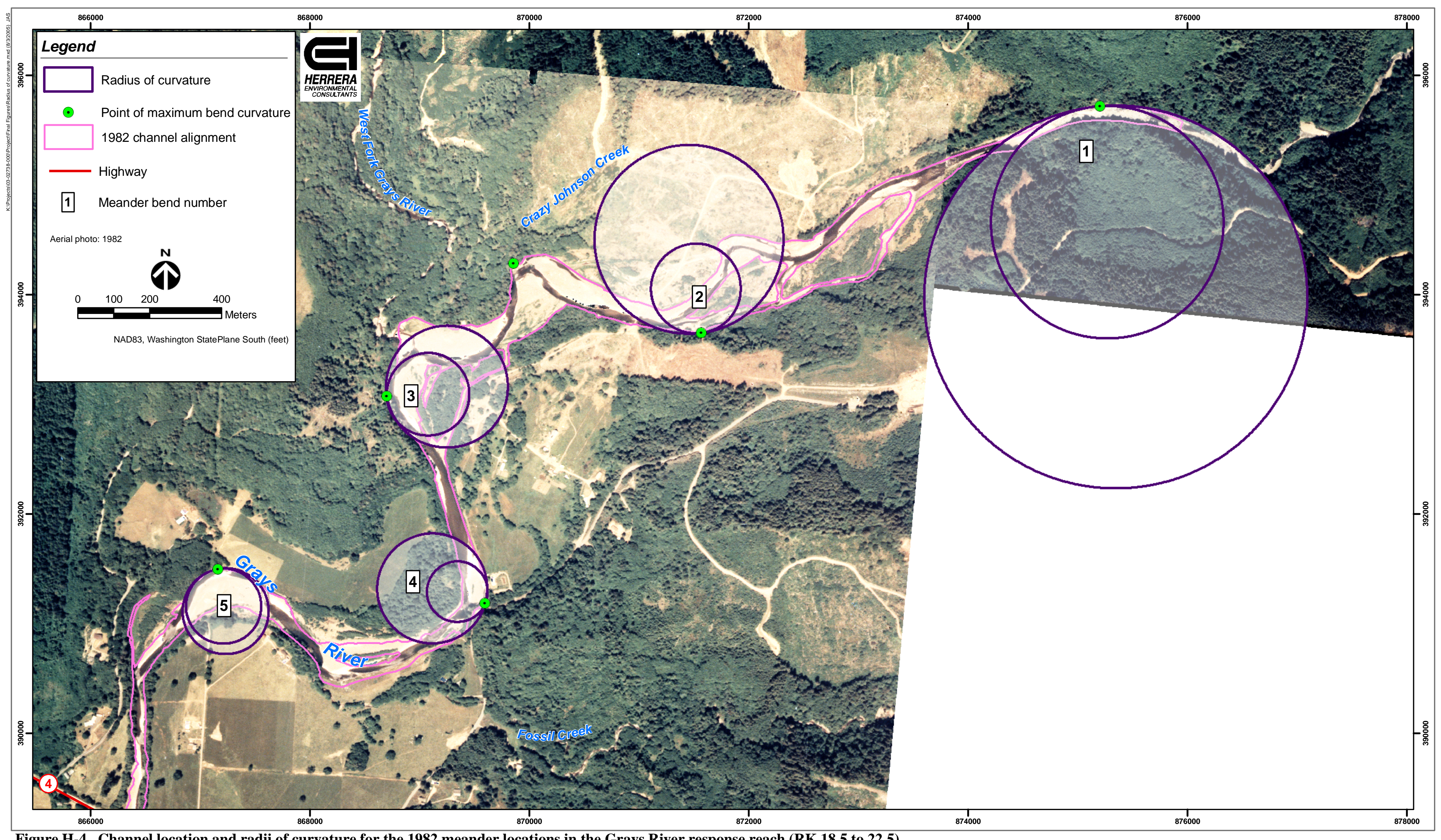

Figure H-4. Channel location and radii of curvature for the 1982 meander locations in the Grays River response reach (RK 18.5 to 22.5). 



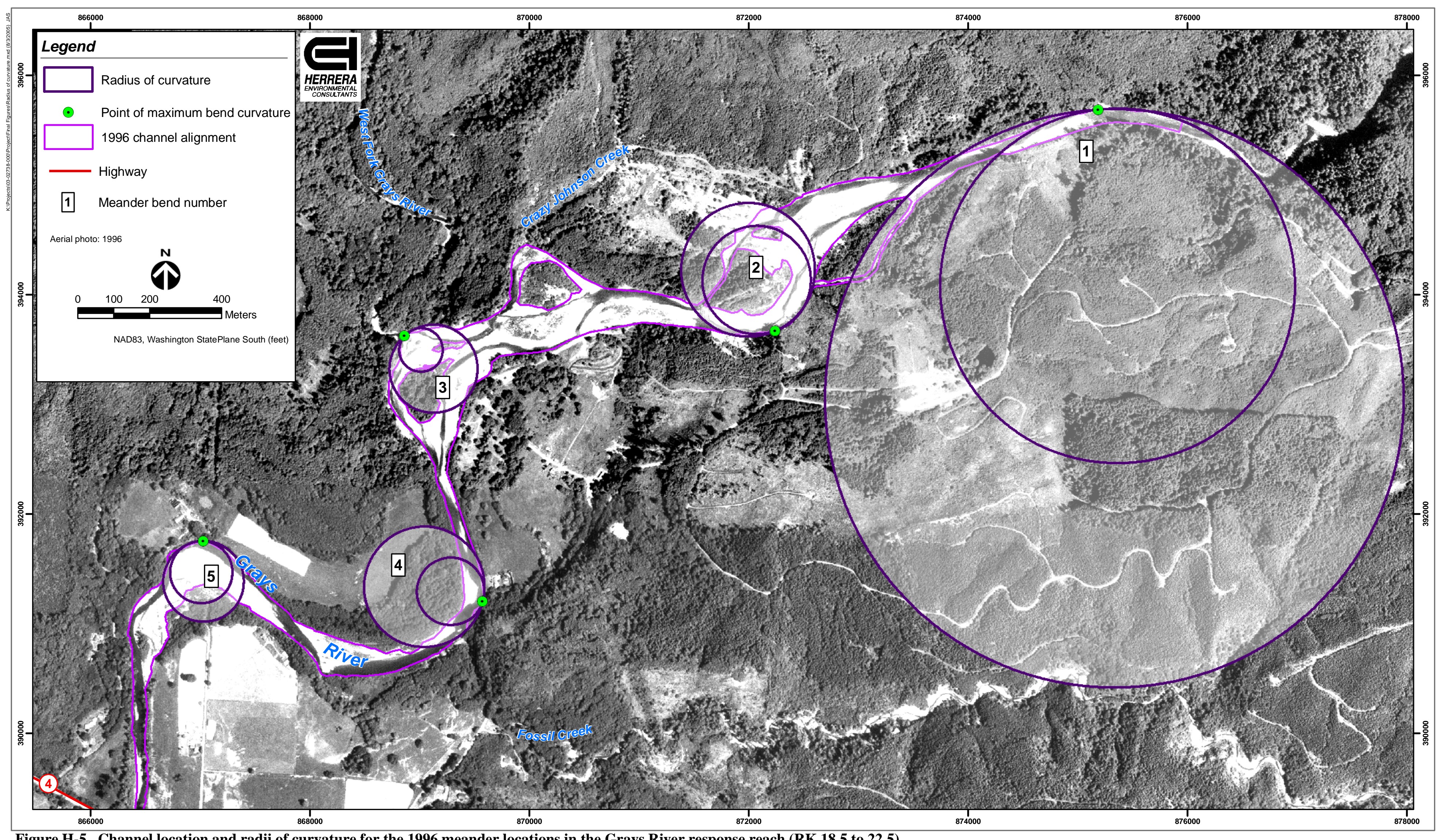

Figure H-5. Channel location and radii of curvature for the 1996 meander locations in the Grays River response reach (RK 18.5 to 22.5). 



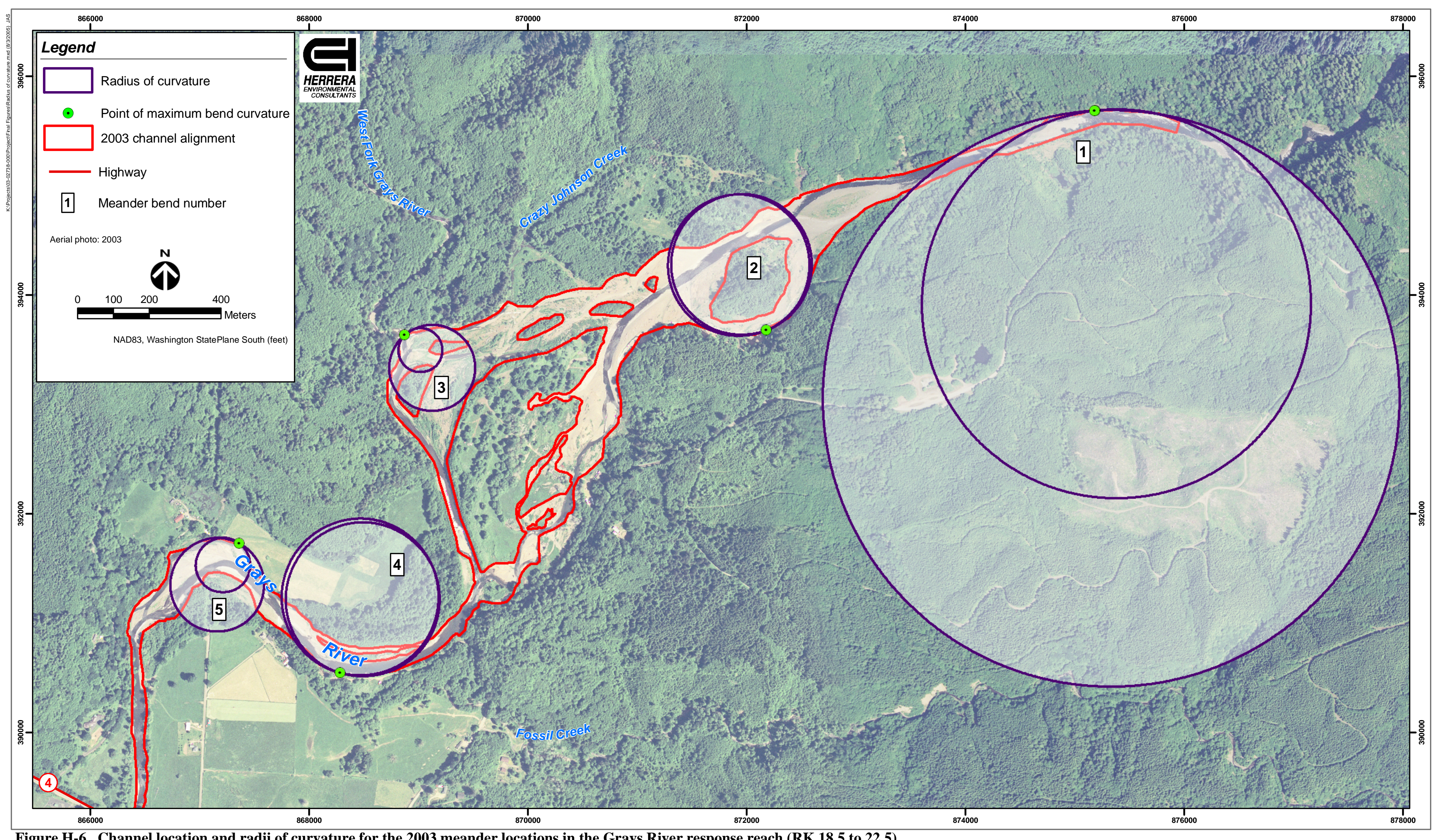

Figure H-6. Channel location and radii of curvature for the 2003 meander locations in the Grays River response reach (RK 18.5 to 22.5). 



\section{APPENDIX I}

Floodplain Cross-sections: Grays River Response Reach 



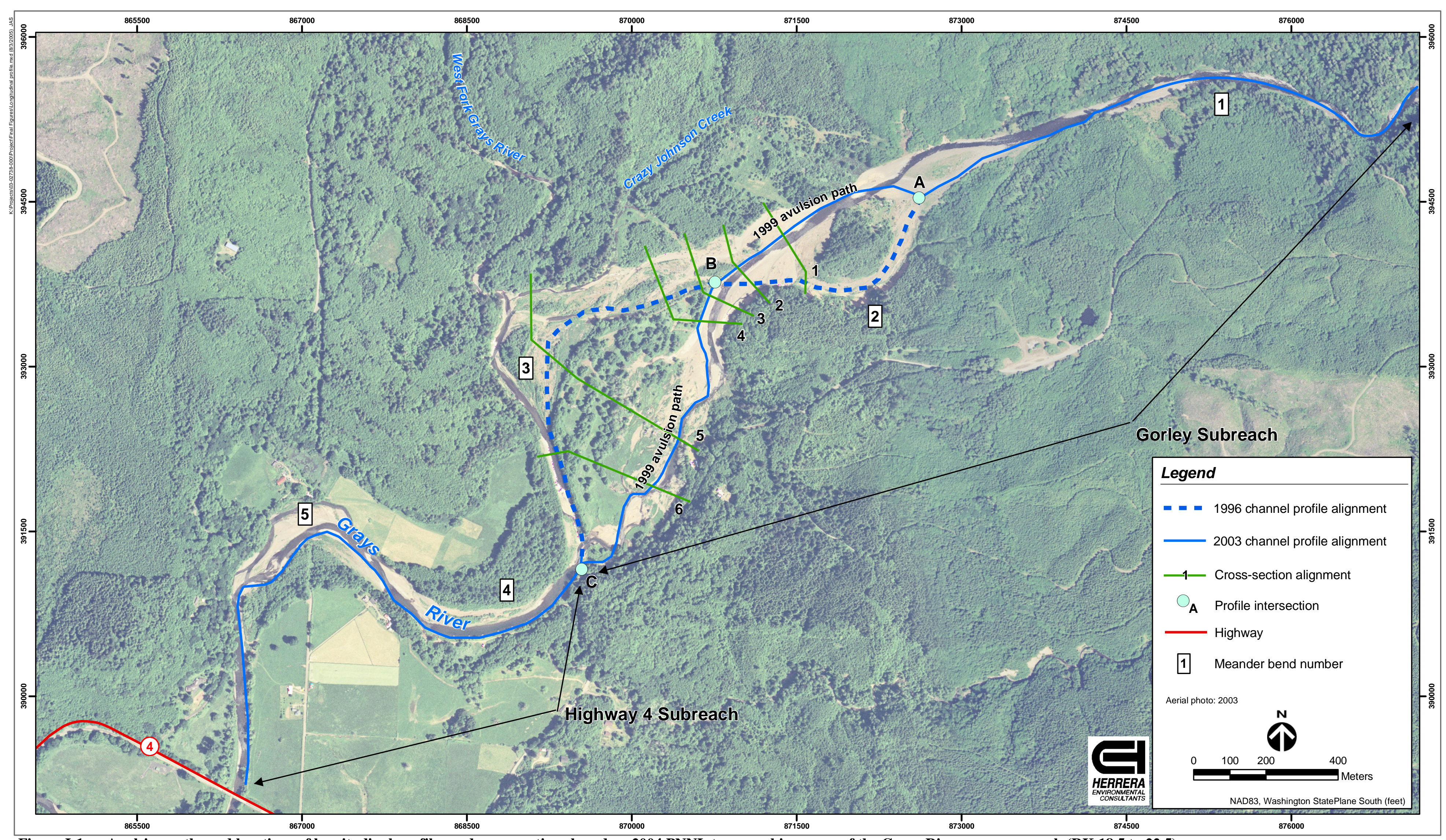

Figure I-1. $\quad$ Avulsion paths and locations of longitudinal profiles and cross-sections based on 2004 PNNL topographic survey of the Grays River response reach (RK 18.5 to 22.5). 



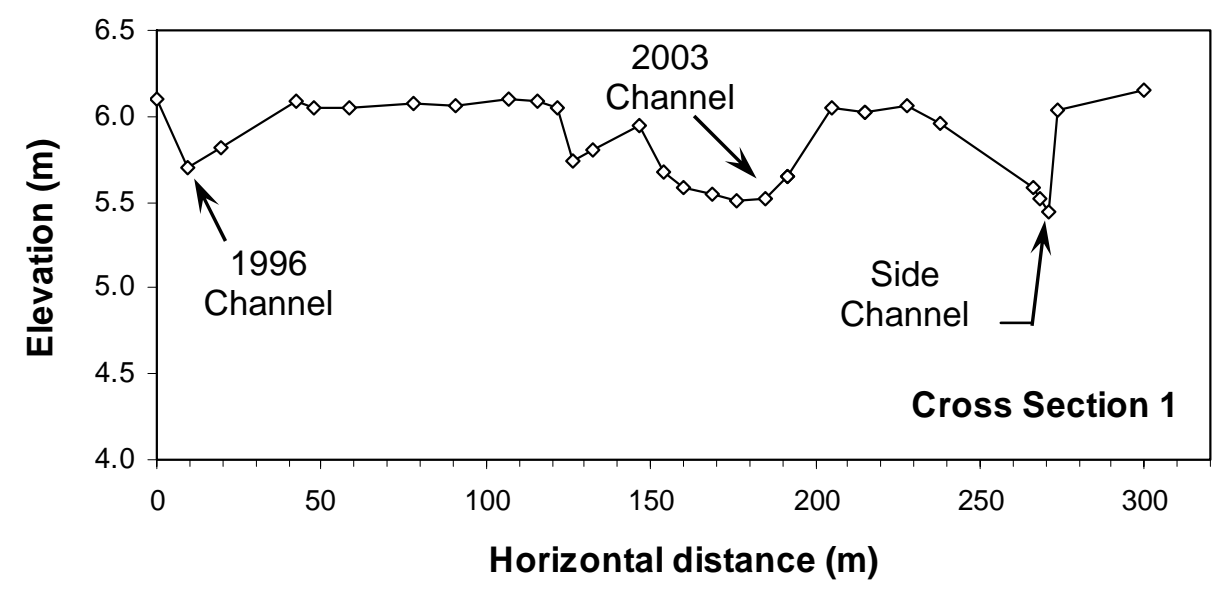

Figure I-2. Cross section 1 of the main stem Grays River floodplain looking downstream (see Figure I-1 for locations).

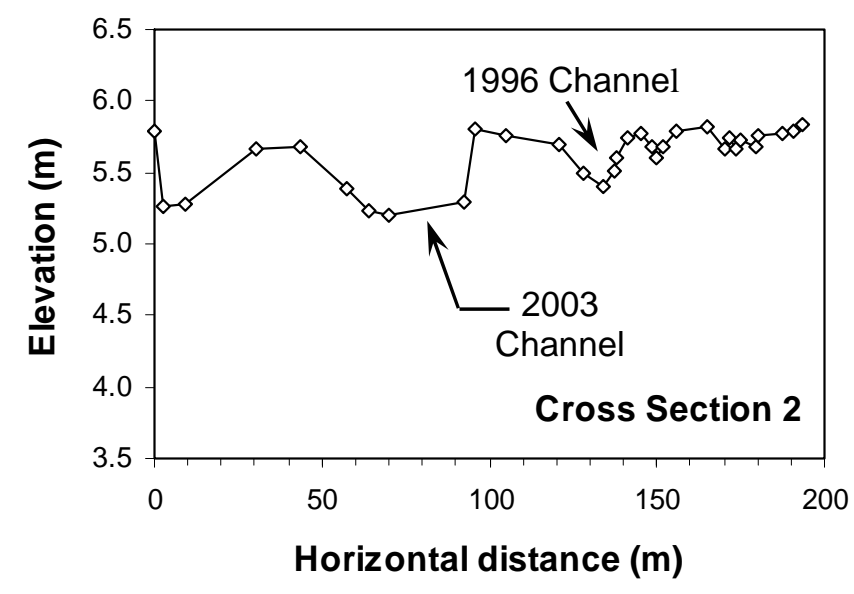

Figure I-3. Cross section 2 of the main stem Grays River floodplain looking downstream (see Figure I-1 for locations). 


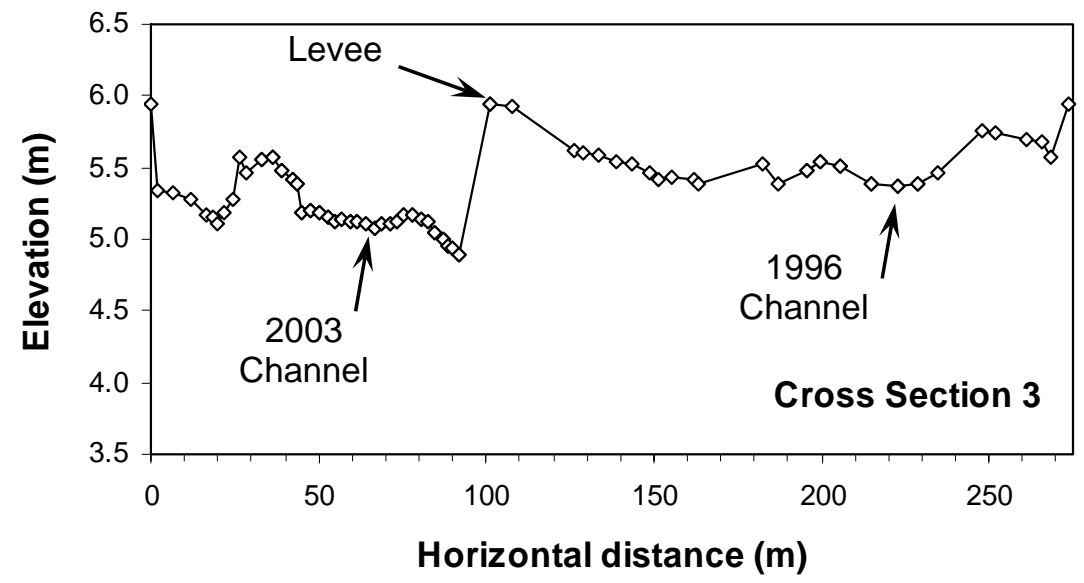

Figure I-4. Cross section 3 of the main stem Grays River floodplain looking downstream (see Figure I-1 for locations).

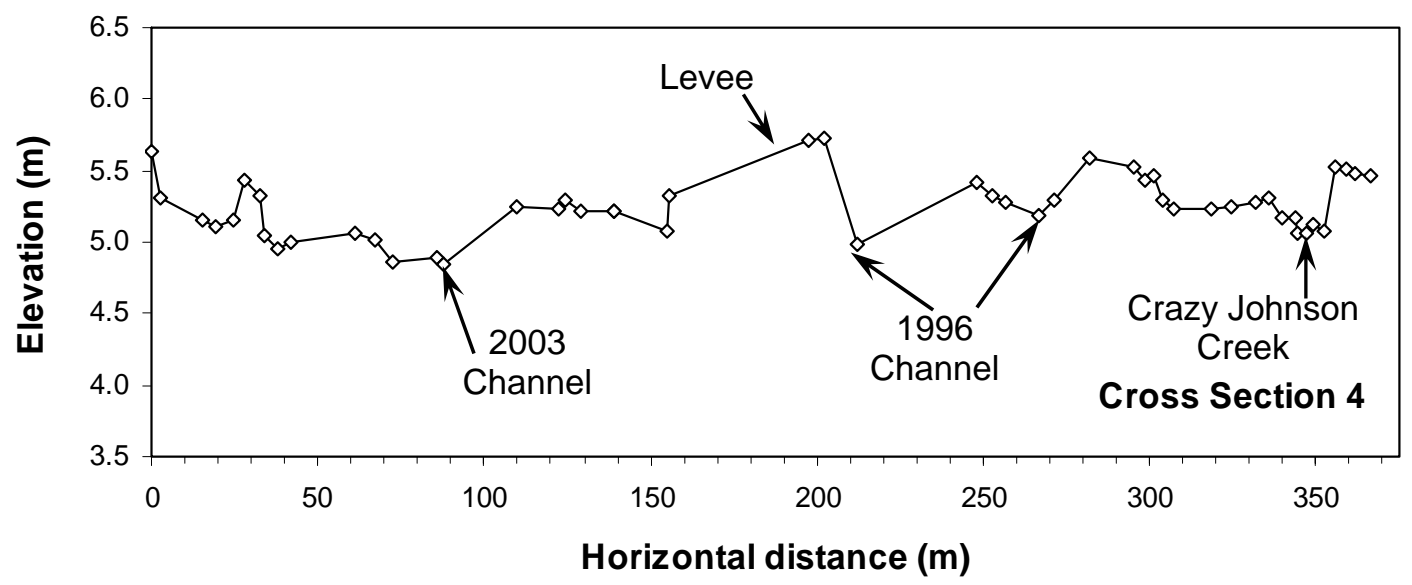

Figure I-5. Cross section 4 of the main stem Grays River floodplain looking downstream (see Figure I-1 for locations). 


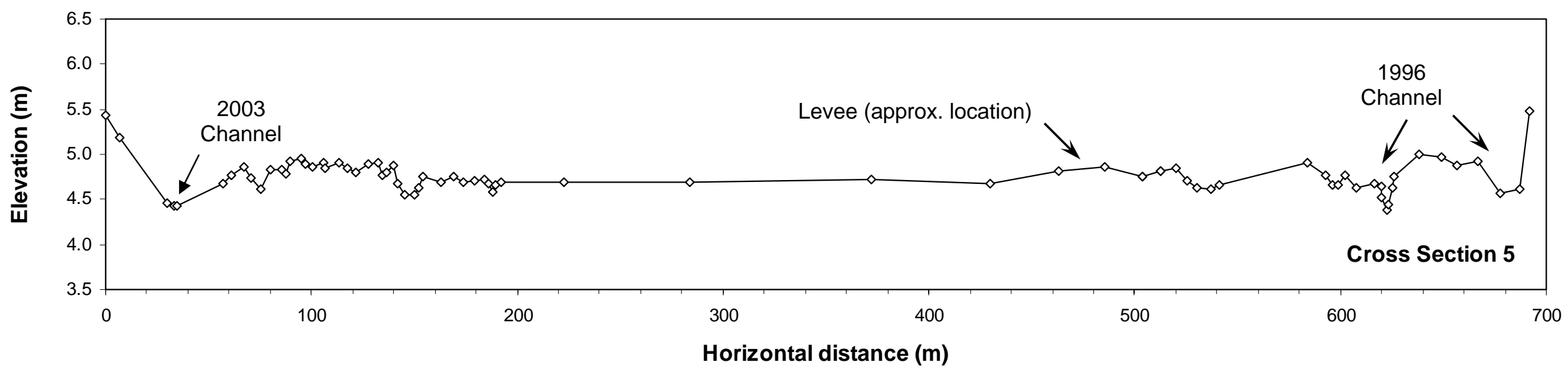

Figure I-6. Cross section 5 of the main stem Grays River floodplain looking downstream (see Figure I-1 for locations).

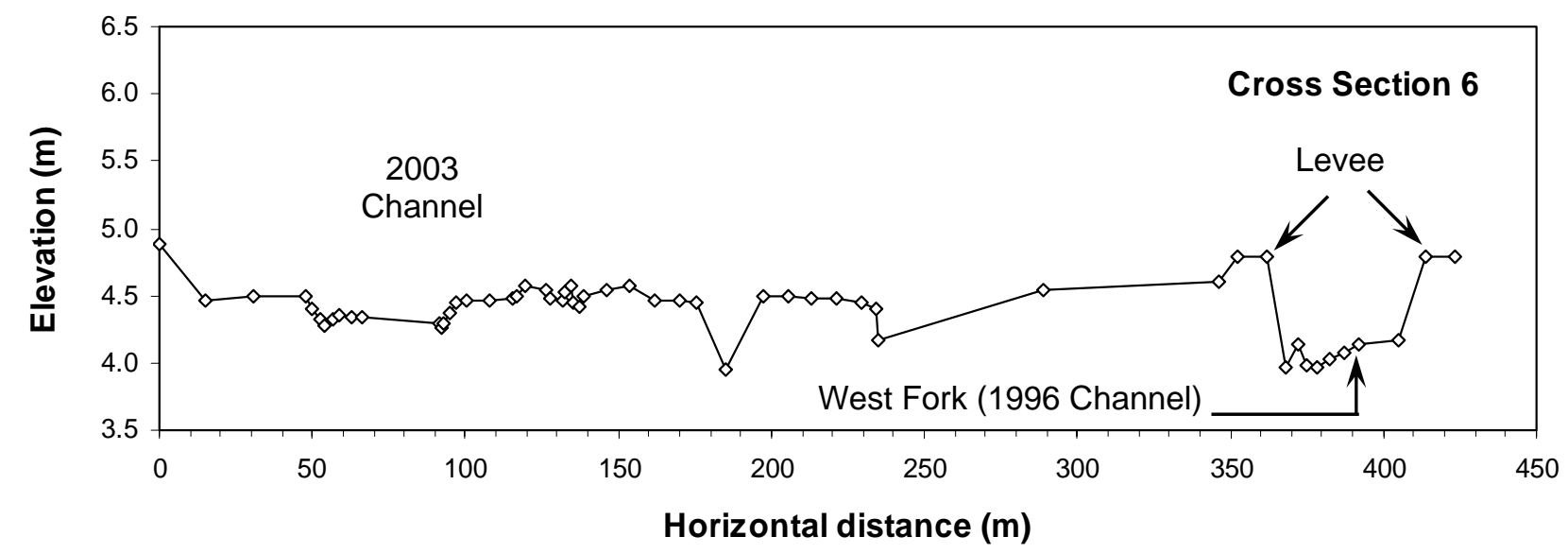

Figure I-7. Cross section 6 of the main stem Grays River floodplain looking downstream (see Figure I-1 for locations). 
